\title{
Students' and instructors' attitudes toward using biometric technology as an *identification method in online courses
}

\author{
Wafi AlBalawi \\ West Virginia University
}

Follow this and additional works at: https://researchrepository.wvu.edu/etd

\section{Recommended Citation}

AlBalawi, Wafi, "Students' and instructors' attitudes toward using biometric technology as an *identification method in online courses" (2004). Graduate Theses, Dissertations, and Problem Reports. 2622.

https://researchrepository.wvu.edu/etd/2622

This Dissertation is protected by copyright and/or related rights. It has been brought to you by the The Research Repository @ WVU with permission from the rights-holder(s). You are free to use this Dissertation in any way that is permitted by the copyright and related rights legislation that applies to your use. For other uses you must obtain permission from the rights-holder(s) directly, unless additional rights are indicated by a Creative Commons license in the record and/ or on the work itself. This Dissertation has been accepted for inclusion in WVU Graduate Theses, Dissertations, and Problem Reports collection by an authorized administrator of The Research Repository @ WVU.

For more information, please contact researchrepository@mail.wvu.edu. 


\title{
Students' and Instructors’ Attitudes Toward Using Biometric Technology as an Identification Method in Online Courses
}

\author{
Wafi AlBalawi \\ Dissertation Submitted to the \\ College of Human Resources \& Education at \\ West Virginia University \\ Toward Partial Fulfillment of the Requirements \\ For the Degree of \\ Doctor of Education \\ In \\ Technology Education \\ David L. McCrory, Ph.D., Chair \\ Deborah J. Hendricks, Ed.D. \\ Daniel Hursh, Ph.D. \\ Neal Shambaugh, Ph.D. \\ Jaci Webb-Dempsey, Ph.D. \\ Department of Advanced studies \\ Morgantown, West Virginia \\ 2004
}

Keywords: Biometric, identification, students' attitude, instructors' attitude, online, distance learning, e-learning

Copyright 2004 C Wafi AlBalawi 


\begin{abstract}
Students' and Instructors' Attitudes Toward Using Biometric Technology as an Identification Method in Online Courses
\end{abstract}

\title{
Wafi AlBalawi
}

This study investigated the social and cultural issues related to the implementation of biometric technology at the College of Human Resources and Education at West Virginia University. The study employed both quantitative and qualitative research methodologies. The researcher verbally interviewed five instructors and five graduate students. The quantitative research methods employed two surveys. The research population involved 30 instructors and 189 graduate students. The researcher utilized independent-sample t-tests to compare different groups. The results obtained from this research support the following: (1) there is a real privacy concern among instructors and students regarding the implementation of biometric technology, (2) religious concerns were not an issue for the research participants and (3) health risk was not a concern for instructors and but it was for students. Health concerns, however, were stronger within the students' group compared with the instructors' group; t-tests confirmed this result. The independent-samples t-test did not find a significant difference between students' and instructors' groups in their responses to the privacy and religious issues, but it showed significant differences between the two groups in their responses to the health issues questions. This research suggests that a public awareness campaign precede consideration of biometric technology implementation. The adoption of hybrid information collection, using both biometric and traditional systems, is supported. When institutions choose to adopt biometric technology, it is essential to put in place very specific and clear policies. 


\section{DEDICATION}

To my father for his inspiration and devotion. M ay A llah bless his soul.

To my mother for your unconditional love, patience and support throughout my life.

To my w ives, my brothers and sisters, thank you for encouraging me to pursue this degree. I know that I w ould not have made it through all of the stress and strain, pain and glory; you are truly a gem.

To my children, Sarah, Ghadah, H ammad, R eem, J umanah, M ohammad and L ujain, the greatest treasure in my life; yes $D$ ad is finally finished his homew ork! 


\section{ACKNOWLEDGMENTS}

First and foremost, thanks due to you Allah for your continued blessings and grace.

Next, I would like to express my sincere gratitude and appreciation to many individuals who helped support my efforts during this endeavor.

My heartfelt thanks go out to Dr. David McCrory, my chair, without whom, none of this would have happened. He always had a word of encouragement and inspiration. I have never worked with a better person. I would also like to thank my dissertation committee members, Drs. Deborah Hendricks, Danial Hursh, Neal Shambaugh and Jaci Webb-Dempsey, for their thoughtful comments and suggestions.

I would also like to note the help that many other professors and students of the College of Human Resources and Education have given me along the way. This place has given me many memories, and I will treasure them.

Special thanks go to my close friend Nawaf Alshammari, for his motivation support and encouragement. Additionally, I would like to thank all my friends and collogues; Drs. Adel Alzenedy, Salah Alharbi, Mohammad Alharthi, Obaid Alshammari and Ras Tsidi Acolatse for their help and feedback throughout the dissertation process. 
Subject

Page number

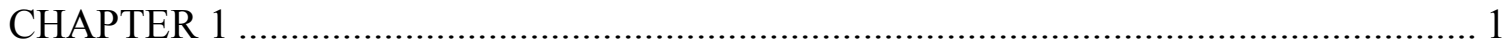

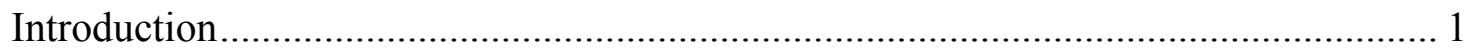

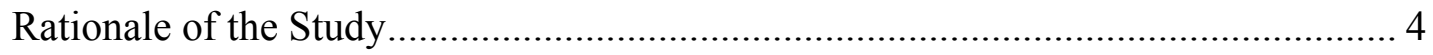

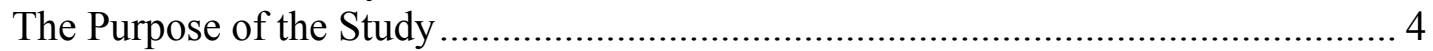

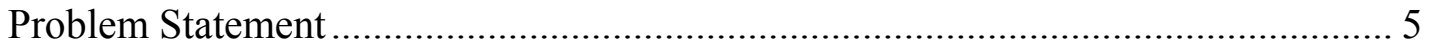

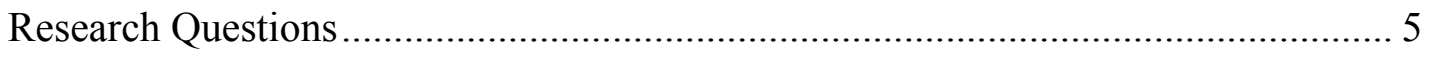

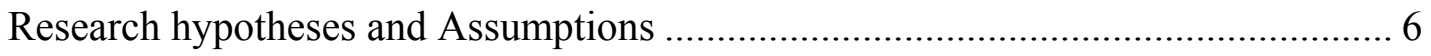

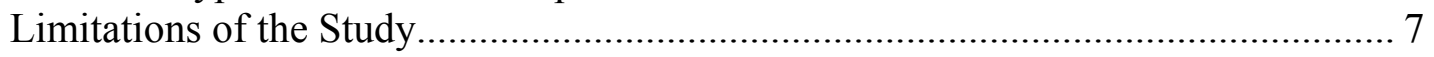

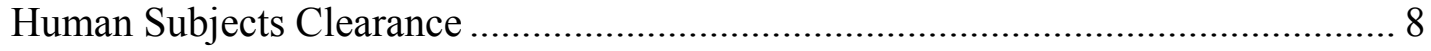

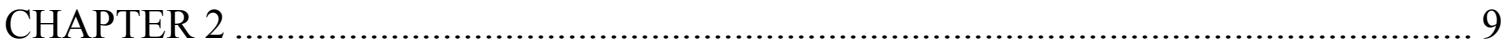

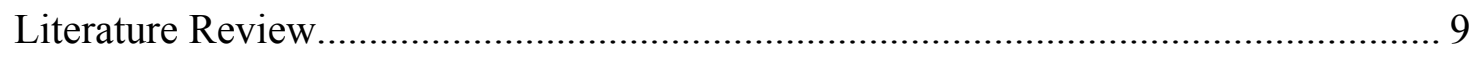

Biometric System Modes and Functions .......................................................... 9

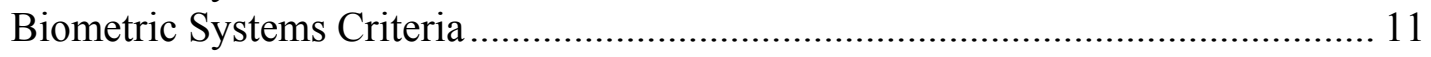

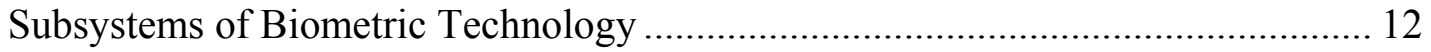

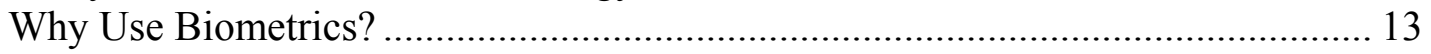

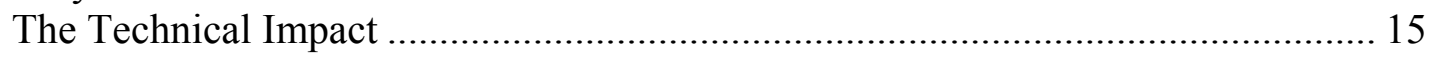

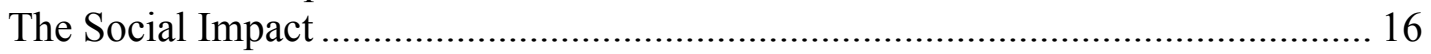

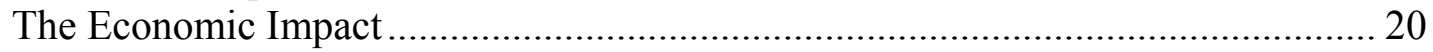

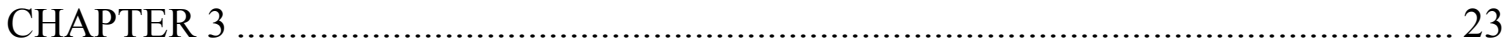

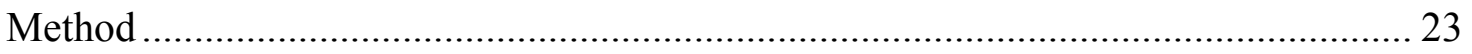

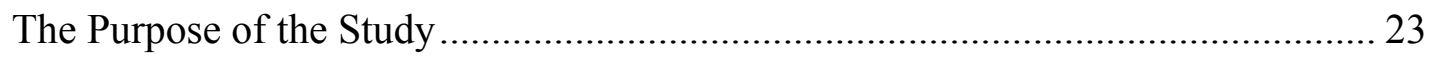

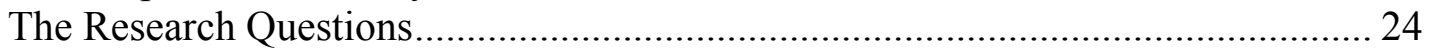

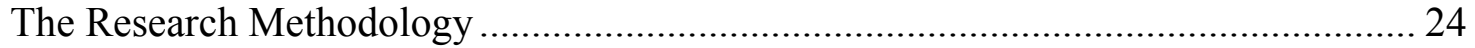

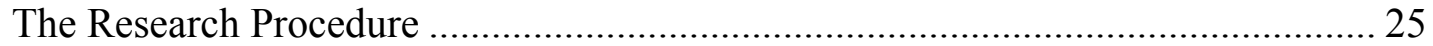

Phase I: The Interview ..................................................................................... 28

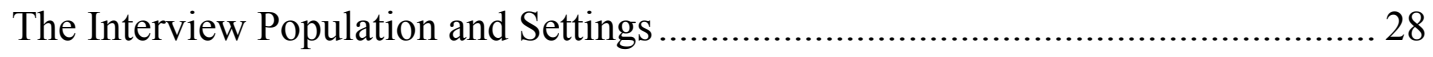

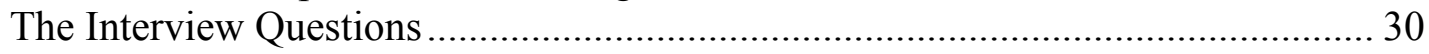

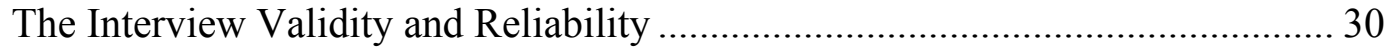

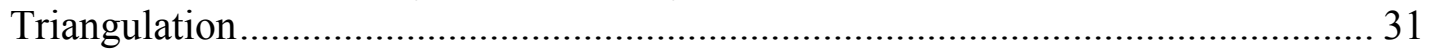

Phase II: Conducting the Pilot Study and Administrating the Surveys ...................... 31

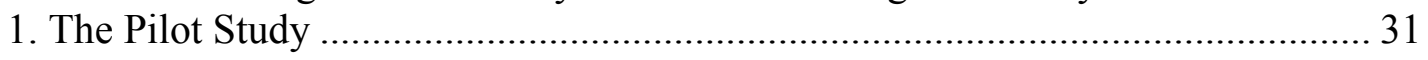

The Pilot Study Population and Settings ....................................................... 32

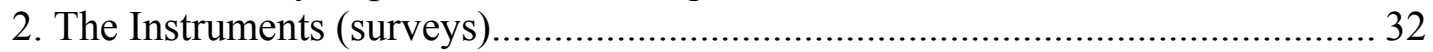

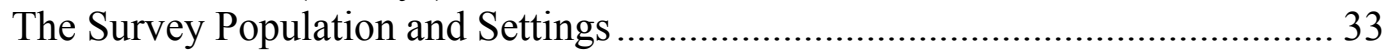

The Survey Validity and Reliability ........................................................... 34

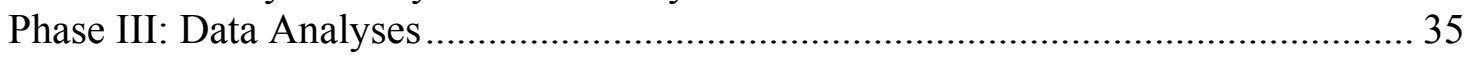

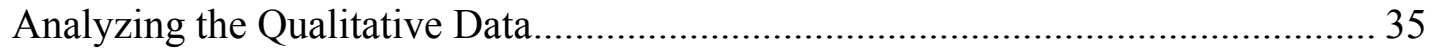

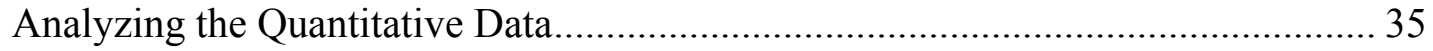

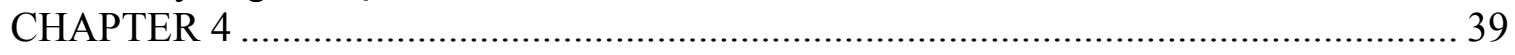

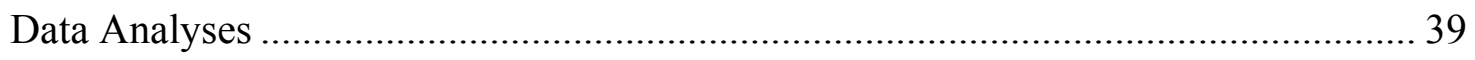

Part I: Qualitative Data Analyses......................................................................... 41

Reviews of the Interview Procedures ........................................................... 41

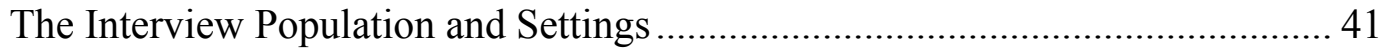

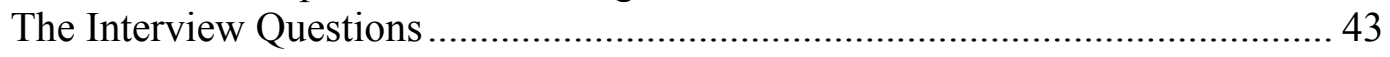




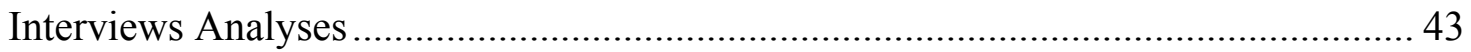

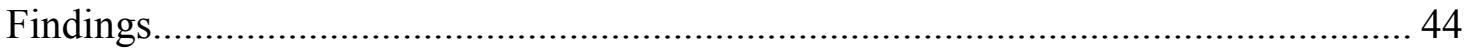

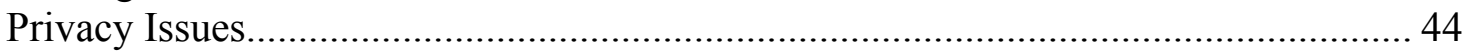

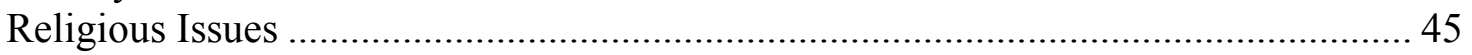

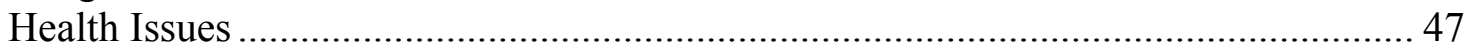

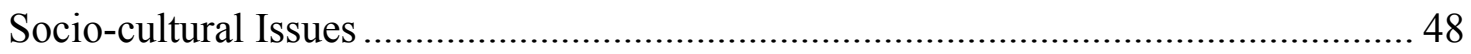

Part II: Quantitative Data Analysis .......................................................................... 49

Review of the Problem Statement.................................................................. 49

Review of Research Questions ....................................................................... 49

1. Analyses of Data Related to the Research First Question (RQ1) "Instructors Group"

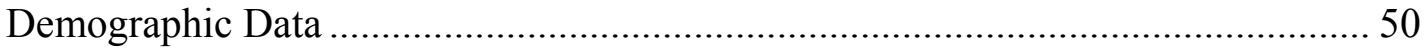

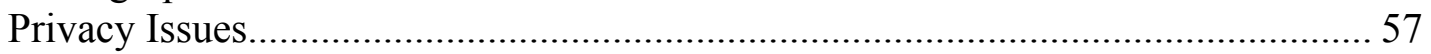

Privacy Concerns of Each Ranked Biometric Technology (Low Medium High) 64

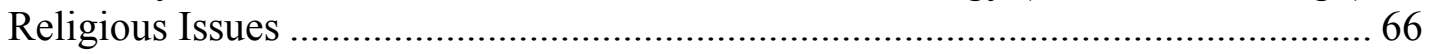

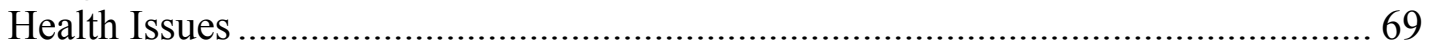

Health Concerns of Each Ranked Biometric Technology (Low Medium High).. 70

Health Concerns of Each Rated Biometric Technology (Comfortability)............ 72

Open-ended Questions ......................................................................................... 74

2. Analyses of Data Related to the Research Second Question (RQ2) "Students Group"

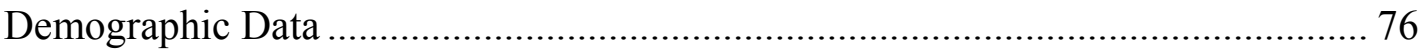

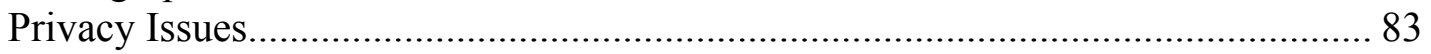

Privacy Concerns of Each Ranked Biometric Technology (Low Medium High) 90

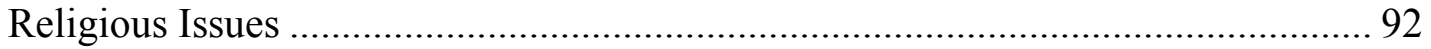

Religious concerns of each ranked biometric technology (Low Medium High).. 95

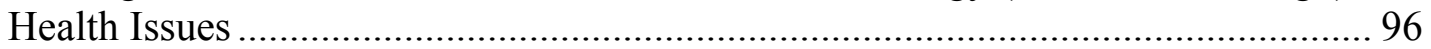

Health concerns of each ranked biometric technology (Low Medium High) ...... 97

Health Concerns of Each Rated Biometric Technology (Comfortability)............ 99

Open-ended Questions ...................................................................................... 102

3. Analyses of Data Related to the Research Third Question (RQ3).......................... 104

Comparing Males and Females Instructors and Students ........................................... 104

3.1 The difference between Students and Instructors groups in their attitude toward the implementation of biometric technology in regard to: ...................... 104

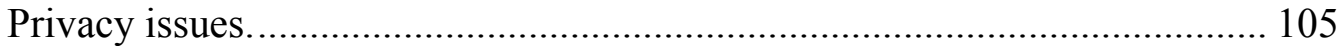

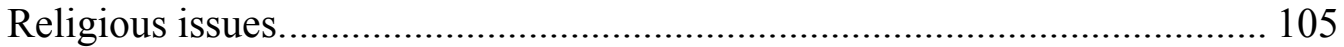

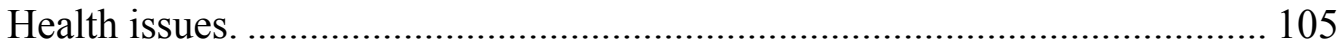

3.2 The difference between Male and Female in the surveyed population in their

attitude toward the implementation of biometric technology in regard to: ........ 107

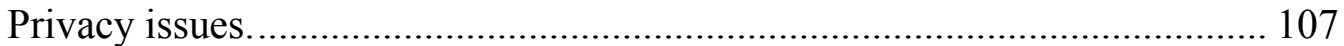

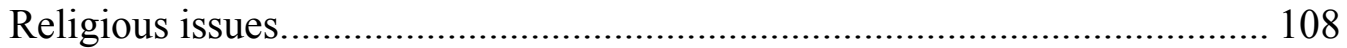

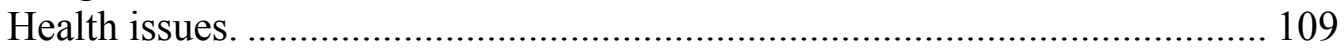

3.3 The differences between Male and Female within Instructors group in regard

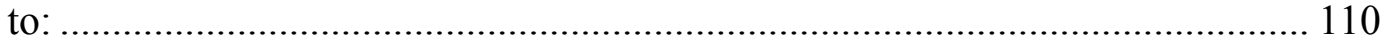

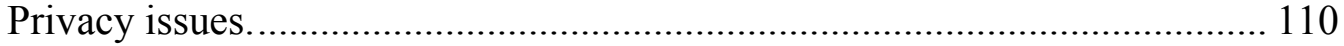

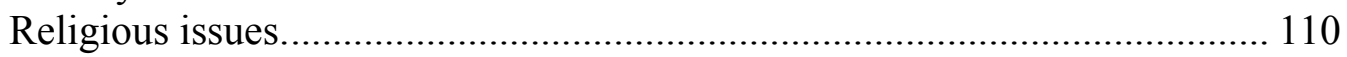


Health issues ........................................................................................... 110

3.4 The differences between Male and Female within Students group in regard to:

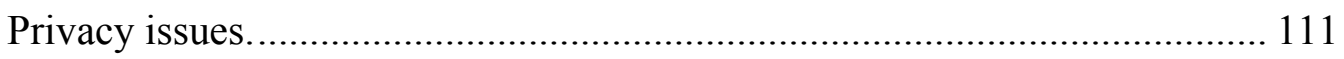

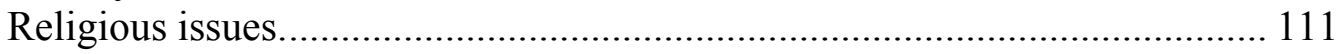

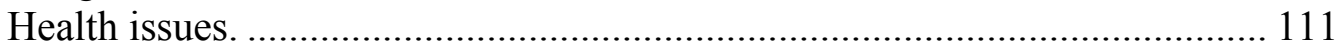

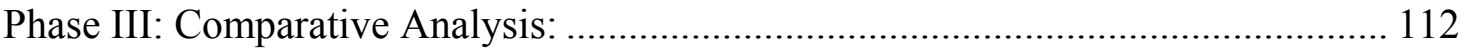

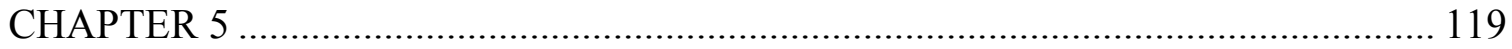

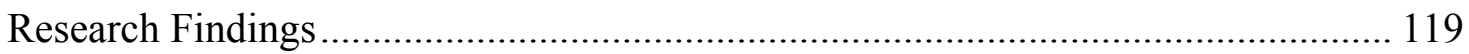

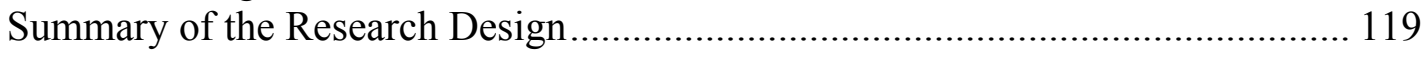

Review of Research Questions and results ........................................................ 120

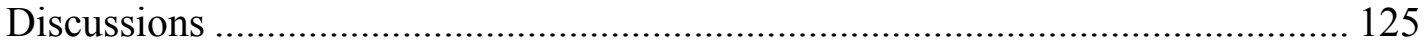

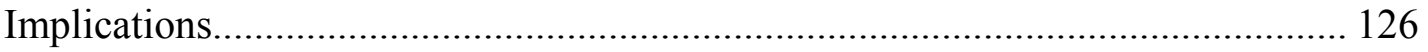

Recommendations and Future Studies ........................................................... 130

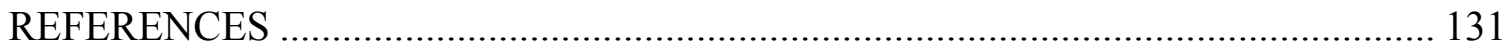

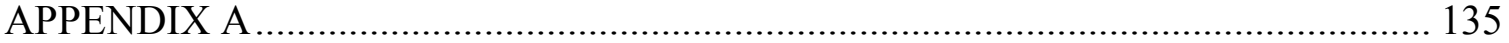

Frequency Tables and Figures related to the Research Question 1(RQ1) ................. 135

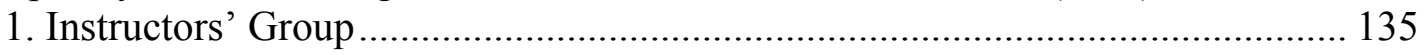

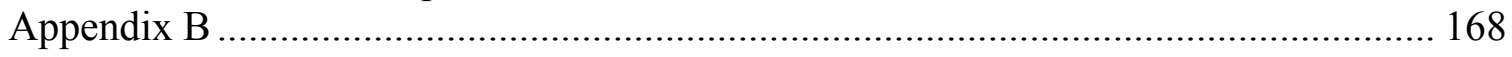

Frequency tables and Figures related to the Research Question 2(RQ2) ................. 168

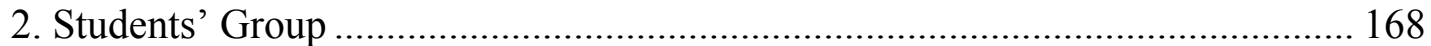

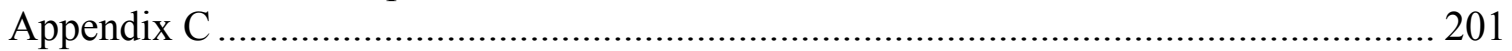

Frequency tables and Figures related to the Research Question 3(RQ3) .................. 201

3. The Differences Between Different Groups ............................................... 201

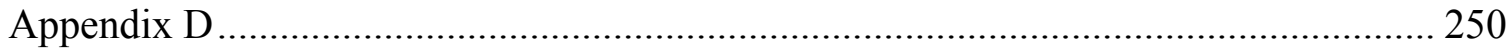

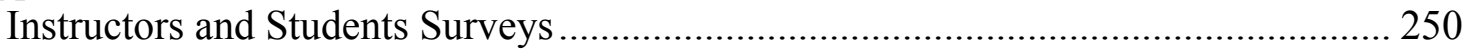

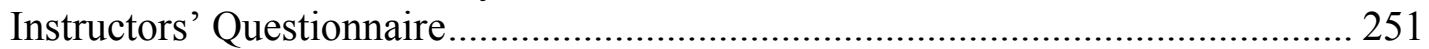

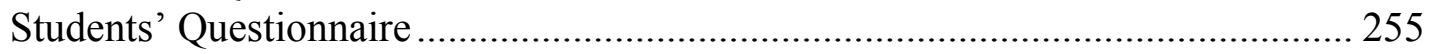

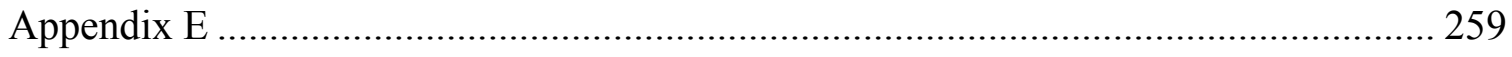

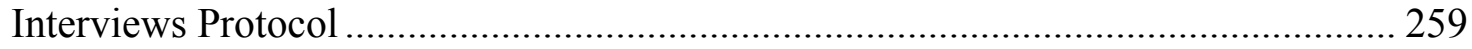

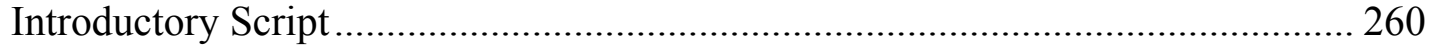

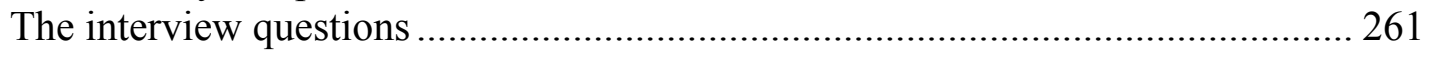

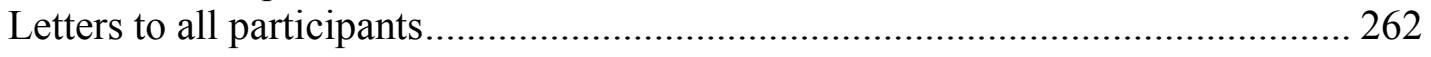




\section{CHAPTER 1}

Introduction

Educational methods have become advanced and changed dramatically in the last decade. The revolution in communication technologies specifically after the invention of the internet, have introduced new methods of teaching. At the top of the list is distance learning, where virtual classes and schools are established all over the world. People from different places, cultures, races and languages who probably never meet each other, take the same classes and learn from each other. Furthermore, they participate in producing fantastic projects and artifacts (Rosenberg, 2001; Sherry, 1996).

In the United States, alone, thousands of educational programs have been launched in the last few years in different schools. West Virginia University is one of the institutions that have introduced online courses, with a variety of choices, ranging from liberal, and science majors to Finance, Information Management, Software Engineering and Nursing. Students or learners acquire knowledge while they work full-time. They can do their assignments and projects from home or during their spare time.

In addition, the distance-learning paradigm provides a variety of alternatives for students to attend classes virtually. They can communicate with the instructor, chat with him or her and with each other or be involved in a conferencing room, as depicted by Figure 1.1. At the same time, they can communicate through bulletin boards, e-mail, or email lists that are used to broadcast or disseminate information among groups (Keegan, 1993; Sherry, 1996). 


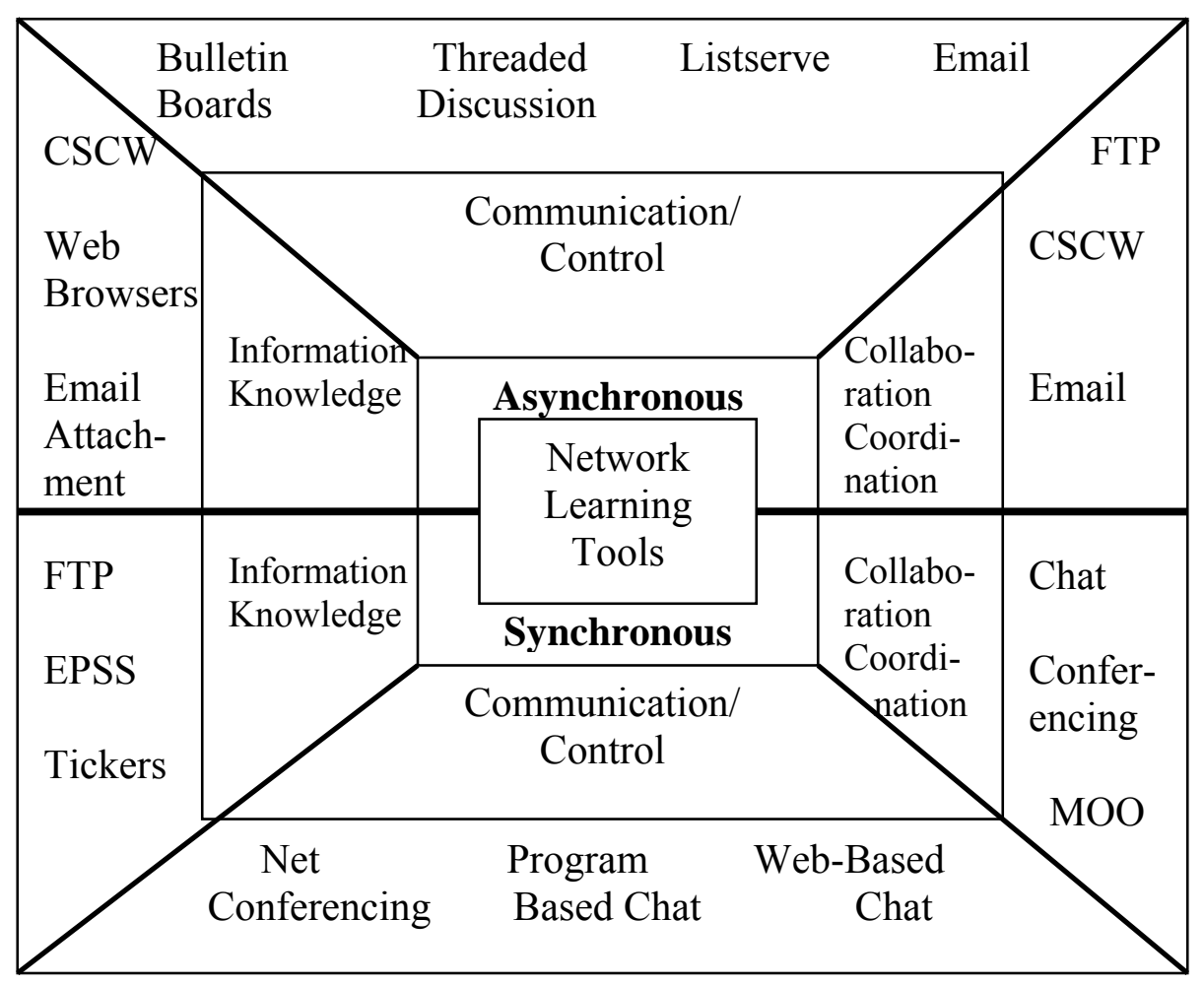

Figure 1.1. Networked learning tools.

Distance learning has many advantages over the traditional face-to-face paradigm.

However, it has drawbacks. The nature of this technology requires extra preparation and infrastructure. Schools are very concerned about the privacy and convenience of their students. Students should be able to access their accounts and records securely and conveniently. Schools and colleges need to verify the identity of their students, since students and instructors meet only virtually. Additionally, the universities and colleges need to comply with the state and the accreditation organization requirements (Charp, 1994; Keegan, 1993; Sherry, 1996).

In the last few years, many schools around the world in general and the US in particular, moved toward a new paradigm of delivering knowledge to learners (Duning \& others, 1993; Lai, 1999). In the last few years, universities and colleges have tended to introduce distance learning as a main trend in their curricula. Different variations of 
distance learning such as e-learning and online learning have been implemented all over the US (Driscoll, 1998). The overall advantages of distance learning technology are obvious to both learners and instructors. The distance-learning paradigm has also played a noticeable role in reducing the cost involved in delivering educational materials.

A few issues have risen because of the new trend of pedagogy. Since both learner and instructor do not meet face to face, the need for a strong authentication method is necessary to verify the identity of people especially during exams or evaluation processes.

Different identity verification methods and protocols have been proposed and deployed (Butler, Engert, Foster, Tuecke, Volmer \& Kesselman, 2000). Biometric systems such as fingerprint, iris scan and voice recognition seem to be the most attractive and promising for the next generation. Schools are using different types of authentication systems, such as usernames and passwords, tokens, and smart cards. Despite the great advantages of these methods, each has some flaws and drawbacks. Systems based on knowledge, such as passwords could be forgotten, stolen, revealed or simply guessed. Others that are based on possession, such as smart cards, might be forgotten, damaged or stolen (Podio 2001; Wayman, 2001a).

Using an individual's characteristic or behavior is difficult to forge or replicate (Jain, Bolle \& Pankanti, 1999; Podio, 2001; Wayman, 2001a). In more detail, the technical, cultural and economic implications of using and deploying biometric systems in distance learning were discussed and investigated through this study. 


\section{Rationale of the Study}

The need for a strong, but acceptable authentication method is essential. Using traditional identification cards is not enough to verify the identity of people attending class, taking exams, and quizzes in distance learning environments. Other alternatives such as proctoring exams through educational centers are not appropriate; it is a very costly process. In addition, in many cases it does not fit with the purpose of the distance learning.

New technologies of authentication have been used and implemented in many places such as banks, hospitals, government buildings and universities. Biometric technology is a new, emerging technology believed to solve the problem of people authentication. This technology is based on the authentication of individual's identity according to their psychological or behavioral traits. It is believed that using biometric technology will help in solving the dilemma of identity, especially in the online paradigm (Matyas, Riha, 2000; Wayman, 2001a).

\section{The Purpose of the Study}

Implementing biometric technology is not an easy task. Many factors should be considered to make the system more efficient and acceptable. Throughout the review of publications related to the implementation of biometric technology, the issue of privacy was highly emphasized. This study investigated the social and cultural issues related to the implementation of biometric technology as an identification method in the distancelearning paradigm.

The study determined issues that were more critical to both instructors and learners. It tested the acceptability of the biometric technology as an authentication 
method in online courses from learners', and instructors' points of view in the College of Human Resources and Education at West Virginia University. It is hoped that the study will help to improve the system performance, if it is implemented. Findings and results of this research will help schools, instructors and learners to better understand the nature of biometric technology, as well as help stakeholders to design and implement the biometric authentication system with minimal side effects.

\section{Problem Statement}

Since there is little knowledge about the implementation of biometric systems as an authentication method in distance learning courses, examining learners and instructors' reactions toward implementing biometric technology is very crucial. The problem of this study was to determine the social and cultural issues related to implementing biometrics technology. Learners have some reservations toward biometric technology; it was therefore important to investigate the impact of implementing biometric systems on privacy. The conflict between implementing biometric system with religious beliefs was clarified. The health effect associated with adopting biometric system was discussed. Instructors have their own concerns about biometric technology that was examined closely.

\section{Research Questions}

1. How concerned are Instructors about the implementation of biometric technology as an identification method in distance learning classes in terms of:
a. Privacy issues?
b. Religious issues? 
c. Health issues?

2. How concerned are Students about the implementation of biometric technology as identification method in distance learning classes in terms of:
a. Privacy issues?
b. Religious issues?
c. Health issues?

3. What differences are there between groups (e.g., Instructors and Students, males and females, etc.) in their responses to items regarding:
a. Privacy issues?
b. Religious issues?
c. Health issues?

\section{Research hypotheses and Assumptions}

This study was performed with the assumption that instructors are concerned about the identity of their learners, specifically during the taking of exams and quizzes. The study also assumed that instructors are not confident that the biometric system would be able to authenticate accurately the identity of learners. The study assumed that instructors believe that implementing the system might negatively affect enrollment of learners in distance learning classes. In addition, the study assumed that students are concerned about the implementation of the biometric system. Students are concerned about the misuse of their biometric data, sharing their data with other agencies, saving their data in non-secure storage, using too intrusive biometric technology and the health implication of using some biometric technology applications. Students are concerned about the negative stigma attached to biometric technology, since fingerprint system 
historically has been associated with criminal investigations; students, in educational institutions, may not welcome using such technology.

The use of qualitative method means that the researcher will be the instrument. It is crucial to check the researcher bias (Fraenkel \& Wallen, 2002; Patton, 2002). Providing background information about the researcher will help better understand his position about the biometric technology in general and this researcher specifically. The researcher received his bachelor of science in Computer Science June 1995 at King Abdul Aziz University, Jeddah, Saudi Arabia. On December 1999, the researcher finished his Master's in Computer science at the University of Missouri-Rolla, Rolla, MO. The researcher conducted some research related to biometric technology at West Virginia University's Computer Science department. According to his plan of study, Computer Science is his minor. He experienced the technology personally at different places during his traveling back and forth to his home country Saudi Arabia. As an international student, the researcher experienced biometric technology at different federal agencies such as, Immigration and Naturalization Services during the special registration post September $11^{\text {th }}$; Department of Motor and Vehicles (DMV) when he obtained a new driving license; point of entry at the JFK airport, NY and when he applied for Visa at the consular section of US General Consulate, Jeddah, Saudi Arabia. Therefore, the researcher is familiar with biometric technology and its applications.

\section{Limitations of the Study}

The participants of the study were selected from the College of Human Resources and Education at West Virginia University. There were two groups of participants. The first 
group was comprised of instructors. The second group included students from the college of Human Resources and Education in the 2004 academic year.

\section{Human Subjects Clearance}

In accordance with University policy, a permission to conduct research involving human subjects was obtained prior to collecting any research data. A copy of the approved application is included in the appendices. 


\section{CHAPTER 2}

Literature Review

Biometric systems have been used and implemented widely throughout history. It has been recorded that the Chinese used fingerprints thousands of years ago. However, using other biometric technologies as a method of authentication is considered an emerging field. According to Wayman (2001a), biometric system identification is based on the authentication of living people's identity according to their physiological or behavioral characteristics. Figure 2.1 depicts the classifications of biometrics.

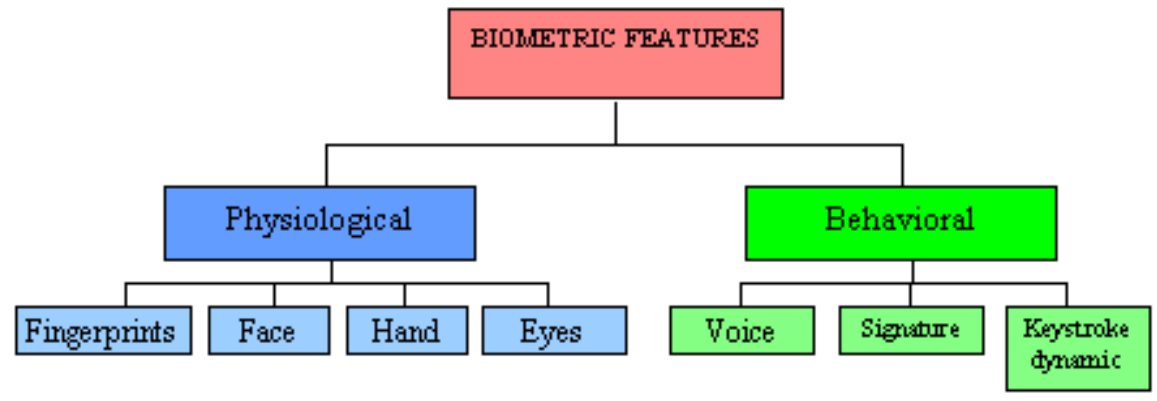

Figure 2.1. Biometric classifications (Biometrika, 2003).

\section{Biometric System Modes and Functions}

The biometric system has two main functions: verification and identification. Verification takes place when the system tries to verify users' identity in order to grant them certain services or privileges. The other function is identification and is used to determine whether a person is known to the system. This is illustrated in Figure 2.2. In the first mode, people provide the system with some information, such as user ID or name and their biometric identifier so that the system checks and compares their 
biometric identifier with the one stored in the database. If it matches, the user is granted access. The matching process in this mode is a one-to-one comparison.

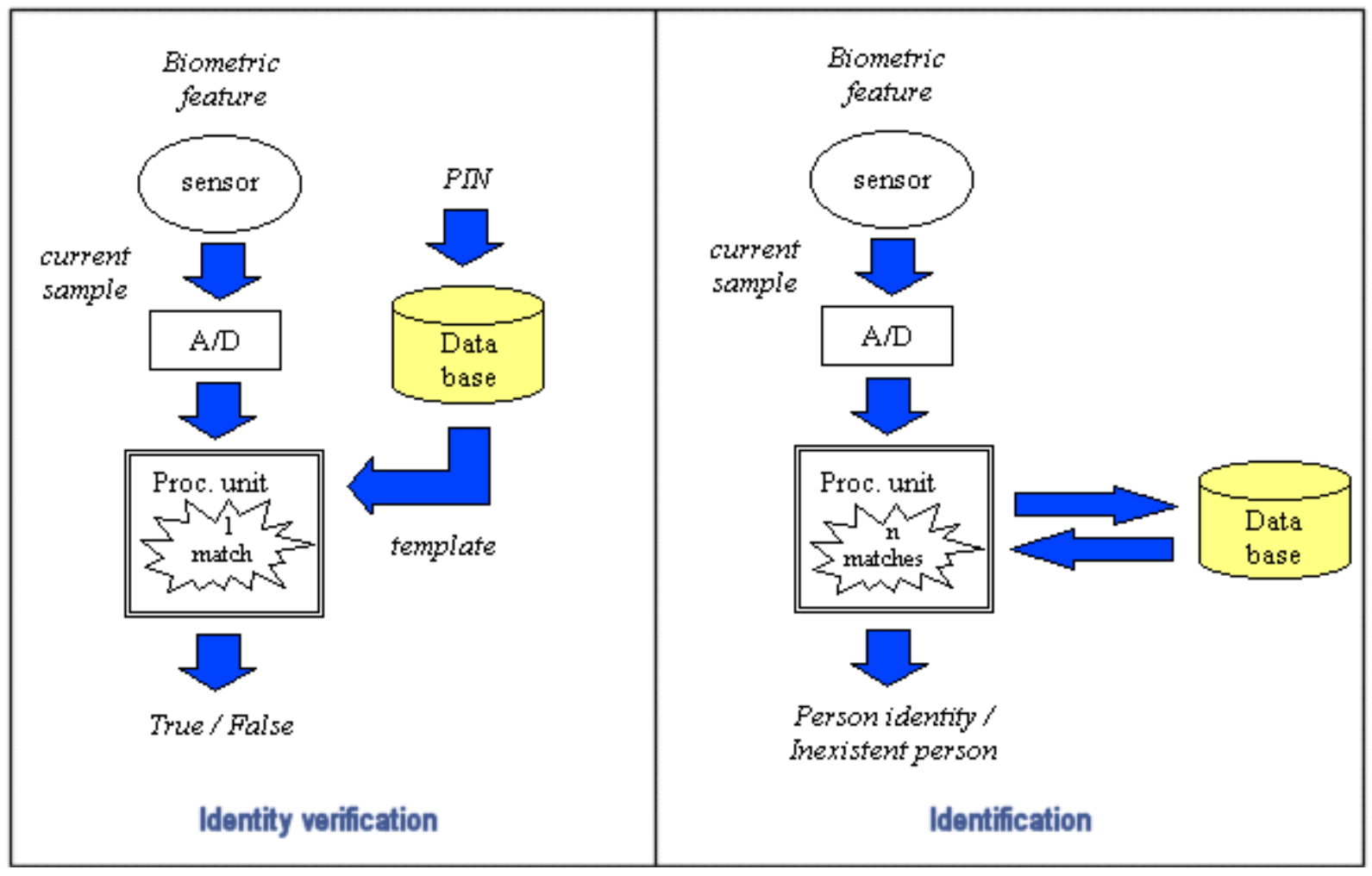

Figure 2.2. Biometric systems modes: Verification \& identification (Biometrika, 2003).

On the other hand, during the identification mode users are exposed to the biometric sensor with or without their knowledge. The system might decide whether they are listed in the database or not. This type of matching is a one-to-many comparison, which is very costly and slow. This type of identification has more applications in government buildings or in high security domains. In general, every user of the system needs first to go through the enrollment step, and then the authentication process takes place. In some cases, the system administrator enrolls or signs up people in the system without their consent -as in the case of monitoring criminals or terrorists (see Figure 2.3). 


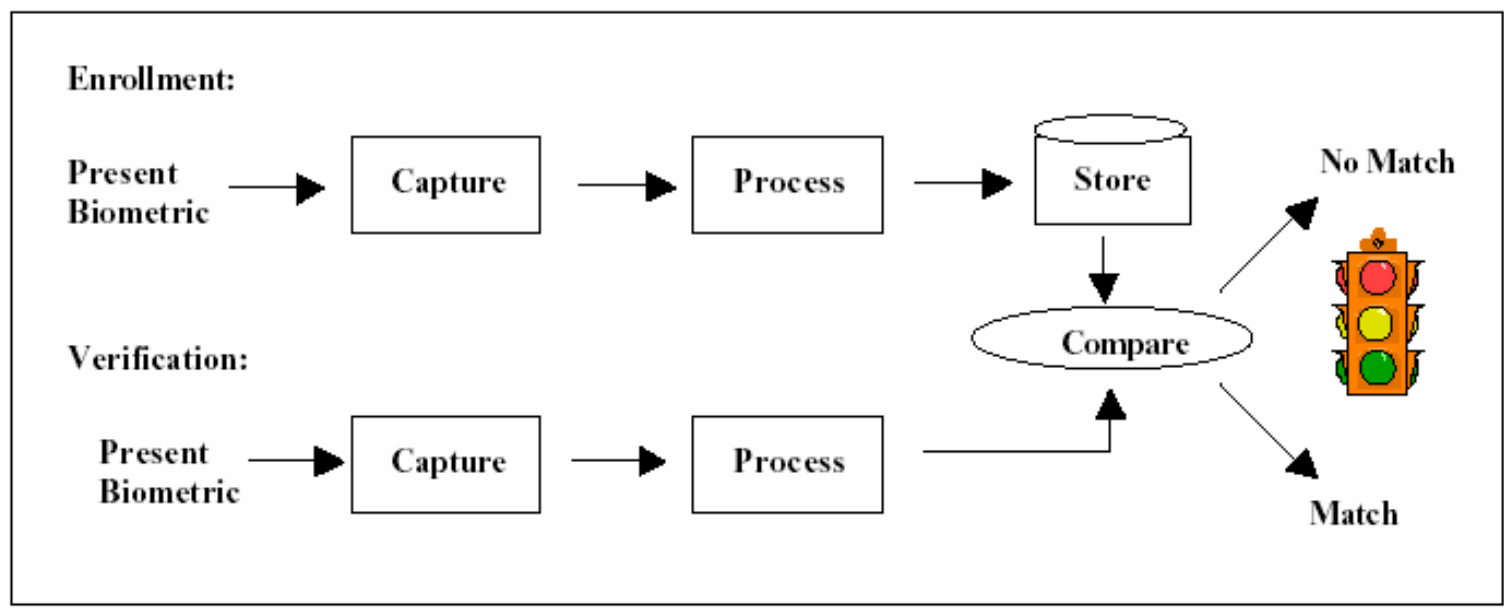

Figure 2.3. The enrollment and authentication steps in biometric systems

Biometrika, 2003).

\section{Biometric Systems Criteria}

Physiological characteristics and behaviors must meet certain criteria before they become candidates for an authentication system. Dr. Wayman (2001a) suggests a few properties such as:

Robustness or stability: It means that the characteristic or behavior is not subject to change largely over time or aging.

Distinctiveness or uniqueness: The chosen biometric identifier is unique for each individual.

Accessibility: This means that the subject's biometric characteristics are easily exposed to a sensor.

Availability or universality: This means that it can be applied to all people.

Acceptability: This means that users perceive the method as a non-intrusive technology. 


\section{Subsystems of Biometric Technology}

The design of a biometric system consists of five subsystems (Wayman, 2001a):

o Data Collection: In this step, data is collected from users.

o Transmission: Data is computed, transmitted, and submitted to the next subsystem either for store (in enrollment stage) or for comparison purposes (in case of authentication).

o Signal Processing: In this subsystem, features are extracted, quality is refined and user might be asked for another attempt if data is not clear.

o Decision: In this stage, the system will decide whether the user is accepted or denied with error margin. The decision is not always accurate; it depends on the accuracy threshold and the clarity of data.

o Data Storage: The template extracted from user's data is stored, in most cases, in central database for future matching. To ensure high security, considering privacy issues, data templates should be irreversible, encrypted by strong encryption (Nicols, 1999; Ratha \& others, 2001). See Figure 2.4. 


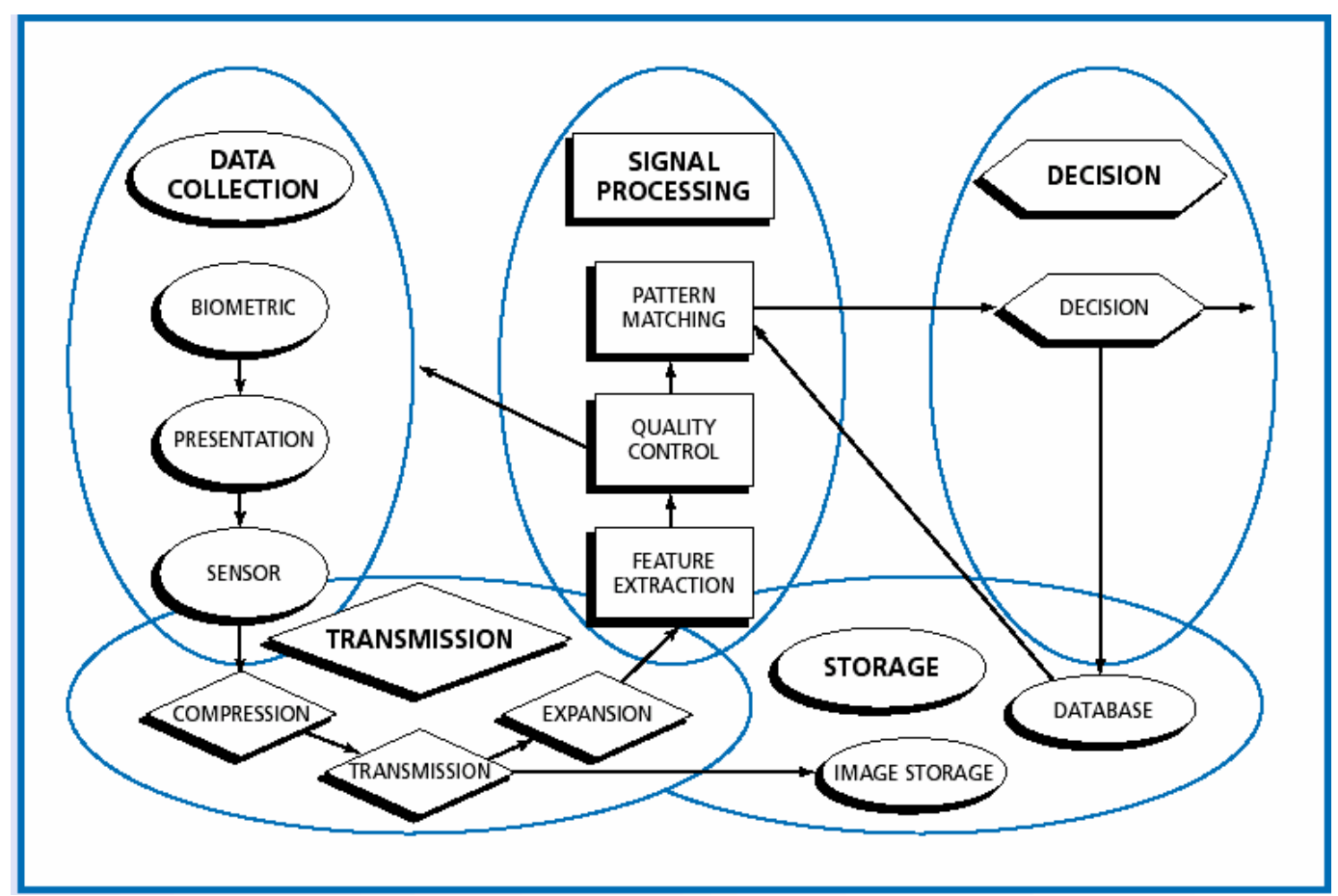

Figure 2.4. The subsystem of the biometric technology (Wayman, 2001a).

\section{Why Use Biometrics?}

Biometric technology has many merits over other traditional systems. It helps in authenticating people as being who they claim to be. There is no way to guess the fingerprint of some one, for example. Tokens might be forgotten at home, stolen, or duplicated (DigitalPersona, 2001; Maltoni , 2003). In biometrics, you do not have to memorize a long password, or to carry a smart card with you. All that you need is to introduce yourself to the system and expose your biological features to the sensor. In some cases, such as in an iris scan, you only need to take a glance at a small lens. General comparisons between the three identification systems are depicted in Table 2.1. 
Table 2.1

Comparison between Current Authentication Techniques

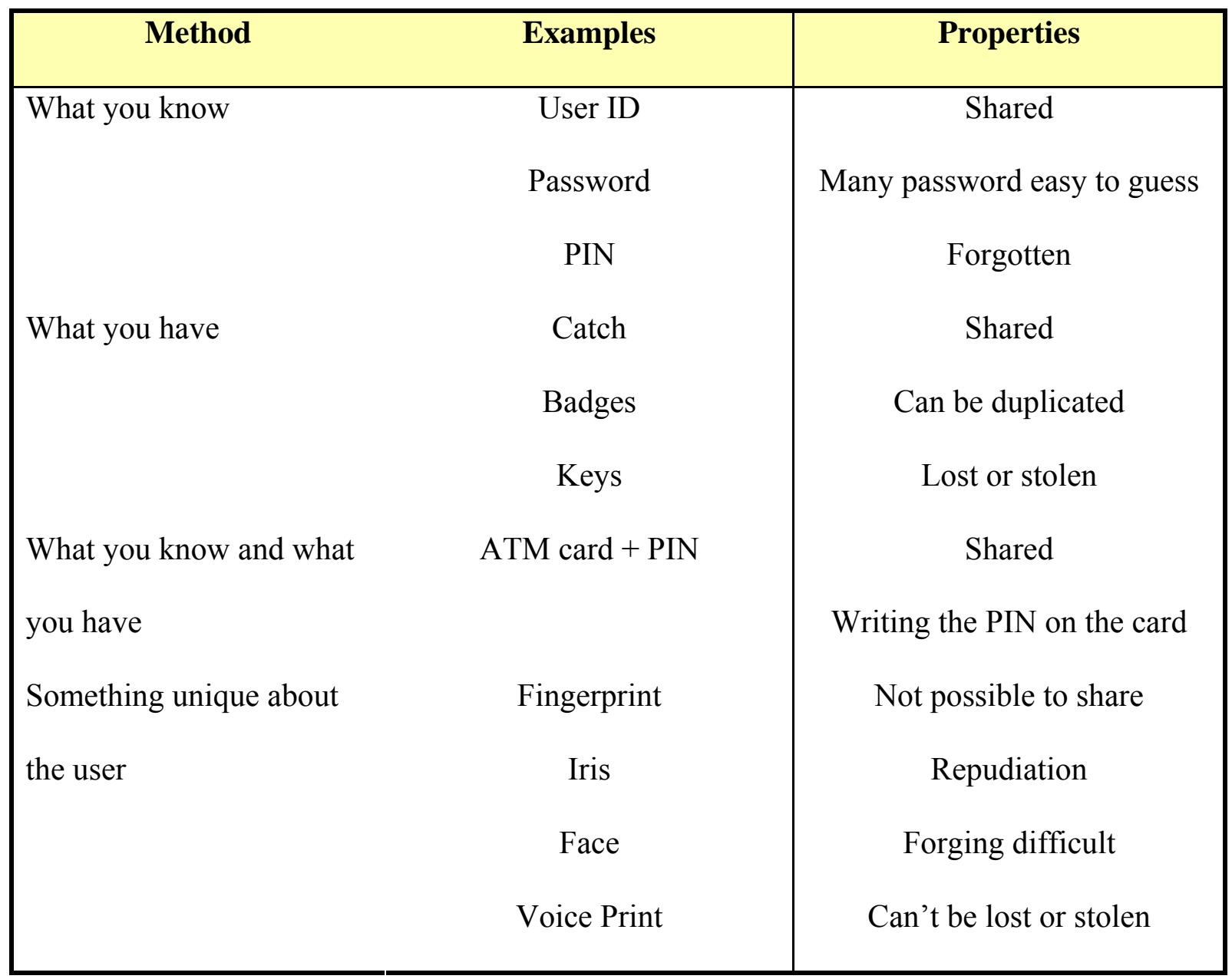

Another advantage of biometric technology is that it prevents people from exchanging or transferring their identity. Using biometrics ensures that users will not be able to access each other's accounts or exchange each other's tokens to access a building or prove attendance. Yet, in some circumstances, biometric systems might be deceived by using photos or a recorded voice (DigitalPersona, 2001). In this case, however, the aliveness of users should be checked using a sensor with thermal properties to solve this problem. 


\section{The Technical Impact}

Biometric systems measure the human property, which vary from time to time due to a variety of reasons, such as aging, injury or sickness. Algorithms used in this calculation must decide how much variation is acceptable. That is why biometric authentication systems are not always $100 \%$ accurate. The percentage of error is divided into two types: False Acceptance Rate (FAR) which happens when the system accepts someone who is not legible, and is False Rejection Rate (FRR) that happens when the system errs and rejects legitimate users (Tistarelli \& others, 2002; Wayman, Jain, Maltoni, \& Maio, 2003).

The trade off between security and convenience is very clear in biometric system authentications. Technically speaking, it is not possible to get rid of the error; yet it could be minimized or decreased. It depends on the type of system and the implementation of policies. If the priority of security is high, then it will be at the expense of conveniences, as the system must require high accuracy. Therefore, a high number of FRRs will be produced. If security is relaxed then more FARs might happen.

The type of technology used has a great impact in producing FARs and FRRs. For example, fingerprint, iris scan, and dynamic signature have the lowest FARs at a rate of 1 in 10,000 or better. On the other hand, voice recognition, hand geometry, and facial recognition are very poor with high FAR rate. These are more convenient to users. (See Table 2.2) 
Table 2.2

The Trade Off Between Different Factors in Biometric Authentication Systems

\begin{tabular}{|l|c|c|c|c|}
\hline $\begin{array}{l}\text { Biometric } \\
\text { Technology }\end{array}$ & Accuracy & Convenience & Cost & Compact \\
\hline Fingerprint & 5 & 5 & 4 & 4 \\
\hline Voice & 1 & 5 & 5 & 5 \\
\hline Face & 2 & 3 & 4 & 3 \\
\hline Hand & 3 & 3 & 2 & 2 \\
\hline Iris & 5 & 2 & 3 & 3 \\
\hline
\end{tabular}

Source: Biometrics : personal identification in networked society

One technical issue is constructing biometric identifiers; it is more complicated and sophisticated compared with generating a traditional password. In the case where a password is revealed, it is easy to revoke it or reset it. However, revoking biometric identifiers is very difficult, if not impossible. Furthermore, the rate of FAR in most cases is higher than the rate of revealing, hacking or stolen password (Ankari, 2001).

\section{The Social Impact}

Many studies have been conducted in the area of biometric technology and its implications on society (Wayman, 2001b). The most comprehensive one was compiled by The ORC International Report, a survey that was conducted in September 2001 and August 2002 (ORC Report, 2002)

Zimmerman and others have discussed the implications of using biometrics technology. Unfortunately, their discussions gave few details, focusing only on business and private companies (Ankari, 2001; Zemmerman, 2002). 
Use of biometric technology for identification purposes raises some social concerns. The first is whether the technology is appropriate. Few questions have been posed about implementing biometrics in hospitals, banks and federal buildings. Many users believe that biometric technology invades their privacy. A few decades ago, when fingerprinting first was introduced, people resisted it. The need for such technology, however, outweighed the public resistance. Today, people are debating whether such technology as retinal scans, iris scans, and facial recognition are too intrusive (Zimmermann, 2002).

The other side of the debate is about the use of data and information. People are concerned about the handling of their data. They believe that their data may be stored improperly or be vulnerable to attack. Some users believe that their data might be abused, shared with other agencies or even sold. The main question is what will happen to their biometric data and how secure will it be from other parties (ORC report, 2002)?

Some legal professionals believe that using biometrics technology is so intrusive that it would violate the Fifth Amendment concerning the protection against selfincrimination. Obtaining very detailed data form people, such as retinal scans and DNA samples, may force self-incrimination (Wayman, 2001b). People are reluctant to try the system because a criminal stigma is still attached to biometrics, specifically fingerprints.

Due to the nature of the system, its accuracy is a crucial concern for both individuals and law enforcement agencies. The FAR rate produced by biometric systems is very sensitive; it has a great impact socially and legally for the acceptability of the technology (ORC Report, 2002). Figure 2.5 shows the comfort ability rating for various biometric technologies. 


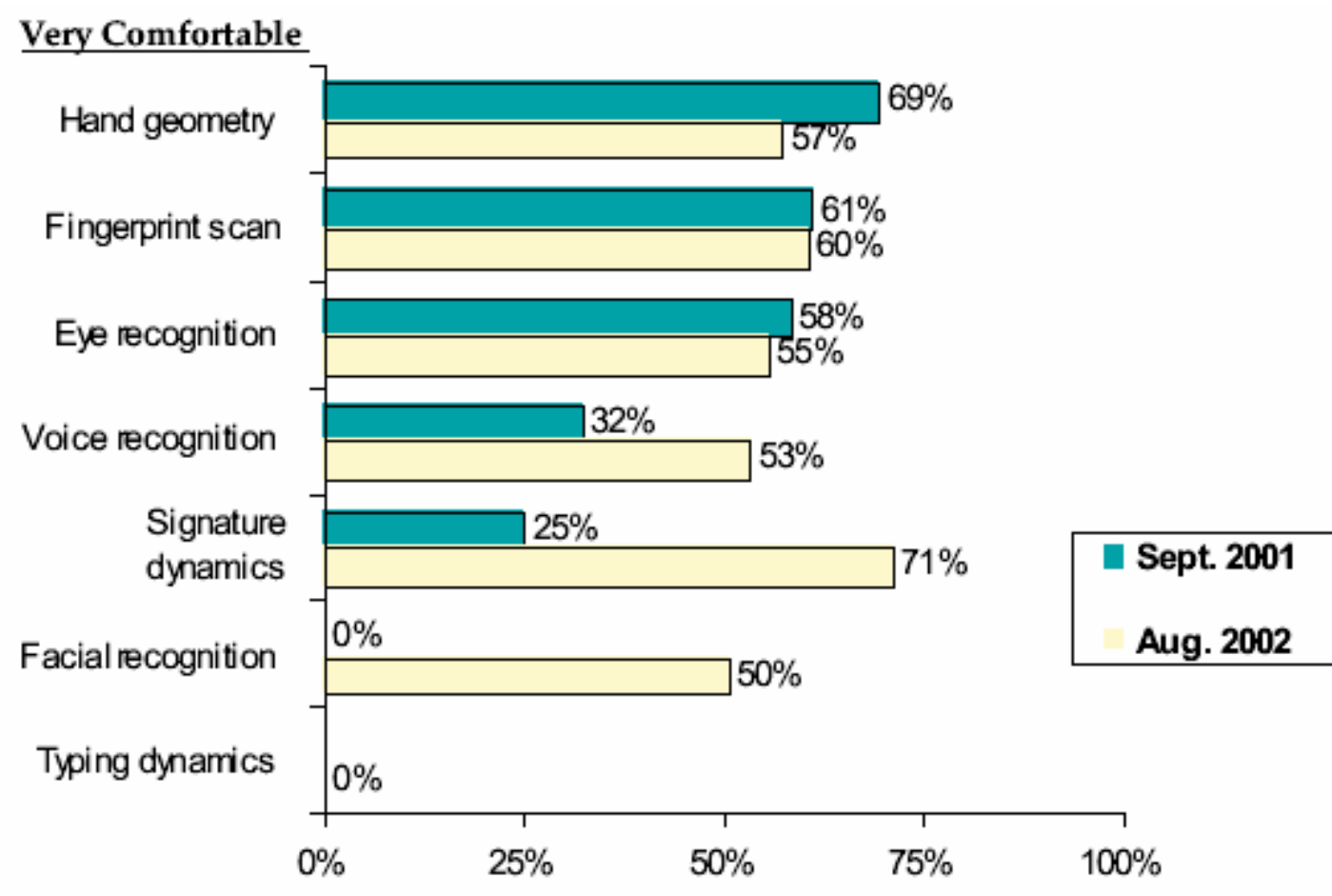

Figure 2.5. Different biometric technologies and their rating on comfortability (ORC report, 2002).

The other factor is the justification of using the system. The figure below (see Figure 2.6) indicates the acceptability of using biometrics for preventing crimes by government and law enforcement, which may not be the same if the system is installed in public schools, private colleges, or even deployed in local businesses (ORC Report, 2002). 

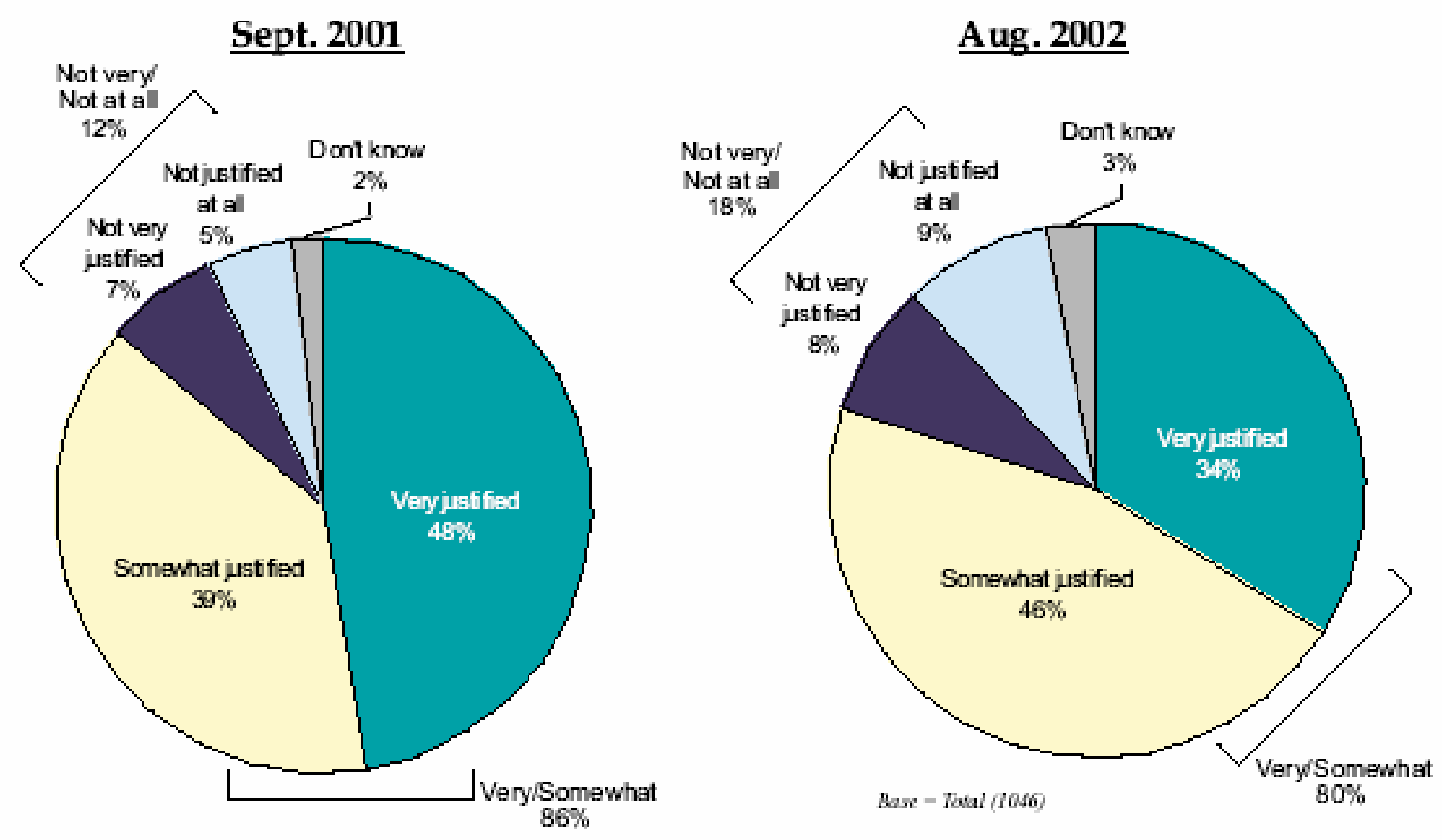

Bas - Tosal $(1017)$

Figure 2.6. The acceptability of using biometrics to prevent crimes (ORC report, 2002).

The technology of biometrics is still in its infancy phase. It takes time for people to know it, trust it, use it, accept it and then adopt it. According to Rogers (1995) in his book "Diffusion of Innovations", the diffusion of technology takes an S-shape before it completes its life cycle. In the case of biometric technology, it takes time to be diffused and adopted by both government agency and private sector.

Religious groups have their own objections toward using biometric technology. Some religious sects believe that using facial recognition or fingerprints contradict their theological teachings. In addition, conservatives stand on the side of the state, supporting the implementation of rigorous identification systems. Their static and rigid doctrine 
might slow them down. On the other side, liberals are willing to accept this new technology, but not at the expense of their privacy and civil liberty.

In conclusion, using biometric technology as a method of identification has significant impact on society. However, technology advocates should balance the rights of individuals and the safety of the society, "Installing privacy code and demonstrating compliance with it [should] be essential to public acceptance" (Privacy and American Business, 2002).

\section{The Economic Impact}

Biometric applications have been used widely in different fields. Businesses, banks and big corporations were among the first innovators of this technology. According to the ORC report (2000), the investment in biometric technology in 2007 will be five times that of 2003 (see Figure 2.7). The cost of both hardware and software is decreasing rapidly, for example, the cost of a fingerprint sensor is about \$100 now (Zimmerman, 2002).

Discussing the implications of implementing biometric technology from economic point of view is very wide. Due to the limitation of the study, this document focuses only on the educational domain, such as distance learning or online. Biometric technology has been introduced to solve the dilemma of identity at the same time, to overcome the drawbacks of other methods such as passwords and tokens.

In contrast, with other methods biometric technology requires specific hardware and software. It mandates specific sensors to capture the target characteristics or behavior. Additionally, specific programs are needed to run the application. In traditional systems, there is no need for specific application, devices or hardware. 

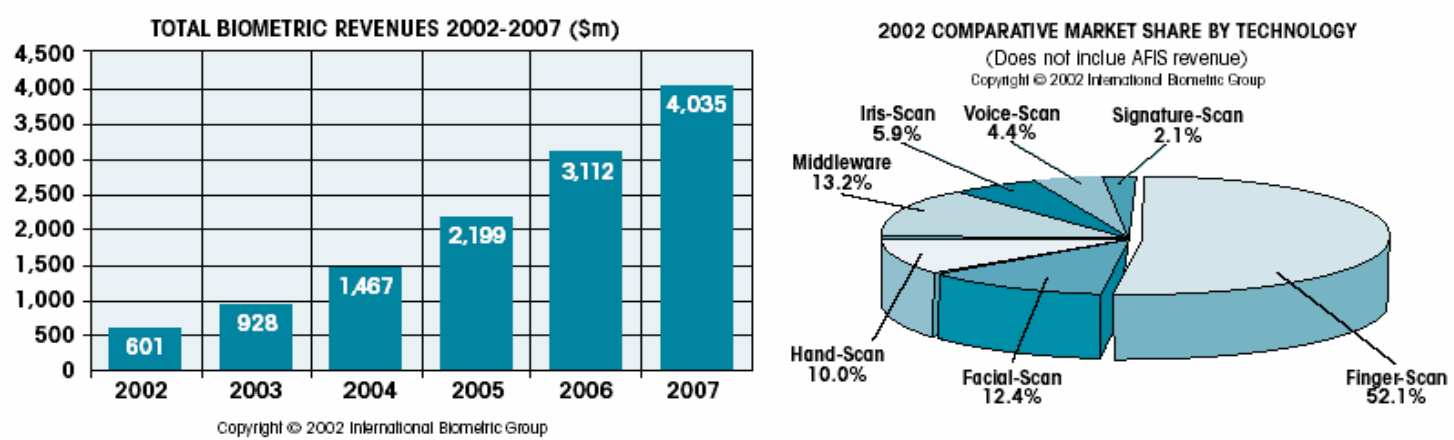

Source: International Biometric Group's Biometric Market Report 2003-2007; 275 pages, 85 figures and charts; September 2002; $\$ 3995$ To order a copy, visit www.ibgweb.com/reports/public/market_report.html or call (212) 809-9491.

Figure 2.7. Comparative market share by technology (ORC report, 2002).

Biometrics helps in cutting the cost involved in tutoring users and provides them with the proper passwords or tokens. However, the technical support and maintenance costs are essential in the case of biometric applications. From an interview conducted with Cindy Hart, extended learning administrator, one of the obstacles of implementing biometric technology is the cost involved. Due to budget cuts, it is extremely difficult for schools and institutions to afford installing such technology. One of the suggestions is to raise the tuition fees to cover any future project, such as installing biometric devices (Hart \& Albalawi, 2003).

Biometric system identification methods have an excellent potential in many areas, including distance learning. It should help users accomplish their goals easily, securely, confidentially, and with high respect to their civil rights. In online, for example, students will be able to access their accounts securely and privately. All over the world, students should be able to enjoy their rights and privileges without trading their privacy or losing their rights. Schools and institutions can impose their policy and regulations smoothly. The accreditation agencies will be able to maintain their standards and credentials. 
As a technology, biometrics has both cons and pros. It has technical, societal and economic implications (i.e. Technological fix). It is our duty to choose the best technology that serves our interest and achieves our objectives with less technical, social, and economic negative affects (see Figure 2.8).

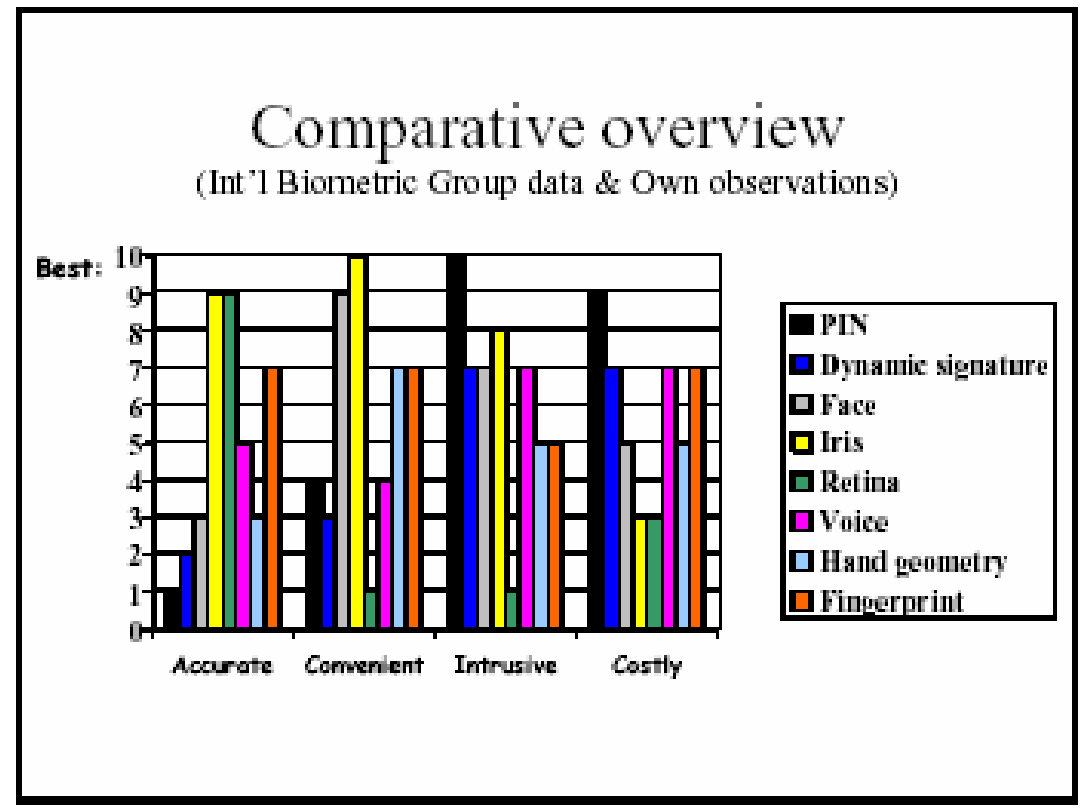

Figure 2.8. The trade-off between different factors in biometric technology (ORC report, 2002). 


\section{CHAPTER 3}

Method

The purpose of this chapter is to describe and discuss the method used in this study. The following summarizes the contents of the chapter:

1. The purpose of the study.

2. The research questions.

3. The research methodology that was used in the study.

4. Description of the instruments, and

5. The statistical procedures that were used to analyze the collected data.

\section{The Purpose of the Study}

Implementing biometric technology is not an easy task. Many factors should be considered to make the system more efficient and acceptable. Throughout the review of publications related to the implementation of biometric technology, the issue of privacy was highly emphasized. This study investigated the social and cultural issues related to the implementation of biometric technology as an identification method in the distancelearning paradigm.

The study determined which issues are more critical to both instructors and learners. In addition, it tested the acceptability of the biometric technology as an authentication method in online courses from the learners', and instructors' points of view in the College of Human Resources and Education at West Virginia University. It is hoped that the study will help to improve the system performance, if it is implemented. Findings and results of this research will help schools, instructors and learners to better 
understand the nature of biometric technology, as well as, help stakeholders to design and implement the biometric authentication system with minimal side effects.

\section{The Research Questions}

1. How concerned are instructors about the implementation of biometric technology as an identification method in distance learning classes in terms of:
a. Privacy issues?
b. Religious issues?
c. Health issues?

2. How concerned are students about the implementation of biometric technology as an identification method in distance learning classes in terms of:
a. Privacy issues?
b. Religious issues?
c. Health issues?

3. What differences are there between groups (e.g., Instructors and Students, males and females, etc.) in their responses to items regarding:
a. Privacy issues?
b. Religious issues?
c. Health issues?

The Research Methodology

Qualitative methods were used initially to establish the basis of the study, followed by a quantitative analysis. Therefore, the study is qual $\longrightarrow$ QUAN (Morse, 1991). This means the study started with qualitative methods and then followed by quantitative methods. This type of mixed method is called "Complementarity Design" 
where findings from quantitative methods are enhanced through findings from qualitative methods (Greene \& Caracelli, 1997).

\section{The Research Procedure}

Mixed methods can be used to strengthen a study. "Qualitative and quantitative data can be fruitfully combined to elucidate complementary aspects of the same phenomenon" (Patton, 2001). For the purposes of clarity, the outline of procedures will be as follows:

In the beginning, during the literature review, the researcher has identified the social and cultural factors that contribute to the adaptation of biometric systems in educational institutions. The researcher reviewed the existing instruments such as questionnaires that were used by others to assess the implementation of biometric systems in other settings. Then the following research procedure phases took place: Phase I:

1. Developed interview protocols used during interviews with specific instructors and students.

2. Identified a sample of instructors who teach online courses, and graduate students who take online courses.

3. Conducted interviews with the sample of Instructors and Students.

4. Analyzed interview data to refine the criteria and factors of the study, and provided more detailed information about the implementation of the biometric technology and its social and cultural impacts.

Phase II: 
1. Developed two different surveys: one for Instructors and another for Students. The surveys were later distributed to a sample of Instructors and Students.

2. Identified a sample of instructors and graduate students for the pilot study.

3. Conducted a pilot study with the sample of instructors and students.

4. Analyzed pilot study data and refined the surveys and determined the content validity of the instruments. The results of the pilot study were discussed in more detail later.

5. Revised the instruments according to the result of the pilot study.

6. Identified a sample of instructors and graduate students for the surveys.

7. Administered the surveys to the selected sample.

8. Coded, analyzed and interpreted the data collected from surveys. The data collected by questionnaires was a mixture of quantitative and categorical data. Therefore, frequency distributions graphs were used for the quantitative data. Pie charts have been used to display the categorical data. Measures of central tendency and variability were calculated by calculating the mean and the standard deviation of responses to each item that produced quantitative data. $t$-Tests for independent means were applied to assess the significance of differences in respect to each item based on group membership (e.g., Instructors and Students, Males and Females, etc.). 


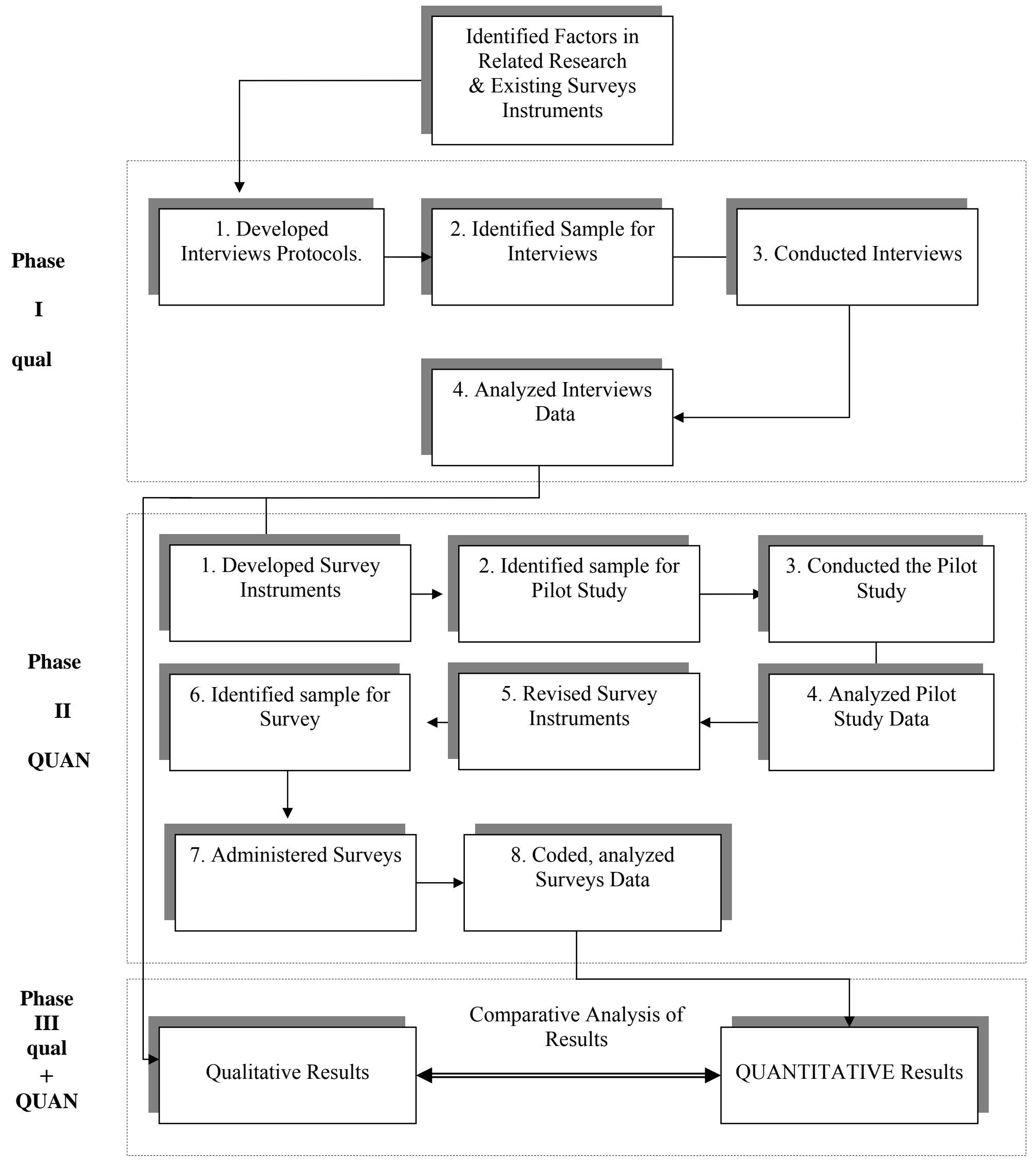

Figure 3.1. The research procedure flow chart. 
Phase III:

Conducted a comparative analysis to data colleted in Phase I (qual) from surveys in phase II (QUANTITATIVE) and answered the research questions. The interviews outcome were used to inform the results of the quantitative methods (Triangulation), as well as to provide more detail, which explained some phenomena that emerged (Fitzpatrick, Sanders \& Worthen, 2004) (see Figure 3.1, for more details).

Phase I: The Interview

Face-to-face interviews were conducted with students and instructors at the College of Human Resources and Education. Interviews were conducted before the surveys were distributed to the target population. Therefore, the instruments were refined and improved. Because the method is qualitative, the researcher tried to point the way rather than leading the way.

During interviews, individual, semi-structured open-ended questions were used which allowed for a direct comparison of data across participants and data sets. In addition, the open-ended format was enough to allow participants to define the issues and inform the researcher of their understanding (Patton, 2001). All interviews were audio taped and transcribed. The researcher then analyzed and interpreted the results; themes and patterns were identified. The relationship between these themes and patterns were assessed. The researcher used different techniques such as open coding and selective coding in order to see visual findings.

\section{The Interview Population and Settings}

According to Patton (2001), "there are no rules for sample size in qualitative inquiry." It depends on the purpose of the study and the limitations on time and resources 
(Patton, 2001). In this study, the researcher interviewed five graduate students who had taken online courses and five faculty members who had taught or plan to teach online courses in the College of Human Resources and Education. The interviews were conducted, with no restrictions on any student or faculty member, including, gender, race, age, religion or major. The interviews took places in faculty member's offices and open lounge areas for the students. The faculty members were chosen from several departments within the College of Human Resources and Education. The researcher chose at least one faculty member who is experienced in teaching online courses; at least one faculty member who is just beginning; and at least one faculty member who never taught online courses.

The researcher chose instructors from different departments and with a variety of experiences. The researcher picked participants randomly when he found more than one choice. At the same time, the researcher asked the instructors to suggest students who could be interviewed (snowball sampling); the researcher asked the instructor to suggest students who have good understanding of online courses -when instructors suggested more than one student- the researcher chose participants randomly (Fraenkel \& Wallen, 2002).

Students were selected from different disciplines within the College of Human Resources and Education. The sample consisted of one student from the Technology Education department, one student from the Special Education department and one student from the Curriculum and Instruction department, which order ensured a cross section of students. The courses schedule was available on the university website and in the dean's office. 


\section{The Interview Questions}

1. Please list the online courses you have taken/taught.

2. Describe the positive aspects of online courses.

3. Describe the negative aspects of online courses.

4. How was verification of student identity handled in the courses you took/taught?

5. Describe the positive aspects of the verification system you used.

6. Describe the negative aspects of the verification system you used.

7. There are several biometric systems that can be used to verify identity, as I list them, please describe your perspective regarding their use in online classes: fingerprints, iris scan, etc.

8. (If they do not describe these issues). Do you believe there are privacy issues related to the use of biometric systems? Cultural issues? Religious issues? Health issues?

9. Given the systems we have discussed, which would you prefer and why would you prefer that system?

\section{The Interview Validity and Reliability}

Since interviewing is a qualitative method, checking its validity and the reliability is different from traditional ones used in the questionnaire instrument. In addition, since the qualitative part of the study does not attempt to explore relationships, internal validity is, strictly speaking, irrelevant. Because of the dependency on the researcher as the instrument and the interpreter of the information, the bias of the researcher is a very common concern (Fraenkel \& Wallen, 2002). 


\section{Triangulation}

The purpose of the triangulation was to strengthen the study findings and to confirm the outcomes of the research by different means. In addition, "corroboration of data through cross-checking and triangulation are two methods used ...to establish credibility" (Fitzpatrick, Sanders \& Worthen, 2004).

The triangulation is employed by four different types: (1) data triangulation, the use of a variety of data sources in a study, (2) investigator triangulation, the use of several different researchers, (3) theory triangulation, the use of multiple perspectives to interpret a single set of data and (4) methodological triangulation (Patton, 2001). In this research, the last type was used; combining more than one method (qualitative and quantitative).In this study there were two different data sources; interviews and surveys. The surveys provided broad, but not deep information, the interviews, however, provided deep, but those interviewees were not necessarily representative (Fitzpatrick \& Others, 2004). In addition, examining the subjectivity of the researcher and utilizing member checking for verification ensured that the researcher was gathering reliable data. These data were used to ensure that the survey items included questions that addressed all types of concerns raised by interviewees.

Phase II: Conducting the Pilot Study and Administrating the Surveys

\section{The Pilot Study}

The researcher performed a pilot study to improve the instruments and determine its content validity and understanding. The instruments were sent to a number of participants chosen conveniently from graduate students and instructors in the College of Human Resources and Education, these participants were not be part of the main study. 
The surveys were pre-tested to assess clarity, readability, and time for completion. For the pre-test, the two surveys were administered to a convenience sample of both students and faculty members who checked each item carefully, revised and suggested better wording or phrasing.

The Pilot Study Population and Settings

The population of the pilot study was a group of graduate students and faculty members in the College of Human Resources and Education. This population was selected to participate in the pilot study in order to validate the instruments by checking for their content validity. The researcher chose a convenient group of students and faculty members to participate in the pilot study; ten students and two faculty members participated in the pilot study. The researcher considered different criteria when he chose the participants; for example, the researcher considered participants' experience with online courses, their gender and their race.

The researcher chose a graduate level course and coordinated with the instructor to conduct the pilot study. The researcher checked courses that were available in summer 2004, coordinated with the instructors and arranged for pilot study. For the online surveys, the researcher conducted it in the computer lab in the College of Human Resources and Education. The researcher asked only graduate students to participate in the study.

\section{The Instruments (surveys)}

An online survey was distributed as well as paper-copies of the survey. The survey method is a useful technique for producing meaningful data and answering research questions (Fraenkel \& Wallen, 2002). While qualitative methods are useful for 
providing additional support, the collection and quantification of data from a survey is more effective because it is cost-effective, time-effective and easy to analyze (Fitzpatrick \& Others, 2004).

\section{The Survey Population and Settings}

When the surveys were improved and refined, they were distributed to samples of graduate students and faculty members in the College of Human Resources and Education. According to the Planning Division census, there were about 1800 graduate students and 56 faculty members in the College of Human Resources and Education. The size of this group was 189 students and 30 faculty members. According to Fraenkel and Wallen, there is no clear-cut way to determine the size of the sample. However, since the study outcomes will not be generalized other than to the population of graduate students and faculty members at the College of Human Resources and Education at West Virginia University, this number was believed to be adequate (Fraenkel \& Wallen, 2002).

In this case, the surveys were distributed purposively in graduate courses taught in the College of Human Resources and Education. The specific purpose of the research was -"to investigate the attitude of the students and instructors toward the implementation of the biometric system as identification method in online course". - Graduate students who had taken online courses or instructors who taught online course fit best for this purpose based on prior knowledge.

The researcher checked the course schedule and coordinated with the course instructor to conduct the survey. The students and instructors were approached in the class by the researcher; the researcher asked participants whether they prefer online questionnaire or a hard copy. Based on their preference the researcher distributed the 
appropriate questionnaire. The researcher collected from participants the paper copies of questionnaires; the online questionnaires results reported to the researchers account automatically.

\section{The Survey Validity and Reliability}

Two surveys (one for faculty and one for students) were developed based on similar studies (ORC, 2002). This survey were modified and used for this study to address specific issues related to the dilemma of identity verification in educational institutions. The pilot study and the interviews were used to revise the surveys and identify the proper questions. Data gathered and analyzed during Phase I was used to add more questions, delete irrelevant questions and adjust other questions as needed. The researcher took into consideration issues emerging during interviews. In addition, during the pilot study, the researcher worked closely with participants. For example, when participants needed further explanations or details about the survey, the researcher answered their questions. The researcher considered their comments and input regarding the survey instruments. In addition, the researcher was able to determine the time for completing the survey.

The validity and the reliability of the instruments were checked in different ways. First, the content validity was checked; the clarity and readability of the questions was tested through the pilot study. The items of the instrument covered all aspects of the study, and complemented by the interview questions. Therefore, the content-related evidence was checked by samples of participants during both the pilot study and the interviews. Reliability of the test instrument is not available. 
Phase III: Data Analyses

\section{Analyzing the Qualitative Data}

Since mixed method is used, the researcher analyzed both data coming from the interviews (qualitative part) and data collected by questionnaires (quantitative part). Data collected from interviews were used to answer the research questions; themes and patterns were identified. The relationship between these themes and patterns were assessed. Researcher used different techniques such as open coding and selective coding in order to see visual findings. Because the method is qualitative, the researcher tried to point the way rather than leading the way. The researcher identified themes and patterns while he interpreted the participants' answers.

\section{Analyzing the Quantitative Data}

Descriptive analyses have been used to analyze the data collected by the questionnaires, since "the major advantage of descriptive statistics is that they permit researchers to describe the information contained in many scores with just a few indices such as the mean or median" (Fraenkel \& Wallen, 2002). The data collected by questionnaires was a mixture of quantitative and categorical data. Therefore, frequency

distributions graphs were used for the quantitative data. In addition, a pie chart was used to indicate the categorical responses of participants. The frequency distributions have been compared by the user's group membership (e.g., student or faculty member). In addition, bar charts and tables were used to display the results. The comparisons were made based on the responses of participants to the items under the major three issues; privacy issues, religious issues, and health issues. Furthermore, measures of central 
tendency were utilized; the mean of each item was calculated. The standard deviation was calculated to assess the variability of the data collected.

The test for statistical significances were conducted with a level of significance $\alpha=0.05$. In this case, the researcher calculated the statistic value of significance then compared it with the critical value obtained from standard tables. Since there were various kinds of assumptions about the nature of the population from which the samples are taken, the use of parametric technique was more suitable. Example of a parametric test is t-test for independent means since we compare the mean scores of two different groups (e.g., students and instructors). For the categorical data, t-test for proportions was used to assess the difference in proportion of one group based on gender, for an example see Table 3.1 and 3.2. 
Table 3.1

The Design Plan for the Interviews and the Surveys

\begin{tabular}{|c|c|c|c|}
\hline \multirow[t]{2}{*}{ Research question } & \multicolumn{2}{|c|}{ Data Sources } & \multirow[t]{2}{*}{ Data Analyses } \\
\hline & Item Type & Item Number & \\
\hline $\begin{array}{l}\text { 1. How concerned are instructors about } \\
\text { the implementation of biometric } \\
\text { technology as an identification method } \\
\text { in distance learning classes in terms of: }\end{array}$ & $\begin{array}{l}\text { Instructors' Interviews } \\
\text { and Surveys }\end{array}$ & $\begin{array}{l}\text { The interviews, } \\
\text { Part II, } \\
\& \\
\text { Part III } \\
\text { of the survey }\end{array}$ & $\begin{array}{l}\text { Analyzing the transcript } \\
\text { of the interviews by } \\
\text { themes. } \\
\text { Descriptive for each item } \\
\text { in the survey; total score, }\end{array}$ \\
\hline \multirow[t]{2}{*}{ 1.a. Privacy issues? } & Likert scale & Items: A.1-7 & frequency polygon \& Pie \\
\hline & $\begin{array}{l}\text { Multiple choice \& Open } \\
\text { Ended }\end{array}$ & $\begin{array}{l}\text { Open-ended } \\
\text { questions }\end{array}$ & charts. \\
\hline \multirow[t]{3}{*}{ 1.b. Religious issues? } & Checklist & Items: B.1-5 & \\
\hline & Multiple choice \& & Open ended & \\
\hline & Open Ended & questions & \\
\hline \multirow[t]{2}{*}{ 1.c. Health issues? } & Likert scale & Items: C.1-3 & \\
\hline & $\begin{array}{l}\text { Multiple choice \& } \\
\text { Open Ended }\end{array}$ & $\begin{array}{l}\text { Open ended } \\
\text { questions }\end{array}$ & \\
\hline \multirow[t]{2}{*}{$\begin{array}{l}\text { 2. How concerned are students about } \\
\text { the implementation of biometric } \\
\text { technology as identification method in } \\
\text { distance learning classes in terms of: }\end{array}$} & $\begin{array}{l}\text { Students' interviews } \\
\text { and survey }\end{array}$ & $\begin{array}{l}\text { The interviews, } \\
\text { Part II, } \\
\&\end{array}$ & $\begin{array}{l}\text { Analyzing the transcript } \\
\text { of the interviews by } \\
\text { themes. }\end{array}$ \\
\hline & & & \\
\hline \multirow{2}{*}{ 2.a. Privacy issues? } & Likert scale & Items: A.1-7 & frequency polygon \& Pie \\
\hline & $\begin{array}{l}\text { Multiple choice \& } \\
\text { Open Ended }\end{array}$ & $\begin{array}{l}\text { Open-ended } \\
\text { questions }\end{array}$ & charts.. \\
\hline \multirow[t]{3}{*}{ 2.b. Religious issues? } & Checklist & Items: B.1-5 & \\
\hline & Multiple choice \& & Open ended & \\
\hline & Open Ended & questions & \\
\hline \multirow[t]{2}{*}{ 2.c. Health issues? } & Likert scale & Items: C.1-3 & \\
\hline & $\begin{array}{l}\text { Multiple choice \& } \\
\text { Open Ended }\end{array}$ & $\begin{array}{l}\text { Open ended } \\
\text { questions }\end{array}$ & \\
\hline \multirow{5}{*}{$\begin{array}{l}\text { 3.What differences are there between } \\
\text { groups according to their } \\
\text { memberships(groups, gender, and } \\
\text { biometric background) in terms of : }\end{array}$} & & & Analyzing the transcript \\
\hline & $\begin{array}{l}\text { Instructors', } \\
\text { Students' Interviews \& }\end{array}$ & The interviews, & of the interviews by \\
\hline & Surveys & Part II & Descriptive for each item \\
\hline & & & in the survey; total score, \\
\hline & & $\begin{array}{l}\text { Part lil } \\
\text { of the survey }\end{array}$ & $\begin{array}{l}\text { frequency polygon } \& \text { Pie } \\
\text { charts. }\end{array}$ \\
\hline \multirow[t]{2}{*}{ 3.a. Privacy issues? } & Likert scale & Items: A.1-7 & \\
\hline & $\begin{array}{l}\text { Multiple choice \& } \\
\text { Open Ended }\end{array}$ & $\begin{array}{l}\text { Open-ended } \\
\text { questions }\end{array}$ & \\
\hline \multirow[t]{3}{*}{ 3.b. Religious issues? } & Checklist & Items: B.1-5 & \\
\hline & Multiple choice \& & Open ended & \\
\hline & Open Ended & questions & \\
\hline \multirow[t]{2}{*}{ 3.c. Health issues? } & Likert scale & Items: C.1-3 & \\
\hline & $\begin{array}{l}\text { Multiple choice \& } \\
\text { Open Ended }\end{array}$ & $\begin{array}{l}\text { Open ended } \\
\text { questions }\end{array}$ & \\
\hline
\end{tabular}


Table 3.2

The Research Matrix of Instructors and Students

\begin{tabular}{|c|c|c|c|c|c|}
\hline & \multicolumn{4}{|c|}{ Instructors' point of view } \\
\hline & & Privacy & Religious & Health & Others \\
\hline $\mathrm{T}$ & TA1 & $\sqrt{ }$ & & & \\
\hline $\mathrm{E}$ & TA2 & $\sqrt{ }$ & & & \\
\hline A & TA3 & $\sqrt{ }$ & & & \\
\hline $\mathrm{C}$ & TA4 & $\sqrt{ }$ & & & \\
\hline $\mathrm{H}$ & TA5 & $\sqrt{ }$ & & & \\
\hline $\mathrm{E}$ & TA6 & $\sqrt{ }$ & & & \\
\hline \multirow[t]{3}{*}{$\mathrm{R}$} & TA7 & $\sqrt{ }$ & & & \\
\hline & TB1 & & $\sqrt{ }$ & & \\
\hline & TB2 & & $\sqrt{ }$ & & \\
\hline \multirow{3}{*}{$\begin{array}{c}\mathrm{Q} \\
\mathrm{U} \\
\mathrm{F}\end{array}$} & TB3 & & $\sqrt{ }$ & & \\
\hline & TB4 & & $\sqrt{ }$ & & \\
\hline & $\mathrm{TC} 1$ & & & $\sqrt{ }$ & \\
\hline $\begin{array}{l}\mathrm{E} \\
\mathrm{S} \\
\mathrm{T}\end{array}$ & TC2 & & & $\sqrt{ }$ & \\
\hline \multirow{4}{*}{$\begin{array}{l}\mathrm{I} \\
\mathrm{I} \\
\mathrm{O} \\
\mathrm{N}\end{array}$} & TC3 & & & $\sqrt{ }$ & \\
\hline & T3.1 & & & & $\sqrt{ }$ \\
\hline & T3.2 & & & & $\sqrt{ }$ \\
\hline & T3.3 & & & & $\sqrt{ }$ \\
\hline
\end{tabular}

\begin{tabular}{|c|c|c|c|c|c|}
\hline & \multicolumn{4}{|c|}{ Students' point of view } \\
\hline & & Privacy & Religious & Health & others \\
\hline $\mathrm{S}$ & SA1 & $\sqrt{ }$ & & & \\
\hline $\mathrm{T}$ & SA2 & $\sqrt{ }$ & & & \\
\hline $\mathrm{U}$ & SA3 & $\sqrt{ }$ & & & \\
\hline D & SA4 & $\sqrt{ }$ & & & \\
\hline E & SA5 & $\sqrt{ }$ & & & \\
\hline $\mathrm{N}$ & SA6 & $\sqrt{ }$ & & & \\
\hline \multirow{11}{*}{$\begin{array}{l}\mathrm{Q} \\
\mathrm{U} \\
\mathrm{E} \\
\mathrm{S} \\
\mathrm{T}\end{array}$} & SA7 & $\sqrt{ }$ & & & \\
\hline & SB1 & & $\sqrt{ }$ & & \\
\hline & SB2 & & $\sqrt{ }$ & & \\
\hline & SB3 & & $\sqrt{ }$ & & \\
\hline & SB4 & & $\sqrt{ }$ & & \\
\hline & $\mathrm{SC} 1$ & & & $\sqrt{ }$ & \\
\hline & $\mathrm{SC} 2$ & & & $\sqrt{ }$ & \\
\hline & $\mathrm{SC} 3$ & & & $\sqrt{ }$ & \\
\hline & S3.1 & & & & $\sqrt{ }$ \\
\hline & S3.2 & & & & $\sqrt{ }$ \\
\hline & S3.3 & & & & $\sqrt{ }$ \\
\hline
\end{tabular}




\section{CHAPTER 4}

Data Analyses

The purpose of this study was to examine instructor and student attitudes toward the use of biometric technology as an identification method in online courses. The aim of this chapter is therefore to provide an elaborate description and analysis of the data that was generated in this study. For purposes of clarity, this chapter was organized and presented under each under-girding research question of this study. Since the study is mixed method - starting with qualitative inquiry followed by quantitative method - the analyses will begin first with the qualitative and then examine the quantitative measurements. In the process of addressing each research question, this chapter was organized into the three major phases:

Phase I: Qualitative data analysis for instructors and students groups.

Phase II: Quantitative data analysis including the following subsections:

1. Analyzing items related to the research question 1(RQ1):

a. Analyzing demographic data,

b. Analyzing question items related to the privacy issues,

c. Analyzing question items related to religious issues,

d. Analyzing question items related to health issues and

e. Analyzing open ended questions

2. Analyzing items related to the research question 2(RQ2):

a. Analyzing demographic data, 
b. Analyzing question items related to privacy issues

c. Analyzing question items related to religion issues,

d. Analyzing question items related to health issues and

e. Analyzing open ended questions

3. Data analyzing related to the research question 3(RQ3):

i. Differences between instructors and students group regarding the three issues:
a. Privacy issues
b. Religion issues
c. Health issues

ii. Difference between male and female in the whole population regarding the three issues:
a. Privacy issues
b. Religion issues
c. Health issues

iii. and iv : Within each group(Instructors and Students) discussing differences between male and female regarding the three major issues:
a. Privacy issues
b. Religious issues 
c. Health issues

Phase III: Comparative analysis: contrast between the results of two major data analyses of the qualitative and quantitative methodologies.

Part I: Qualitative Data Analyses

Reviews of the Interview Procedures

Face-to-face interviews were conducted with five students and five instructors at the College of Human Resources and Education. Interviews were conducted before the surveys were distributed to the target population. Through this procedure, the instruments were refined and improved.

During the interviews, individual, semi-structured open-ended questions were used that allowed for a direct comparison of data across participants and data sets. In addition, the open-ended format was enough to allow participants to define the issues and inform the researcher of their understanding. All interviews were audio taped and transcribed. The researcher then analyzed and interpreted the results; themes and patterns were identified. The relationship between these themes and patterns were assessed.

\section{The Interview Population and Settings}

In this study, the researcher interviewed five graduate students who had taken online courses and five faculty members who had taught or plan to teach online courses. The interviews took places in faculty member's offices and open lounge areas for the students. The faculty members were chosen from several departments within the College of Human Resources and Education. The researcher chose two faculty members who are experienced in teaching online courses; one faculty member who is just beginning; and one faculty member who has never taught online courses. The ethnicity of the faculty 
members was white/Non-Hispanic. The gender distribution was three male and two female. The religious affiliation of all Instructors was Christianity.

The researcher chose instructors from different departments and with a variety of experiences. One faculty member was from the Social Science Foundation department, two faculty members were from Curriculum and Instruction and two faculty members were from the Special Education department. The researcher picked participants randomly when he found more than one choice. At the same time, the researcher asked the instructors to suggest students who could be interviewed (snowball sampling); the researcher asked the instructors to suggest students who have good understanding of online courses -when instructors suggested more than one student- the researcher chose participants randomly.

Interviewed students were selected from different disciplines within the College of Human Resources and Education. The sample consisted of two students from the Technology Education department, one student from the Special Education department, one student from the Curriculum and Instruction department and one student from the Pathology and Audiology department.

The race and ethnicities of the interviewees were as follows: One African American student, two White/non-Hispanic students, one Asian student and one student who identified herself as international. The dominating gender was female; three females versus two males were interviewed. The religious affiliations were three Christian, one Muslim and one Buddhist. The diversity of students' majors, race, gender and religion ensured a cross section of students. 


\section{The Interview Questions}

1. Please list the online courses you have taken/taught.

2. Describe the positive aspects of online courses.

3. Describe the negative aspects of online courses.

4. How was verification of student identity handled in the courses you took/taught?

5. Describe the positive aspects of the verification system you used.

6. Describe the negative aspects of the verification system you used.

7. There are several biometric systems that can be used to verify identity, as I list them, please describe your perspective regarding their use in online classes: fingerprints, iris scan, etc.

8. (If they do not describe these issues). Do you believe there are privacy issues related to the use of biometric systems? Cultural issues? Religious issues? Health issues?

9. Given the systems we have discussed, which would you prefer and why would you prefer that system?

\section{Interviews Analyses}

The researcher employed a variety of techniques in analyzing the interview's data. Both Instructors' and Students' interviews were transcribed from audiotapes. Features pertaining to reactions to the implementation of biometric technology were noted and coded. The researcher also used comparative and contrastive frameworks in analyzing the data. Regarding the reactions of Instructors and Students to the privacy, religious and health issues associated with the implementation of biometric identification technology, as well as their preference for particular biometric technologies, the researcher compared 
and contrasted the composite self-reports given by both Instructors and Students during the interviews.

\section{Findings}

The research question sought to find out what instructors and students perceive as some of the problems associated with the implementation of biometric identification technology in the distance education marketplace. Of the few issues identified, privacy seemed to be the preponderant concern. Other issues of concern were religion and the potential for health problems associated with some biometric technologies.

\section{Privacy Issues}

The majority of students and instructors felt that biometric identification technology would grossly invade their privacy. Interestingly, the researcher found that participants' concern with the invasion of their privacy was driven by two main factors:

- The privacy concerns were strongly related to the lack of trust between the public institutes (state, school, etc.) and their clients. And

- The fear of the unknown "Pandora's Box"; in this case the biometric technology.

Through the interviews, the researcher categorized the pattern of privacy concerns into two types:

- Students' private information might be misused or abused by the "powers that be", whom some referred to as "BIG BROTHER".

- The commercial uses of the students biometric data.

As reported by two instructors: 
I just don't wanna big brother in my affairs-they're in my affairs enough... ....oh yeah, that is what it is, a privacy issue. For me it's private, cultural, political, now I know every time I go to order a book on the amazon.com, somebody knows, somebody is sitting there figuring out ; this guy likes philosophy, history. Next, you get on, they have already figured out what books you want. It bothers me a little bit, but I can't live with that kind of feeling. I am still concerned about the BIG BROTHERISM...

In addition, all of the students whom were interviewed expressed their concern very clearly, as one is quoted here stating:

Practically speaking, I would tend to go ahead and do it and not be concerned (referring to having his biometric information taken and stored). But I'm somewhat skeptical in nature and I think there is the possibility for misuse and abuse.

One student, however, would not mind having his biometric information stored electronically. This student, however, was concerned that his information could be hacked by technically proficient criminals, and hence asked that every effort be made to procure secure storage for such data before the biometric information is collected. The student put it so aptly when he said in response to the privacy issue: “....I don't trust this things...if someone wants to hack my account he can unlock any door and nothing is gonna prevent him."

\section{Religious Issues}

Another issue explored in this study was the respondents' perceptions about the religious implications of the implementation of biometric identification technology in the 
distance-learning domain. Here, most respondents did not anticipate any direct impact of the technology on religion. One students' response aptly represents this majority viewpoint: “...I don’t see any religious link.”

The majority of both instructors and students were hesitant to comments about religious concerns. One instructor responded by saying: "I guess I don't see any, may be I don't think at the levels of such, religious issues, I am not sure if that kind of identification would provide a religious issue, I am just not sure of the issues related to this".

During interviews, one student reacted to the question about the religious issue and its contradiction with biometric technology with a perplexing answer:

I think there would come a point when there would be a line that I would not wanna crossover. As far as where that line is, I couldn't see that line right now, but I think that yes, there would be a line I don't wanna cross for religious reasons.

However, one incident relates to the topic of biometric technology and religious issues. One instructor narrated a very interesting story, related to personal photos that might ensue during the implementation of biometric technology. This is part of what she said during her interview:

We used to have photos of the students we used to play on the television when they spoke since we can't see them and we had a student who asked not to do that since her religion would forbid images of and of course I honor that. So, I could see in this state there are a number of fundamentalist Christian groups where that 
might become an issue. Certainly, internationally, there might be some groups for whom this might become an issue.

\section{Health Issues}

Another interesting finding gleaned from student and professor responses was the potential health implications of biometric identification technology. Most people did not find any severe and adverse health problems associated with the technology, although there were a few mild concerns about possible health hazards. One student was very concerned about the potential health implications, and this is what he had to say:

I would definitely be concerned about iris scan, because I believe eye could be damaged by whatever kind of light, just like X-ray have been found to be harmful in certain doses...I would be hesitant to try because of the potential risks involved.

Health was not an issue within the Instructor group. Some of the interviewees were in doubt about the health implication. They thought that the side effects of the technology would take time to appear. One teacher was quoted as saying:

Well, I guess they are probably the opportunities for that; there is no question about it. I've been in this building since it opened up and it's full of asbestos and I hear by the rumors that they will close it the next year to completely get it all out of here, but I've been here for 36 years, yeah it's probably had an impact on my health. 


\section{Socio-cultural Issues}

Some issues emerged during the interviews related to the socio-cultural and moral implications of the implementation of biometric identification technology. Most respondents were unclear as to whether or not they believed there was a direct sociocultural impact. However, some respondents did give vague responses as exemplified by one student's comment: “...again I suspect it could happen. Absolutely, I don't know how it would be misused, but certainly it is a possibility".

The biometric identifications could be exploited by the state authority as a potent tool for racial profiling, especially within the African American community. This is what one African-American student expressed during interview. Listen to the student's comments:

You know I come from the African American community and coming from such community....I mean such things can be used to guess you; I mean you just never know. So, I think that it can't be used as a gift because we come from this disenfranchised group. There were certain racist parts of our culture where people could possibly use something like that. I don't wanna use this technology. I just know it's a Pandora's Box.

In another incident, one student questioned the morality of using such technology. During the interview, the student expressed a strong aversion for technology, and not just because of its privacy, religious, or health implications. It is evident that this student has an issue with the perceived unbridled wave of scientific and technological advancement:

This whole advancement and technology we have, we want this entire surge and boom, I don't like it because like I said it's a Pandora's Box it seems like we keep 
pushing the limit, we wanna create robots at some time, we wanna create things that can identify people, we want artificial intelligence, well where does this stop. You want to replicate human. You want them to be human. I just have a problem with it. It is not just a religious issue; it is the personal thing that I have a problem with.

\section{Part II: Quantitative Data Analysis}

The findings of this study were analyzed and presented in a format that addresses each study question. Data was coded for computer handling and analyzed using the Statistical Package for Social Sciences (SPSS) version 11.0 software. Before any analysis was done, raw data was keyed into the online questionnaires and later exported to SPSS (version 11.0) software for analyses. (Norusis, 1999; Foster, 1998)

To answer the research questions, this study utilized descriptive statistics that included: (1) measures of central tendency such as mean, mode and median, (2) frequencies, (3) standard deviations and (4) percentages.

\section{Review of the Problem Statement}

The primary goal of this study was to examine Instructors' and Students' attitude toward the use of biometric technology in online courses. The research problem addressed in this study was therefore to explore the social and cultural issues related to the implementation of biometric technology in online courses.

\section{Review of Research Questions}

There were three major research questions used in this study. The six research questions included: 
1. How concerned are instructors about the implementation of biometric technology as an identification method in distance learning classes in terms of:
a. Privacy issues?
b. Religious issues?
c. Health issues?

2. How concerned are students about the implementation of biometric technology as an identification method in distance learning classes in terms of:
a. Privacy issues?
b. Religious issues?
c. Health issues?

3. What differences are there between groups (e.g., instructors and students, males and females, etc.) in their responses to items regarding:
a. Privacy issues?
b. Religious issues?
c. Health issues?

1. Analyses of Data Related to the Research First Question (RQ1) "Instructors Group"

\section{Demographic Data}

The population of this study involved Instructors from various departments of the College of Human Resources and Education at the West Virginia University $(n=30)$. A survey instrument was used to collect data from the study participants. Demographic data that was collected included the following informational elements: (1) the academic position of the respondent, (2) respondents' department (3) respondents' gender, (4) respondents' race or ethnicity, (5) respondents' religious orientation or persuasion, (6) 
respondents' knowledge about biometric technology and (7) respondents' experience with different type of biometric identification technology.

The demographic data were collected and analyzed to obtain profiles of the respondents and to verify the faculty members being studied. In addition, demographic data helped to identify and define the characteristics of the survey respondents, see Table 4.1.

Table 4.1

Summary of Instructors’ Demographic Data

\begin{tabular}{|c|c|c|c|c|c|c|}
\hline & & 1.) Position & $\begin{array}{c}\text { 2.) } \\
\text { Department: }\end{array}$ & 3.) Gender: & $\begin{array}{l}\text { 4.) Ethnicity } \\
\text { / Race: }\end{array}$ & 5.) Religion: \\
\hline \multirow[t]{2}{*}{$\bar{N}$} & Valid & 27 & 27 & 30 & 30 & 25 \\
\hline & Missing & 3 & 3 & 0 & 0 & 5 \\
\hline \multicolumn{2}{|c|}{ Mean } & 11.59 & 7.15 & 1.50 & 4.97 & 3.08 \\
\hline \multicolumn{2}{|c|}{ Median } & 12.00 & 7.00 & 1.50 & 5.00 & 3.00 \\
\hline \multicolumn{2}{|c|}{ Mode } & 13 & 11 & $1^{\mathrm{a}}$ & 5 & 3 \\
\hline \multicolumn{2}{|c|}{ Std. Deviation } & 2.291 & 3.516 & .509 & .183 & .640 \\
\hline \multicolumn{2}{|c|}{ Variance } & 5.251 & 12.362 & .259 & .033 & .410 \\
\hline
\end{tabular}

a. Multiple modes exist. The smallest value is shown

This section provides a brief summary of the characteristics of the respondents that participated in this study. First-demographic item on the survey asked for the academic position of the participants. Out of 30 faculty members who participated in the study, 1(3.3\%) was a visiting instructor, 2(6.7\%) were visiting assistant professors, $5(16.6 \%)$ were assistant professors, $17(23.3 \%)$ were associate professor, $11(36.7 \%)$ were professor, $1(3.3 \%)$ was a professor emeritus and $3(10.0 \%)$ did not identify their academic positions. See Figure 4.1 for more details. 


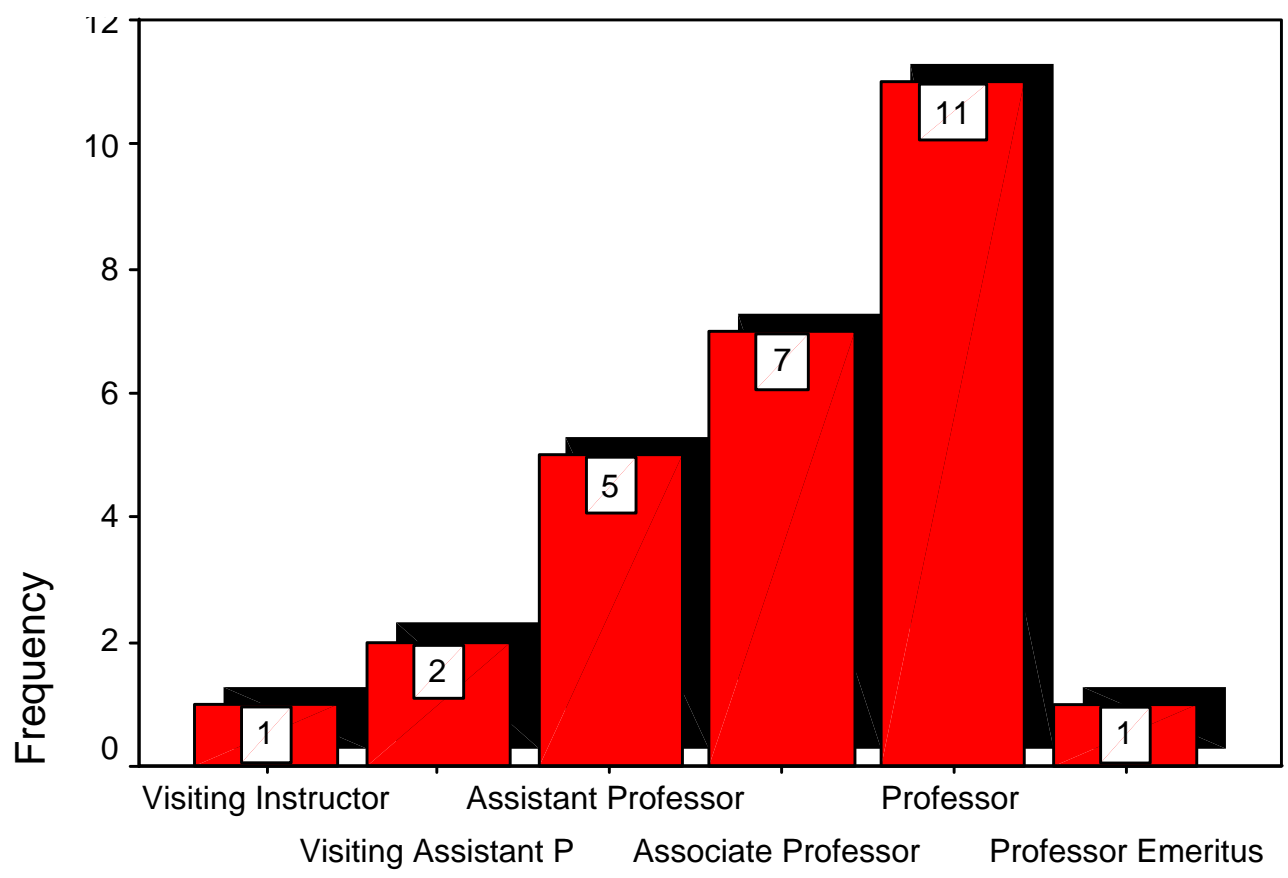

Figure 4.1. The academic position of instructors.

Second characteristic is the name of the department where the respondent is working. Out of the 30 Instructors who completed and submitted the survey, 6(20\%) were from Speech Pathology and Audiology, 4(13.3\%) were from Curriculum and Instruction, 4(13.3\%) were from Educational Psychology, 3(10.0\%) were from Reading, $3(10.0 \%)$ were from Special Education, 3(10.0\%) did not identify their department, 2 (6.7\%) were from Counseling Psychology, 2(6.7\%) were from Educational Leadership, 2(6.7\%) were from Technology Education and 1(3.3\%) was from Rehabilitation Counseling. Figure 4.2 shows the distribution of instructors at different departments. 


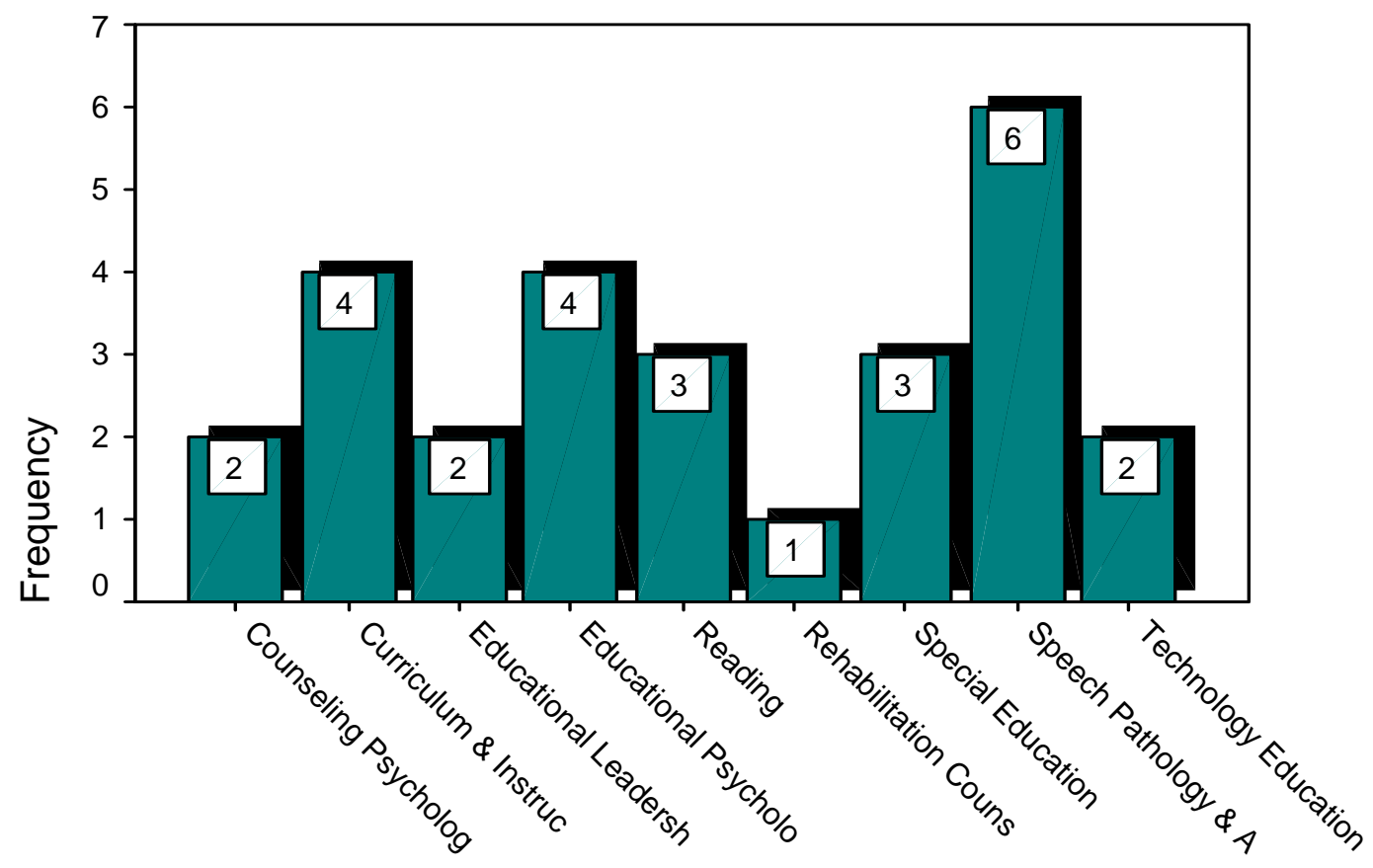

Figure 4.2. The department distribution of all instructors.

Third-demographic item on the survey asked respondents to indicate their gender. The gender composition was divided evenly between male and female. Out of the 30 survey respondents, 15 respondents $(50.0 \%)$ were female and 15 respondents $(50.0 \%)$ were male. This demographic data is presented in Figure 4.3. 


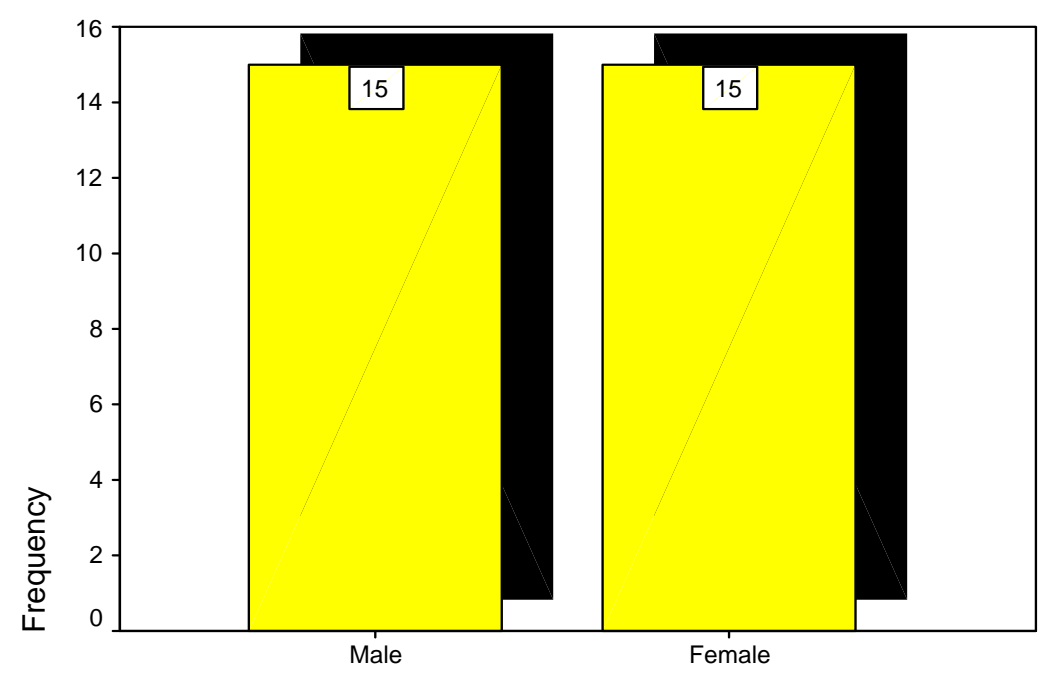

Figure 4.3. Instructors' gender distribution.

Forth-demographic item on the survey asked respondents to indicate their race or ethnicity. Out of the survey respondents, a majority 29 respondents $(96.7 \%)$ were NonHispanic Whites while only 1 respondent (3.3\%) was of Native American/American Indian descent. This demographic data is presented in Figure 4.4.

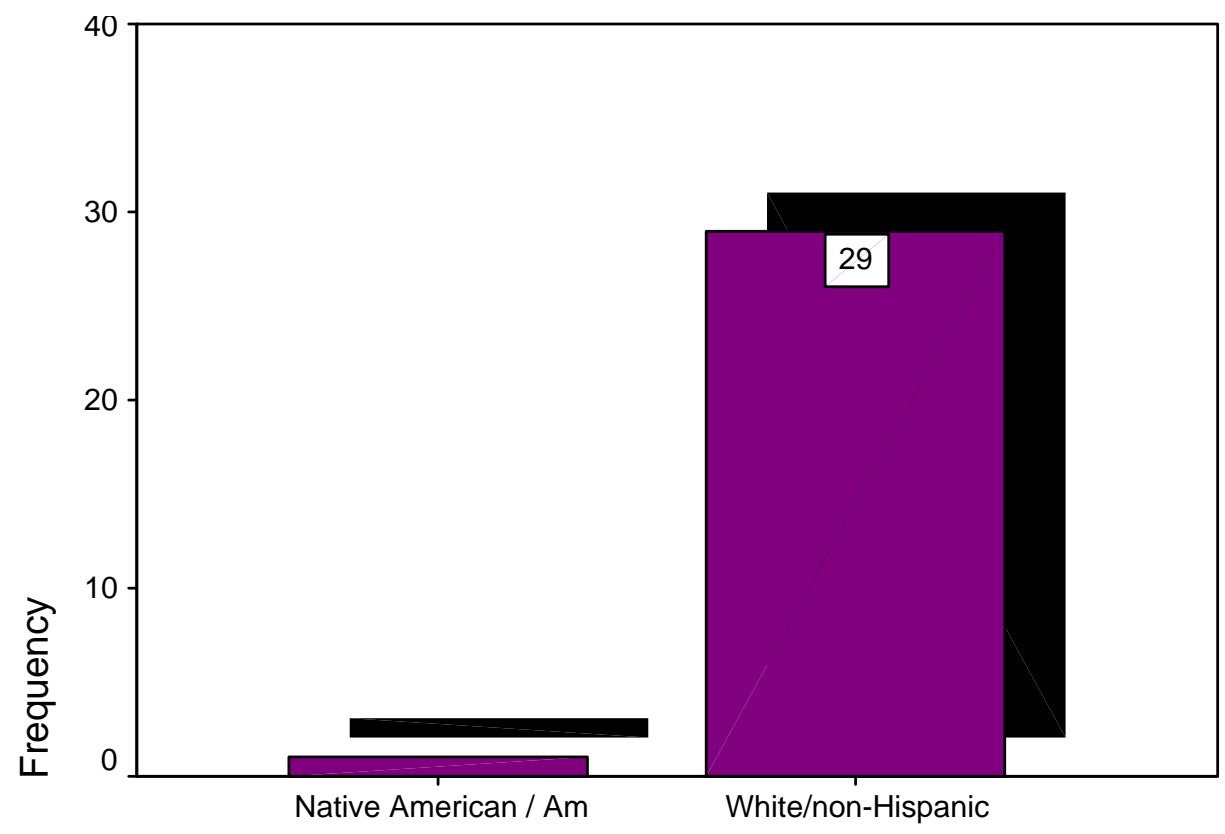

Figure 4.4. Instructors' Race/Ethnicity distributions. 
Fifth-demographic item asked respondents to indicate their religious persuasion or affiliation. Of the survey returned, 21 respondents (70.0\%) were Christian, 2 respondent (6.7\%) were Buddhist, 2(6.7\%) were Jewish, and 5(16.7\%) did not indicate their religion. This demographic data is presented in Figure 4.5.

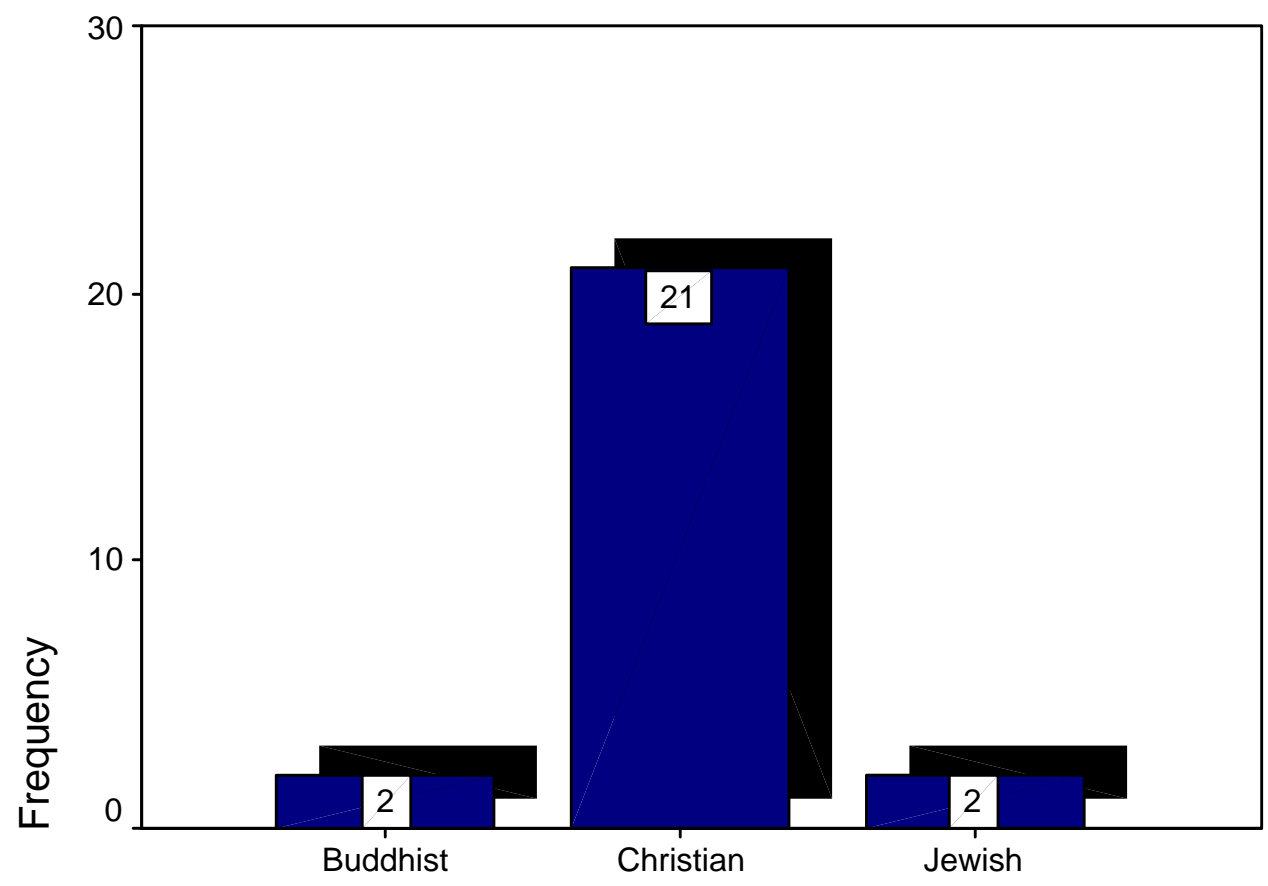

Figure 4.5. Instructors' religion distributions.

Sixth-demographic item asked respondents to indicate if they knew what biometric technology was. Of the survey returned, 24 respondents $(80.0 \%)$ indicated they knew what biometric technology was while 6 respondents $(20.0 \%)$ indicated they did not know what biometric technology was. This demographic data is presented in Figure 4.6. 


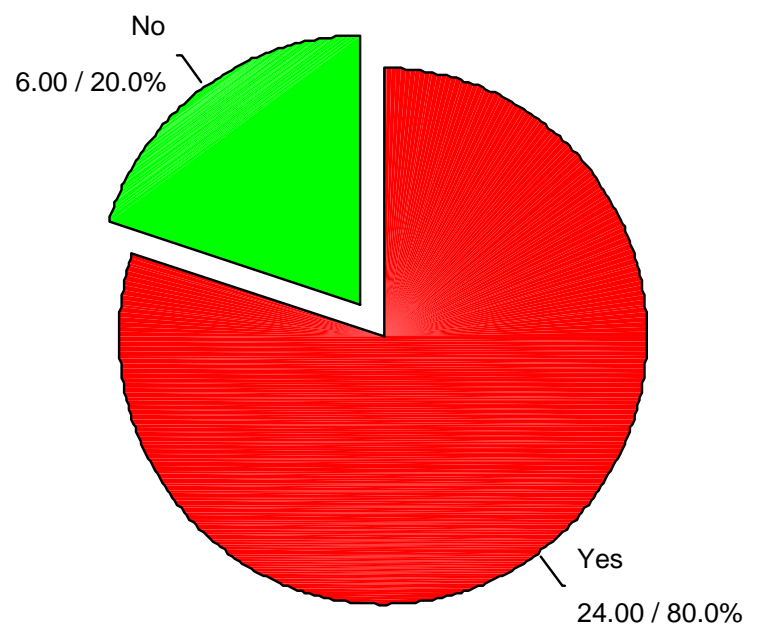

Figure 4.6. Instructors' knowledge about biometric technology.

Seventh-demographic item asked participants to check all that apply from a list of six places where they had used biometric technology. Of the 30 participants who responded to the survey only $6(20.0 \%)$ respondents checked this question. Table 4.2 summarizes these findings.

Table 4.2

The Instructors’ Experiences with Biometric Technology at Different Places

\begin{tabular}{|lrc|}
\hline \hline 8. Have you ever used it in (Check all that apply). & & \\
School & Response Percent & Response Total \\
Airport & $0 \%$ & 0 \\
Bank & $17 \%$ & 1 \\
ATM & $17 \%$ & 1 \\
Hospital & $0 \%$ & 0 \\
Federal Building & $17 \%$ & 1 \\
Other & $17 \%$ & 1 \\
& $50 \%$ & 3 \\
& Question Responses & 6 \\
\hline
\end{tabular}


For more details about each location in their frequency tables, check tables at appendix A (Tables A.7 through Tables A.13).

The type of technology that was used by participants is summarized in Table 4.3. It indicates that fingerprint is the highest technology experienced by the study participant. Out of 6 participants, 4(57.0\%), used fingerprint. Followed by voice recognition $2(29.0 \%)$, then facial and voice recognition $1(14.0 \%)$, and finally iris scan signature dynamic, and hand geometry which had never been experienced by any participants. The Table 4.3 below shows this statistics.

Table 4.3

Instructors’ Experiences with Different Types of Biometric Technology

\begin{tabular}{|c|c|c|}
\hline \multicolumn{3}{|c|}{ 9. What Type of Technology did you use (check all that apply): } \\
\hline & Response Percent & Response Total \\
\hline Fingerprint & $57 \%$ & 4 \\
\hline I ris scan & $0 \%$ & 0 \\
\hline $\begin{array}{l}\text { Facial } \\
\text { recognition }\end{array}$ & $14 \%$ & 1 \\
\hline Hand geometry & $0 \%$ & 0 \\
\hline $\begin{array}{l}\text { Voice } \\
\text { recognition }\end{array}$ & $29 \%$ & 2 \\
\hline $\begin{array}{l}\text { Signature } \\
\text { dynamic }\end{array}$ & $0 \%$ & 0 \\
\hline \multirow[t]{3}{*}{ Others } & $0 \%$ & 0 \\
\hline & Question Responses & 7 \\
\hline & Skipped & 23 \\
\hline
\end{tabular}

\section{Privacy Issues}

The participants responded to two sets of questions. The first set of questions was made up of six questions. Each question was ranked 1-5, with 1= being very concerned; 2 
=being somewhat concerned; $3=$ being not very concerned; $4=$ being not concerned and 5=being I don't know. The second set of questions were rating questions item that sought to find out the respondent's perception of the level of intrusiveness of six biometric technologies. For more details, see Tables 4.4 and 4.5.

Table 4.4

\section{Summary of Instructors' Responses to Items Related to Privacy Issues questions}

\begin{tabular}{|c|c|c|c|c|c|c|c|}
\hline & & $\begin{array}{c}\text { 10.1) How } \\
\text { concerned are } \\
\text { you about } \\
\text { having } \\
\text { students' } \\
\text { biometric data } \\
\text { collected? }\end{array}$ & $\begin{array}{c}\text { 10.2) How } \\
\text { concerned are } \\
\text { you about } \\
\text { having } \\
\text { students' } \\
\text { biometric data } \\
\text { stored in } \\
\text { non-secure } \\
\text { storage? }\end{array}$ & $\begin{array}{c}\text { 10.3) How } \\
\text { concerned are } \\
\text { you about } \\
\text { having } \\
\text { students' } \\
\text { biometric data } \\
\text { used by third } \\
\text { party? }\end{array}$ & $\begin{array}{c}\text { 10.4) How } \\
\text { concerned are } \\
\text { you about } \\
\text { having } \\
\text { students' } \\
\text { biometric data } \\
\text { misused by } \\
\text { WVU? }\end{array}$ & $\begin{array}{c}\text { 10.5) How } \\
\text { concerned are } \\
\text { you about the } \\
\text { invasion of } \\
\text { students' } \\
\text { privacy by } \\
\text { WVU, when } \\
\text { biometric } \\
\text { technology is } \\
\text { implemente } \\
\text { d? }\end{array}$ & $\begin{array}{c}\text { 10.6) How } \\
\text { concerned are } \\
\text { you about the } \\
\text { negative } \\
\text { stigma } \\
\text { attached to } \\
\text { the use of } \\
\text { biometric } \\
\text { technology? }\end{array}$ \\
\hline \multirow[t]{2}{*}{$\bar{N}$} & Valid & 30 & 30 & 30 & 30 & 30 & 30 \\
\hline & Missing & 0 & 0 & 0 & 0 & 0 & 0 \\
\hline & 2.67 & 1.43 & 1.30 & 2.30 & 2.50 & 3.23 \\
\hline \multicolumn{2}{|c|}{ Median } & 3.00 & 1.00 & 1.00 & 2.00 & 2.00 & 3.00 \\
\hline \multicolumn{2}{|c|}{ Mode } & 2 & 1 & 1 & 2 & 2 & 3 \\
\hline \multicolumn{2}{|c|}{ Std. Deviation } & 1.124 & .774 & .535 & 1.119 & 1.009 & 1.165 \\
\hline \multicolumn{2}{|c|}{ Variance } & 1.264 & .599 & .286 & 1.252 & 1.017 & 1.357 \\
\hline
\end{tabular}


Table 4.5

The Summary of Findings of the First Set of Questions Related to Privacy Issues

\begin{tabular}{|c|c|c|c|c|c|c|}
\hline 10. & A. The $p$ & rivacy is & ssues & & & \\
\hline \multirow[b]{2}{*}{$\begin{array}{l}\text { How concerned } \\
\text { are you about } \\
\text { having students' } \\
\text { biometric data } \\
\text { collected? }\end{array}$} & $\begin{array}{c}\text { Very } \\
\text { Concerned }\end{array}$ & $\begin{array}{l}\text { Somewhat } \\
\text { concerned }\end{array}$ & $\begin{array}{c}\text { Not very } \\
\text { Concerned }\end{array}$ & $\begin{array}{c}\text { Not } \\
\text { Concerned }\end{array}$ & $\begin{array}{l}\text { I don't } \\
\text { know }\end{array}$ & $\begin{array}{c}\text { Response } \\
\text { Total }\end{array}$ \\
\hline & $5(17 \%)$ & $9(30 \%)$ & $8(27 \%)$ & $7(23 \%)$ & $1(3 \%)$ & 30 \\
\hline $\begin{array}{l}\text { How concerned } \\
\text { are you about } \\
\text { having students' } \\
\text { biometric data } \\
\text { stored in non- } \\
\text { secure storage? }\end{array}$ & $21(70 \%)$ & $6(20 \%)$ & $2(7 \%)$ & $1(3 \%)$ & $0(0 \%)$ & 30 \\
\hline $\begin{array}{l}\text { How concerned } \\
\text { are you about } \\
\text { having students' } \\
\text { biometric data } \\
\text { used by third } \\
\text { party? }\end{array}$ & $22(73 \%)$ & $7(23 \%)$ & $1(3 \%)$ & $0(0 \%)$ & $0(0 \%)$ & 30 \\
\hline $\begin{array}{l}\text { How concerned } \\
\text { are you about } \\
\text { having students' } \\
\text { biometric data } \\
\text { misused by } \\
\text { WVU? }\end{array}$ & $8(27 \%)$ & $11(37 \%)$ & $6(20 \%)$ & $4(13 \%)$ & $1(3 \%)$ & 30 \\
\hline $\begin{array}{l}\text { How concerned } \\
\text { are you about } \\
\text { the invasion of } \\
\text { students' privacy } \\
\text { by WVU, when } \\
\text { biometric } \\
\text { technology is } \\
\text { implemented? }\end{array}$ & $4(13 \%)$ & $13(43 \%)$ & $8(27 \%)$ & $4(13 \%)$ & $1(3 \%)$ & 30 \\
\hline $\begin{array}{l}\text { How concerned } \\
\text { are you about } \\
\text { the negative } \\
\text { stigma attached }\end{array}$ & $2(7 \%)$ & $6(20 \%)$ & $10(33 \%)$ & $7(23 \%)$ & $5(17 \%)$ & 30 \\
\hline & & & & Questior & Responses & 30 \\
\hline & & & & & Skipped & 0 \\
\hline
\end{tabular}


The first privacy question asked respondents to indicate how concerned they were about having student biometric data collected. Of the 30 participants who responded to this question, 9(30\%) indicated they were 'somewhat concerned', $8(27 \%)$ indicated they were 'not very concerned', 7(23\%) indicated they were 'not concerned', 5(17\%) indicated they were 'very concerned' and 1(3\%) indicated 'I don't know'. See Figure 4.7 for more details.

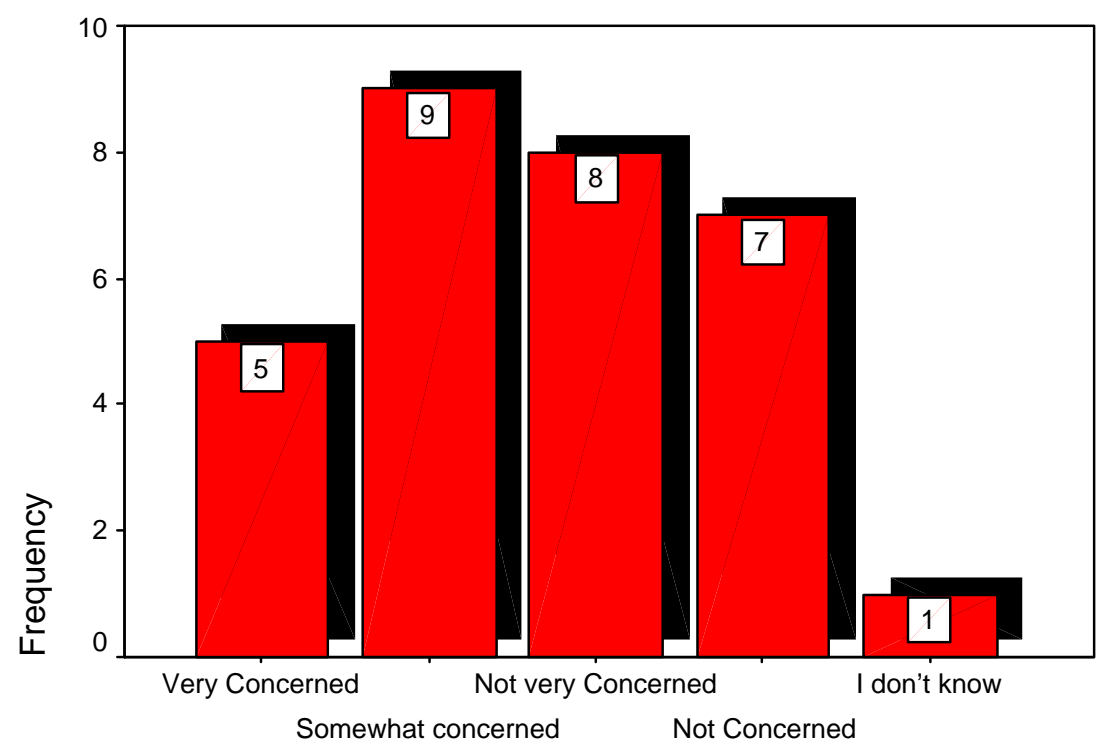

Figure 4.7. Instructors' responses to first question of the privacy issue.

'How concerned are you about having students' biometric data stored in nonsecure storage', was the second privacy question. Of the 30 respondents, $21(70 \%)$ indicated they were 'very concerned', 6(20\%) indicated that they were 'somewhat concerned' and 1(3\%) was 'not concerned'. See Figure 4.8 for more details. 


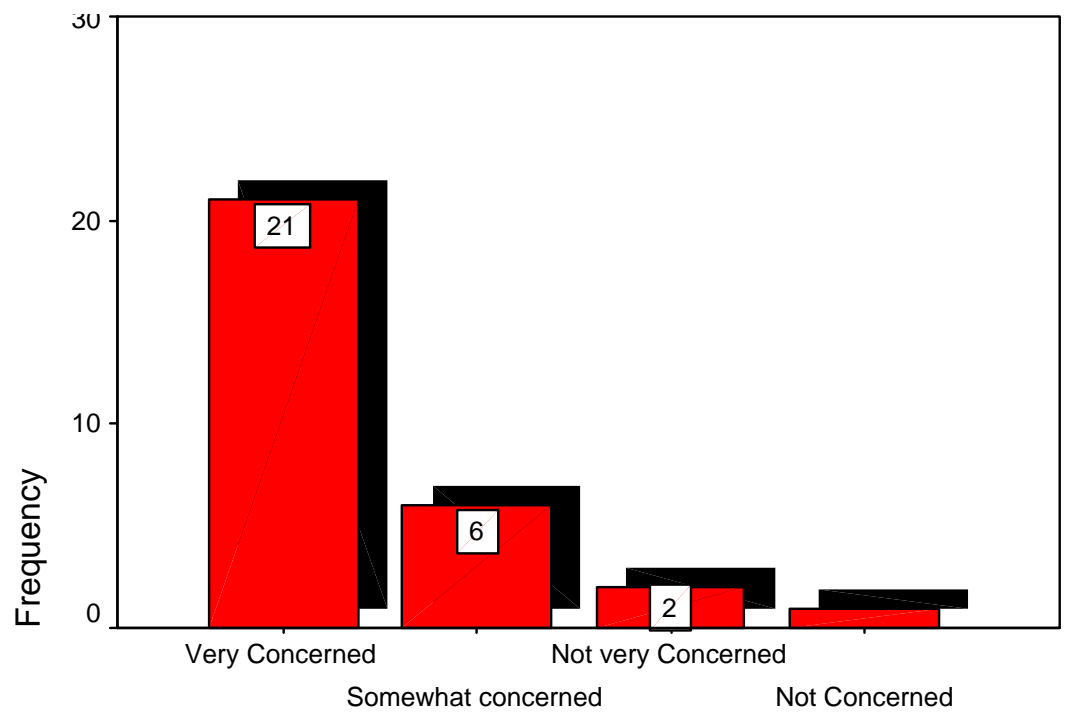

Figure 4.8. Instructors' responses to second question of the privacy issues.

The third privacy question asked respondents to indicate how concerned they were about having students' biometric data used by third party. Of the 30 respondents, $22(73 \%)$ indicated they were 'very concerned', $9(23 \%)$ indicated they were 'somewhat concerned' and 1(3\%) was 'not very concerned'. See Figure 4.9 for more details.

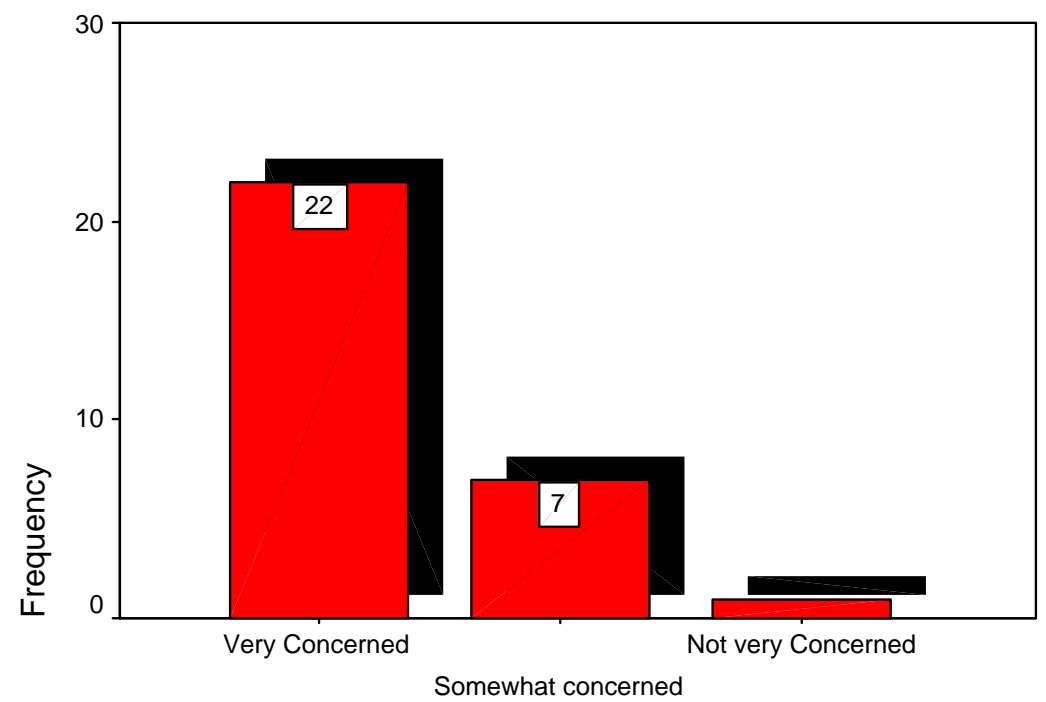

Figure 4.9. Instructors' responses to third question of the privacy issues.

How concerned are you about having students' biometric data misused by WVU was the forth privacy question. Of the 30 respondents, 11(37\%) indicated they were 
'somewhat concerned', 8(27\%) indicated they were 'very concerned', 6(20\%) indicated they were 'not very concerned', 4(13\%) indicated they were 'not concerned' and 1(3\%) said 'I don't know'. See Figure 4.10 for more details.

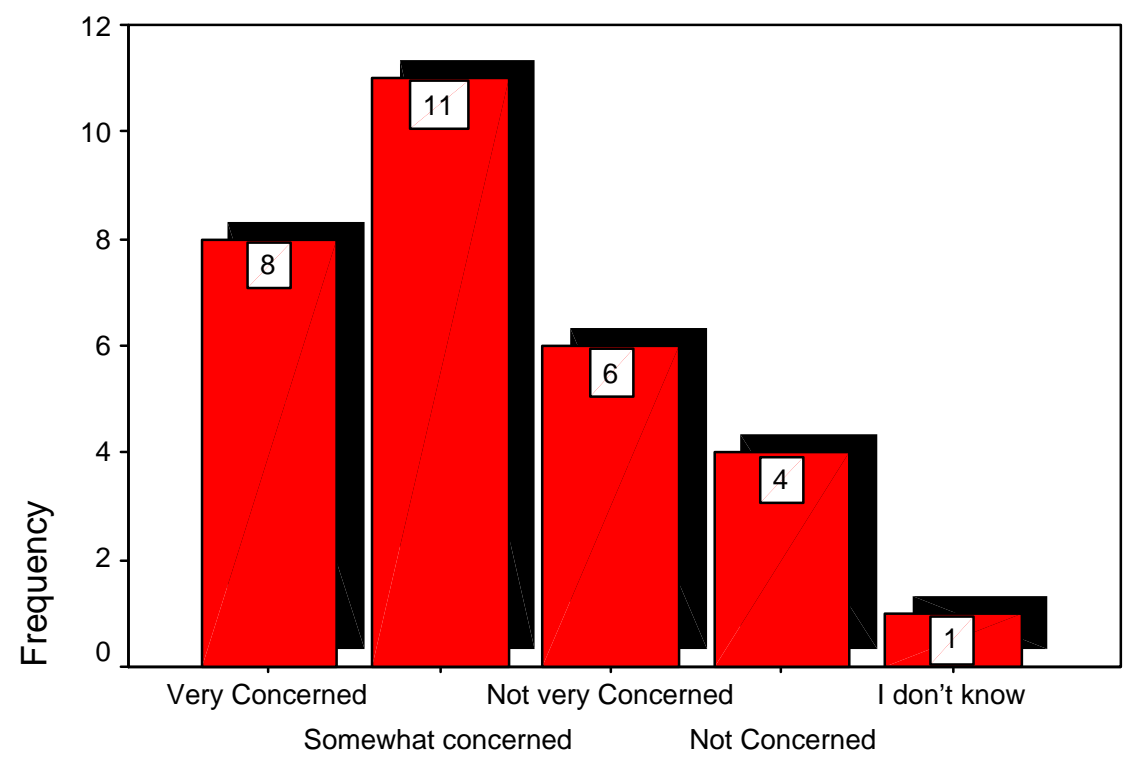

Figure 4.10. Instructors' responses to fourth question of the privacy issues.

The fifth privacy question asked respondents to indicate how concerned they would be about the invasion of students' privacy when WVU implements biometric technology. Of the 30 respondents, 13(43\%) indicated they would be 'somewhat concerned', 8(27\%) indicated they would not 'not very concerned', 4(13\%) indicated they would be 'concerned and 1(3\%) indicated 'I don't know. See Figure 4.11 for more details. 


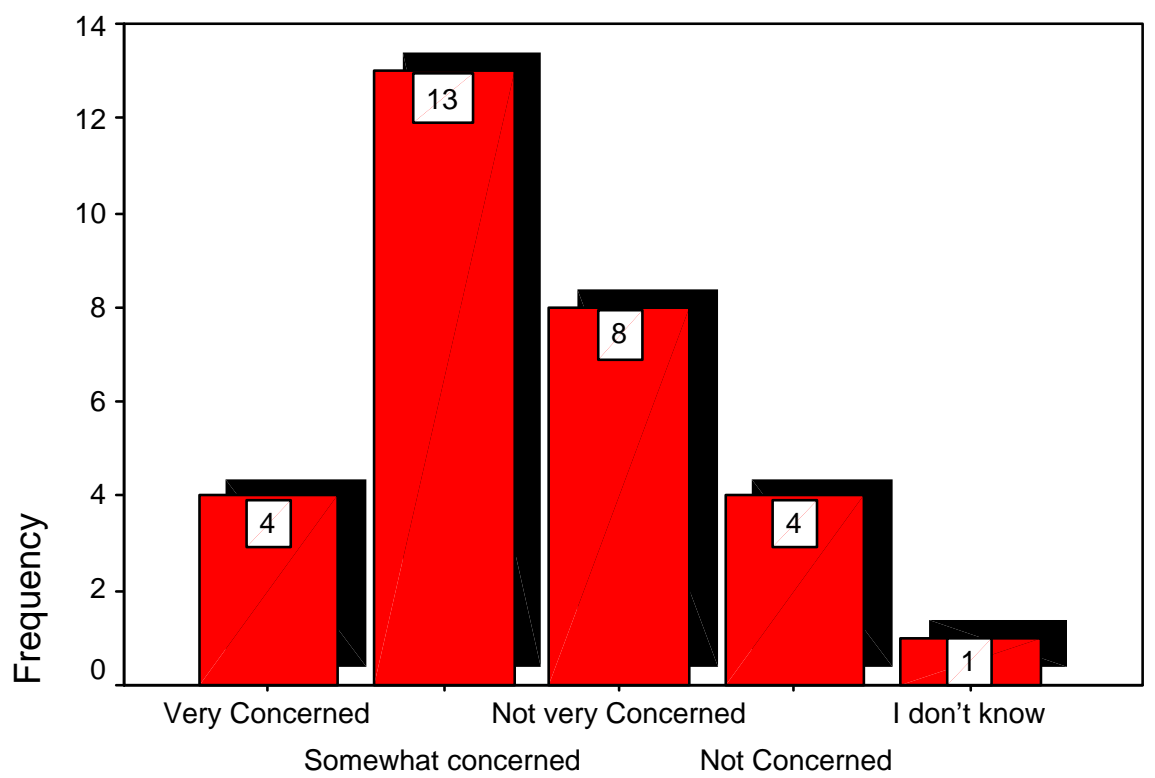

Figure 4.11. Instructors' responses to fifth question of the privacy issue.

'How concerned are you about the negative stigma attached to the use of biometric technology' was the sixth privacy question. Of the 30 respondents, $10(33 \%)$ indicated they were not 'very concerned', 7(23\%) indicated they were 'not concerned', $6(20 \%)$ indicated they were 'somewhat concerned', 5(17\%) indicated 'I don't know' and 2(7\%) indicated they 'very concerned'. See Figure 4.12 for more details.

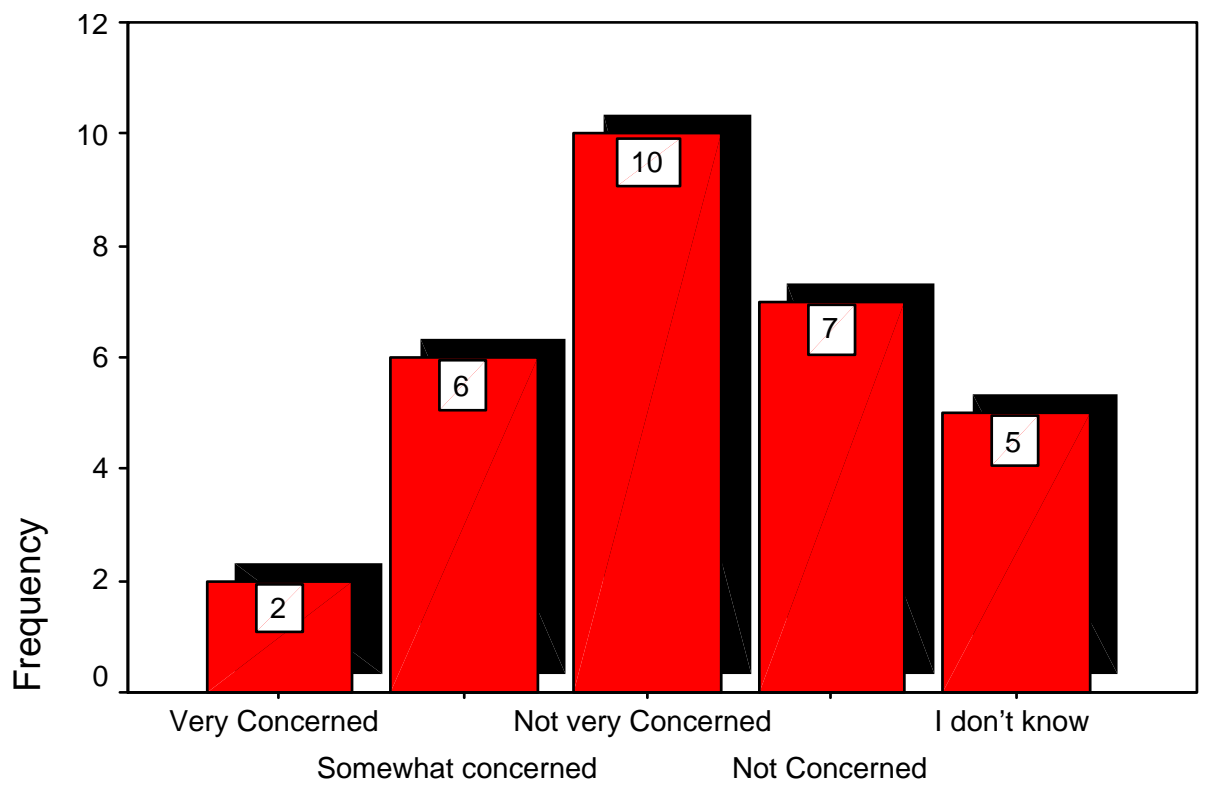

Figure 4.12. Instructors' responses to sixth question of the privacy issues. 


\section{Privacy Concerns of Each Ranked Biometric Technology (Low Medium High)}

The second set of privacy question asked respondents to individually rank six biometric technologies: 'fingerprint' 'iris scan', 'facial recognition', 'hand geometry', 'voice recognition' and 'signature dynamic', according to their level of intrusiveness, ranging from 'low', 'medium', 'high' to 'I don't know'. According to the Instructors' responses with regard to technology intrusiveness, Signature dynamic was considered the lowest while Iris scan was ranked the highest. Tables 4.6 and 4.7 summarize these findings.

Table 4.6

Summary of Instructors’ Responses to Different Biometric Technologies According to their Intrusiveness

\begin{tabular}{|l|r|r|r|r|r|r|}
\hline & $\begin{array}{c}11.1) \\
\text { Fingerprint }\end{array}$ & $\begin{array}{c}\text { 11.2) Iris } \\
\text { scans }\end{array}$ & $\begin{array}{c}\text { 11.3) Facial } \\
\text { recognition }\end{array}$ & $\begin{array}{c}\text { 11.4) Hand } \\
\text { geometry }\end{array}$ & $\begin{array}{c}\text { 11.5) Voice } \\
\text { recognition }\end{array}$ & $\begin{array}{c}\text { 11.6) } \\
\text { Signature } \\
\text { dynamic }\end{array}$ \\
\hline $\mathrm{N}$ & 30 & 30 & 30 & 30 & 30 & 30 \\
Mean & 0 & 0 & 0 & 0 & 0 & 0 \\
Medid & 2.00 & 2.37 & 2.10 & 2.23 & 2.17 & 1.90 \\
Mode & 2.00 & 3.00 & 2.00 & 2.00 & 2.00 & 2.00 \\
Std. Deviation & 1 & 3 & 1 & 2 & 2 & 2 \\
Variance & .983 & 1.066 & .960 & 1.073 & .874 & .995 \\
& .966 & 1.137 & .921 & 1.151 & .764 & .990 \\
\hline
\end{tabular}


Table 4.7

The Instructors Ranking of Different Biometric Technologies According to their Intrusiveness

\begin{tabular}{|c|c|c|c|c|c|}
\hline \multicolumn{6}{|c|}{ 11. Rank each technology according to their intrusiveness } \\
\hline & Low & Medium & High & I don't know & Response Total \\
\hline Fingerprint & $12(40 \%)$ & $8(27 \%)$ & $8(27 \%)$ & $2(7 \%)$ & 30 \\
\hline $\begin{array}{l}\text { I ris scans } \\
\text { "eye scan" }\end{array}$ & $9(30 \%)$ & $5(17 \%)$ & $12(40 \%)$ & $4(13 \%)$ & 30 \\
\hline $\begin{array}{l}\text { Facial } \\
\text { recognition }\end{array}$ & $10(33 \%)$ & $9(30 \%)$ & $9(30 \%)$ & $2(7 \%)$ & 30 \\
\hline $\begin{array}{l}\text { Hand } \\
\text { geometry }\end{array}$ & $8(27 \%)$ & $13(43 \%)$ & $3(10 \%)$ & $6(20 \%)$ & 30 \\
\hline $\begin{array}{l}\text { Voice } \\
\text { recognition }\end{array}$ & $6(20 \%)$ & $16(53 \%)$ & $5(17 \%)$ & $3(10 \%)$ & 30 \\
\hline \multirow[t]{3}{*}{$\begin{array}{l}\text { Signature } \\
\text { dynamic }\end{array}$} & $12(40 \%)$ & $13(43 \%)$ & $1(3 \%)$ & $4(13 \%)$ & 30 \\
\hline & \multicolumn{4}{|c|}{ Question Responses } & 30 \\
\hline & \multicolumn{4}{|r|}{ Skipped } & 0 \\
\hline
\end{tabular}

Fingerprint was ranked as follows. Of the 30 respondents, $12(40 \%)$ ranked it as 'low', $8(27 \%)$ ranked it as 'medium', another $8(27 \%)$ ranked it as 'high' and $2(7 \%)$ indicated 'I don't know'.

Iris scan was ranked as follows. Of the 30 respondents, $9(30 \%)$ ranked it as 'high', 5(16.7\%) ranked it as 'low', 12(40.0\%) ranked it as 'medium' and 4(13.3\%) indicated 'I don't know'.

Facial recognition was ranked as follows. Of the 30 respondents, $10(33.3 \%)$ ranked it as 'low', $9(30.0 \%)$ ranked it as 'medium', another $9(30.0 \%)$ ranked it as 'high' and $2(6.7 \%)$ indicated 'I don't know'. 
Hand geometry was ranked as follows. Of the 30 respondents, $8(26.7 \%)$ ranked it as 'medium', 13(43.3\%) ranked it as 'low', 6(20\%) indicated 'I don't know' and 3(10\%) ranked it as 'high'.

Voice recognition was ranked as follows. Of the 30 respondents, $16(53.3 \%)$ ranked it as 'medium', 6(20.0\%) ranked it as 'low', 5(16.7\%) ranked it as 'high' and $3(10.0 \%)$ indicated 'I don't know'.

Signature dynamic was ranked as follows. Of the 30 respondents, $13(43.3 \%)$ ranked it as 'medium', 12(40.0\%) ranked it as 'low', 4(13.3\%) indicated 'I don't know' and $1(3.3 \%)$ ranked it as 'high'

For more details, see appendix A, Tables A20 through A.25 and Figures A.1 through A.6.

\section{Religious Issues}

The study addressed this issue by asking participants two major questions. The first question addressed the appropriateness of implementing biometric technologies as an identification method for online classes. The Table 4.8 summarizes these findings. 
Table 4.8

Summary of Instructors’ Responses to Items Related to Religious Issues

\begin{tabular}{|c|c|c|c|}
\hline & & $\begin{array}{l}\text { 12.) In terms } \\
\text { of religious } \\
\text { conflicts, how } \\
\text { appropriate } \\
\text { do you think } \\
\text { the } \\
\text { implementing } \\
\text { of the } \\
\text { biometric } \\
\text { systems in } \\
\text { the WVU are? } \\
\text { (as described } \\
\text { in the } \\
\text { scenario } \\
\text { above) }\end{array}$ & $\begin{array}{c}\text { 13.) Do you } \\
\text { think the } \\
\text { implementatio } \\
\mathrm{n} \text { of biometric } \\
\text { technology at } \\
\text { WVU } \\
\text { contradicts } \\
\text { your religious } \\
\text { beliefs? } \\
13 .)\end{array}$ \\
\hline \multirow{7}{*}{$\begin{array}{l}M \\
M \\
M \\
S t \\
V\end{array}$} & Valid & 30 & 29 \\
\hline & Missing & 0 & 1 \\
\hline & & 3.00 & 2.00 \\
\hline & & 3.00 & 2.00 \\
\hline & & 5 & 2 \\
\hline & & 1.576 & .267 \\
\hline & & 2.483 & .071 \\
\hline
\end{tabular}

The survey offered five choices: 'Very appropriate', 'Somewhat appropriate', 'Not appropriate', 'Not very appropriate' and 'I don't know'. Out of 30 participants, $6(20.0 \%)$ responded with 'Very appropriate', 8(26.7\%) responded with 'Somewhat appropriate', 6(20.0\%) responded with 'Not appropriate', none of the participants answered with 'Not very appropriate' but $10(30.3 \%)$ responded to this question with 'I don't know'. See Tables 4.9 and 4.10.for more details. 
Table 4.9

Summary of Instructors' Responses to First Question Related to Religious Issues

\begin{tabular}{|l|c|c|}
\hline \multicolumn{2}{|c|}{$\begin{array}{c}\text { 12. In terms of religious conflicts, how appropriate do you think the implementing of the } \\
\text { biometric systems in the WVU are? }\end{array}$} & $\begin{array}{c}\text { Response Percent } \\
\text { Response Total }\end{array}$ \\
Very appropriate & $20 \%$ & 6 \\
Somewhat & $27 \%$ & 8 \\
appropriate & $20 \%$ & 6 \\
Not appropriate & $0 \%$ & 0 \\
Not very & $33 \%$ & 10 \\
appropriate & Question Responses & 30 \\
I don't know & Skipped & 0 \\
\hline
\end{tabular}

The second question about the religious issues asked participants if implementing biometric technologies contradicted their beliefs. Out of 30 participants, only one participant skipped this question. $27(93 \%)$ of the participants said 'No', 1(3.0\%) said 'Yes' and 1(3.0\%) said 'I don't know'. See Table 4.10 for more details.

Table 4.10

Summery of Instructors’ Responses to Second Question Related to Religious Issues

13. Do you think the implementation of biometric technology at WVU contradicts your religious beliefs?

\begin{tabular}{l|ccc} 
& & Response Percent & $\begin{array}{c}\text { Response } \\
\text { Total }\end{array}$ \\
Yes & $3 \%$ & 1 \\
No & $93 \%$ & 27 \\
I don't & $3 \%$ & 1 \\
know & Question Responses & 29 \\
& Skipped & 1 \\
& & &
\end{tabular}


Part of the previous question asked respondents to rank each technology according to its religious concerns. Since only two of the 30 participants have some religious concerns about the implementation of biometric technology in online classes, only these two participants responded to this question. For more details, see Appendix A (Tables A.26, Table A.27 through Tables A.32 and Figures A.7 through Figures A.13).

\section{Health Issues}

The third factor investigated by this study related to the health issues of the implementation of biometric technology in online classes. The participants responded to three sets of questions.

The first health question asked respondents how concerned they would be when biometric technology was introduced. Responses ranged from 1-5. 1= being very concerned; 2 =being somewhat concerned; 3=being not very concerned; 4=being not concerned and 5=being I don't know.

Of the 30 participants who responded to this question, 1(3\%) indicated they did not know whether they would be concerned. Most of the participants $14(47.0 \%)$ said that they were "Not concerned", 10(33\%) "Not very concerned", 5(17\%) somewhat concerned and none of the participants said he/she was "very concerned". See Table 4.11.for more details. 
Table 4.11

Summary of Instructors’ Responses to First Question of Health Issues

\begin{tabular}{|c|c|c|}
\hline \multicolumn{3}{|c|}{$\begin{array}{l}\text { 16. When biometric technology is implemented, how concerned are you about the } \\
\text { health risk which might be rendered: }\end{array}$} \\
\hline & $\begin{array}{l}\text { Response } \\
\text { Percent }\end{array}$ & $\begin{array}{l}\text { Response } \\
\text { Total }\end{array}$ \\
\hline Very concerned & $0 \%$ & 0 \\
\hline $\begin{array}{l}\text { Somewhat } \\
\text { concerned }\end{array}$ & $17 \%$ & 5 \\
\hline $\begin{array}{l}\text { Not very } \\
\text { concerned }\end{array}$ & $33 \%$ & 10 \\
\hline Not concerned & $47 \%$ & 14 \\
\hline \multirow[t]{3}{*}{ I don't know } & $3 \%$ & 1 \\
\hline & n Responses & 30 \\
\hline & Skipped & 0 \\
\hline
\end{tabular}

Health Concerns of Each Ranked Biometric Technology (Low Medium High)

The second health question asked respondents to individually rank six biometric technologies: 'fingerprint' 'iris scan', 'facial recognition', 'hand geometry', 'voice recognition' and 'signature dynamic', according to their (the respondents') level of health concern, ranging from 'low', 'medium', 'high' to 'don't know'. According to the Instructors' responses concerning technology health, Fingerprint was considered the lowest and Iris scan ranked the highest. Table 4.12 summarizes the instructors' responses to different technologies from the health point of view. 
Table 4.12

Summary of Biometric Technologies and its Rank by Instructors According to its Health Concerns

\begin{tabular}{|c|c|c|c|c|c|}
\hline & Low & Medium & High & I don't know & Response Total \\
\hline Fingerprint & $25(83 \%)$ & $2(7 \%)$ & $0(0 \%)$ & $3(10 \%)$ & 30 \\
\hline I ris scans & $13(43 \%)$ & $10(33 \%)$ & $2(7 \%)$ & $5(17 \%)$ & 30 \\
\hline Facial recognition & $22(73 \%)$ & $5(17 \%)$ & $0(0 \%)$ & $3(10 \%)$ & 30 \\
\hline Hand geometry & $22(73 \%)$ & $3(10 \%)$ & $0(0 \%)$ & $5(17 \%)$ & 30 \\
\hline Voice recognition & $23(77 \%)$ & $4(13 \%)$ & $0(0 \%)$ & $3(10 \%)$ & 30 \\
\hline Signature dynamic & $22(73 \%)$ & $2(7 \%)$ & $0(0 \%)$ & $6(20 \%)$ & 30 \\
\hline \multicolumn{5}{|c|}{ Question Responses } & 30 \\
\hline \multicolumn{5}{|r|}{ Skipped } & 0 \\
\hline
\end{tabular}

Fingerprint was ranked as follows. Of the 30 respondents, 25(83\%) ranked it as 'low', three (10\%) indicated 'I don't know' and two (7\%) ranked it as 'medium'.

Iris scan was ranked as follows. Of the 30 respondents, 13(42\%) ranked it as 'low', $10(33 \%)$ ranked it as 'medium', two (7\%) ranked it as high and five (17\%) indicated 'I don't know'.

Facial recognition was ranked as follows. Of the 30 respondents, $22(73 \%)$ ranked it as 'low', five (17\%) ranked it as 'medium' and three (10\%) indicated 'I don't know'.

Hand geometry was ranked as follows. Of the 30 respondents, 22(73\%) ranked it as 'low', 5(17\%) indicated 'I don't know' and 3(10\%) ranked it as 'medium'.

Voice recognition was ranked as follows. Of the 30 respondents, 23(77\%) ranked it as 'low', 4(13\%) ranked it as 'medium' and 3(10\%) indicated 'I don't know.'

Signature dynamic was ranked as follows. Of the 30 respondents, $22(73 \%)$ ranked it as 'low, 6(20\%) indicated 'I don't know' and 2(7\%) ranked it as 'medium'. 
For more details, see appendix A, Tables A40 through A.46 and Figures A.14 through A.21.

Health Concerns of Each Rated Biometric Technology (Comfortability)

The third health question asked respondents to rate (in terms of health concerns) their level of Comfortability toward the use of these biometric technologies: 'fingerprint' ‘iris scan', 'facial recognition', ‘hand geometry', 'voice recognition', and 'signature dynamic', ranging from 1=being 'very comfortable', 2=being 'somewhat comfortable', 3=being 'not very comfortable', 4=being 'not comfortable' and 5=being 'I don't know'. According to the Instructors' responses concerning technology comfortability, Fingerprint was considered the best and Iris scan ranked the lowest. See Table 4.13 and 4.14 for more details.

Table 4.13

Summary of Instructors' Responses to Different Technologies According to its Level of Comfortability

\begin{tabular}{|c|c|c|c|c|c|c|c|}
\hline & & $\begin{array}{c}18.1) \\
\text { Fingerprint }\end{array}$ & 18.2) Iris scan & $\begin{array}{l}\text { 18.3) Facial } \\
\text { recognition }\end{array}$ & $\begin{array}{l}\text { 18.4)Hand } \\
\text { geometry }\end{array}$ & $\begin{array}{l}\text { 18.5) Voice } \\
\text { recognition }\end{array}$ & $\begin{array}{c}\text { 18.6) } \\
\text { Signature } \\
\text { dynamic }\end{array}$ \\
\hline \multirow[t]{2}{*}{$\mathrm{N}$} & Valid & 30 & 30 & 30 & 30 & 30 & 30 \\
\hline & Missing & 0 & 0 & 0 & 0 & 0 & 0 \\
\hline \multicolumn{2}{|c|}{ Mean } & 1.70 & 2.37 & 1.77 & 2.17 & 1.93 & 1.87 \\
\hline \multicolumn{2}{|c|}{ Median } & 1.00 & 2.00 & 1.00 & 1.00 & 1.00 & 1.00 \\
\hline \multicolumn{2}{|c|}{ Mode } & 1 & 1 & 1 & 1 & 1 & 1 \\
\hline \multicolumn{2}{|c|}{ Std. Deviation } & 1.264 & 1.377 & 1.305 & 1.599 & 1.388 & 1.456 \\
\hline \multicolumn{2}{|c|}{ Variance } & 1.597 & 1.895 & 1.702 & 2.557 & 1.926 & 2.120 \\
\hline
\end{tabular}


Table 4.14

Summary of Instructors' Responses to Different Biometric Technologies According to its Level of Comfortability

\begin{tabular}{|c|c|c|c|c|c|c|}
\hline \multicolumn{7}{|c|}{$\begin{array}{l}\text { 18. In terms of health concerns, please rate your comfortability toward the use of these five } \\
\text { biometric technologies }\end{array}$} \\
\hline & $\begin{array}{l}\text { Very } \\
\text { comfortable }\end{array}$ & $\begin{array}{l}\text { Somewhat } \\
\text { comfortable }\end{array}$ & $\begin{array}{l}\text { Not very } \\
\text { Comfortable }\end{array}$ & $\begin{array}{l}\text { Not } \\
\text { Comfortable }\end{array}$ & $\begin{array}{l}\text { I don't } \\
\text { know }\end{array}$ & $\begin{array}{l}\text { Response } \\
\text { Total }\end{array}$ \\
\hline Fingerprint & $21(70 \%)$ & $3(10 \%)$ & $2(7 \%)$ & $2(7 \%)$ & $2(7 \%)$ & 30 \\
\hline I ris scan & $11(37 \%)$ & $7(23 \%)$ & $5(17 \%)$ & $4(13 \%)$ & $3(10 \%)$ & 30 \\
\hline Facial recognition & $19(63 \%)$ & $6(20 \%)$ & $1(3 \%)$ & $1(3 \%)$ & $3(10 \%)$ & 30 \\
\hline Hand geometry & $17(57 \%)$ & $4(13 \%)$ & $1(3 \%)$ & $3(10 \%)$ & $5(17 \%)$ & 30 \\
\hline Voice recognition & $18(60 \%)$ & $4(13 \%)$ & $3(10 \%)$ & $2(7 \%)$ & $3(10 \%)$ & 30 \\
\hline \multirow[t]{3}{*}{$\begin{array}{l}\text { Signature } \\
\text { dynamic }\end{array}$} & $20(67 \%)$ & $3(10 \%)$ & $2(7 \%)$ & $1(3 \%)$ & $4(13 \%)$ & 30 \\
\hline & \multicolumn{5}{|c|}{ Question Responses } & 30 \\
\hline & & & & & Skipped & 0 \\
\hline
\end{tabular}

Fingerprint was rated as follows. Of the 30 respondents, $21(70 \%)$ indicated they were very comfortable, $3(10 \%)$ indicated they were somewhat comfortable, $2(7 \%)$ indicated they were not very comfortable, another 2(7\%) indicated they were not comfortable; yet another 2(7\%) indicted I don't know.

Iris Scan was rated as follows. Of the 30 respondents, 11(37\%) indicated they were very comfortable, $7(23 \%)$ indicated they were somewhat comfortable, $5(17 \%)$ indicated they not very comfortable, $4(13 \%)$ indicated they not comfortable and 3(10\%) indicated I don't know.

Facial recognition was rated as follows. Of the 30 respondents, 19(63\%) indicted they were very comfortable, 6(20\%) indicated they were somewhat comfortable, $3(10 \%)$ indicated I don't know, 1(3\%) was not very comfortable and another 1(3\%) was not comfortable. 
Hand geometry was rated as follows. O f the 30 respondents, 17(57\%) indicated they were very comfortable, 5(17\%) indicated I don't know, 4(13\%) indicated they were somewhat comfortable, $3(10 \%)$ indicated they were not comfortable and $1(3 \%)$ indicated not comfortable.

Voice recognition was rated as follows. Of the 30 respondents, $18(60 \%)$ indicated they were very comfortable, $4(13 \%)$ indicated they were somewhat comfortable, $3(10 \%)$ indicated they were not very comfortable, another 3(10\%) indicated I don't know and $2(7 \%)$ indicated not comfortable.

Signature dynamic was rated as follows. Of the 30 respondents, 20(67\%) indicted they were very comfortable, 4(13\%) indicated I don't know, 3(10\%) indicated they were somewhat comfortable, $2(7 \%)$ indicated they were not very comfortable and 1(3\%) indicated not very comfortable.

For more details, see appendix A, Tables A47 through A.52 and Figures A.21 through A.26.

\section{Open-ended Questions}

The purpose of this section was to give participants the chance to provide more details and information about the implementation of biometric technology as an identification method in online classes. The research comprises three questions. These questions and participants' responses will be discussed in the next following section.

1. Do you have any comments or suggestions regarding the use of biometric technology as an authentication method in online or distance learning classes?

Out of 30 instructors who participated in the survey, 17 answered the first question of the Open-ended section. The participants suggested few items. Most of them 
did not welcome the technology and viewed it as "overkill", too intrusive, not needed, not necessary, not feasible or not practical. Another group believed that it is important to adopt this technology but was concerned about the ethical issue. They suggested adopting the least possible obtrusive technology. Finally, a few participants went into more detail and suggested 'fingerprint' as the best method among all biometric technologies.

2. Do you have any concerns or reservations, not mentioned in the survey, about the implementation of biometric technology in online course at WVU?

In answering this question only half of the participants decided to comment. Their comments and concern approached three main issues. The first issue addressed the technical aspects of implementing biometric technology: Is biometric technology a practical and reliable innovation? The second issue covered the ethical and moral aspects of implementing biometric technology at educational institutes. The concluding issue identified the cost involved in the implementation and adopting of biometric technology. 3. In your opinion, how can WVU improve the implementation of biometric technology?

Sixteen out-of thirty participants responded to this above question. Instructors suggested little to improve the adaptation of any technology, in general, and biometric technology in specific. First, they suggested that the schools should share their decisions with the students; make sure all parties understood why the technology was being implemented; and that sufficient measures had been taken to ensure confidentiality. Some instructors suggested that schools should create forums to discuss the implications and long-term consequences of biometric technology before such a decision is made. Second, if schools decided to adopt a technology, then they should take every measure to keep biometric data confidential and secured. Some of the instructors emphasized the 
importance of training people and personnel to maximize the benefits and minimize the side effects of biometric technology.

2. Analyses of Data Related to the Research Second Question (RQ2) "Students Group"

\section{Demographic Data}

The population of this study involved graduate students in various departments of the College of Human Resources and Education at the West Virginia University $(n=189)$. A survey instrument was used to collect data from the study participants. Demographic data that was collected includes the following informational elements: (1) major of the respondent, (2) respondents' gender, (3) respondent's age, (4) respondents' race or ethnicity, (5) respondents' religious orientation or persuasion, (6) respondents' knowledge about biometric technology and (7) respondents' experience with different type of biometric identification technology. This demographic data was collected and analyzed to obtain profiles of the respondents and to verify the students being studied. In addition, demographic data helped to identify and define the characteristics of the survey respondents. See table 4.15 for more details. 
Table 4.15

Summary of Students’ Demographic Data

\begin{tabular}{|c|c|c|c|c|c|c|}
\hline & & 1.) Major: & 2.) Gender: & 3.) Age: & $\begin{array}{l}\text { 4.) Ethnicit) } \\
\text { / Race: }\end{array}$ & 5.) Religion: \\
\hline \multirow[t]{2}{*}{$\mathrm{N}$} & Valid & 189 & 189 & 189 & 183 & 177 \\
\hline & Missing & 0 & 0 & 0 & 6 & 12 \\
\hline \multicolumn{2}{|c|}{ Mean } & 7.79 & 1.69 & 3.58 & 4.83 & 3.03 \\
\hline \multicolumn{2}{|c|}{ Median } & 9.00 & 2.00 & 3.00 & 5.00 & 3.00 \\
\hline \multicolumn{2}{|c|}{ Mode } & 10 & 2 & 2 & 5 & 3 \\
\hline \multicolumn{2}{|c|}{ Std. Deviation } & 3.594 & .462 & 1.571 & .710 & .686 \\
\hline \multicolumn{2}{|c|}{ Variance } & 12.920 & .214 & 2.468 & .504 & .471 \\
\hline
\end{tabular}

This section provides a brief summary of the characteristics of the respondents that participated in this study. First-demographic item on the survey asked for the name the department in that the respondent was a graduate student. Out of the 189 students who completed and submitted the survey, 12 (6.3\%) were from Speech Pathology and Audiology, 33 (17.5\%) were from Curriculum and Instruction, $6(3.2 \%)$ were from Educational Psychology 15 (7.9\%) were from Reading, 41 (21.7\%) were from Special education, $16(8.5 \%)$ did not identify their department(s), 8 (4.2\%) were from Counseling Psychology, 9 (4.8\%) were from Educational Leadership, 17 (9\%) were from Technology Education, 13 (6.9\%) were from Elementary Education, 17 (9\%) were from Secondary Education and $2(1.1 \%)$ were from Counseling. These demographic data are presented in Figure 4.13 below. 


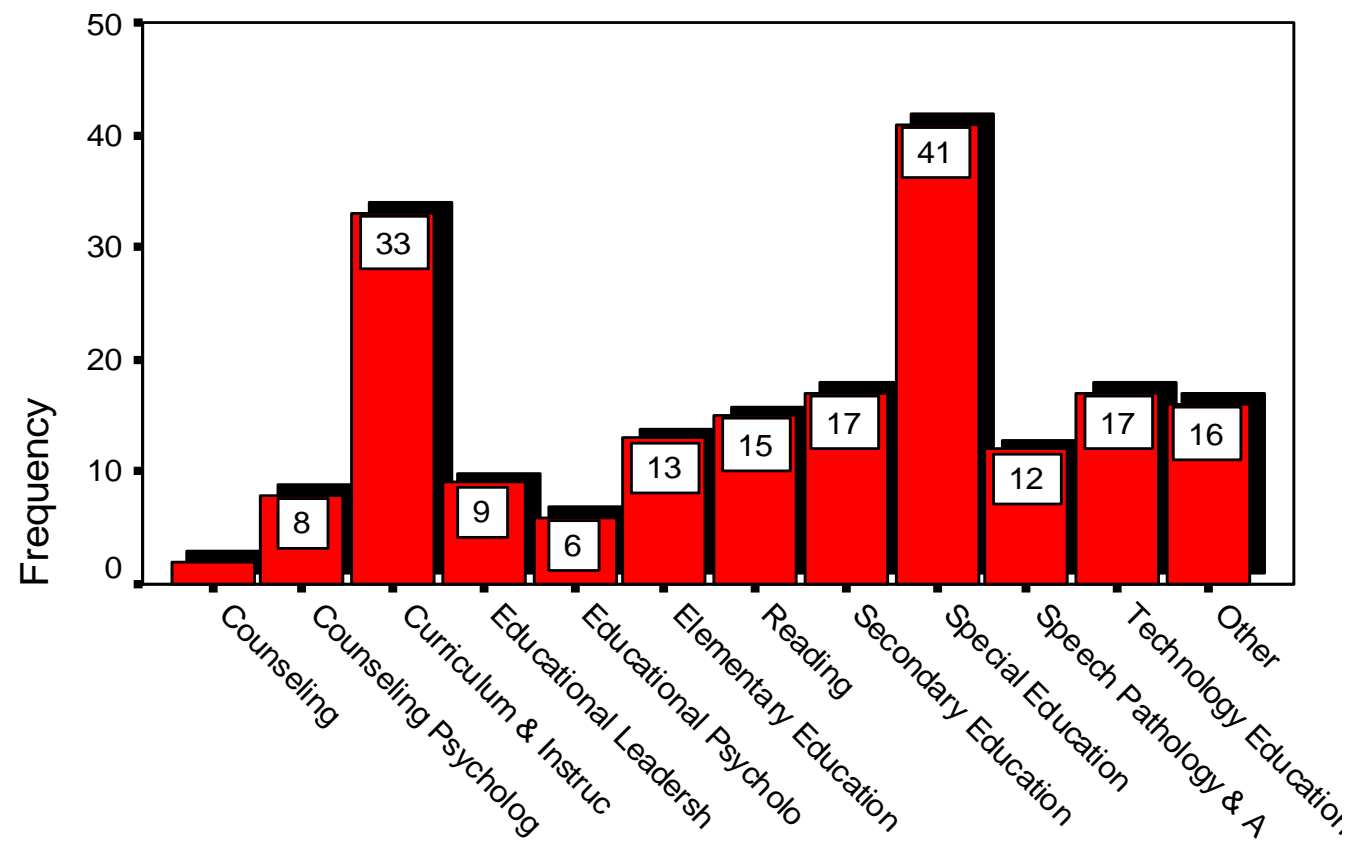

Figure 4.13. Students' majors.

Second-demographic item on the survey asked respondents to indicate their gender. The gender composition was predominately female. Out of the 189 survey respondents, 131 respondents $(69.3 \%)$ were female and 58 respondents $(30.7 \%)$ were male. This demographic data is presented in Figure 4.14 below.

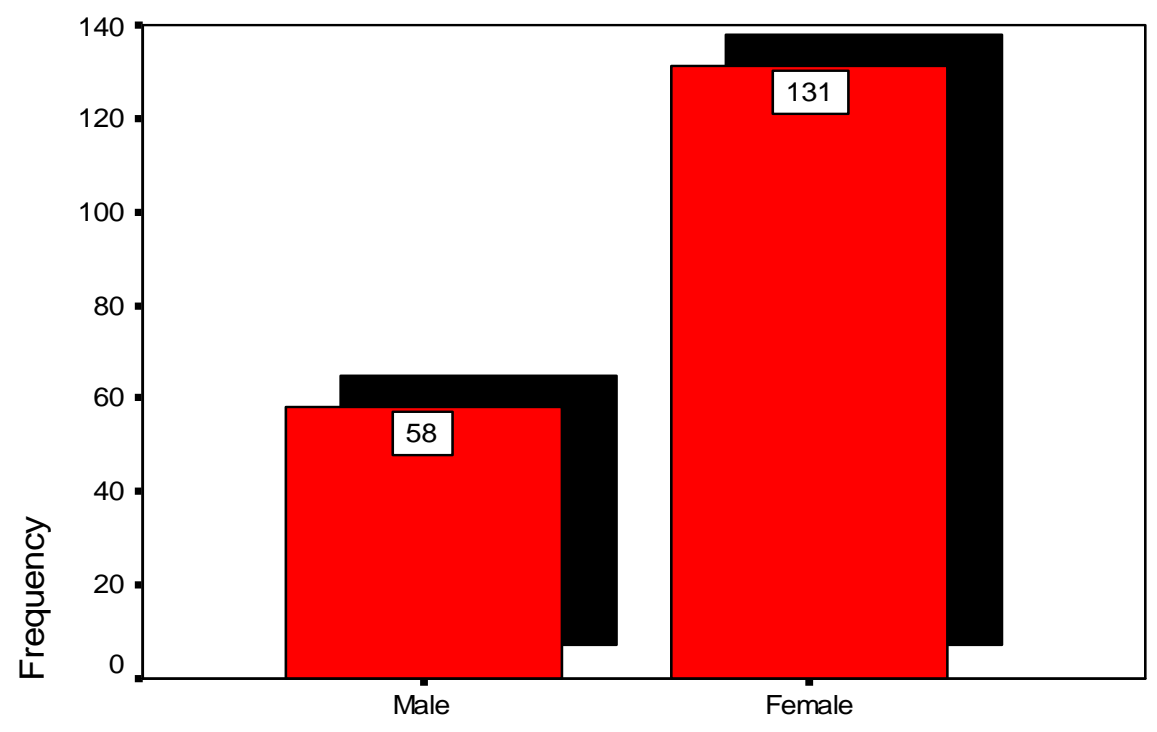


Figure 4.14. Students' gender distributions.

Third-demographic item on the survey asked respondents to indicate their age. The item was later divided into six groups. According to the survey, no participant was under 21 years old, $68(36.0 \%)$ of the respondents were in the group 21-25 years old, 42 $(22.2 \%)$ were between 26 and 30, $22(11.6 \%)$ were 31 and 35, $15(7.9 \%)$ were between 36 and 40 and $42(22.2 \%)$ were above age 41 . This demographic data is presented in Figure 4.15 .

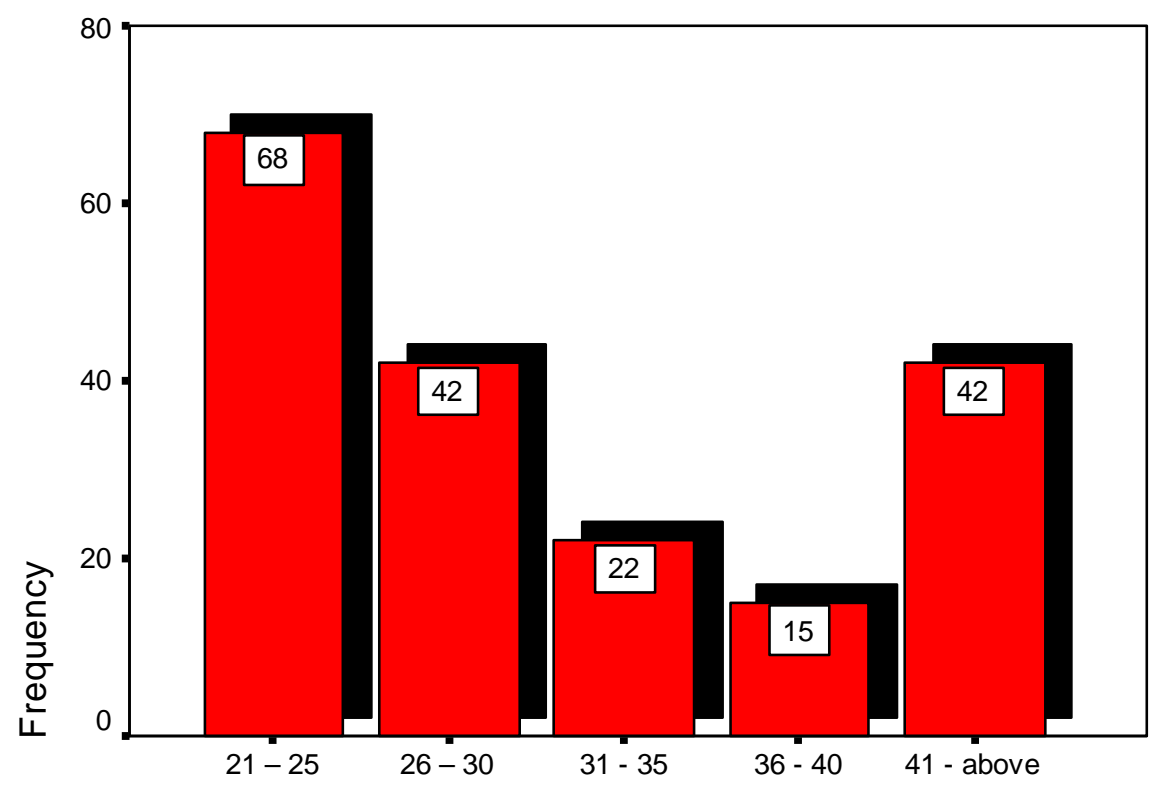

Figure 4.15. Students' age distributions

Forth-demographic item on the survey asked respondents to indicate their race or ethnicity. Out of the survey respondents, a majority 172 respondents $(91.0 \%)$ were NonHispanic Whites while only 1 respondent $(0.5 \%)$ was of Native American/American Indian descent, 3 respondents (1.6\%) were of African American descent, 4 respondents $(2.1 \%)$ were of Asian/Pacific descent, 3 respondents (1.6\%) were of Hispanic descent and 
6 respondents $(3.2 \%)$ identified themselves as other. This demographic data is presented in Figure 4.16.

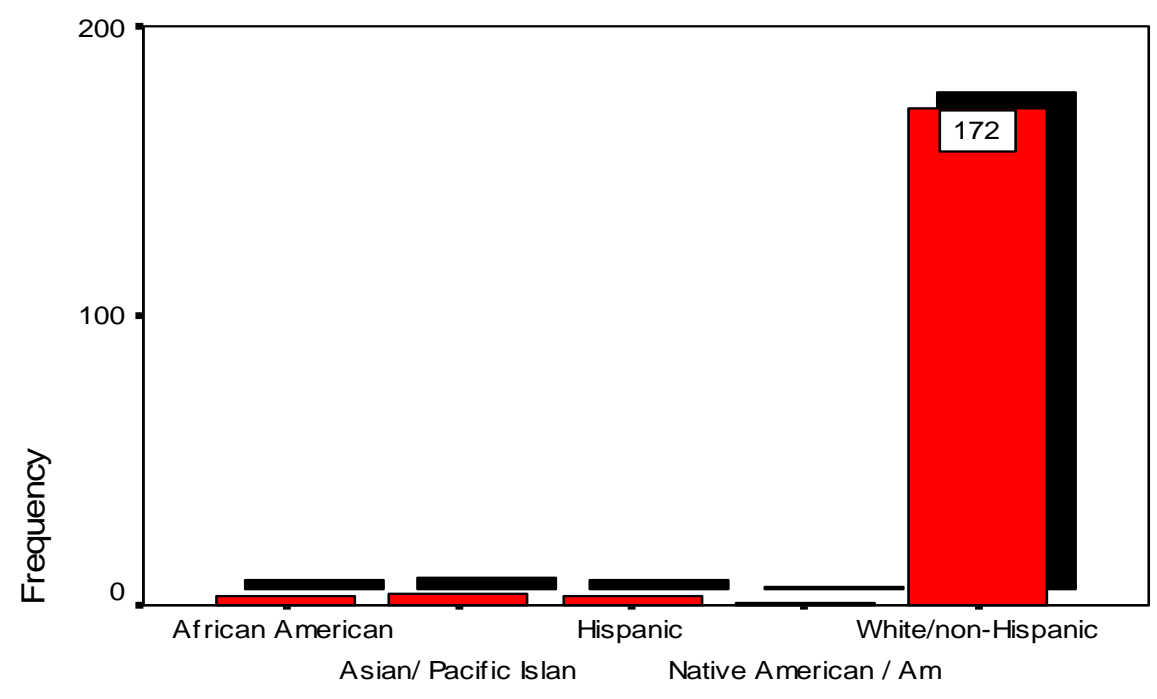

Figure 4.16. Students' ethnicity/ race distributions

Fifth-demographic item asked respondents to indicate their religious persuasion or affiliation. Of the surveys returned, 161 respondents $(85.2 \%)$ were Christian, 7 respondents $(3.7 \%)$ were Atheist, 5 respondents (2.6\%) were Muslim, 1 respondent $(0.5 \%)$ was Buddhist, 1 respondent $(0.5 \%)$ was Hindu, 2 respondents $(1.1 \%)$ were Jewish and $12(6.3 \%)$ did not indicate their religion. This demographic data is presented in Figure 4.17 below. 


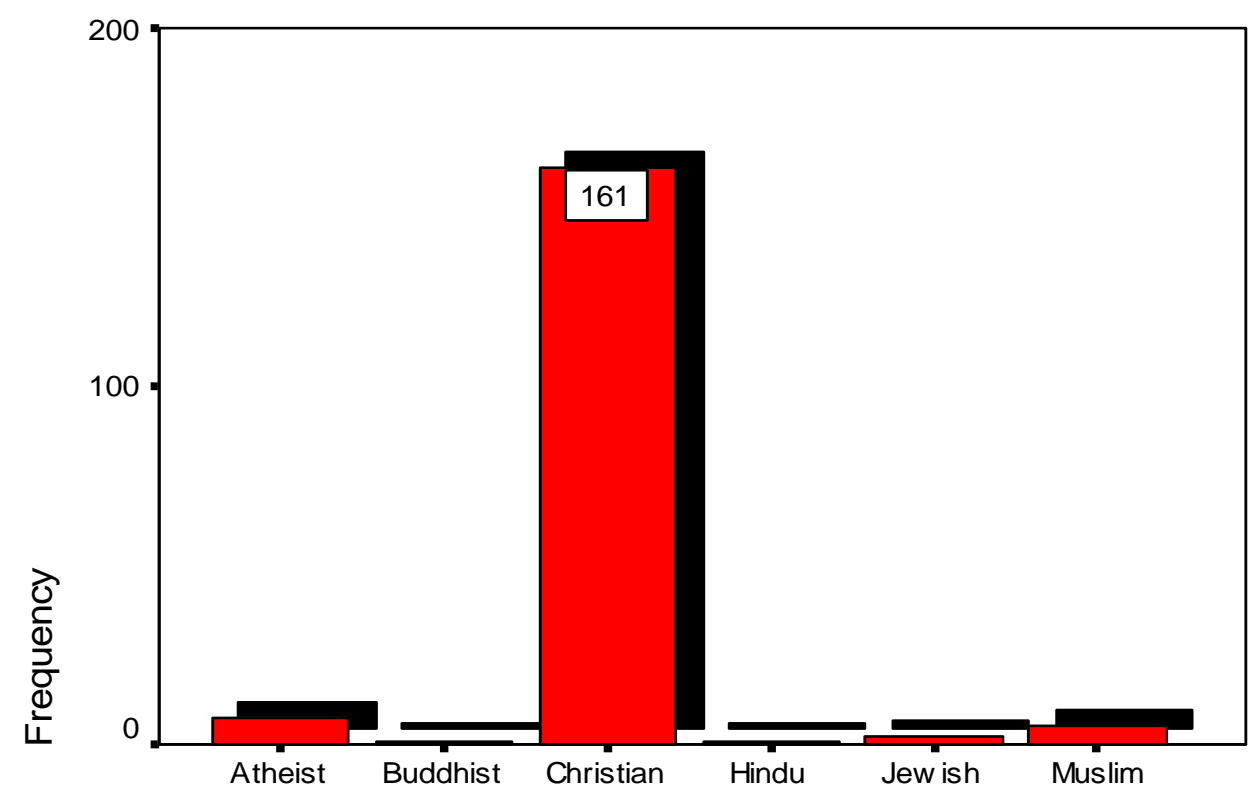

Figure 4.17. Students' religions distributions

Sixth-demographic item asked respondents to indicate if they knew what biometric technology was. Of the survey returned, 121 respondents $(64 \%)$ indicated that they knew what biometric technology was while 68 respondents $(36 \%)$ indicated that they did not know what biometric technology was. This demographic data is presented in Figure 4.18 below.

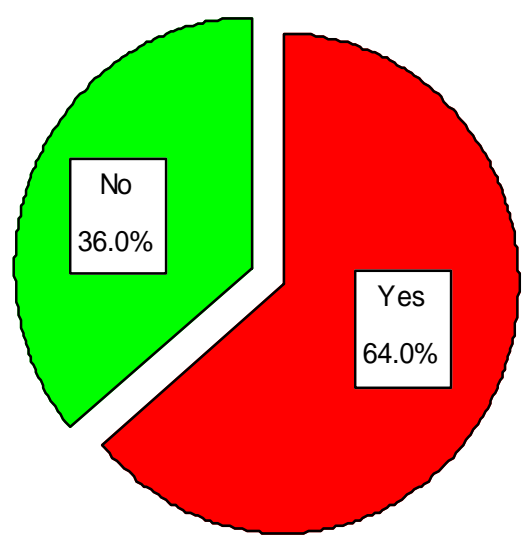

Figure 4.18. students' background about biometric technologies. 
Seventh-demographic item asked participants to check all that apply from a list of six places where they had used biometric technology. Of the 189 participants who responded to the survey, only $76(40.2 \%)$ respondents checked this question. See Table 4.16 for more details.

Table 4.16

Students’ Responses to Question about Using Biometric Technology at Different Locations

\begin{tabular}{|c|c|c|}
\hline \multicolumn{3}{|c|}{ 7. Have you ever used it in (Check all that apply): } \\
\hline & $\begin{array}{c}\text { Response } \\
\text { Percent }\end{array}$ & $\begin{array}{c}\text { Response } \\
\text { Total }\end{array}$ \\
\hline School & $33 \%$ & 25 \\
\hline Airport & $12 \%$ & 9 \\
\hline Bank & $33 \%$ & 25 \\
\hline ATM & $14 \%$ & 11 \\
\hline | Hospital & $9 \%$ & 7 \\
\hline Federal Building & $14 \%$ & 11 \\
\hline \multirow[t]{3}{*}{ Other } & $38 \%$ & 29 \\
\hline & Question Responses & 76 \\
\hline & Skipped & 113 \\
\hline
\end{tabular}

For more details about each item and their frequency tables, see Appendix B. (Tables B.6-B.7 \& B.13).

The following table (Table 4.17) summarizes the types of technologies previously used by student participants. It indicates that fingerprint is the highest technology experienced by the study participant. Out of 76 participants 66 of them (75\%) used fingerprint, followed by signature dynamic 21 (24\%), then facial and voice recognition $11(12 \%)$, hand geometry $10(11 \%)$ and iris scan 5(6\%). Finally, of the other technology, 
which was not mentioned in the survey, one respondent made up (1\%) of the total responses.

Table 4.17

Students’ Responses to Question about Different Types of Biometric Technologies

8. What Type of Technology did you use (check all that apply):

\begin{tabular}{|c|c|c|}
\hline & $\begin{array}{c}\text { Response } \\
\text { Percent }\end{array}$ & Response Total \\
\hline Fingerprint & $75 \%$ & 66 \\
\hline I ris scan & $6 \%$ & 5 \\
\hline Facial recognition & $12 \%$ & 11 \\
\hline Hand geometry & $11 \%$ & 10 \\
\hline Voice recognition & $12 \%$ & 11 \\
\hline Signature dynamic & $24 \%$ & 21 \\
\hline Other & $1 \%$ & 1 \\
\hline & Question Responses & 88 \\
\hline & Skipped & 101 \\
\hline
\end{tabular}

\section{Privacy Issues}

The participants responded to two sets of questions. The first set of questions was made up of six question items. Each question was ranked 1-5 with $1=$ being very concerned; 2 =being somewhat concerned; $3=$ being not very concerned; 4=being not concerned and 5=being I don't know. See Table 5.48 for more details. The second question was a one-question item, which sough to find out the respondent's perception of the level of intrusiveness of six biometric technologies. See Tables 4.18 and 4.19 for more details. 
Table 4.18

Summary of Students’ Responses to Items Related to Privacy Issues

\begin{tabular}{|c|c|c|c|c|c|c|c|}
\hline \multicolumn{2}{|c|}{$\begin{array}{l}\text { 9.) How } \\
\text { concerned are } \\
\text { you about }\end{array}$} & $\begin{array}{c}9.1 \text { having } \\
\text { your biometric } \\
\text { data } \\
\text { collected? }\end{array}$ & $\begin{array}{c}\text { 9.2) your } \\
\text { biometric data } \\
\text { stored in non- } \\
\text { secure } \\
\text { storage? }\end{array}$ & $\begin{array}{l}\text { 9.3) your } \\
\text { biometric } \\
\text { data used } \\
\text { by third } \\
\text { party? }\end{array}$ & $\begin{array}{c}9.4) \text { your } \\
\text { biometric data } \\
\text { misused by } \\
\text { WVU? }\end{array}$ & $\begin{array}{l}\text { 9.5) invasion of } \\
\text { your privacy by } \\
\text { WVU, when } \\
\text { biometric } \\
\text { technology is } \\
\text { implemented? }\end{array}$ & $\begin{array}{l}\text { 9.6) the negative } \\
\text { stigma attached } \\
\text { to the use of } \\
\text { biometric } \\
\text { technology? }\end{array}$ \\
\hline $\mathrm{N}$ & Valid & 189 & 189 & 189 & 189 & 189 & 189 \\
\hline & $\begin{array}{l}\text { Missin } \\
\mathrm{g}\end{array}$ & 0 & 0 & 0 & 0 & 0 & 0 \\
\hline & & 2.50 & 1.58 & 1.62 & 1.89 & 1.96 & 2.46 \\
\hline & & 2.00 & 1.00 & 1.00 & 2.00 & 2.00 & 2.00 \\
\hline Mo & & 2 & 1 & 1 & 1 & 1 & 2 \\
\hline & tion & 1.055 & .984 & .957 & 1.086 & 1.046 & 1.141 \\
\hline & & 1.113 & .968 & .917 & 1.180 & 1.094 & 1.303 \\
\hline
\end{tabular}


Table 4.19

Findings Summary of the First Set of Questions Related to Privacy Issues

\begin{tabular}{|c|c|c|c|c|c|c|}
\hline \multirow[t]{2}{*}{9.} & \multicolumn{6}{|c|}{ A. The privacy issues } \\
\hline & $\begin{array}{c}\text { Very } \\
\text { Concerned }\end{array}$ & $\begin{array}{l}\text { Somewhat } \\
\text { concerned }\end{array}$ & $\begin{array}{l}\text { Not very } \\
\text { Concerned }\end{array}$ & $\begin{array}{c}\text { Not } \\
\text { Concerned }\end{array}$ & $\begin{array}{l}\text { I don't } \\
\text { know }\end{array}$ & $\begin{array}{c}\text { Response } \\
\text { Total }\end{array}$ \\
\hline $\begin{array}{l}\text { How concerned are } \\
\text { you about having } \\
\text { your biometric data } \\
\text { collected? }\end{array}$ & 31 (16\%) & $76(40 \%)$ & $46(24 \%)$ & $29(15 \%)$ & $7(4 \%)$ & 189 \\
\hline $\begin{array}{l}\text { How concerned are } \\
\text { you about having } \\
\text { your biometric data } \\
\text { stored in non- } \\
\text { secure storage? }\end{array}$ & $122(65 \%)$ & $44(23 \%)$ & $8(4 \%)$ & $10(5 \%)$ & $5(3 \%)$ & 189 \\
\hline $\begin{array}{l}\text { How concerned are } \\
\text { you about having } \\
\text { your biometric data } \\
\text { used by third party? }\end{array}$ & $113(60 \%)$ & $51(27 \%)$ & $13(7 \%)$ & $7(4 \%)$ & $5(3 \%)$ & 189 \\
\hline $\begin{array}{l}\text { How concerned are } \\
\text { you about having } \\
\text { your biometric data } \\
\text { misused by WVU? }\end{array}$ & $91(48 \%)$ & $52(28 \%)$ & 27 (14\%) & $13(7 \%)$ & $6(3 \%)$ & 189 \\
\hline $\begin{array}{l}\text { How concerned are } \\
\text { you about the } \\
\text { invasion of your } \\
\text { privacy by WVU, } \\
\text { when biometric } \\
\text { technology is } \\
\text { implemented? }\end{array}$ & $80(42 \%)$ & 60 (32\%) & 30 (16\%) & $15(8 \%)$ & $4(2 \%)$ & 189 \\
\hline $\begin{array}{l}\text { How concerned are } \\
\text { you about the } \\
\text { negative stigma } \\
\text { attached to the use } \\
\text { of biometric } \\
\text { technology? }\end{array}$ & $42(22 \%)$ & 65 (34\%) & $45(24 \%)$ & 27 (14\%) & $10(5 \%)$ & 189 \\
\hline & & & & Question I & Responses & 189 \\
\hline & & & & & Skipped & 0 \\
\hline
\end{tabular}

The first privacy question asked respondents to indicate how concerned they were about having student biometric data collected. Of the 189 participants who responded to this question, 31(16.4\%) indicated they were 'Very concerned', 76(40.2\%) indicated they 
were 'Somewhat concerned', 46(24.3\%) indicated they were 'Not very concerned', $29(15.3 \%)$ indicated they were 'Not concerned' and 7(3.7\%) indicated 'I don't know'. See Figure 4.19 for more details.

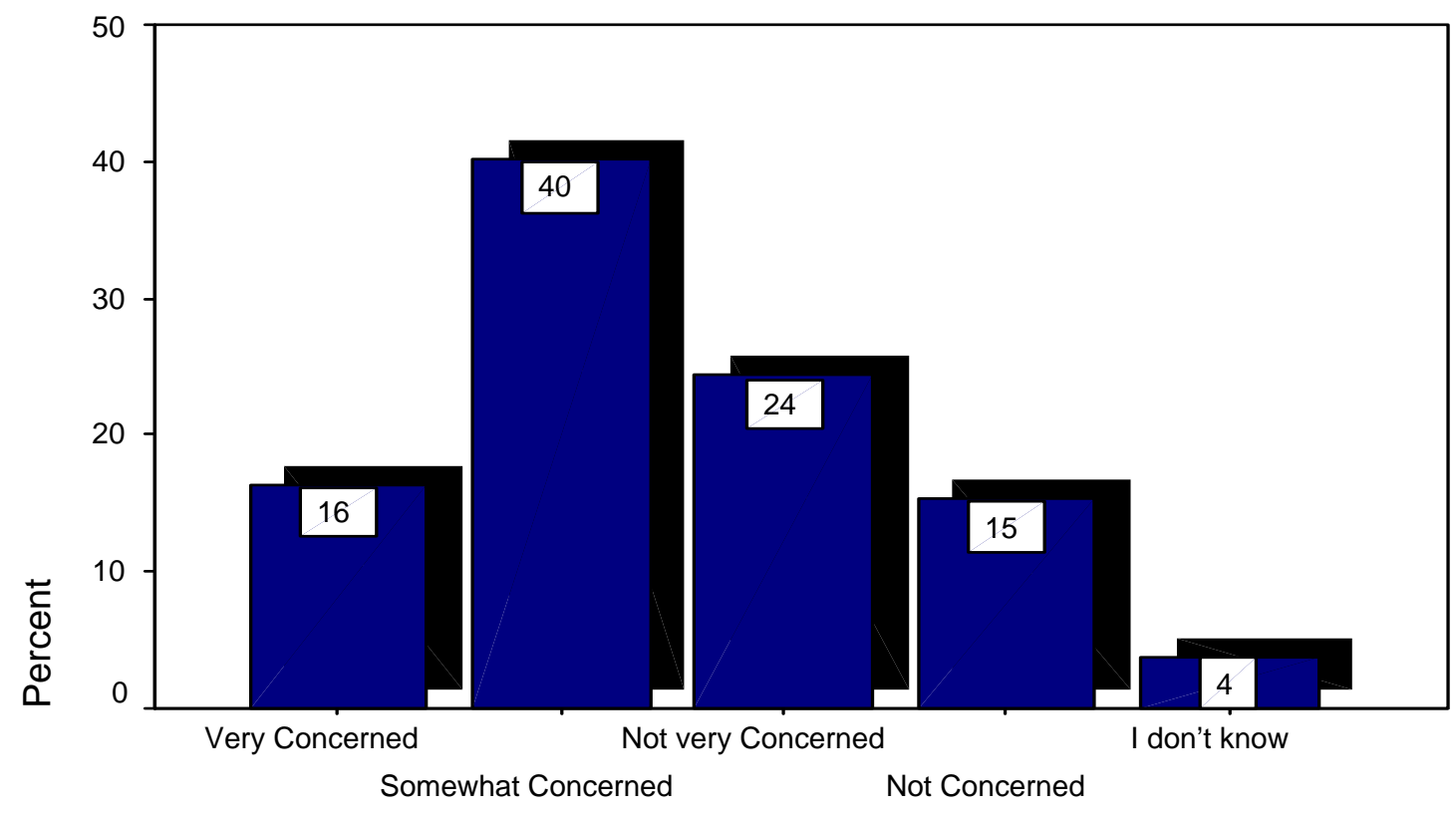

Figure 4.19. Students' concerns about data collections.

'How concerned are you about having students' biometric data stored in nonsecure storage', was the second privacy question. Of the 189 respondents, $122(64.6 \%)$ indicated they were 'very concerned', 44(23.3\%) indicated that they were 'somewhat concerned', $8(4.2 \%)$ indicated they were 'Not very concerned', 10(5.3\%) indicated they were 'Not concerned' and 5(2.6\%) responded by 'I don't know'. See Figure 4.20 for more details. 


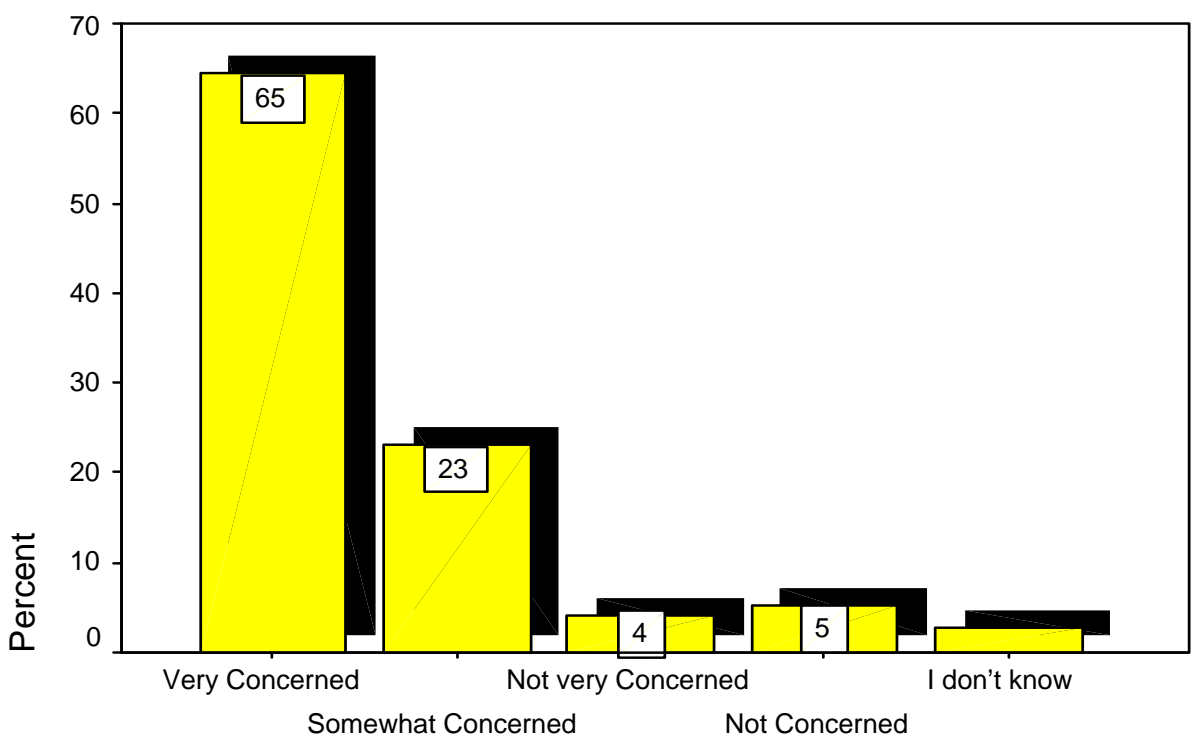

Figure 4.20. Students' concerns about storing data in non-secure storage.

The third privacy question asked respondents to indicate how concerned they were about having students' biometric data used by third party. Of the 189 respondents, $113(59.8 \%)$ indicated they were 'very concerned', 51(27.0\%) indicated that they were 'somewhat concerned', 13(6.9\%) indicated they were 'Not very concerned', 7(3.7\%) indicated they were 'Not concerned' and 5(2.6\%) responded by 'I don't know'. See Figure 4.21 for more details.

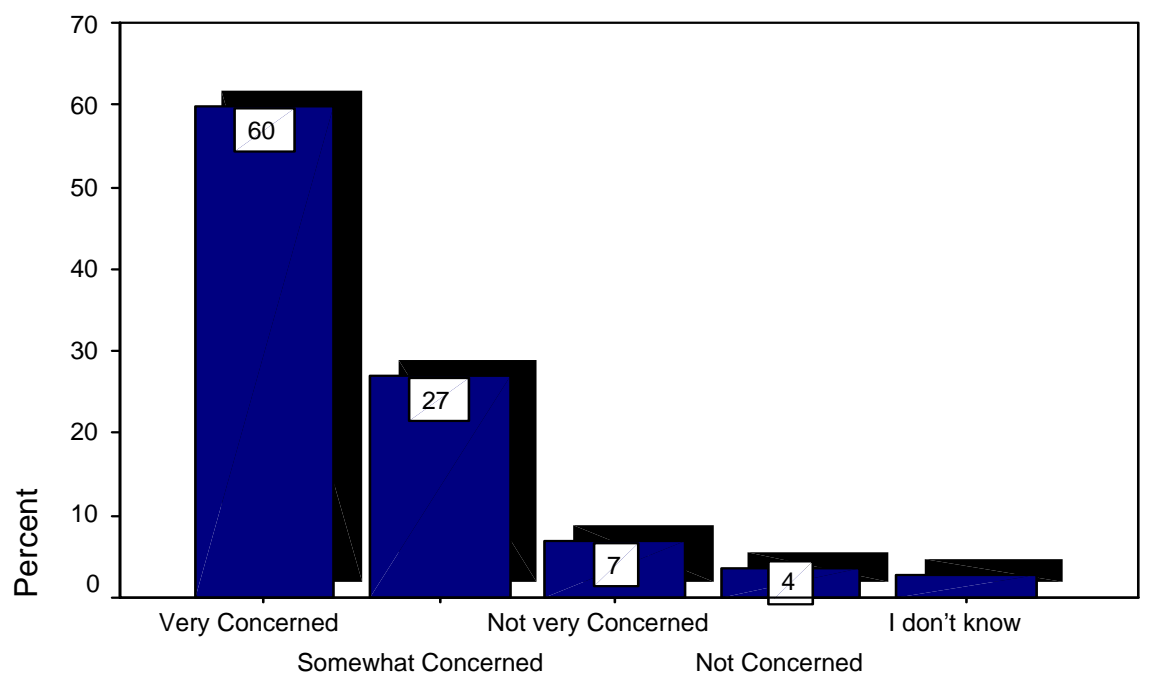

Figure 4.21. Students' concerns about using data by third party. 
'How concerned are you about having students' biometric data misused by WVU was the forth privacy question. Of the 189 respondents, 91(48.1\%) indicated they were 'very concerned', 52(27.5\%) indicated that they were 'somewhat concerned', 27(14.3\%) indicated they were 'Not very concerned', 6(3.2\%) indicated they were 'Not concerned' and $6(3.2 \%)$ responded by 'I don't know'. See Figure 4.22 for more details.

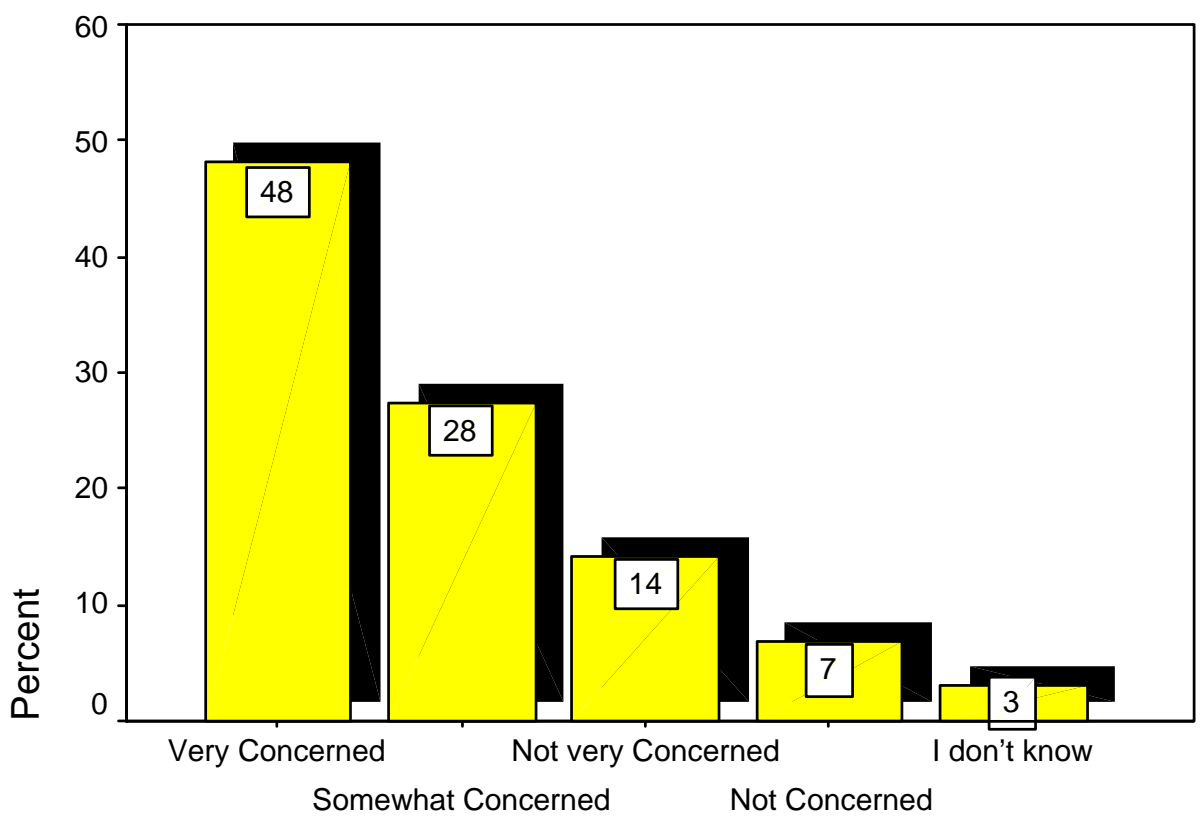

Figure 4.22. Students' concerns about misusing data by WVU.

The fifth privacy question asked respondents to indicate how concerned they would be about the invasion of students' privacy when WVU implements biometric technology. Of the 189 respondents, 80(42.3\%) indicated they were 'very concerned', $60(31.7 \%)$ indicated that they were 'somewhat concerned', 30(15.9\%) indicated they were 'Not very concerned', 15(7.9\%) indicated they were 'Not concerned' and 4(2.1\%) responded by 'I don't know'. See Figure 4.23 for more details. 


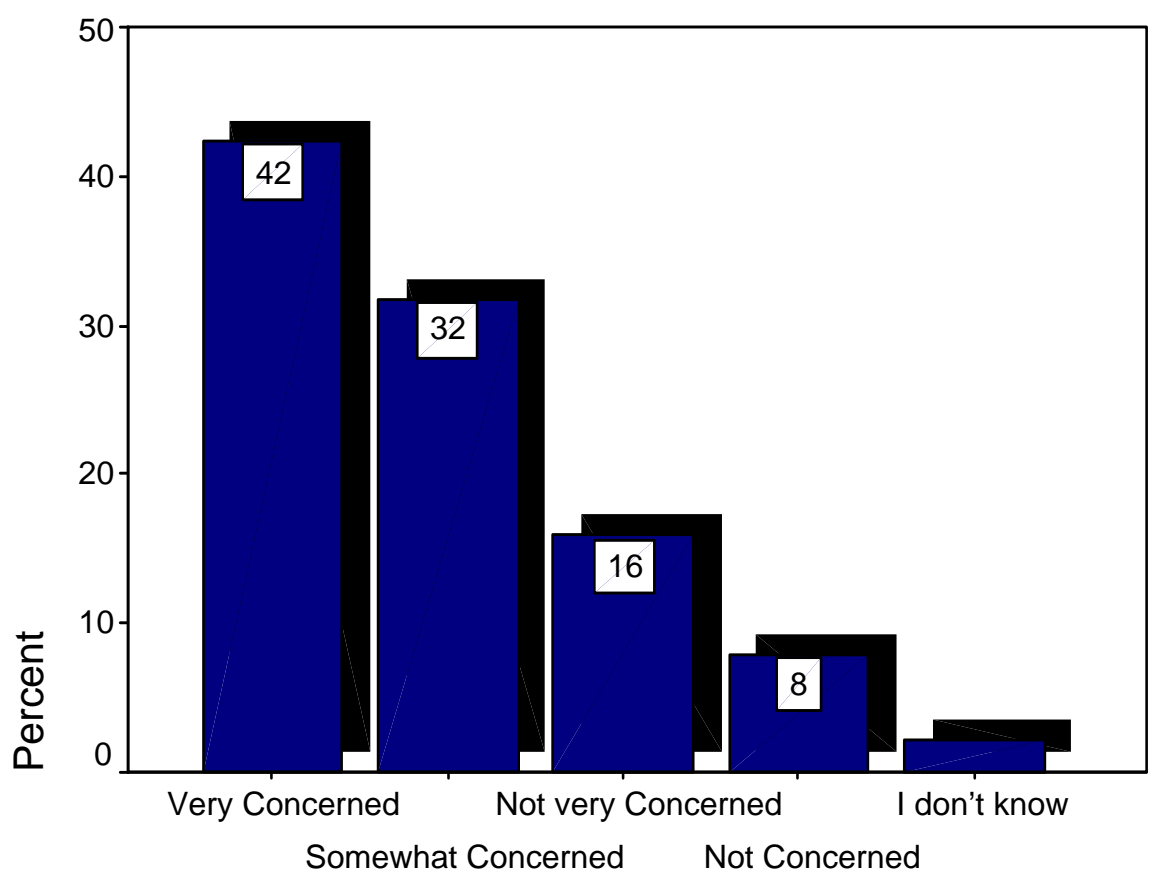

Figure 4.23. Students' concerns about invasion of privacy.

'How concerned are you about the negative stigma attached to the use of biometric technology' was the sixth privacy question. Of the 189 respondents, $42(22.2 \%)$ indicated they were 'very concerned', 65(34.4\%) indicated that they were 'somewhat concerned', 45(23.8\%) indicated they were 'Not very concerned', 72(14.3\%) indicated they were 'Not concerned' and 10(5.3\%) responded by 'I don't know'. These findings are reported in Figure 4.24 for more details. 


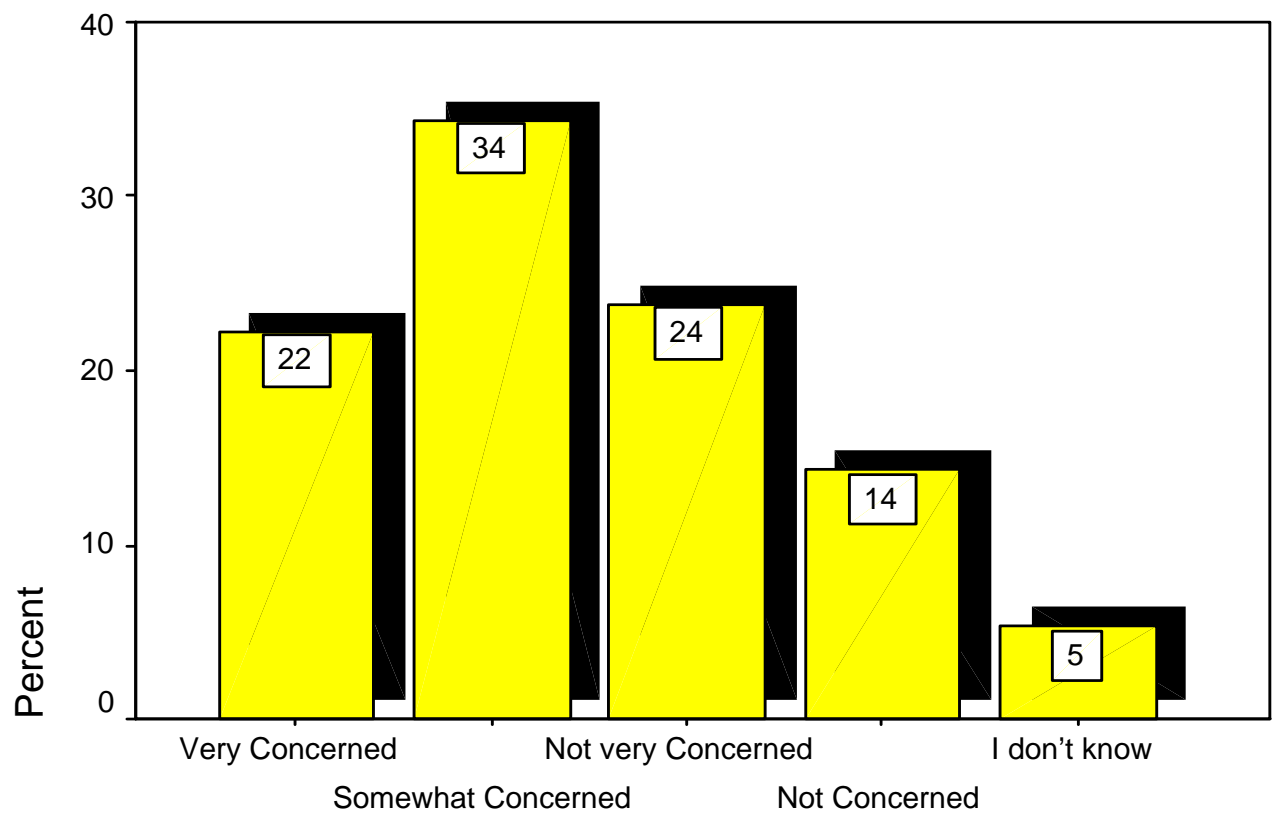

Figure 4.24. Students' concerns about negative stigma.

\section{Privacy Concerns of Each Ranked Biometric Technology (Low Medium High)}

The second set of privacy questions asked respondents to individually rank six biometric technologies: 'fingerprint' ‘iris scan', 'facial recognition', 'hand geometry', 'voice recognition' and 'signature dynamic', according to its level of intrusiveness, ranging from 'low', 'medium', 'high' to 'don't know'. According to the Students' responses concerning technology intrusiveness, 'Signature dynamic' was considered the lowest while 'Iris scan' ranked the highest. The tables below (Tables 4.20 and 4.21) summarize the findings related to the second question followed by a detailed discussion about each technology. 
Table 4.20

Students’ Responses to Different Biometric Technologies

\begin{tabular}{|c|c|c|c|c|c|c|c|}
\hline & & $\begin{array}{l}\text { 10.1) Rank } \\
\text { each } \\
\text { technology } \\
\text { according to } \\
\text { their } \\
\text { intrusiveness } \\
\text { - Fingerprint }\end{array}$ & $\begin{array}{l}\text { 10.2) Rank } \\
\text { each } \\
\text { technology } \\
\text { according to } \\
\text { their } \\
\text { intrusiveness } \\
\text { - Iris scans } \\
\text { "eye scan" }\end{array}$ & \begin{tabular}{|c|} 
10.3) Rank \\
each \\
technology \\
according to \\
their \\
intrusiveness \\
- Facial \\
recognition
\end{tabular} & $\begin{array}{l}\text { 10.4) Rank } \\
\text { each } \\
\text { technology } \\
\text { according to } \\
\text { their } \\
\text { intrusiveness } \\
\text { - Hand } \\
\text { geometry }\end{array}$ & $\begin{array}{l}\text { 10.5) Rank } \\
\text { each } \\
\text { technology } \\
\text { according to } \\
\text { their } \\
\text { intrusiveness } \\
\text { - Voice } \\
\text { recognition }\end{array}$ & $\begin{array}{l}\text { 10.6) Rank } \\
\text { each } \\
\text { technology } \\
\text { according to } \\
\text { their } \\
\text { intrusiveness } \\
\text { - Signature } \\
\text { dynamic }\end{array}$ \\
\hline \multirow[t]{2}{*}{$\bar{N}$} & Valid & 189 & 189 & 189 & 189 & 189 & 189 \\
\hline & Missing & 0 & 0 & 0 & 0 & 0 & 0 \\
\hline \multicolumn{2}{|c|}{ Mean } & 2.04 & 2.51 & 2.30 & 2.14 & 2.15 & 2.03 \\
\hline \multicolumn{2}{|c|}{ Median } & 2.00 & 3.00 & 2.00 & 2.00 & 2.00 & 2.00 \\
\hline \multicolumn{2}{|c|}{ Mode } & 1 & 3 & 2 & 2 & 2 & 1 \\
\hline \multicolumn{2}{|c|}{ Std. Deviation } & .975 & .796 & .873 & .947 & .893 & .948 \\
\hline \multicolumn{2}{|c|}{ Variance } & .951 & .634 & .763 & .896 & .797 & .898 \\
\hline
\end{tabular}

Table 4.21

Findings Summary of Second Set of Questions Related to the Privacy Issues

\begin{tabular}{|l|c|c|c|c|c|}
\hline \multicolumn{7}{|l|}{ 10. Rank each technology according to their intrusiveness } \\
\hline Fingerprint & Low & Medium & High & I don't know & Response Total \\
\hline Iris scans & $74(39 \%)$ & $46(24 \%)$ & $57(30 \%)$ & $12(6 \%)$ & 189 \\
Facial recognition & $21(11 \%)$ & $65(34 \%)$ & $88(47 \%)$ & $15(8 \%)$ & 189 \\
Hand geometry & $56(20 \%)$ & $71(38 \%)$ & $66(35 \%)$ & $14(7 \%)$ & 189 \\
Voice recognition & $51(27 \%)$ & $71(38 \%)$ & $55(29 \%)$ & $12(6 \%)$ & 189 \\
Signature dynamic & $68(36 \%)$ & $62(33 \%)$ & $45(24 \%)$ & $14(7 \%)$ & 189 \\
\hline & & & Question Responses & 189 \\
\hline
\end{tabular}

Fingerprint was ranked as follows. Of the 189 respondents, 74(39.2\%) ranked it as 'low', 46(24.3\%) ranked it as 'medium', 57(30.2\%) ranked it as 'high' and 12(6.3\%) indicated 'I don't know'. 
Iris scan was ranked as follows. Of the 189 respondents, $88(46.6 \%)$ ranked it as 'high', 21(11.1\%) ranked it as 'low', 65(34.4\%) ranked it as 'medium' and 15(7.9\%) indicated 'I don't know'.

Facial recognition was ranked as follows. Of the 189 respondents, 38(20.1\%) ranked it as 'low', 71(37.6\%) ranked it as 'medium', 66(34.9\%) ranked it as 'high' and 14(7.4\%) indicated 'I don't know'.

Hand geometry was ranked as follows. Of the 189 respondents, 68(36.0\%) ranked it as 'medium', 56(29.6\%) ranked it as 'low', 17(9.0\%) indicated 'I don't know' and $48(25.4 \%)$ ranked it as 'high'.

Voice recognition was ranked as follows. Of the 189 respondents, 71(37.6\%) ranked it as 'medium', 51(27.0\%) ranked it as 'low', 55(29.1\%) ranked it as 'high' and $12(6.3 \%)$ indicated 'I don't know'.

Signature dynamic was ranked as follows. Of the 189 respondents, 62(32.8\%) ranked it as 'medium', 68(36.0\%) ranked it as 'low', 14(7.4\%) indicated 'I don't know' and $45(23.8 \%)$ ranked it as 'high'. Table 4.73 and Figure 4.54 summarize these findings.

For more details, see appendix B, Tables B.20 through B.25 and Figures B.1 through B.6.

\section{Religious Issues}

The study addressed this issue by asking participants two major questions (see Table 4.22 for more details). The first question was about the appropriateness of implementing biometric technologies as an identification method for online classes. 
Table 4.22

Summary of Students’ Responses to Items Related to Religious Issues

\begin{tabular}{|c|c|c|c|}
\hline & & $\begin{array}{l}\text { 11.) In terms } \\
\text { of religious } \\
\text { conflicts, how } \\
\text { appropriate } \\
\text { do you think of } \\
\text { implementing } \\
\text { the biometric } \\
\text { systems as } \\
\text { described in } \\
\text { the scenario } \\
\text { below? }\end{array}$ & $\begin{array}{l}\text { 12.) Do you } \\
\text { think the } \\
\text { implementatio } \\
\mathrm{n} \text { of biometric } \\
\text { technology at } \\
\text { WVU } \\
\text { contradicts } \\
\text { your religious } \\
\text { beliefs? }\end{array}$ \\
\hline $\bar{N}$ & $\begin{array}{l}\text { Valid } \\
\text { Missing }\end{array}$ & $\begin{array}{r}189 \\
0\end{array}$ & $\begin{array}{r}189 \\
0\end{array}$ \\
\hline \multicolumn{2}{|c|}{ Mean } & 3.33 & 2.13 \\
\hline \multicolumn{2}{|c|}{ Median } & 3.00 & 2.00 \\
\hline \multicolumn{2}{|c|}{ Mode } & 5 & 2 \\
\hline \multicolumn{2}{|c|}{ Std. Deviation } & 1.451 & .482 \\
\hline \multicolumn{2}{|c|}{ Variance } & 2.105 & .232 \\
\hline
\end{tabular}

There were five choices: 'Very appropriate', 'Somewhat appropriate', 'Not appropriate', 'Not very appropriate' and 'I don't know'. Out of 189 participants $17(9.0 \%)$ responded with 'Very appropriate', 56(29.6\%) responded with 'Somewhat appropriate', 34(18.0\%) responded with 'Not appropriate', 12(6.3) answered with 'Not very appropriate' and 70(37.0\%) responded to this question with 'I don't know'. For more details, see Table 4.23 . 
Table 4.23

Findings Summary of First Question

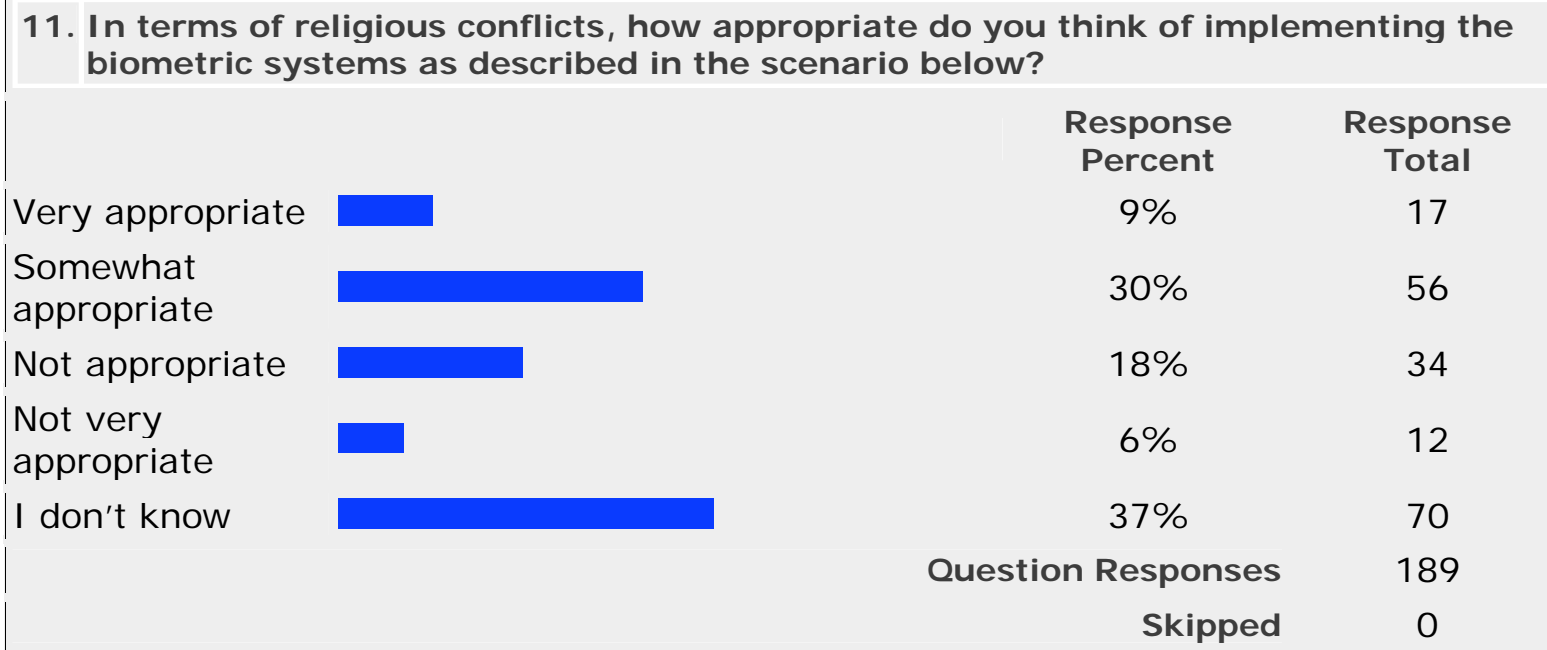

The second question related to the religious issue directly asked participants whether or not implementing biometric technologies contradicted their beliefs. Out of 189 participants $142(75.1 \%)$ of the participants said 'No', 11(5.80\%) said 'Yes' and 36(19.0\%) said 'I don't know'. See Table 4.24 for more details.

Table 4.24

Findings Summary Related to Second Question of Religious Issues.

12. Do you think the implementation of biometric technology at WVU contradicts your religious beliefs?

\begin{tabular}{lrrr|} 
& Response Percent & Response Total \\
'Yes & $6 \%$ & 11 \\
'No & $75 \%$ & 142 \\
I don't know & $19 \%$ & 36 \\
& Question Responses & 189 \\
& Skipped & 0 \\
\hline
\end{tabular}


Religious concerns of each ranked biometric technology (Low Medium High)

Part of the previous question asked to rank each technology according to its religious concerns. Since only 41 of 189(21.69\%) participants have some religious concerns about the implementation of biometric technology in online classes, 15 participants responded to this question. The table below (Table 4.25) indicates the frequencies and percentages of each technology and its rank. According to the Students' responses in regard to technology religious concerns, 'Fingerprint' was considered the lowest while 'Iris scan' was ranked the highest.

Table 4.25

Summary of Students' Ranking Different Biometric Technology According to their Religious Concerns

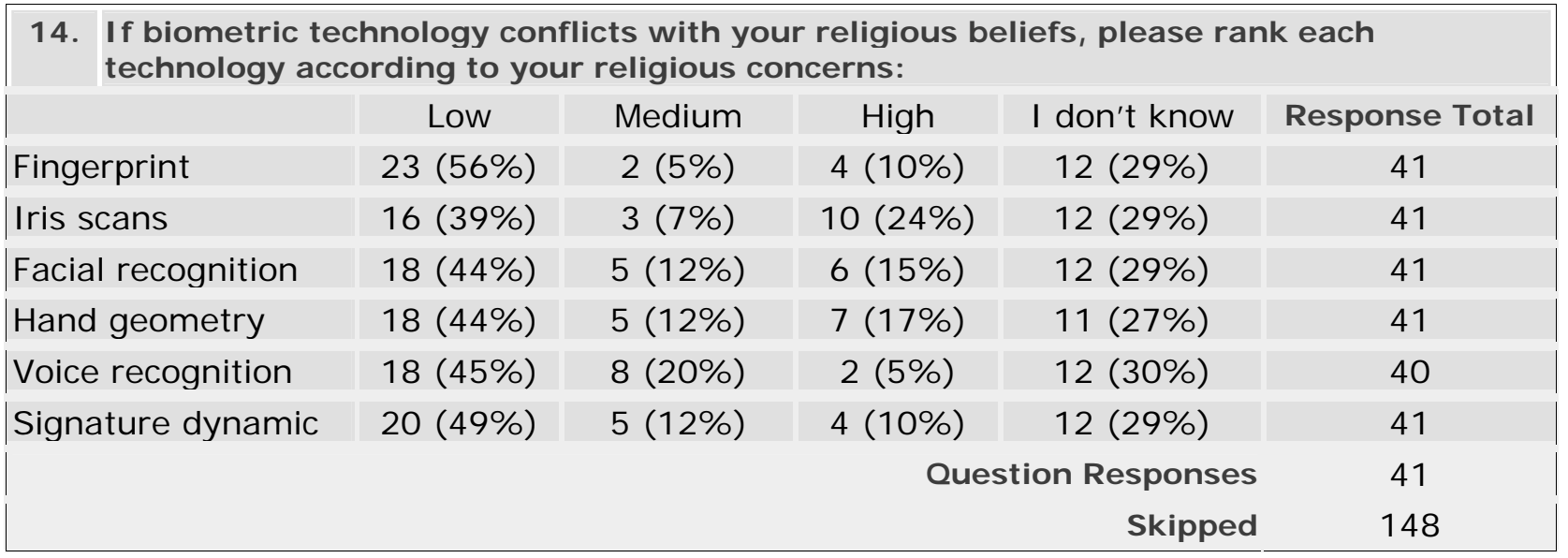

The following tables indicate the rank of each technology according to its perceived religious interference. Out of 41 participants $23(12.2 \%)$ ranked fingerprint as 'Low', 2(1.1\%) said it is 'Medium', 4(2.1\%) responded by 'High' and finally $12(6.3 \%)$ said they do not know. 
For Iris scan technology, only 41 participated in the ranking process. Out of 41 participants $16(8.5 \%)$ ranked iris scan as 'Low', 3(1.6\%) said it is 'Medium', $10(5.3 \%)$ responded by 'High' and finally $12(6.3 \%)$ said they do not know.

In facial recognition, 41 participated in the ranking process. Out of 41 participants $18(9.5 \%)$ ranked facial recognition as 'Low', 5(2.6\%) said it is 'Medium', $6(3.2 \%)$ responded by 'High' and finally $12(6.3 \%)$ said they do not know.

For hand geometry, 41 participated in the ranking process. Out of 41 participants $18(9.5 \%)$ ranked hand geometry as 'Low', $5(2.6 \%)$ said it is 'Medium', $7(3.7 \%)$ responded by 'High' and finally, 11(5.8\%) said they do not know.

For voice recognition, 41 participated in the ranking process. Out of 41 participants $18(9.5 \%)$ ranked voice recognition as 'Low', $8(4.2 \%)$ said it is 'Medium', 2(1.2\%) responded by 'High' and finally, 12(6.3\%) said they do not know.

Finally, for dynamic signature, 41 participated in the ranking process. Out of 41 participants 20(10.62\%) ranked fingerprint as 'Low', 5(2.6\%) said it is 'Medium', 4(2.1\%) responded by 'High' and finally, 12(6.3\%) said they do not know.

For more details, see appendix B, Tables B.26 through B.31 and Figures B.7 through B.12.

\section{Health Issues}

The third factor that investigated in this study addresses the health issues related to the implementation of biometric technology in online classes. The participants responded to three sets of questions.

The first health question asked respondents how concerned they would be when biometric technology is introduced. Responses ranged from 1-5. 1= being very concerned; 
2 =being somewhat concerned; $3=$ being not very concerned; $4=$ being not concerned, and $5=$ being I don't know.

Of the 189 participants who responded to this question, 21(11.1\%) indicated they did not know whether they would be concerned. The highest group of the participants 67(35.4\%) said that they were "Somewhat concerned", 55(29.1\%) were "Not very concerned", 31(16.4\%) were Not concerned and 15(7.9\%) of the participants said he/she was "Very concerned". See Table 4.26 for more details.

Table 4.26

It shows a Summary of Students' Responses to First Question of Health Issues

15. When biometric technology is implemented, how concerned are you about the health risk which might be rendered:

Very concerned
Somewhat concerned

Not very concerned

Not concerned

I don't know

\section{Response Percent}

$8 \%$

$35 \%$

$29 \%$

$16 \%$

$11 \%$

Question Responses

Skipped
Response Total

15

67

55

31

21

189

\section{Health concerns of each ranked biometric technology (Low Medium High)}

The second health question asked respondents to individually rank six biometric technologies: 'fingerprint' 'iris scan', 'facial recognition', 'hand geometry', 'voice recognition' and 'signature dynamic', according to their (the respondents') level of health concern, ranging from 'low', 'medium', 'high' to 'don't know'. According to the Students' responses in regard to technology health ranks, 'Signature dynamic' was 
considered the lowest while 'Iris scan' was ranked the highest. See Table 4.27 for more details.

\section{Table 4.27}

The Following Table Summarizes the Ranking of Different Biometric Technologies According to their Health Concerns

16. Rank each technology according to your health concerns:

\begin{tabular}{|llllll|} 
& Low & Medium & High & I don't know & Response Total \\
|Fingerprint & $131(69 \%)$ & $32(17 \%)$ & $9(5 \%)$ & $17(9 \%)$ & 189 \\
Iris scans & $51(27 \%)$ & $55(29 \%)$ & $62(33 \%)$ & $21(11 \%)$ & 189 \\
Facial recognition & $94(50 \%)$ & $43(23 \%)$ & $30(16 \%)$ & $22(12 \%)$ & 189 \\
Hand geometry & $105(56 \%)$ & $43(23 \%)$ & $17(9 \%)$ & $24(13 \%)$ & 189 \\
Voice recognition & $124(66 \%)$ & $36(19 \%)$ & $10(5 \%)$ & $19(10 \%)$ & 189 \\
Signature dynamic & $135(71 \%)$ & $29(15 \%)$ & $5(3 \%)$ & $20(11 \%)$ & 189 \\
Question Responses & & & & & 189 \\
\hline Skipped & & & & & 0
\end{tabular}

Fingerprint ranked as follows. Of the 189 respondents, 131(69.3\%) ranked it as 'low', 32(16.9\%) ranked it 'Medium', 9(4.8\%) ranked it 'High' and 17(9.0\%) indicated 'I don't know'.

Iris scan ranked as follows. Of the 189 respondents, 51(27.0\%) ranked it as 'Low', 55(29.1\%) ranked it as 'Medium', 62(32.8\%) ranked it as 'High' and 21(11.1\%) indicated 'I don't know'.

Facial recognition ranked as follows. Of the 189 respondents, 94(49.7\%) ranked it as 'Low', 43(22.8\%) ranked it as 'Medium', 30(15.9\%) ranked it as 'High' and 22(11.6\%) indicated 'I don't know'. 
Hand geometry ranked as follows. Of the 189 respondents, $105(55.6 \%)$ ranked it as 'Low', 43(22.8\%) ranked it as 'Medium', 17(9.0\%) ranked it as 'High' and 24(12.7\%) indicated 'I don't know'.

Voice recognition ranked as follows. Of the 189 respondents, $124(65.6 \%)$ ranked it as 'Low', 36(19.0\%) ranked it as 'Medium', 10(5.3\%) ranked it as 'High' and 19(10.1\%) indicated 'I don't know'.

Signature dynamic ranked as follows. Of the 189 respondents, $135(71.4 \%)$ ranked it as 'Low', 29(15.3\%) ranked it as 'Medium', 5(2.6\%) ranked it as 'High' and 20(10.6\%) indicated 'I don't know'.

For more details, see appendix B, Tables B.32 through B.37 and Figures B.13 through B.18.

Health Concerns of Each Rated Biometric Technology (Comfortability)

The third health question asked respondents to rate (in terms of health concerns) their level of Comfortability toward the use of these biometric technology: 'fingerprint' 'iris scan', 'facial recognition', 'hand geometry', 'voice recognition', and 'signature dynamic', ranging from 1=being 'very comfortable', 2=being 'somewhat comfortable', 3=being 'not very comfortable', 4=being 'not comfortable' and 5=being 'I don't know'. According to Students' responses in regard to technology Comfortability, 'Fingerprint' was considered the best while 'Iris scan' ranked the worst. See Table 4.28 and 4.29 for more details. 
Table 4.28

The Summary of Different Biometric Technologies and its Ranking According to Comfortability

\begin{tabular}{|c|c|c|c|c|c|c|c|}
\hline & & Fingerprint & Iris scan & $\begin{array}{c}\text { Facial } \\
\text { recognition }\end{array}$ & $\begin{array}{c}\text { Hand } \\
\text { geometry }\end{array}$ & $\begin{array}{c}\text { Voice } \\
\text { recognition }\end{array}$ & $\begin{array}{l}\text { Signature } \\
\text { dynamic }\end{array}$ \\
\hline \multirow[t]{2}{*}{$\mathrm{N}$} & Valid & 189 & 189 & 189 & 189 & 189 & 189 \\
\hline & Missing & 0 & 0 & 0 & 0 & 0 & 0 \\
\hline \multicolumn{2}{|c|}{ Mean } & 1.84 & 2.89 & 2.57 & 2.36 & 2.25 & 2.07 \\
\hline \multicolumn{2}{|c|}{ Median } & 2.00 & 3.00 & 2.00 & 2.00 & 2.00 & 2.00 \\
\hline \multicolumn{2}{|c|}{ Mode } & 1 & 3 & 2 & 2 & 2 & 1 \\
\hline \multicolumn{2}{|c|}{ Std. Deviation } & 1.065 & 1.185 & 1.234 & 1.271 & 1.220 & 1.192 \\
\hline \multicolumn{2}{|c|}{ Variance } & 1.134 & 1.404 & 1.523 & 1.615 & 1.488 & 1.420 \\
\hline
\end{tabular}

Table 4.29

Students’ Response Summary to Different Biometric Technologies from Health

Perspective

17. In terms of health concerns, please rate your comfortability toward the use of these five biometric technologies

Very Somewhat Not very Not I don't Response comfortable comfortable Comfortable Comfortable know Total

\begin{tabular}{|c|c|c|c|c|c|c|}
\hline Fingerprint & $90(48 \%)$ & $65(34 \%)$ & $16(8 \%)$ & $10(5 \%)$ & $8(4 \%)$ & 189 \\
\hline I ris scan & $28(15 \%)$ & $44(23 \%)$ & $52(28 \%)$ & $50(26 \%)$ & $15(8 \%)$ & 189 \\
\hline $\begin{array}{l}\text { Facial } \\
\text { recognition }\end{array}$ & $43(23 \%)$ & $56(30 \%)$ & $45(24 \%)$ & $29(15 \%)$ & $16(8 \%)$ & 189 \\
\hline $\begin{array}{l}\text { Hand } \\
\text { geometry }\end{array}$ & $52(28 \%)$ & $74(39 \%)$ & $27(14 \%)$ & $15(8 \%)$ & $\begin{array}{c}21 \\
(11 \%)\end{array}$ & 189 \\
\hline $\begin{array}{l}\text { Voice } \\
\text { recognition }\end{array}$ & $61(32 \%)$ & $64(34 \%)$ & 35 (19\%) & $13(7 \%)$ & $16(8 \%)$ & 189 \\
\hline \multirow[t]{3}{*}{$\begin{array}{l}\text { Signature } \\
\text { dynamic }\end{array}$} & $73(39 \%)$ & $68(36 \%)$ & $24(13 \%)$ & $9(5 \%)$ & $15(8 \%)$ & 189 \\
\hline & & & & \multicolumn{2}{|c|}{ Question Responses } & 189 \\
\hline & & & & & Skipped & 0 \\
\hline
\end{tabular}

Fingerprint rated as follows. Of the 189 respondents, 90(47.6\%) indicated they were 'Very comfortable', 65(34.4\%) indicated they were 'Somewhat comfortable', 
$16(8.5 \%)$ indicated they were 'Not very comfortable', 10(5.3\%) indicated they were 'Not comfortable; yet another 8(4.2\%) indicted 'I don't know'.

Iris scan rated as follows. Of the 189 respondents, $28(14.8 \%)$ indicated they were 'Very comfortable', 44(23.3\%) indicated they were 'Somewhat comfortable', 52(27.5\%) indicated they were 'Not very comfortable', 50(26.5\%) indicated they were 'Not comfortable; yet another 15(7.9\%) indicted 'I don't know'.

Facial recognition rated as follows. Of the 189 respondents, 43(22.8\%) indicated they were 'Very comfortable', 56(29.6\%) indicated they were 'Somewhat comfortable', 45(23.8\%) indicated they were 'Not very comfortable', 29(15.3\%) indicated they were 'Not comfortable; yet another 16(8.5\%) indicted 'I don't know'.

Hand geometry rated as follows. Of the 189 respondents, 52(27.5\%) indicated they were 'Very comfortable', 74(39.2\%) indicated they were 'Somewhat comfortable', $27(14.3 \%)$ indicated they were 'Not very comfortable', $15(7.9 \%)$ indicated they were 'Not comfortable; yet another 21(11.1\%) indicted 'I don't know'.

Voice recognition rated as follows. Of the 189 respondents, $61(32.3 \%)$ indicated they were 'Very comfortable', 64(33.9\%) indicated they were 'Somewhat comfortable', $35(18.5 \%)$ indicated they were 'Not very comfortable', 13(6.9\%) indicated they were 'Not comfortable'; yet another 16(8.5\%) indicted 'I don't know'.

Signature dynamic rated as follows. Of the 189 respondents, 73(38.6\%) indicated they were 'Very comfortable', 68(36.0\%) indicated they were 'Somewhat comfortable', 24(12.7\%) indicated they were 'Not very comfortable', 9(4.8\%) indicated they were 'Not comfortable'; yet another 15(7.9\%) indicted 'I don't know'. 
For more details, see appendix B, Tables B.38 through B.48 and Figures B.19 through B.24.

\section{Open-ended Questions}

The purpose of this section was to give participants a chance to provide more detailed information about their attitude toward the implementation of biometric technology as an identification method for online classes. The research was comprised of three questions. The participants' responses will be discussed in the following section.

1. Do you have any comments or suggestions regarding the use of biometric technology as an authentication method in online or distance learning classes?

Out of 189 students who participated in the survey, 82 students answered the first question of the open-ended section. Some students showed great interest in this technology. They pointed to the crucial need for reliable technology that might help in distance learning classes. Some of them were very excited to see the outcome of this study. Some participants, however, expressed concern about this study. Students' suggestions and comments categorized into three main classifications.

First classification: students concerns related to the invasion of students privacy. These students were concerned about the "BIG BROTHERSIM". Therefore, they suggested many ways to encrypt data; store it in a safe place; and prohibit its being sold to any outside party. Biometric data must be used solely for the individual student's good.

The second classification examined the feasibility and reliability of biometric technology; students questioned the validity of the biometric technology. They expressed concern about the convenience of the technology with one student referring to biometric 
technology as "Hostile technology". The students challenged the ability of biometric technology to ensure that students will not be able to deteriorate it.

The third classification addressed the cost issue. Most of the students expressed concern about the cost involved in the process of implementing biometric technology. In addition, they expressed concern about the increase of tuition fees as a direct outcome.

As an alternative, students suggested a few items that might solve the problem of identity or serve to better implement biometric technology. One student suggested that the school could implement an "Honor Code" that is signed by each student claiming that they have not received any help. This Honor code would be similar to what the service academies currently use (USNA, ARMY, USAF, and USCG).

More than one student suggested that schools should list any risk related to technology prior to adopting it; this will build trust between schools and their students. In order to protect students' biometric data, group of students suggested that schools should destroy biometric data as soon as they have completed the distance classes. In addition, they have suggested the use of signature dynamic; since it is less intrusive compared with other biometric technologies. Moreover, students thought that schools should also have a wide range of biometric processes to cater to the unique religious and health needs of certain students.

2. Do you have any concerns or reservations, not mentioned in the survey, about the implementation of biometric technology in online course at WVU?

In answering this question, 68 of the participants decided to comment. Their comments and concern were redundant and repetitive of issues discussed in the survey. Some students, however, anticipated a drop in the online classes due to a rise in costs. 
One student commented on this question by saying that, "This technology introduces the concept of "BIG BROTHER" in educational institutes". A few students commented that it is more suitable to install biometric technology in locations such stadiums and recreational centers.

3. In your opinion, how can WVU improve the implementation of biometric technology?

Regarding this question, 66 out of 189 participants responded. Some participants deem that it is important to combine more that one technology. Some participants suggested that the school offer several methods of biometric identification, so that students can pick the technology they are the most comfortable with. The university should also have an alternative for those with religious or other objections, "and make the alternative very well known”. Some participants suggested more information and public awareness before implementing such technology, by educating students as to the reasons why it is being implemented, at least several months before it is used. Newspaper, television, instructors, etc could do this. One student suggested that schools have to ensure that people who handle biometric data have stringent guidelines, and keep government and other institutions from obtaining the information. This information would have to be in stored in a highly secure environment by implementing very hard policies.

3. Analyses of Data Related to the Research Third Question (RQ3) Comparing Males and Females Instructors and Students 3.1 The difference between Students and Instructors groups in their attitude toward the implementation of biometric technology in regard to: 
Privacy issues.

An independent-samples t-test was performed to determine if there was a significant difference between the mean average of privacy concerns between instructors and students groups. In this question the t-statistic was not significant at the critical alpha level $\alpha=0.05,(t=1.356 ; \mathrm{df}=104 ; \mathrm{p}=.178)$. Therefore, the researcher concluded that there was no significant difference between instructors and students.

Religious issues.

An independent-samples t-test was performed to determine if there was a significant difference between the mean average of religious concerns between instructors and students groups. In this question the t-statistic was not significant at the critical alpha level $\alpha=0.05,(\mathrm{t}=-1.851 ; \mathrm{df}=76 ; \mathrm{p}=.068)$. Therefore, the researcher concluded that there was no significant difference between instructors and students.

Health issues.

An independent-samples t-test was performed to determine if there was a significant difference between the mean average of health concerns between instructors and students groups. In this question the t-statistic was significant at the critical alpha level $\alpha=0.05,(\mathrm{t}=3.218 ; \mathrm{df}=108 ; \mathrm{p}=.002)$. Therefore, the researcher concluded that there was a significant difference between instructors and students in regard to their concerns about health issues. For more details, see Tables 4.30 and Figure 4.25. 
Table 4.30

Comparison between Students and Instructors Groups Regarding Health Issues

\begin{tabular}{|ll|r|r|r|r|}
\hline \multicolumn{1}{|c|}{ Group Statistics } \\
\hline & Groups & $\mathrm{N}$ & Mean & Std. Deviation & $\begin{array}{c}\text { Std. Error } \\
\text { Mean }\end{array}$ \\
\hline $\begin{array}{l}\text { 15.) When biometric } \\
\text { technology is } \\
\text { implemented, how } \\
\begin{array}{l}\text { concerned are you about } \\
\text { the health risk which } \\
\text { might be rendered: }\end{array}\end{array}$ instructors & students & 29 & 3.31 & .761 & .141 \\
\hline
\end{tabular}

Independent Samples Test

\begin{tabular}{|c|c|c|c|c|c|c|c|c|c|}
\hline & \multicolumn{2}{|c|}{$\begin{array}{l}\text { Levene's Test for } \\
\text { quality of Variance }\end{array}$} & \multicolumn{7}{|c|}{ t-test for Equality of Means } \\
\hline & \multirow[b]{2}{*}{$\mathrm{F}$} & \multirow[b]{2}{*}{ Sig. } & \multirow[b]{2}{*}{$\mathrm{t}$} & \multirow[b]{2}{*}{ df } & \multirow[b]{2}{*}{ pig. (2-tailed } & \multirow{2}{*}{$\begin{array}{l}\text { Mean } \\
\text { Difference }\end{array}$} & \multirow{2}{*}{$\begin{array}{l}\text { Std. Error } \\
\text { Difference }\end{array}$} & \multicolumn{2}{|c|}{$\begin{array}{l}95 \% \text { Confidence } \\
\text { Interval of the } \\
\text { Difference }\end{array}$} \\
\hline & & & & & & & & Lower & Upper \\
\hline $\begin{array}{l}\text { 15.) When biometric Equal variand } \\
\text { technology is assumed } \\
\text { implemented, how } \\
\text { concerned are you c Equal variand } \\
\text { the health risk whick not assumed } \\
\text { might be rendered: }\end{array}$ & .789 & .377 & $\begin{array}{l}3.218 \\
3.454\end{array}$ & 56.932 & $\begin{array}{l}.002 \\
.001\end{array}$ & .59 & .172 & .250 & .939 \\
\hline
\end{tabular}




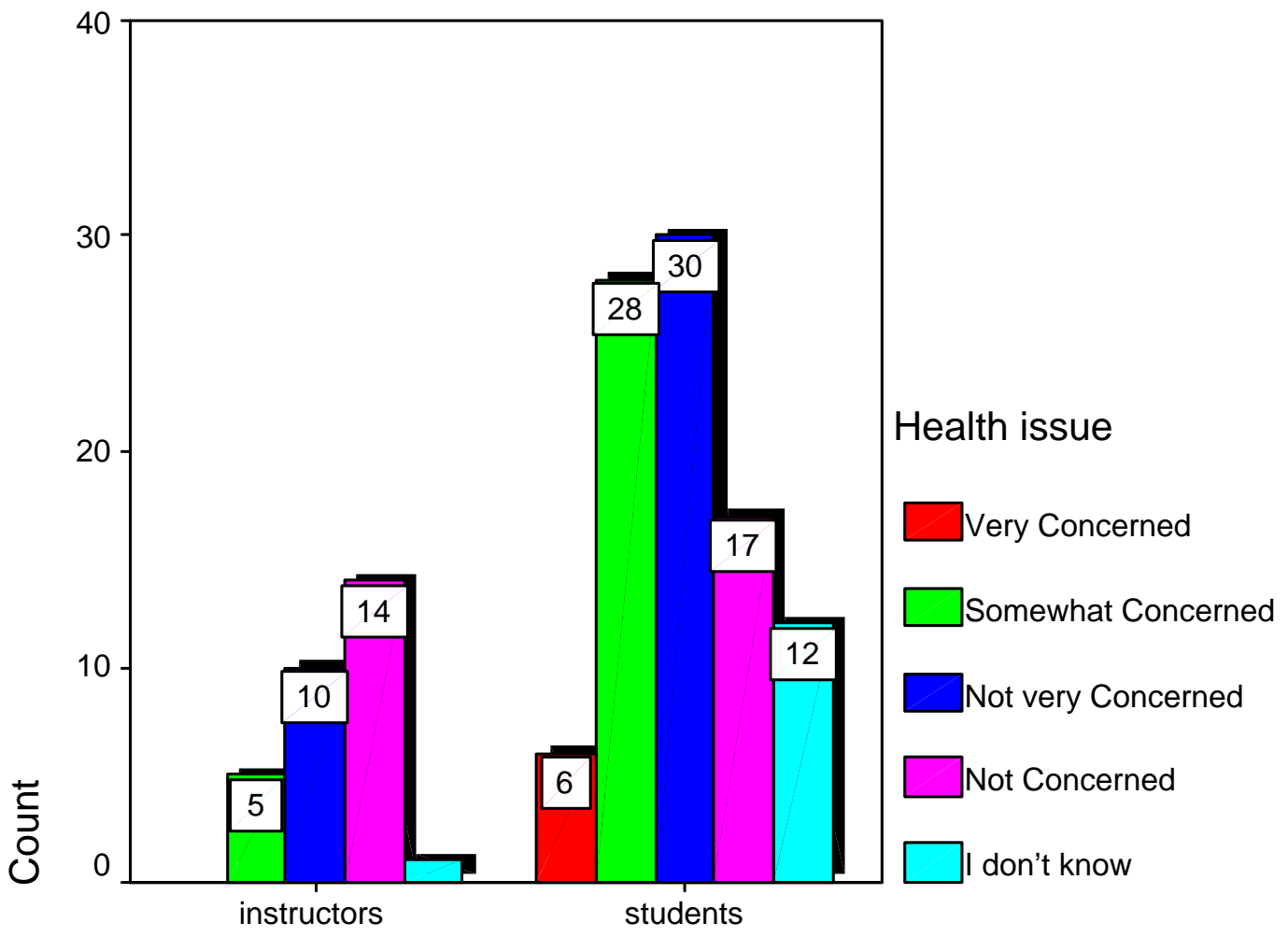

Figure 4.25. Instructors and students responses to question regarding the Health issues.

3.2 The difference between Male and Female in the surveyed population in their attitude toward the implementation of biometric technology in regard to:

Privacy issues.

An independent-samples t-test was performed to determine if there was a significant difference between the mean average of privacy concerns between male and female in the survey population. In this question the t-statistic was not significant at the critical alpha level $\alpha=0.05,(t=1.470 ; d f=195 ; p=.108)$. Therefore, the researcher concluded that there was no significant difference between male and female regarding the privacy issue in the surveyed population. 


\section{Religious issues.}

An independent-samples t-test was performed to determine if there was a significant difference between the mean average of religious concerns between male and female in the survey population. In this question the t-statistic was significant at the critical alpha level $\alpha=0.05,(t=-2.393 ; \mathrm{df}=137 ; \mathrm{p}=.018)$. Therefore, the researcher concluded that there was a significant difference between male and female regarding religious concerns.

Table 4.31

The Summary Case for First Question Related to Religious Issues

Group Statistics

\begin{tabular}{|c|c|c|c|c|c|}
\hline & 2.) Gender: & $\mathrm{N}$ & Mean & Std. Deviation & $\begin{array}{l}\text { Std. Error } \\
\text { Mean }\end{array}$ \\
\hline $\begin{array}{l}\text { 11.) In terms of } \\
\text { religious conflicts, how } \\
\text { appropriate do you } \\
\text { think of implementing } \\
\text { the biometric systems } \\
\text { as described in the } \\
\text { scenario below? }\end{array}$ & $\begin{array}{l}\text { Male } \\
\text { Female }\end{array}$ & $\begin{array}{l}56 \\
83\end{array}$ & $\begin{array}{l}2.09 \\
2.43\end{array}$ & $\begin{array}{l}.900 \\
.784\end{array}$ & $\begin{array}{l}.120 \\
.086\end{array}$ \\
\hline
\end{tabular}

Independent Samples Test

\begin{tabular}{|c|c|c|c|c|c|c|c|c|c|}
\hline & \multicolumn{2}{|c|}{$\begin{array}{l}\text { Levene's Test for } \\
\text { quality of Variances }\end{array}$} & \multicolumn{7}{|c|}{ t-test for Equality of Means } \\
\hline & \multirow[b]{2}{*}{$\mathrm{F}$} & \multirow[b]{2}{*}{ Sig. } & \multirow[b]{2}{*}{$\mathrm{t}$} & \multirow[b]{2}{*}{$d f$} & \multirow[b]{2}{*}{ big. (2-tailed) } & \multirow{2}{*}{$\begin{array}{c}\text { Mean } \\
\text { Difference }\end{array}$} & \multirow{2}{*}{$\begin{array}{l}\text { Std. Error } \\
\text { Difference }\end{array}$} & \multicolumn{2}{|c|}{$\begin{array}{l}95 \% \text { Confidence } \\
\text { Interval of the } \\
\text { Difference }\end{array}$} \\
\hline & & & & & & & & Lower & Upper \\
\hline $\begin{array}{l}\text { 11.) In terms of Equal varianc } \\
\text { religious conflicts, I assumed } \\
\text { appropriate do you } \\
\text { think of implementi } \\
\text { the biometric syste Equal varianc } \\
\text { as described in the not assumed } \\
\text { scenario below? }\end{array}$ & .210 & .647 & $\begin{array}{l}-2.393 \\
-2.329\end{array}$ & 106.918 & .022 & -.34 & .148 & -.638 & -.060 \\
\hline
\end{tabular}




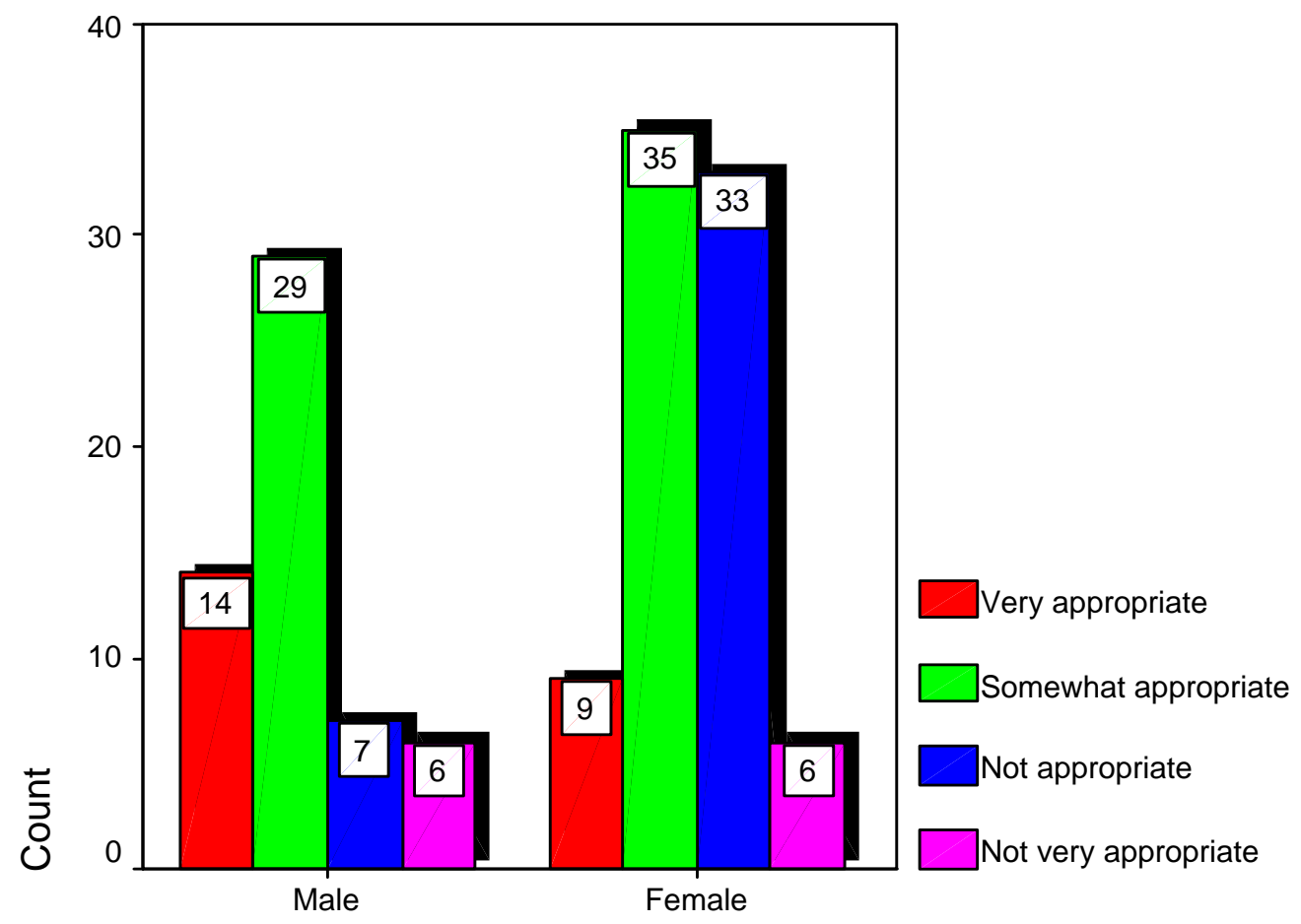

Figure 4.26. Males and females responses to question regarding the religious issues.

Health issues.

An independent-samples t-test was performed to determine if there was a significant difference between the mean average of health concern between male and female in the surveyed population. In this question the t-statistic was not significant at the critical alpha level $\alpha=0.05,(\mathrm{t}=.864 ; \mathrm{df}=195 ; \mathrm{p}=.389)$. Therefore, the researcher concluded that there was no significant difference between male and female regarding health issues in the survey population. 


\section{Instructors' Group}

3.3 The differences between Male and Female within Instructors group in regard to: Privacy issues.

An independent-samples t-test was performed to determine if there was a significant difference between the mean average of privacy concerns between male and female at instructors group. In this question the t-statistic was not significant at the critical alpha level $\alpha=0.05,(t=-1.636 ; \mathrm{df}=22 ; \mathrm{p}=.116)$. Therefore, the researcher concluded that there was no significant difference between males and females.

\section{Religious issues.}

An independent-samples t-test was performed to determine if there was a significant difference between the mean average of religious concerns between male and female in instructors group. The t-statistic was not significant at the critical alpha level $\alpha=0.05,(t=-1.826 ; \mathrm{df}=18 ; \mathrm{p}=.085)$. Therefore, the researcher concluded that there was no significant difference between males and females.

\section{Health issues}

An independent-samples t-test was performed to determine if there was a significant difference between the mean average of health concerns between male and female in instructors group. The t-statistic was not significant at the critical alpha level $\alpha=0.05,(t=-1.862 ; \mathrm{df}=27 ; \mathrm{p}=.073)$. Therefore, the researcher concluded that there was no significant difference between males and females. 


\section{Students’ Group}

3.4 The differences between Male and Female within Students group in regard to:

Privacy issues.

An independent-samples t-test was performed to determine if there was a significant difference between the mean average of privacy concerns between male and female in students group. In this question the t-statistic was not significant at the critical alpha level $\alpha=0.05,(t=1.925 ; \mathrm{df}=171 ; \mathrm{p}=.056)$. Therefore, the researcher concluded that there was no significant difference between males and females.

\section{Religious issues.}

An independent-samples t-test was performed to determine if there was a significant difference between the mean average of religious concerns between male and female in instructors group. The t-statistic was not significant at the critical alpha level $\alpha=0.05,(t=-1.614 ; \mathrm{df}=117 ; \mathrm{p}=.109)$. Therefore, the researcher failed to reject the null hypothesis and concluded that there was no significant difference between males and females.

Health issues.

An independent-samples t-test was performed to determine if there was a significant differences between the mean average concerns between male and female in instructors group. The t-statistic was not significant at the critical alpha level $\alpha=0.05$, $(t=1.037 ; \mathrm{df}=166 ; \mathrm{p}=.301)$. Therefore, the researcher concluded that there was no significant difference between males and females. 
Phase III: Comparative Analysis:

In this section, a comparative analysis between both methods qualitative and quantitative took place. Since the research is a complementary qualitative, QUANTITATIVE method, analysis of the interviews were discussed in the beginning of this chapter. Here both analyses were contrasted, compared and integrated. The discussion is based on the three main research questions.

1. How concerned are instructors about the implementation of biometric technology as an identification method in distance learning classes in terms of:
a. Privacy issues?
b. Religious issues?
c. Health issues?

2. How concerned are students about the implementation of biometric technology as identification method in distance learning classes in terms of:
a. Privacy issues?
b. Religious issues?
c. Health issues?

3. What differences are there between groups (e.g., instructors and students, males and females, social and cultural backgrounds) in their responses to items regarding:
a. Privacy issues?
b. Religious issues?
c. Health issues? 
The attitude of instructors and students toward the implementation of biometric technology as an identification method for online classes was very clear from the perspective of privacy and health. Instructors for example, expressed their thoughts and concerns that implementing such systems might contribute to the invasion of student privacy. On the other hand, students were very nervous, and afraid, that such biometric systems might exemplify BIGBROTER in their schools.

The quantitative data collected through surveys confirmed that fear. In answering set of questions rating their privacy such as 1='Very Concerned', 2='Somewhat Concerned', 3='Not Very Concerned', 4= 'Not Concerned' and 5= 'I don't know'. Both instructors and students were considered "Somewhat Concerned", the Mean for instructors is 2.11 , and 1.90 for students. Only 6 instructors out of 30 and 107 students out of 189 who decided to respond to any question with 'I don't know', which not counted in calculating the Mean of the privacy issue.

In the next issue, "The Religion issue", as it was discussed in the interviews analysis, instructors and students were not sure about the implication of biometric technology on people's beliefs. The majority of people who interviewed did not express any type of concern related to religious issue. On the other hand, the return of surveys were evident that people is not concerned from religious point of view about implementing biometric technology and religious beliefs. For example, 20 out of 30 (66.66\%) of Instructors answered the question which related to the appropriateness of using biometric technology from religious point of view. On the other side, few students answered the same question, only 30(68\%) responded with Mean 2.4. 
In answering second question related to religious concerns: "Do you think the implementation of biometric technology at WVU contradicts your religious beliefs?" 29 out of $30(97 \%)$ of the Instructors said 'No' and 142 out of $153(92.81 \%)$ who answered the question said 'No'.

The last issue is the health concerns. The interviews analyses indicate that Instructors have no health concerns about implementing biometric technology. Students, however, were not sure about the health implication of biometric technology. They did not express their feeling clearly. Comparing this result with surveys results which indicate that Instructors responded to health question with Mean $=3.31$ where 3 is 'Not Concerned'. Students, however, answered the health question with Mean=2.72.

The third question of the research (RQ3) was to compare between groups; Instructors and Students, Male and female, in the surveyed population or within each group. The research question 3.1-A,B and C were to compare between Instructors and Students groups in their response to questions related to the three major issues privacy, religious and health issues. An independent-samples t-test was performed to determine if there was a significant difference between the mean of privacy concerns between Instructors and students groups (RQ3.1-a). The t-statistic was not significant at the critical alpha level $\alpha=0.05,(t=1.356 ; \mathrm{df}=104 ; \mathrm{p}=.178)$. Therefore, the researcher failed to reject the null hypothesis and concluded that there was no significant difference between Instructors and Students' responses about the privacy concerns.

Regarding the religious issue (RQ3.1-b), an independent-samples t-test was performed to determine if there was a significant difference between the mean average of religious concerns between Instructors and students groups. The t-statistic was not 
significant at the critical alpha level $\alpha=0.05,(\mathrm{t}=-1.851 ; \mathrm{df}=76 ; \mathrm{p}=.068)$. Therefore, the researcher failed to reject the null hypothesis and concluded that there was no significant difference between Instructors and Students about the religious concerns.

Regarding the health issue (RQ3.1-c), an independent-samples t-test was performed to determine if there was a significant difference between the mean average of health concerns between Instructors and students groups. The t-statistic was significant at the critical alpha level $\alpha=0.05,(t=3.218 ; d f=108 ; p=.002)$. Therefore, the researcher succeeded to reject the null hypothesis and thus concluded that there was a significant difference between Instructors and Students in regard to their concerns about health issues.

The research question 3.2-A, B and C were to compare between Male and Female in the surveyed population in their responses to questions related to three major issues privacy, religious and health issues. The regarding the privacy issue (RQ3.2-a), an independent-samples t-test was performed to determine if there was a significant difference between the mean average of privacy concerns between male and female in the survey population. The t-statistic was not significant at the critical alpha level $\alpha=0.05$, $(t=1.470 ; \mathrm{df}=195 ; \mathrm{p}=.108)$. Therefore, the researcher failed to reject the null hypothesis and concluded that there was no significant difference between male and female regarding the privacy issue in the surveyed population.

The regarding the religious issues (RQ3.2-b), an independent-samples t-test was performed to determine if there was a significant difference between the mean average of religious concerns between male and female in the survey population. The t-statistic was significant at the critical alpha level $\alpha=0.05,(\mathrm{t}=-2.393 ; \mathrm{df}=137 ; \mathrm{p}=.018)$. Therefore, 
the researcher succeeded to reject the null hypothesis and thus concluded that there was a significant difference between male and female regarding religious concerns.

The regarding the health issues (RQ3.2-c), an independent-samples t-test was performed to determine if there was a significant difference between the mean average of health concern between male and female in the surveyed population. The t-statistic was not significant at the critical alpha level $\alpha=0.05,(t=.864 ; \mathrm{df}=195 ; \mathrm{p}=.389)$. Therefore, the researcher failed to reject the null hypothesis and thus concluded that there was no significant difference between male and female regarding health issues in the survey population.

The research question 3.3-A, B and C were to compare between Male and female within Instructors group, in their responses to questions related to privacy, religious and health issues. Regarding the research question (RQ3.3-a), an independent-samples t-test was performed to determine if there was a significant difference between the mean average of privacy concerns between male and female in Instructors group. The t-statistic was not significant at the critical alpha level $\alpha=0.05,(t=-1.636 ; \mathrm{df}=22 ; \mathrm{p}=.116)$.

Therefore, the researcher failed to reject the null hypothesis and concluded that there was no significant difference between males and females.

Regarding the research question (RQ3.3-b), an independent-samples t-test was performed to determine if there was a significant difference between the mean average of religious concerns between male and female in Instructors group. The t-statistic was not significant at the critical alpha level $\alpha=0.05,(\mathrm{t}=-1.826 ; \mathrm{df}=18 ; \mathrm{p}=.085)$. Therefore, the researcher failed to reject the null hypothesis and concluded that there was no significant difference between males and females. 
Regarding the research question (RQ3.3-c), an independent-samples t-test was performed to determine if there was a significant difference between the mean average of health concerns between male and female in Instructors group. The t-statistic was not significant at the critical alpha level $\alpha=0.05,(\mathrm{t}=-1.862 ; \mathrm{df}=27 ; \mathrm{p}=.073)$. Therefore, the researcher failed to reject the null hypothesis and concluded that there was no significant difference between males and females regarding the health issues.

The research question 3.4-A, B and $\mathrm{C}$ were to compare between Male and female within Students' group, in their responses to questions related to privacy, religious and health issues. Regarding the researcher question (3.4-a), an independent-samples t-test was performed to determine if there was a significant difference between the mean average of privacy concerns between male and female in students group. The t-statistic was not significant at the critical alpha level $\alpha=0.05,(t=1.925 ; \mathrm{df}=171 ; \mathrm{p}=.056)$. Therefore, the researcher failed to reject the null hypothesis and concluded that there was no significant difference between males and females concerning the privacy issue.

Regarding the researcher question (3.4-b), an independent-samples t-test was performed to determine if there was a significant difference between the mean average of religious concerns between male and female in Instructors group. The t-statistic was not significant at the critical alpha level $\alpha=0.05,(t=-1.614 ; \mathrm{df}=117 ; \mathrm{p}=.109)$. Therefore, the researcher failed to reject the null hypothesis and concluded that there was no significant difference between males and females.

Regarding the researcher question (3.4-c), an independent-samples t-test was performed to determine if there was a significant difference between the mean average concerns between male and female in Instructors group. The t-statistic was not significant 
at the critical alpha level $\alpha=0.05,(\mathrm{t}=1.037 ; \mathrm{df}=166 ; \mathrm{p}=.301)$. Therefore, the researcher failed to reject the null hypothesis and concluded that there was no significant difference between males and females concerning the health issues. 


\section{CHAPTER 5}

\section{Research Findings}

\section{Summary of the Research Design, Discussions, Implications and Recommendations}

This chapter includes four brief sections. These sections are intended to provide the following information: (1) a summary of the research design and findings, (2) a discussion of the results, (3) implications of the study, and (4) recommendations for future research.

\section{Summary of the Research Design}

The purpose of this study was to examine Instructors and Students' attitudes toward using biometric technology as an identification method in online courses. The study was designed to determine which issues are more critical to both Instructors and learners in the College of Human Resources and Education at West Virginia University, as well as to test the acceptability of biometric technology as an authentication method in online courses from both points of view. Findings and results of this research will help schools, Instructors and learners better understand the nature of biometric technology, as well as, help stakeholders to design and implement the biometric authentication system with minimal side effects.

Qualitative methods were used initially to establish the basis of this study, followed by a quantitative instrument. This quantitative method makes up the main part of the study. For the purpose of clarity, the outlines of procedures are listed below. The researcher has previously identified social and cultural factors that contribute to the adaptation of biometric systems in educational institutions. Furthermore, the existing 
instruments such as questionnaires that were used by others to assess the implementation of biometric systems in other settings were reviewed.

\section{Review of Research Questions and results}

The following are the main findings of this study. They are presented below based on the three research questions that were being investigated in this study. To address these questions, the researcher used a mixed method. Detailed interviews were conducted with five Instructors and five Students at the College of Human Resources and Education. The analyses of the interviews are provided in CHAPTER 4.

There were three major research questions used in this study. These were further divided into three sub-questions. These three research questions included the following:

1. How concerned are instructors about the implementation of biometric technology as an identification method in distance learning classes in terms of:
a. Privacy issues?
b. Religious issues?
c. Health issues?

2. How concerned are students about the implementation of biometric technology as an identification method in distance learning classes in terms of:
a. Privacy issues?
b. Religious issues?
c. Health issues?

3. What differences are there between groups (e.g., Instructors and Students, Males and Females, etc.) in their responses to items regarding:
a. Privacy issues? 


\section{b. Religious issues?}

c. Health issues?

Research Question 1-A (RQ1a) sought to find out how concerned Instructors are about the Privacy issues related to the implementation of biometric technology in online classes. The outcomes of interviews indicated that there were privacy concerns among Instructors about implementing biometric technology in online classes. The surveys, in addition, confirmed the same results.

The next item was related to the religious issues, Research Question 1-B (RQ1b) was about Instructors' religious concerns related to the implementation of biometric technology in online classes. Interviews indicated that Instructors were not sure about the implication of biometric technology on people's beliefs. The majority of people who interviewed did not express any type of concern related to religious issue. On the other hand, the returns of surveys were evident that people are not concerned about biometric technology when religion is the factor.

Research Question 1-C (RQ1c) was about the health implications related to the implementation of biometric technology from Instructors perspectives. According to interviews, Instructors did not express their opinion clearly. Surveys, on the other hand, concluded that Instructors did not have any concern toward biometric when health risk is considered.

Research Question 2-A (RQ2a) sought to find out how concerned Students are about the Privacy issues related to the implementation of biometric technology in online classes. The outcomes of interviews indicated that there were privacy concerns among 
Students about implementing biometric technology in online classes. The surveys, confirmed the same result.

The next item was related to the religious issues, Research Question 2-B (RQ2b) was about Students' religious concerns related to the implementation of biometric technology in online classes. Interviews indicated that Students did not express a clear concern regarding the contradiction between biometric technology and their beliefs. On the other hand, the returns of surveys were evident that people are not concerned about biometric technology when religion is the factor.

Research Question 2-C (RQ2c) was about the health implications related to the implementation of biometric technology from students perspectives. According to interviews, Students were concerned about the health risk related to biometric technology, particularly the Iris scan. Surveys, on the other hand, confirmed that Students were 'Somewhat Concerned' toward biometric technology when health risk is considered.

The third question of the research (RQ3) was to compare between different groups; The t-test for independent samples employed to measure the differences between Instructors and Students groups and their concerns toward implementing biometric technology from privacy, religious and health point of views (RQ3.1-A,B and C). The researcher concluded that there was no significant difference between Instructors and Students group except in their responses to the questions related to the health issues.

Additionally, the t-test for independent samples employed to measure the differences between Male and Female in the surveyed population and their concerns toward implementing biometric technology from privacy, religious and health point of views (RQ3.2-A,B and C). The researcher concluded that there was no significant 
difference between Male and Female in the surveyed population except in their responses to the questions related to the religious issues.

Furthermore, the t-test for independent samples employed to measure the differences between Male and Female at Instructors' group and their concerns toward implementing biometric technology from privacy, religious and health point of views(RQ3.3-A,B and C). The researcher concluded that there was no significant difference between Male and Female in Instructors' group in their response to the survey questions.

Finally, the t-test for independent samples employed to measure the differences between Male and Female at Students' group and their concerns toward implementing biometric technology from privacy, religious and health point of views (RQ3.4-A,B and C). The researcher concluded that there was no significant difference between Male and Female in Students' group in their response to the survey questions. 
Table 5.1

Summary of the study findings

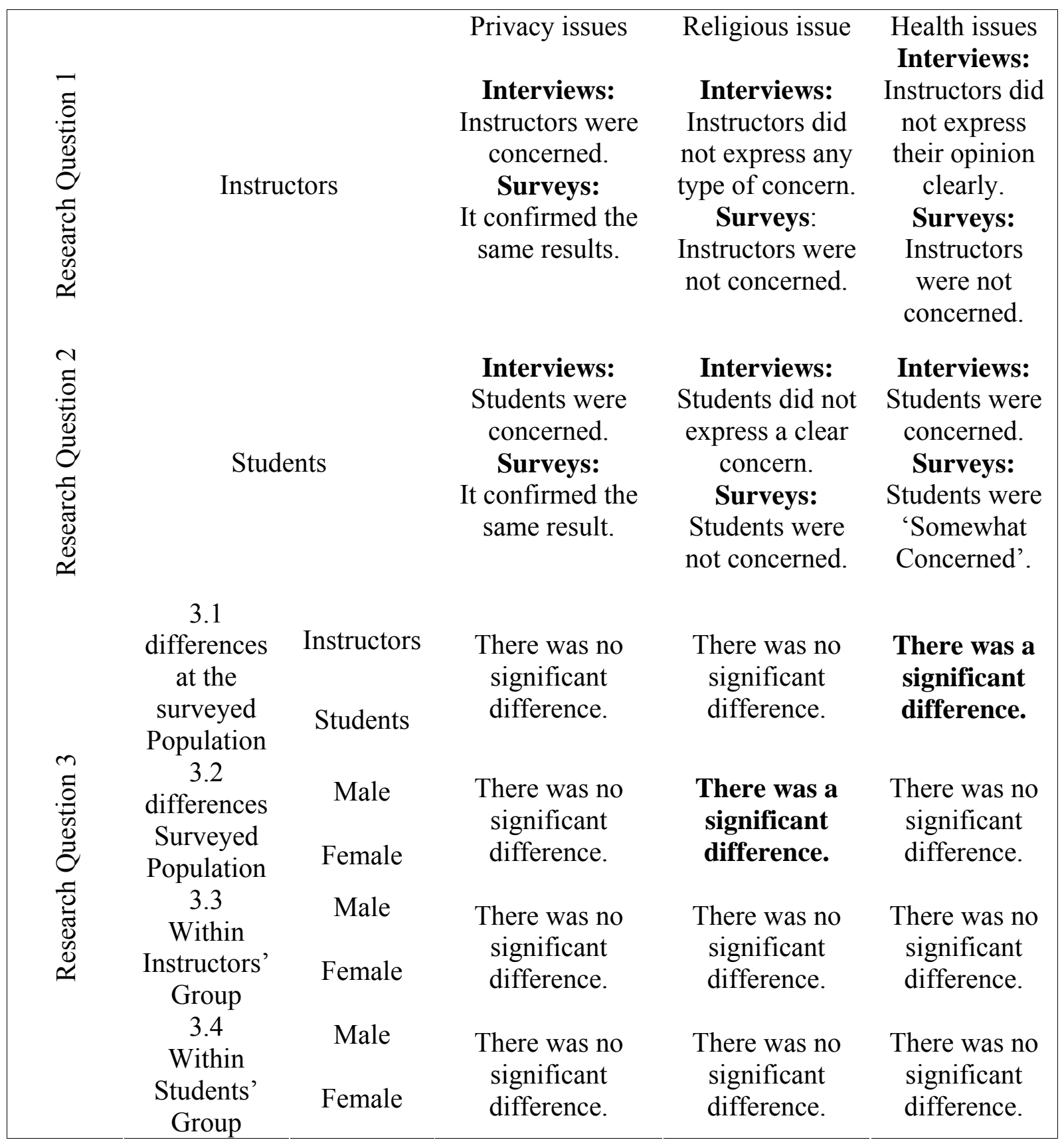




\section{Discussions}

In general, privacy was a concern for both instructors and students. The notion of invasion of privacy, the intrusiveness of the technology and the Big brother-issue was highly emphasized during the study. Other people in other researches and studies expressed the same concerns. The literature review pointed out that people questioned the appropriateness of biometric technology (Wayman, 2001b). Many users believed that biometric technology invades their privacy. A few decades ago, when fingerprinting was first introduced, people resisted it (Ankari, 2001; Zimmerman, 2002). Wayman warned users about the ethical issues related to the use of biometric technology (Wayman, 2001b). During the interviews, students questioned the ethics and morality of using biometric technology in educational institutes.

As far as religious issues are considered, the research did not find any strong evidence of contradiction between biometric technology and religious beliefs. In some other studies, religious sects believed that using facial recognition or fingerprints contradict their theological teachings (ORC report, 2002), but this concern was largely unsupported by this study. However, it bares mention that one instructor recalled an incident of a student's refusal to allow her photo be taken because of religious reasons.

Concerning health hazards Zimmermann stated, "People are debating whether such technology as retinal scans, iris scans, and facial recognition are too intrusive" (Zimmermann, 2002). This concern held true for Students but not for Instructors. For example, the study showed that the highest intrusiveness is iris scan.

The third research question was about comparison between different groups; Students and Instructors; Males and Females. The outcome of the research was not a 
surprise. Students and Instructors had no significant differences between them concerning the privacy issues. It was a surprise that there was not was not a real concern for both groups regarding religious issues. Students and Instructors did not see a direct correlation between using biometric technology and religious beliefs. However, religious affiliation of participants was not diverse; ( $85 \%$ of Students and $70 \%$ of Instructors were Christian).

Health issues, however, were important to students but not for instructors. One possible justification for this difference is that students will be subjected directly to the use of biometric technology more than will instructors.

\section{Implications}

As Rogers mentions in his book "Diffusion of Innovation", the consequences of innovation come afterward, following the adoption of the innovation. In the case of biometric technology, consequences are desirable versus undesirable, direct versus indirect and anticipated versus unanticipated (Rogers, 1995).

Some of the consequences are good (desirable), some are not good (undesirable). As Rogers mentioned in one of his generalizations "undesirable, indirect and unanticipated consequences come together, in the other hand, desirable, direct and anticipated consequences come together".

This study assessed implementing biometric technology at virtual classes in educational institutions. The following is a summary of the implications: 
The desirable, direct and anticipated consequences of implementing biometric technology are as follows:

- First, conduct a needs assessment before implementing biometric technology, followed by a public awareness campaign. For example, one instructor was quoted saying: "I would suggest serious consideration of the NEED for this before any attempts to implement are completed". Another instructor pointed to the need for more information about the technology: "More education on exactly what it is and why it is needed".

- Biometric technology may not be able to authenticate an individual's identity accurately in all cases. For example, one student was concerned about the technical aspect of the technology; he was quoted as saying, "I am concerned that the technology is not adequate, that identification errors may occur". Therefore, combining biometric technology with a traditional system (hybrid technology) will improve its efficiency (Wayman \& others, 2003).

- There are varieties of choices among biometric technologies such as fingerprint, iris scan, signature dynamic, etc. This enables institutions to choose the technology that fits them best. The participants reacted differently to different biometric technologies. They showed more acceptances to signature dynamic over iris scan. In other studies, some technologies were accepted and adopted differently due to their nature and accuracy (Tistarelli \& others, 2002).

- Biometric technology gives more prestige to institutions. This is especially important during the accreditation processes. Some students and instructors were excited to see the technology implemented in their school. One student expressed 
his feeling saying, "I think it can be a powerful tool in order to make DL [Distance Learning] classes more reliable, regarding attendance and participation". Another student thought that the school should adopt new technology other than traditional systems. He was quoted saying, "It would definitely replace the usernames and login passwords, which might increase security”.

- Biometric technology provides more privacy, security, confidentiality and integrity to users' data as compared to traditional methods of identification, yet it has its own drawbacks.

The undesirable, indirect and unanticipated consequences associated with biometric technology are:

- Cost involved in implementing, maintaining and adopting biometric technology might place an unwanted financial burden on students within the institution. For example, one instructor posed this question: "Will the cost and inconvenience be worth it?" In addition, one student was quoted saying:

I think the concept is a great idea, but I think the cost outweighs the benefits. Not a lot of students take online courses, and it is just as easy for them to be identified via an ID number just as on campus courses.

Also, one instructor emphasized the implication of cost involved in this process. The instructor was quoted saying:

I have a concern about the cost-benefit ratio for the university and for students. I would think it would be expensive for WVU to install on campus, without any proof that cheating by surrogates is a major problem. 
For students taking courses on their home or work computers, installing the hardware and software to transmit the data to campus are likely to be a significant additional expense that could be incurred for a single course.

In contrast, with other methods, biometric technology requires specific hardware and software. It mandates specific sensors to capture target characteristics or behavior. Additionally, there is a need for specific programs to run the applications. In traditional systems, there is no need for specific application, devices or hardware (Hart \& Albalawi, 2003; ORC, 2000).

- The health hazards associated with certain biometric technologies are uncertain; however, there still exist concerns within those who use the technology. The study suggests signature dynamic as a biometric technology with less health implications. This research suggests it wise to avoid technology associated with the possibility (either perceived or real) of high health risk. The study indicated that iris scan was perceived as the worst.

- Implementing biometric technology might drive people away from online classes due to their intrusive nature and cost. One student expressed this concern by saying "This technology will impact the number of classes I will not take on-line due to rise in costs".

- When adopting biometric technology, it is essential to put in place very clear and hard policies to protect the collected biometric data; data collected must not be shared with other parties. Stating rules and policies, by itself, is a sophisticated process; it might generate some conflicts within local, state or federal constitutions. The failure to provide these policies, however, might result in 
catastrophic implications (Wayman, 2001b). Participants were very concerned about the potential abuse of their biometric data. Supporting this contention, other studies (Ankari, 2001), speculated the disastrous consequences of revealing biometric data.

\section{Recommendations and Future Studies}

The outcomes of this research indicate that it is important to conduct deep research in the area of biometric technologies and its implications on societies. Since this research was limited to the graduate students and instructors of the College of Human Resources and Education, future studies might be conducted with a mixed method with more participants from different groups such as students, instructors, staff, administration and technicians. It will be helpful to investigate the logistical and technical aspect of the implication of implementing biometric technology on educational institutes. Deep interviews and comprehensive document analysis combined with detailed surveys will be a great technique to uncover unknown reasons behind the resistance to adopting biometric technology.

Such long-term broad research should be conducted at different colleges and schools in order to bring more diversity in terms of race, gender, religious affiliations and experiences. In addition, it is recommended to focus on privacy issues; since most of this study's participants emphasized its importance during interviews and in their responses to surveys questions. 


\section{REFERENCES}

Ankari. (2001). What is Biometric Authentication? Retrieved on Nov. 20, 2001, from: http://www.ankari.com

Biometrika. (2003). Introduction to Biometric System. Retrieved on Dec. 12, 2003, from: http://www.biometrika.it/eng/wp biointro.html

Butler, R., Engert, D., Foster, I., Tuecke, S., Volmer, J., \& Kesselman, C. (2000). A National-Scale Authentication Infrastructure. IEEE-Compute, pp. 60-66.

Charp, S. (1994). Viewpoint. The On-line Chronicle of Distance Education and Communication. New York, NY: John Wiley \& Sons.

DigitalPersona Inc. (2001). Enhancing Security with Biometric Authentication. Retrieved on Dec.12, 2003 from: http://www.rfrancis.com/digital_persona/EnhancingSecurity.pdf

Driscoll, M. (1998). Web-based training: Using technology to design adult learning experiences. San Francisco, CA: Jossey-Bass/Pfeiffer.

Duning, B. S., Van Kekerix, M. J., \& Zaborowski, L. M. (1993). Reaching learners through telecommunications. San Francisco, CA: Jossey-Bass.

Fitzpatrick, J. Sanders, J., \& Worthen, B. (2004). Program Evaluation: alternative approaches and practical guidelines. Needham Heights, MA: Allyn \& Bacon.

Foster, Jeremy, J. (1998). Data Analysis using SPSS for Windows. San Francisco, CA: Sage.

Fraenkel, J. \& Wallen N. (2002) How to Design and Evaluate Research in Education. New York, NY: McGraw Hill. 
Greene, J. C., \& Caracelli, V. J. (Eds.) (1997). Advances in mixed-method evaluation: The challenges and benefits of integrating diverse paradigms. New Directions for Program Evaluation. San Francisco, CA: Jossey-Bass.

Hart, C., \& AlBalawi, W. (2003, Dec.). The future of distance learning at West Virginia University and the integration of Biometric technology. Morgantown, WV.

Jain, A., Bolle, R., \& Pankanti, S. (1999) BIOMETRICS: Personal Identification in Networked Society. Norwell, MA : Kluwer Academic Publishers.

Keegan, D. (1993). Theoretical principles of distance education. New York, NY: Routledge.

Lai, K. (1999). Net-working: Teaching, learning \& professional development with the Internet. Dunedin, New Zealand: University of Otago Press.

Maltoni, D., Maio, D., Jain, A., \& Prabhakar, S. (2003) Handbook of Fingerprint Recognition. New York, NY: Springer Verlag.

Matyas, V., \& Riha ,Z. (2000). BIOMETRIC AUTHENTICATION—security and usability, Retrieved on March 23, 2004 from the site: http://www.fi.muni.cz/usr/matyas/cms_matyas_riha_biometrics.pdf

Nicols, R. (1999) ICSA: Guide to Cryptography, Biometric Encryption. New York, NY: McGraw-Hill.

Norusis, Marija J. (1999). SPSS 9.0 Guide to Data Analysis. Upper Saddle River, NJ: Prentice Hall Inc.

ORC International report. (2002). Public Attitudes toward the uses of biometric identification technologies by government and private sector, retrieved on Nov. 
13, 2003 from the site:

http://www.search.org/policy/bio_conf/Biometricsurveyfindings.pdf

Patton, M. (2001) Qualitative Research \& Evaluation Methods. San Francisco, CA: Sage.

Podio, F., \& Dunn, J. (2001). Biometric Authentication Technology: From the Movies to Your Desktop. Biometric Consortium.

Privacy and American Business (2002, Dec). Electronic News letter: Volume 9, Number 8. pp. 5-12.

Ratha, N., Connell, J., \& Bolle R. (2001). Enhancing security and privacy in biometricsbased authentication systems. IBM Systems Journal. Vol. 40. pp. 614-635.

Rogers, E.M. (1995). Diffusion of innovations $\left(4^{\text {th }}\right.$ ed.). New York, NY: The Free Press. Rosenberg, M. (2001). e-Learning: Strategies For Delivering Knowledge in the Digital Age. New York, NY: McGraw-Hill.

Sherry, L. (1996). Issues in Distance Learning. International Journal of Educational Telecommunications, 1 (4), 337-365. Retrieved on March 15, 2004 from the site: $\underline{\text { http://carbon.cudenver.edu/ /sherry/pubs/issues.html\#management }}$ Tistarelli, M., Bigun, J., \& Jain, A. (2002, June). Biometric Authentication. ECCV Workshop. New York, NY: Springer Verlag.

Wayman, J. (2001a). The Functions of Biometric Identification Devices. National Biometric Center. Retrieved on Nov. 10, 2001 from the site: http://www.engr.sjsu.edu/biometrics/publications_tech.html 
Wayman, J. (2001b). Biometric Applications: Legal and Societal Considerations. National Biometric Center. Retrieved on Nov. 10, 2001 from the site: http://www.engr.sjsu.edu/biometrics/publications consideration.html

Wayman, J., Jain, A., Maltoni, D., \& Maio, D. (2003). Biometric Systems: Technology, Design and Performance Evaluation. New York, NY: Springer Verlag.

Zimmerman, M. (2002). Biometric and User Authentication. SANS institute publications. 


\section{APPENDIX A}

Frequency Tables and Figures related to the Research Question 1(RQ1)

\section{Instructors' Group}




\section{Demographic Data}

Table A.1

The Academic Positions of Instructors

\begin{tabular}{|ll|r|r|r|r|}
\hline & Frequency & Percent & Valid Percent & $\begin{array}{c}\text { Cumulative } \\
\text { Percent }\end{array}$ \\
\hline Valid & Visiting Instructor & 1 & 3.3 & 3.7 & 3.7 \\
& Visiting Assistant & 2 & 6.7 & 7.4 & 11.1 \\
& Professor & 5 & 16.7 & 18.5 & 29.6 \\
& Assistant Professor & 5 & 23.3 & 25.9 & 55.6 \\
& Associate Professor & 7 & 36.7 & 40.7 & 96.3 \\
& Professor & 11 & 3.3 & 3.7 & 100.0 \\
& Professor Emeritus & 1 & 100.0 & \\
& Total & 27 & 90.0 & & \\
Missing & System & 3 & 10.0 & & \\
Total & & 30 & 100.0 & & \\
\hline
\end{tabular}

Table A.2

The Distribution of Instructors at Different Departments

\begin{tabular}{|ll|r|r|r|r|}
\hline & Frequency & Percent & Valid Percent & \multicolumn{2}{c|}{$\begin{array}{c}\text { Pumulative } \\
\text { Percent }\end{array}$} \\
\hline Valid & Counseling Psychology & 2 & 6.7 & 7.4 & 7.4 \\
& Curriculum \& Instruction & 4 & 13.3 & 14.8 & 22.2 \\
& Educational Leadership & 2 & 6.7 & 7.4 & 29.6 \\
& Educational Psychology & 4 & 13.3 & 14.8 & 44.4 \\
& Reading & 3 & 10.0 & 11.1 & 55.6 \\
& Rehabilitation & 1 & 3.3 & 3.7 & 59.3 \\
& Counseling & 3 & 10.0 & 11.1 & 70.4 \\
& Special Education & 6 & 20.0 & 22.2 & 92.6 \\
& Speech Pathology \& & 2 & 6.7 & 7.4 & 100.0 \\
& Audiology & 27 & 90.0 & 100.0 & \\
& Technology Education & 3 & 10.0 & & \\
Missing & Total & 30 & 100.0 & & \\
Total & System & & & \\
\hline
\end{tabular}


Table A.3

The Distribution of Gender at Instructors' Group

\begin{tabular}{|c|c|c|c|c|c|}
\hline & & Frequency & Percent & Valid Percent & $\begin{array}{c}\text { Cumulative } \\
\text { Percent }\end{array}$ \\
\hline \multirow[t]{3}{*}{ Valid } & Male & 15 & 50.0 & 50.0 & 50.0 \\
\hline & Female & 15 & 50.0 & 50.0 & 100.0 \\
\hline & Total & 30 & 100.0 & 100.0 & \\
\hline
\end{tabular}

Table A.4

The Distribution of Race/Ethnicity at Instructors' Group

\begin{tabular}{|ll|r|r|r|r|}
\hline & & & & \multicolumn{2}{c|}{$\begin{array}{c}\text { Cumulative } \\
\text { Percent }\end{array}$} \\
\hline Valid & Frequency & Percent & Valid Percent & 3.3 \\
& American Indian & 1 & 3.3 & 3.3 & 100.0 \\
White/non-Hispanic & 29 & 96.7 & 96.7 & \\
Total & 30 & 100.0 & 100.0 & \\
\hline
\end{tabular}

Table A.5

The Distribution of Religions at Instructors' Group

\begin{tabular}{|ll|r|r|r|r|}
\hline & & & & $\begin{array}{c}\text { Cumulative } \\
\text { Percent }\end{array}$ \\
\hline Valid & Buddhist & 2 & 6.7 & 8.0 & 8.0 \\
& Christian & 21 & 70.0 & 84.0 & 92.0 \\
& Jewish & 2 & 6.7 & 8.0 & 100.0 \\
& Total & 25 & 83.3 & 100.0 & \\
Missing & System & 5 & 16.7 & & \\
Total & 30 & 100.0 & & \\
\hline
\end{tabular}


Table A.6

Distribution of Instructors and their Knowledge about Biometric Technology

\begin{tabular}{|ll|r|r|r|r|}
\hline & & & & $\begin{array}{c}\text { Cumulative } \\
\text { Percent }\end{array}$ \\
\hline Valid & Yes & 24 & 80.0 & 80.0 & 80.0 \\
& No & 6 & 20.0 & 20.0 & 100.0 \\
& Total & 30 & 100.0 & 100.0 & \\
\hline
\end{tabular}

Tables A.7-A.13

Statistics

\begin{tabular}{|c|c|c|c|c|c|c|c|c|}
\hline & & 8.1) School & 8.2) Airpor & 8.3) Bank & 8.4) ATM & 8.5) Hospital & $\begin{array}{l}\text { 8.6) Federa } \\
\text { Building }\end{array}$ & 8.7) Other \\
\hline \multirow[t]{2}{*}{$\overline{\mathrm{N}}$} & Valid & 0 & 1 & 1 & 0 & 1 & 1 & 3 \\
\hline & Missing & 30 & 29 & 29 & 30 & 29 & 29 & 27 \\
\hline \multicolumn{2}{|c|}{ Mean } & & 2.00 & 3.00 & & 5.00 & 6.00 & 7.00 \\
\hline \multicolumn{2}{|c|}{ Median } & & 2.00 & 3.00 & & 5.00 & 6.00 & 7.00 \\
\hline \multicolumn{2}{|c|}{ Mode } & & 2 & 3 & & 5 & 6 & 7 \\
\hline \multicolumn{2}{|c|}{ Std. Deviation } & & & & & & & .000 \\
\hline \multicolumn{2}{|c|}{ Variance } & & & & & & & .000 \\
\hline
\end{tabular}

Frequency Table

\section{1) School}

\begin{tabular}{|ll|r|r|}
\hline & & Frequency & Percent \\
\hline Missing & System & 30 & 100.0 \\
\hline
\end{tabular}

\section{2) Airport}

\begin{tabular}{|ll|r|r|r|r|}
\hline & Frequency & Percent & Valid Percent & $\begin{array}{c}\text { Cumulative } \\
\text { Percent }\end{array}$ \\
\hline Valid & 2 & 1 & 3.3 & 100.0 & 100.0 \\
Missing & System & 29 & 96.7 & & \\
Total & 30 & 100.0 & & \\
\hline
\end{tabular}




\section{3) Bank}

\begin{tabular}{|c|c|c|c|c|c|}
\hline & & Frequency & Percent & Valid Percent & $\begin{array}{c}\text { Cumulative } \\
\text { Percent }\end{array}$ \\
\hline Valid & 3 & 1 & 3.3 & \multirow[t]{3}{*}{100.0} & \multirow[t]{3}{*}{100.0} \\
\hline Missing & System & 29 & 96.7 & & \\
\hline Total & & 30 & 100.0 & & \\
\hline
\end{tabular}

8.4) ATM

\begin{tabular}{|ll|r|r|}
\hline & & Frequency & Percent \\
\hline Missing & System & 30 & 100.0 \\
\hline
\end{tabular}

\section{5) Hospital}

\begin{tabular}{|ll|r|r|r|c|}
\hline & Frequency & Percent & Valid Percent & $\begin{array}{c}\text { Cumulative } \\
\text { Percent }\end{array}$ \\
\hline Valid & 5 & 1 & 3.3 & 100.0 & 100.0 \\
Missing & System & 29 & 96.7 & & \\
Total & 30 & 100.0 & & \\
\hline
\end{tabular}

\section{6) Federal Building}

\begin{tabular}{|c|c|c|c|c|c|}
\hline & & Frequency & Percent & Valid Percent & $\begin{array}{c}\text { Cumulative } \\
\text { Percent }\end{array}$ \\
\hline$\overline{\text { Valid }}$ & 6 & 1 & 3.3 & 100.0 & 100.0 \\
\hline Missing & System & 29 & 96.7 & & \\
\hline Total & & 30 & 100.0 & & \\
\hline
\end{tabular}

\section{7) Other}

\begin{tabular}{|c|c|c|c|c|c|}
\hline & & Frequency & Percent & Valid Percent & $\begin{array}{c}\text { Cumulative } \\
\text { Percent }\end{array}$ \\
\hline Valid & 7 & 3 & 10.0 & 100.0 & 100.0 \\
\hline Missing & System & 27 & 90.0 & & \\
\hline Total & & 30 & 100.0 & & \\
\hline
\end{tabular}


Privacy Issues

Table A.15

Instructors’ Responses to First Question of the Privacy Issues

10.1) How concerned are you about having students' biometric data collected?

\begin{tabular}{|ll|r|r|r|r|}
\hline & Frequency & Percent & Valid Percent & $\begin{array}{c}\text { Cumulative } \\
\text { Percent }\end{array}$ \\
\hline Valid & Very Concerned & 5 & 16.7 & 16.7 & 16.7 \\
& Somewhat concerned & 9 & 30.0 & 30.0 & 46.7 \\
Not very Concerned & 8 & 26.7 & 26.7 & 73.3 \\
Not Concerned & 7 & 23.3 & 23.3 & 96.7 \\
I don't know & 1 & 3.3 & 3.3 & 100.0 \\
Total & 30 & 100.0 & 100.0 & \\
\hline
\end{tabular}

Table A. 16

Instructors' Responses to Second Question of the Privacy Issues

10.2) How concerned are you about having students' biometric data stored in non-secure storage?

\begin{tabular}{|ll|r|r|r|r|}
\hline & & & & Cumulative \\
& & Frequency & Percent & Valid Percent & \multicolumn{1}{c|}{ Percent } \\
\hline Valid & Very Concerned & 21 & 70.0 & 70.0 & 70.0 \\
& Somewhat concerned & 6 & 20.0 & 20.0 & 90.0 \\
Not very Concerned & 2 & 6.7 & 6.7 & 96.7 \\
Not Concerned & 1 & 3.3 & 3.3 & 100.0 \\
Total & 30 & 100.0 & 100.0 & \\
\hline
\end{tabular}


Table A. 17

Instructors' Responses to Third Question of the Privacy Issues

10.3) How concerned are you about having students' biometric data used by third party?

\begin{tabular}{|ll|r|r|r|r|}
\hline & & & & Cumulative \\
& & Frequency & Percent & Valid Percent & Percent \\
\hline Valid & Very Concerned & 22 & 73.3 & 73.3 & 73.3 \\
& Somewhat concerned & 7 & 23.3 & 23.3 & 96.7 \\
& Not very Concerned & 1 & 3.3 & 3.3 & 100.0 \\
Total & 30 & 100.0 & 100.0 & \\
\hline
\end{tabular}

Table A.18

Instructors Responses to Fourth Question of Privacy Issues

10.4) How concerned are you about having students' biometric data misused by WVU?

\begin{tabular}{|ll|r|r|r|r|}
\hline & & & & Cumulative \\
& Frequency & Percent & Valid Percent & \multicolumn{1}{c|}{ Percent } \\
\hline Valid & Very Concerned & 8 & 26.7 & 26.7 & 26.7 \\
& Somewhat concerned & 11 & 36.7 & 36.7 & 63.3 \\
Not very Concerned & 6 & 20.0 & 20.0 & 83.3 \\
Not Concerned & 4 & 13.3 & 13.3 & 96.7 \\
I don't know & 1 & 3.3 & 3.3 & 100.0 \\
Total & 30 & 100.0 & 100.0 & \\
\hline
\end{tabular}


Table A. 18

Instructors' Responses to Fifth Question of Privacy Issues

10.5) How concerned are you about the invasion of students' privacy by WVU, when biometric technology is implemented?

\begin{tabular}{|ll|r|r|r|r|}
\hline & & & & Cumulative \\
& Frequency & Percent & Valid Percent & Percent \\
\hline Valid & Very Concerned & 4 & 13.3 & 13.3 & 13.3 \\
& Somewhat concerned & 13 & 43.3 & 43.3 & 56.7 \\
Not very Concerned & 8 & 26.7 & 26.7 & 83.3 \\
Not Concerned & 4 & 13.3 & 13.3 & 96.7 \\
I don't know & 1 & 3.3 & 3.3 & 100.0 \\
Total & 30 & 100.0 & 100.0 & \\
\hline
\end{tabular}

Table A.19

Instructors Responses to the Sixth Question of Privacy Issues

10.6) How concerned are you about the negative stigma attached to the use of biometric technology?

\begin{tabular}{|c|c|c|c|c|c|}
\hline & & Frequency & Percent & Valid Percent & $\begin{array}{c}\text { Cumulative } \\
\text { Percent }\end{array}$ \\
\hline \multirow[t]{6}{*}{ Valid } & Very Concerned & 2 & 6.7 & 6.7 & 6.7 \\
\hline & Somewhat concerned & 6 & 20.0 & 20.0 & 26.7 \\
\hline & Not very Concerned & 10 & 33.3 & 33.3 & 60.0 \\
\hline & Not Concerned & 7 & 23.3 & 23.3 & 83.3 \\
\hline & I don't know & 5 & 16.7 & 16.7 & 100.0 \\
\hline & Total & 30 & 100.0 & 100.0 & \\
\hline
\end{tabular}


Privacy Concerns of Each Ranked Biometric Technology (Low Medium High)

Table A.20

Instructors Ranking to Fingerprint According to their Intrusiveness

\begin{tabular}{|c|c|c|c|c|c|}
\hline & & Frequency & Percent & Valid Percent & $\begin{array}{c}\text { Cumulative } \\
\text { Percent }\end{array}$ \\
\hline \multirow[t]{5}{*}{ Valid } & Low & 12 & 40.0 & 40.0 & 40.0 \\
\hline & Medium & 8 & 26.7 & 26.7 & 66.7 \\
\hline & High & 8 & 26.7 & 26.7 & 93.3 \\
\hline & I don't know & 2 & 6.7 & 6.7 & 100.0 \\
\hline & Total & 30 & 100.0 & 100.0 & \\
\hline
\end{tabular}

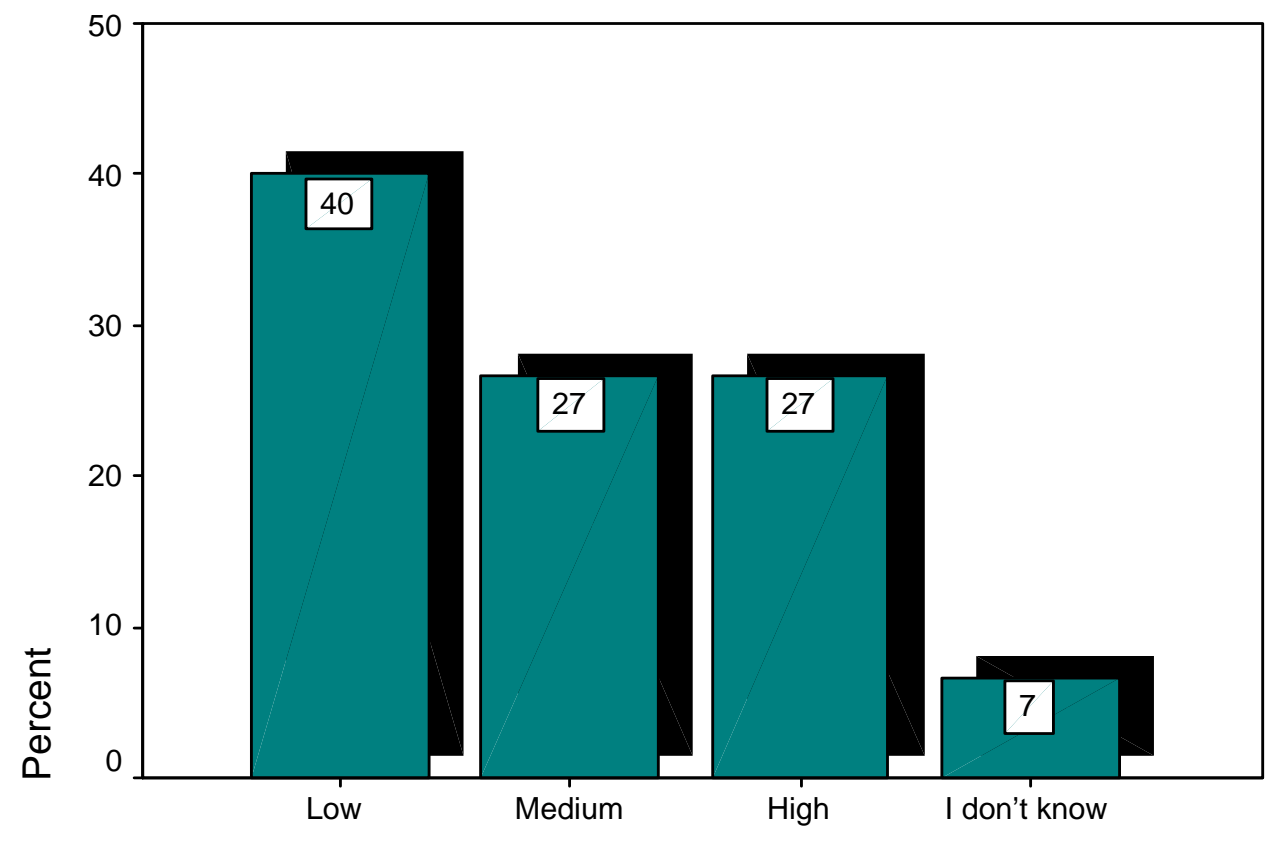

Figure A.1. Instructors ranking to fingerprint according to their intrusiveness 
Table A.21

Instructors’ Ranking to Iris Scan According to their Intrusiveness

\begin{tabular}{|ll|r|r|r|r|}
\hline & & & & \multicolumn{2}{c|}{$\begin{array}{c}\text { Cumulative } \\
\text { Percent }\end{array}$} \\
\hline Valid & Low & 9 & 30.0 & Valid Percent & 30.0 \\
& Medium & 5 & 16.7 & 16.7 & 46.7 \\
& High & 12 & 40.0 & 40.0 & 86.7 \\
I don't know & 4 & 13.3 & 13.3 & 100.0 \\
Total & 30 & 100.0 & 100.0 & \\
\hline
\end{tabular}

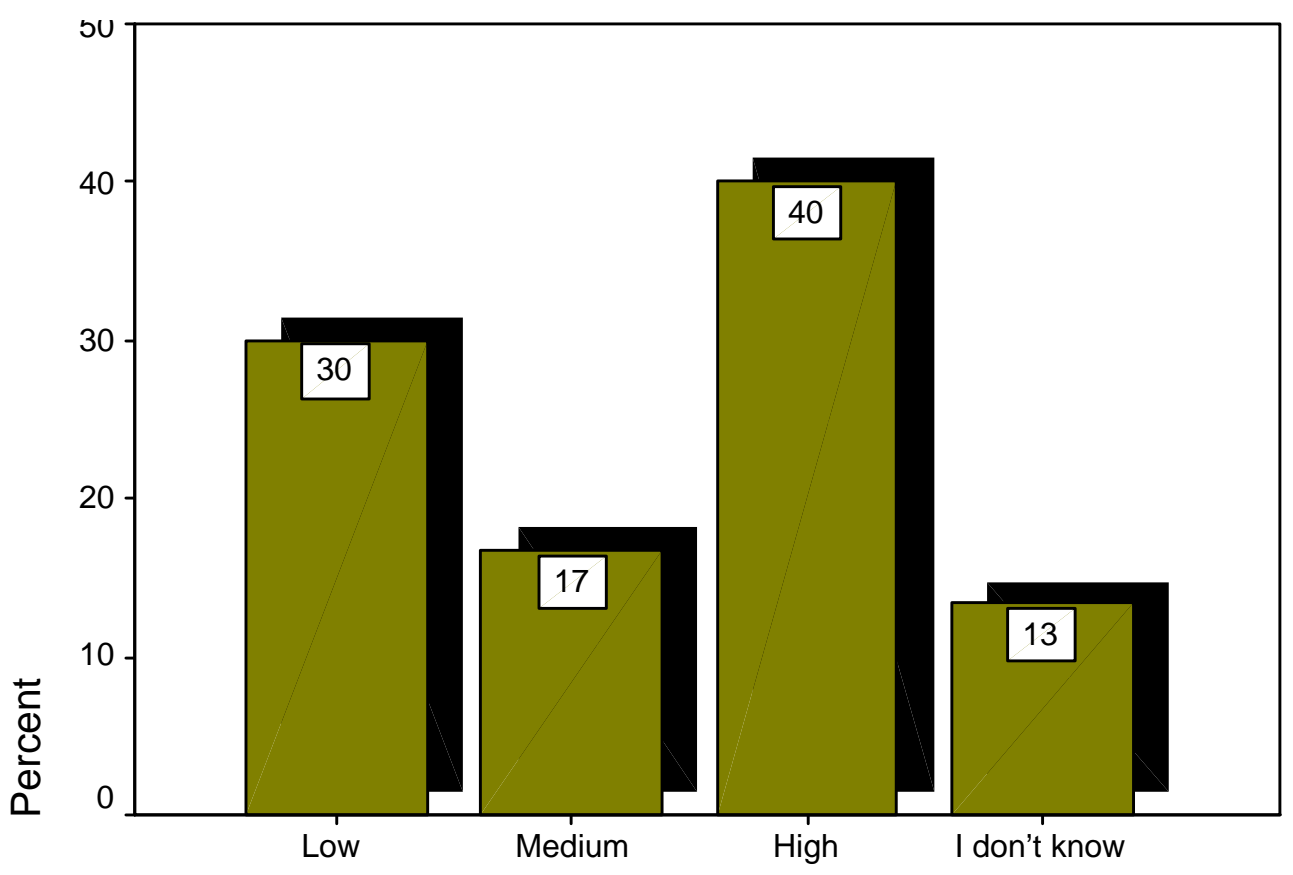

Figure A.2. Instructors' ranking to iris scan according to their intrusiveness 
Table A.22

Instructors Ranking to Facial Recognition According to their Intrusiveness

\begin{tabular}{|c|c|c|c|c|c|}
\hline & & Frequency & Percent & Valid Percent & $\begin{array}{l}\text { Cumulative } \\
\text { Percent }\end{array}$ \\
\hline \multirow[t]{5}{*}{ Valid } & Low & 10 & 33.3 & 33.3 & 33.3 \\
\hline & Medium & 9 & 30.0 & 30.0 & 63.3 \\
\hline & High & 9 & 30.0 & 30.0 & 93.3 \\
\hline & I don't know & 2 & 6.7 & 6.7 & 100.0 \\
\hline & Total & 30 & 100.0 & 100.0 & \\
\hline
\end{tabular}

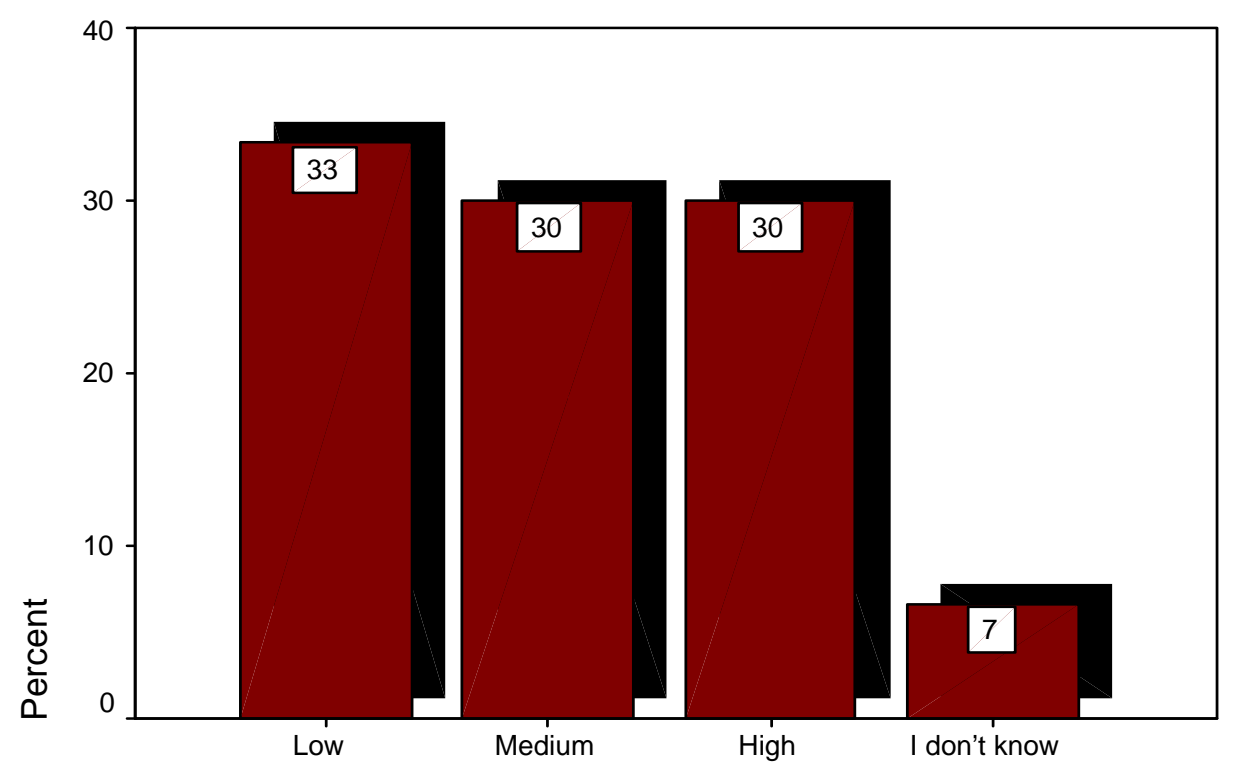

Figure A.3. Instructors' ranking to facial recognition according to their intrusiveness 
Table A.23

Instructors’ Ranking to Hand Geometry According to their Intrusiveness

\begin{tabular}{|ll|r|r|r|r|}
\hline & Frequency & Percent & Valid Percent & $\begin{array}{c}\text { Cumulative } \\
\text { Percent }\end{array}$ \\
\hline Valid & Low & 8 & 26.7 & 26.7 & 26.7 \\
& Medium & 13 & 43.3 & 43.3 & 70.0 \\
& High & 3 & 10.0 & 10.0 & 80.0 \\
I don't know & 6 & 20.0 & 20.0 & 100.0 \\
Total & 30 & 100.0 & 100.0 & \\
\hline
\end{tabular}

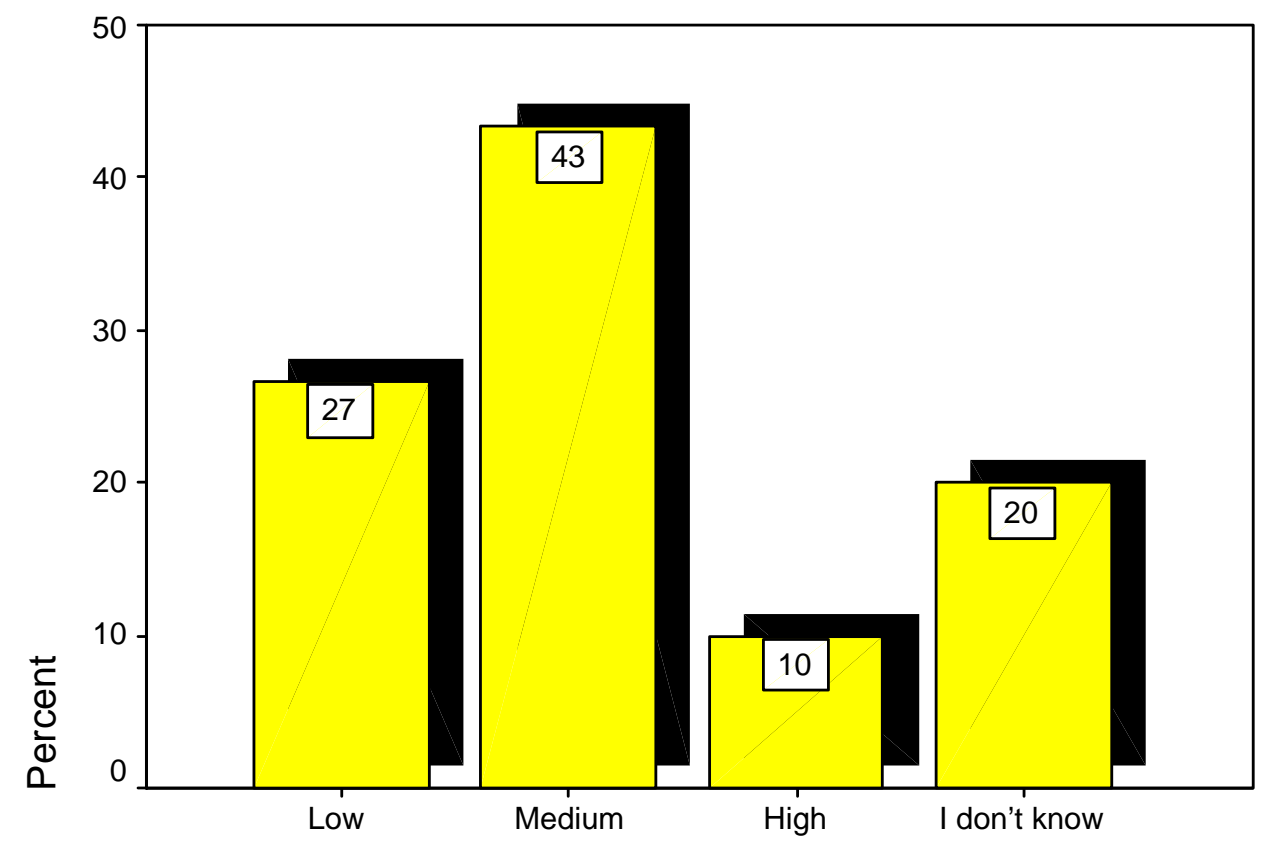

Figure A.4. Instructors ranking to hand geometry according to their intrusiveness 
Table A.24

Instructors' Ranking to Voice Recognition According to their Intrusiveness

\begin{tabular}{|ll|r|r|r|r|}
\hline & & & & Cumulative \\
& & Frequency & Percent & Valid Percent & Percent \\
\hline Valid & Low & 6 & 20.0 & 20.0 & 20.0 \\
& Medium & 16 & 53.3 & 53.3 & 73.3 \\
& High & 5 & 16.7 & 16.7 & 90.0 \\
I don't know & 3 & 10.0 & 10.0 & 100.0 \\
Total & 30 & 100.0 & 100.0 & \\
\hline
\end{tabular}

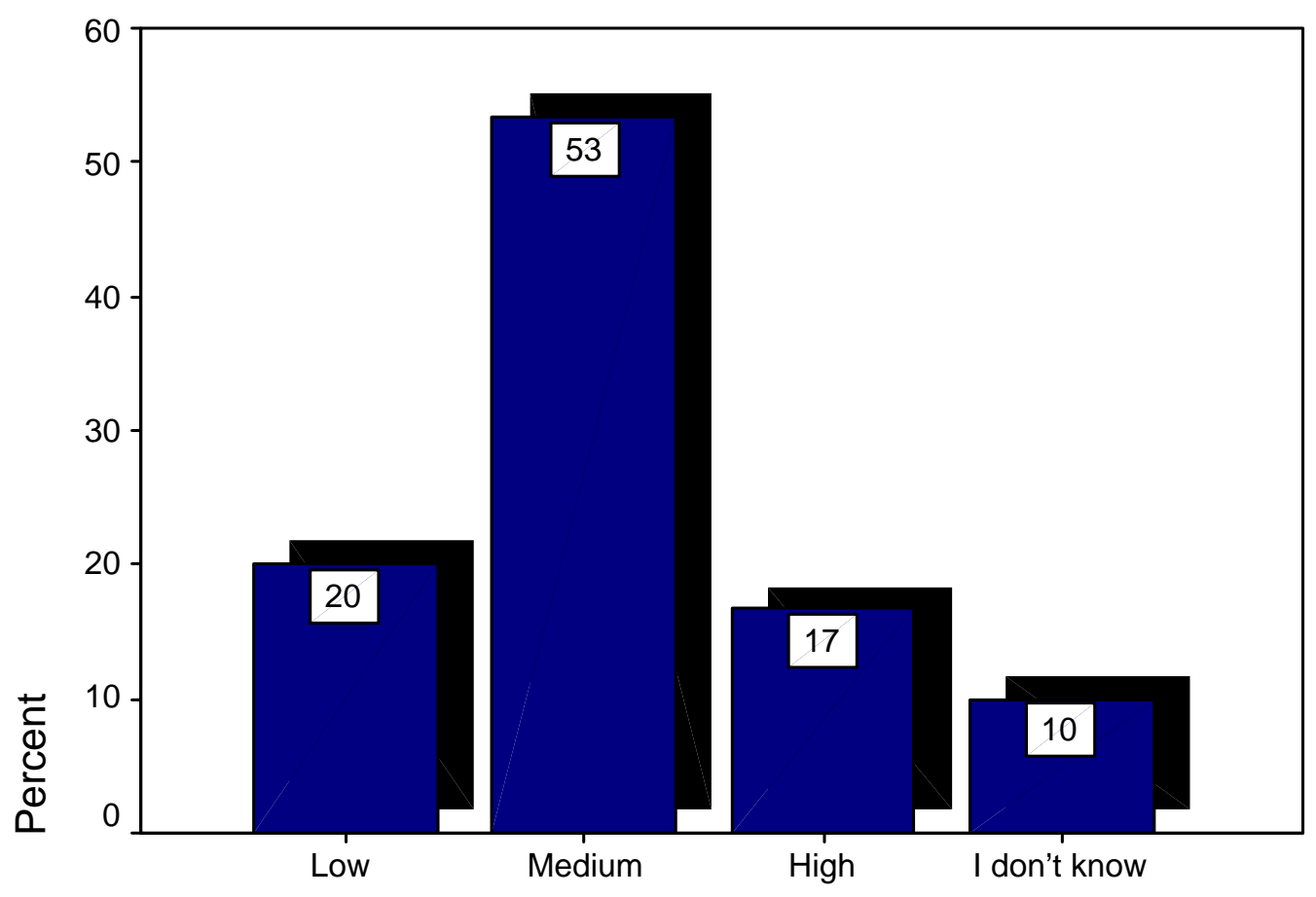

Figure A.5. Instructors ranking to voice recognition according to their intrusiveness 
Table A.25

Instructors’ Ranking to Signature Dynamic According to their Intrusiveness

\begin{tabular}{|ll|r|r|r|r|}
\hline & & & & \multicolumn{1}{c|}{$\begin{array}{c}\text { Cumulative } \\
\text { Percent }\end{array}$} \\
\hline Valid & Low & 12 & 40.0 & 40.0 & 40.0 \\
& Medium & 13 & 43.3 & 43.3 & 83.3 \\
& High & 1 & 3.3 & 3.3 & 86.7 \\
I don't know & 4 & 13.3 & 13.3 & 100.0 \\
Total & 30 & 100.0 & 100.0 & \\
\hline
\end{tabular}

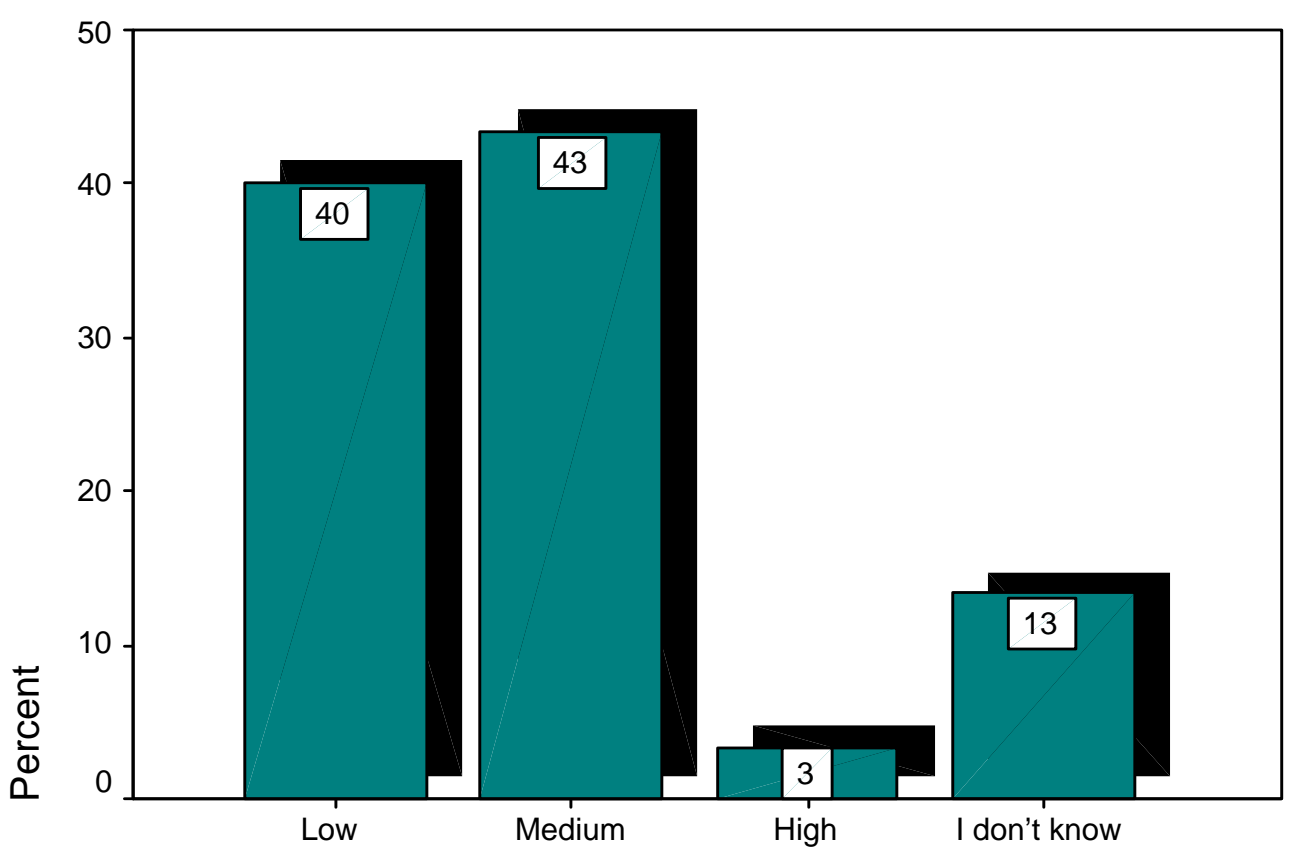

Figure A.6. Instructors ranking to signature dynamic according to their intrusiveness 
Religious Issues

Table A.26

Statistics

\begin{tabular}{|ll|r|r|r|r|r|r|}
\hline & $\begin{array}{c}14.1) \\
\text { Fingerprint }\end{array}$ & $\begin{array}{c}\text { 14.2) Iris } \\
\text { scan }\end{array}$ & $\begin{array}{c}\text { 14.3) Facial } \\
\text { recognition }\end{array}$ & $\begin{array}{c}\text { 14.4) Hand } \\
\text { geometry }\end{array}$ & $\begin{array}{c}\text { 14.5) Voice } \\
\text { recognition }\end{array}$ & $\begin{array}{c}\text { 14.6) } \\
\text { Signature } \\
\text { dynamic }\end{array}$ \\
\hline N & Valid & 0 & 1 & 0 & 1 & 1 & 1 \\
& Missing & 30 & 29 & 30 & 29 & 29 & 29 \\
Mean & & 2.00 & & 4.00 & 5.00 & 6.00 \\
\hline
\end{tabular}

Table A.27 - A.32

\section{1) Fingerprint}

\begin{tabular}{|ll|r|r|}
\hline & Frequency & Percent \\
\hline Missing & System & 30 & 100.0 \\
\hline
\end{tabular}

14.2) Iris scan

\begin{tabular}{|ll|r|r|r|r|}
\hline & & & & $\begin{array}{c}\text { Cumulative } \\
\text { Percent }\end{array}$ \\
\hline Valid & 2 & 1 & 3.3 & 100.0 & 100.0 \\
Missing & System & 29 & 96.7 & & \\
Total & 30 & 100.0 & & \\
\hline
\end{tabular}

14.3) Facial recognition

\begin{tabular}{|ll|r|r|}
\hline & Frequency & Percent \\
\hline Missing & System & 30 & 100.0 \\
\hline
\end{tabular}

\section{4) Hand geometry}

\begin{tabular}{|ll|r|r|r|c|}
\hline & Frequency & Percent & Valid Percent & $\begin{array}{c}\text { Cumulative } \\
\text { Percent }\end{array}$ \\
\hline Valid & 4 & 1 & 3.3 & 100.0 & 100.0 \\
Missing & System & 29 & 96.7 & & \\
Total & 30 & 100.0 & & \\
\hline
\end{tabular}


14.5) Voice recognition

\begin{tabular}{|c|c|c|c|c|c|}
\hline & & Frequency & Percent & Valid Percent & $\begin{array}{c}\text { Cumulative } \\
\text { Percent }\end{array}$ \\
\hline Valid & 5 & 1 & 3.3 & \multirow{3}{*}{100.0} & \multirow{3}{*}{100.0} \\
\hline Missing & System & 29 & 96.7 & & \\
\hline Total & & 30 & 100.0 & & \\
\hline
\end{tabular}

14.6) Signature dynamic

\begin{tabular}{|ll|r|r|r|c|}
\hline & & & & & Cumulative \\
Percent
\end{tabular}


Instructors' Frequencies tables and Figures for rating different biometric technology according to their religious concerns

Table A.33

Statistics

\begin{tabular}{|c|c|c|c|c|c|c|c|}
\hline & & $\begin{array}{c}15.1) \\
\text { Fingerprint }\end{array}$ & $\begin{array}{c}15.2) \text { Iris } \\
\text { scans }\end{array}$ & $\begin{array}{l}\text { 15.3) Facial } \\
\text { recognition }\end{array}$ & $\begin{array}{l}\text { 15.4) Hand } \\
\text { geometry }\end{array}$ & $\begin{array}{l}15.5) \text { Voice } \\
\text { recognition }\end{array}$ & $\begin{array}{c}15.6) \\
\text { Signature } \\
\text { dynamic }\end{array}$ \\
\hline \multirow[t]{2}{*}{$\bar{N}$} & Valid & 2 & 2 & 2 & 2 & 2 & 2 \\
\hline & Missing & 28 & 28 & 28 & 28 & 28 & 28 \\
\hline \multicolumn{2}{|c|}{ Mean } & 2.50 & 3.50 & 3.00 & 3.00 & 3.50 & 3.00 \\
\hline \multicolumn{2}{|c|}{ Median } & 2.50 & 3.50 & 3.00 & 3.00 & 3.50 & 3.00 \\
\hline \multicolumn{2}{|c|}{ Mode } & $1^{\mathrm{a}}$ & $3^{a}$ & $2^{\mathrm{a}}$ & $2^{a}$ & $3^{a}$ & $2^{a}$ \\
\hline \multicolumn{2}{|c|}{ Std. Deviation } & 2.121 & .707 & 1.414 & 1.414 & .707 & 1.414 \\
\hline \multicolumn{2}{|c|}{ Variance } & 4.500 & .500 & 2.000 & 2.000 & .500 & 2.000 \\
\hline
\end{tabular}

a. Multiple modes exist. The smallest value is shown

Frequency Table A.34 - A.39

15.1) Fingerprint

\begin{tabular}{|ll|r|r|r|r|}
\hline & & & & \multicolumn{1}{c|}{$\begin{array}{c}\text { Cumulative } \\
\text { Percent }\end{array}$} \\
\hline Valid & Low & 1 & 3.3 & 50.0 & 50.0 \\
& I don't know & 1 & 3.3 & 50.0 & 100.0 \\
& Total & 2 & 6.7 & 100.0 & \\
Missing & System & 28 & 93.3 & & \\
Total & & 30 & 100.0 & & \\
\hline
\end{tabular}

15.2) Iris scans

\begin{tabular}{|c|c|c|c|c|c|}
\hline & & Frequency & Percent & Valid Percent & $\begin{array}{c}\text { Cumulative } \\
\text { Percent }\end{array}$ \\
\hline \multirow[t]{3}{*}{ Valid } & High & 1 & 3.3 & 50.0 & 50.0 \\
\hline & I don't know & 1 & 3.3 & 50.0 & 100.0 \\
\hline & Total & 2 & 6.7 & 100.0 & \\
\hline Missing & System & 28 & 93.3 & & \\
\hline Total & & 30 & 100.0 & & \\
\hline
\end{tabular}

15.3) Facial recognition

\begin{tabular}{|ll|r|r|r|r|}
\hline & & & & Cumulative \\
& & Frequency & Percent & Valid Percent & Percent \\
\hline Valid & Medium & 1 & 3.3 & 50.0 & 50.0 \\
& I don't know & 1 & 3.3 & 50.0 & 100.0 \\
& Total & 2 & 6.7 & 100.0 & \\
Missing & System & 28 & 93.3 & & \\
Total & & 30 & 100.0 & & \\
\hline
\end{tabular}


15.4) Hand geometry

\begin{tabular}{|ll|r|r|r|r|}
\hline & & & & \multicolumn{1}{c|}{$\begin{array}{c}\text { Cumulative } \\
\text { Percent }\end{array}$} \\
\hline Valid & Medium & 1 & 3.3 & 50.0 & 50.0 \\
& I don't know & 1 & 3.3 & 50.0 & 100.0 \\
& Total & 2 & 6.7 & 100.0 & \\
Missing & System & 28 & 93.3 & & \\
Total & & 30 & 100.0 & & \\
\hline
\end{tabular}

15.5) Voice recognition

\begin{tabular}{|ll|r|r|r|r|}
\hline & & & & \multicolumn{1}{c|}{$\begin{array}{c}\text { Cumulative } \\
\text { Percent }\end{array}$} \\
\hline Valid & High & 1 & 3.3 & 50.0 & 50.0 \\
& I don't know & 1 & 3.3 & 50.0 & 100.0 \\
& Total & 2 & 6.7 & 100.0 & \\
Missing & System & 28 & 93.3 & & \\
Total & & 30 & 100.0 & & \\
\hline
\end{tabular}

15.6) Signature dynamic

\begin{tabular}{|c|c|c|c|c|c|}
\hline & & Frequency & Percent & Valid Percent & $\begin{array}{c}\text { Cumulative } \\
\text { Percent }\end{array}$ \\
\hline \multirow[t]{3}{*}{ Valid } & Medium & 1 & 3.3 & 50.0 & 50.0 \\
\hline & I don't know & 1 & 3.3 & 50.0 & 100.0 \\
\hline & Total & 2 & 6.7 & 100.0 & \\
\hline Missing & System & 28 & 93.3 & & \\
\hline Total & & 30 & 100.0 & & \\
\hline
\end{tabular}

Figures A.7- A.13

\section{1) Fingerprint}

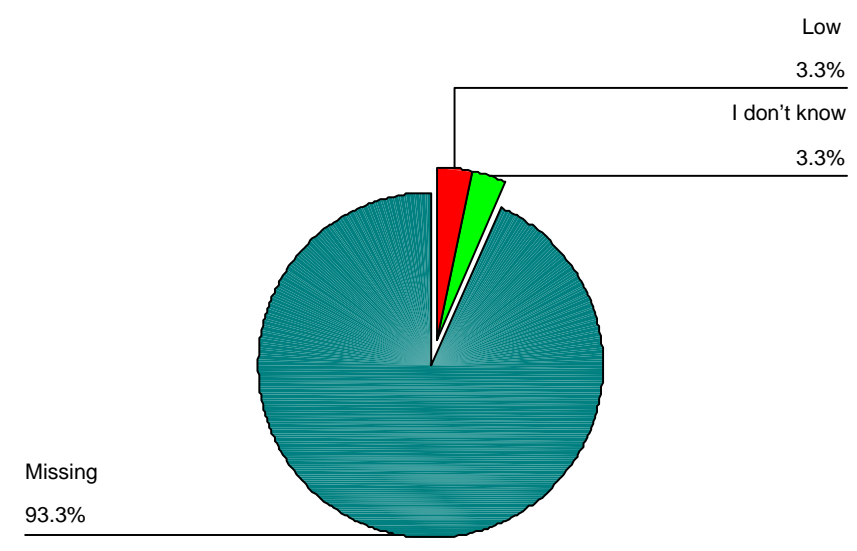


15.2) Iris scans

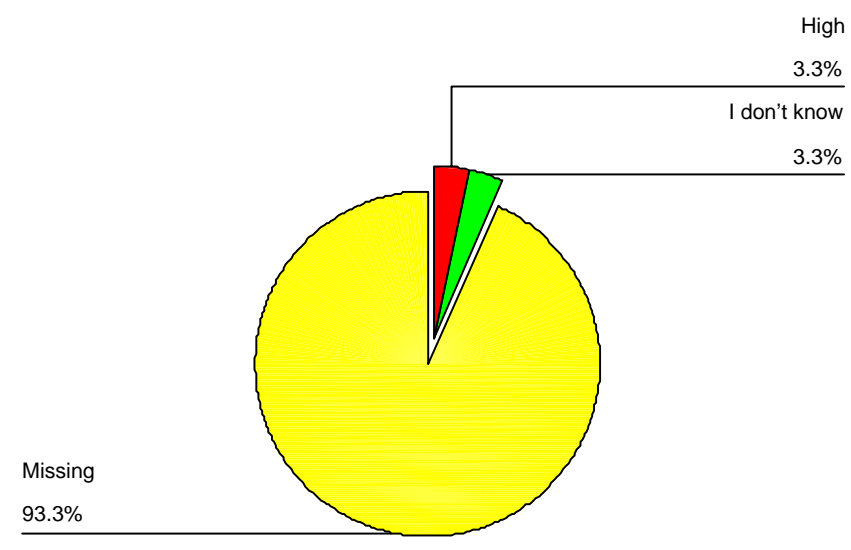

15.3) Facial recognition

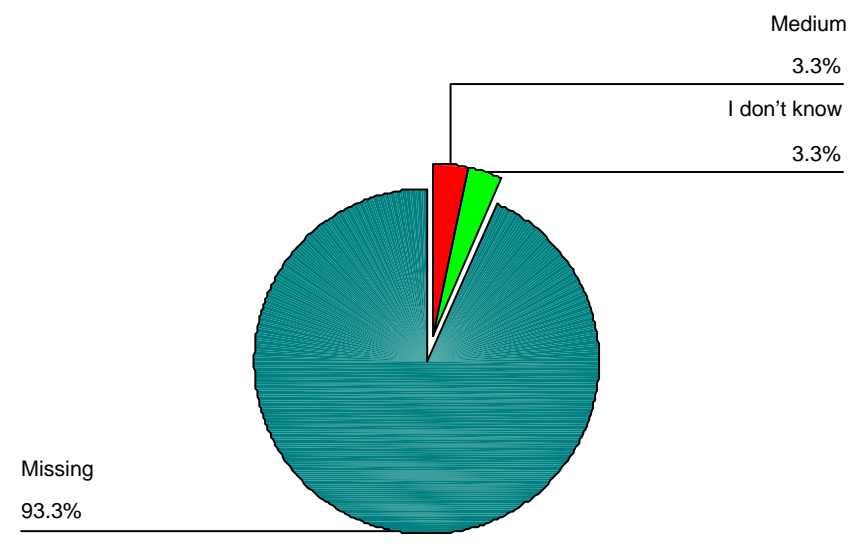

15.4) Hand geometry

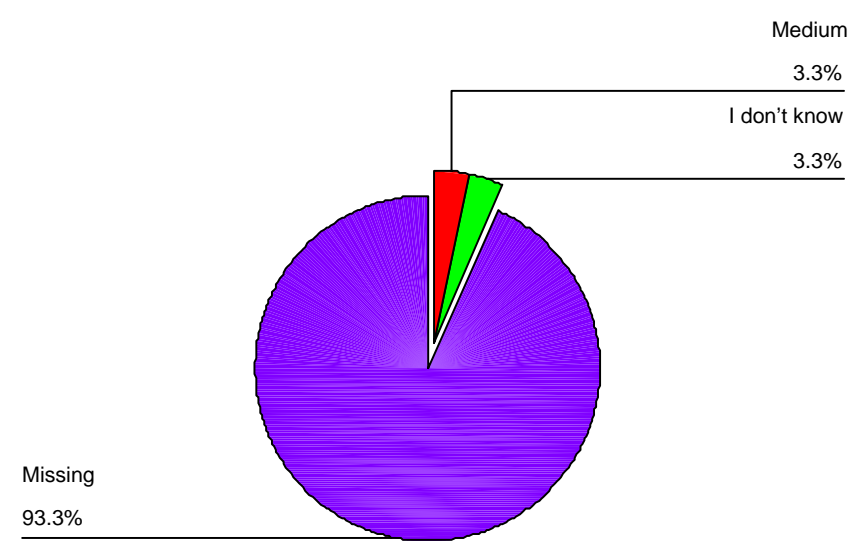




\section{5) Voice recognition}

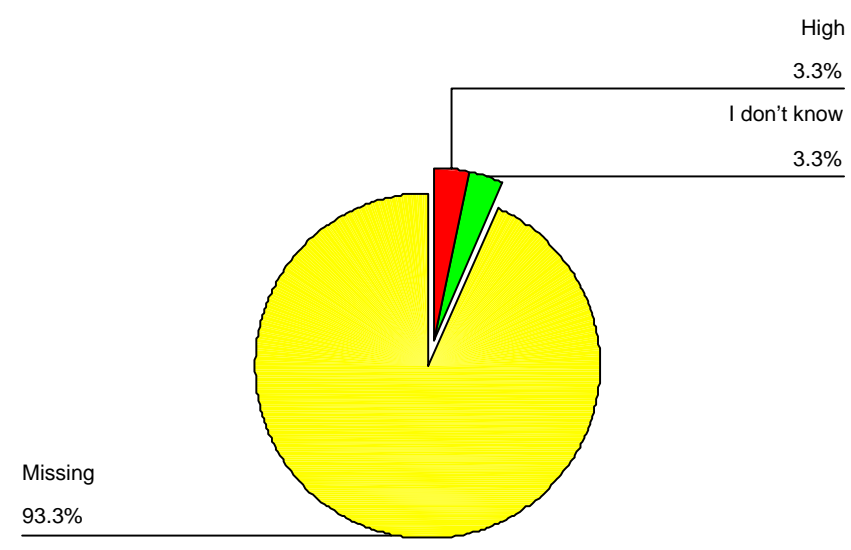

15.6) Signature dynamic

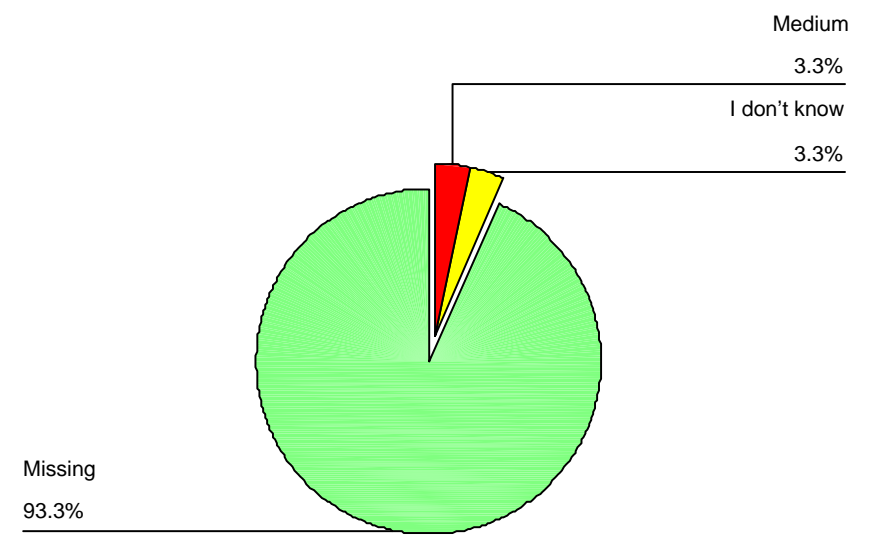


health issues

Table A.40

Summary of Instructors' Responses to First Question Related to Health Issues

16.) When biometric technology is implemented, how concerned are you about the health risk which might be rendered:

\begin{tabular}{|c|c|c|c|c|c|}
\hline & & Frequency & Percent & Valid Percent & $\begin{array}{l}\text { Cumulative } \\
\text { Percent }\end{array}$ \\
\hline \multirow[t]{5}{*}{ Valid } & Somewhat concerned & 5 & 16.7 & 16.7 & 16.7 \\
\hline & Not very concerned & 10 & 33.3 & 33.3 & 50.0 \\
\hline & Not concerned & 14 & 46.7 & 46.7 & 96.7 \\
\hline & I don't know & 1 & 3.3 & 3.3 & 100.0 \\
\hline & Total & 30 & 100.0 & 100.0 & \\
\hline
\end{tabular}

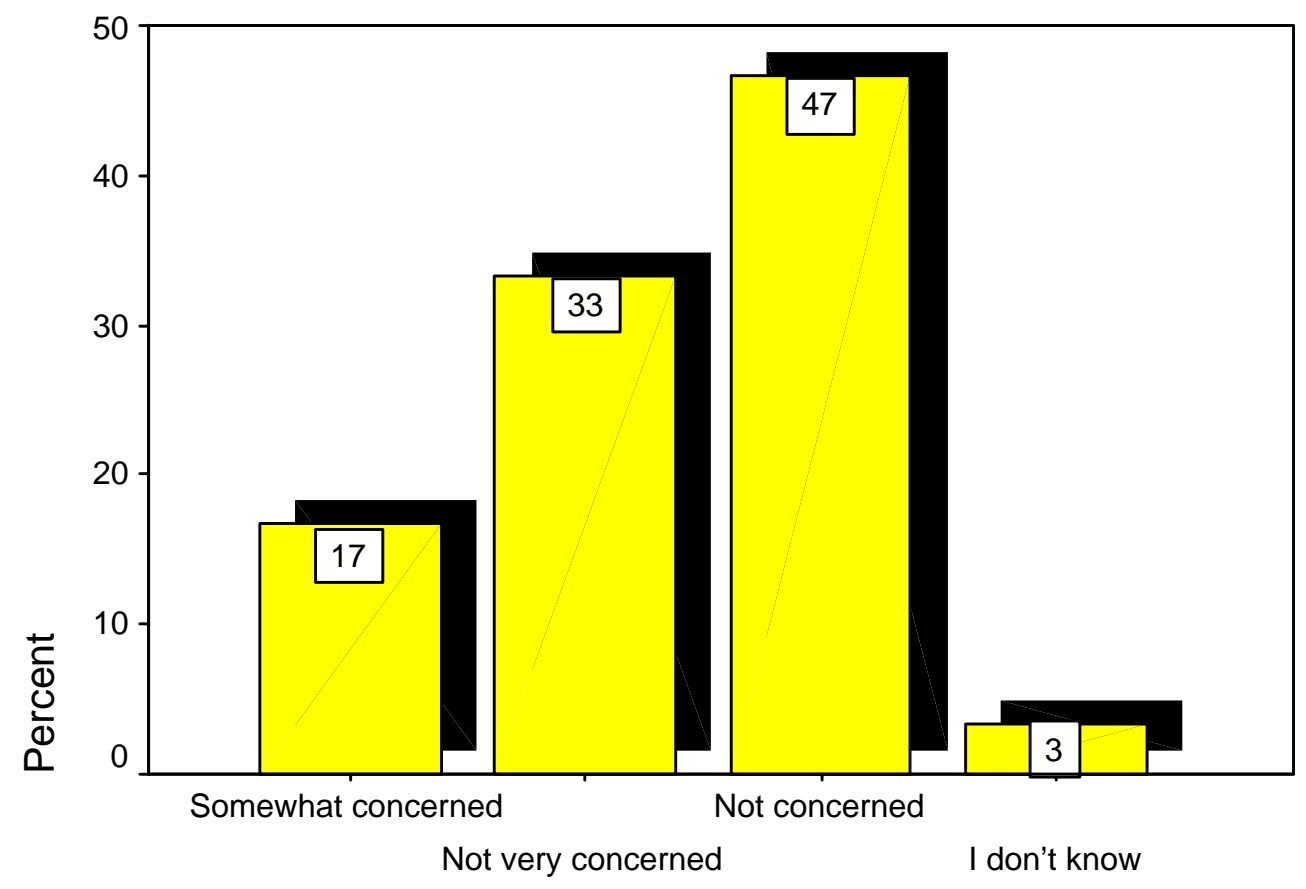

Figure A.14.Instructors' responses to health issues first question 
Health Concerns of Each Ranked Biometric Technology (Low Medium High)

Table A.41

Instructors' Ranking to Fingerprint According to its Health Concerns

\begin{tabular}{|ll|r|r|r|r|}
\hline & & & & Cumulative \\
& & Frequency & Percent & Valid Percent & Percent \\
\hline Valid & Low & 25 & 83.3 & 83.3 & 83.3 \\
& Medium & 2 & 6.7 & 6.7 & 90.0 \\
& I don't know & 3 & 10.0 & 10.0 & 100.0 \\
& Total & 30 & 100.0 & 100.0 & \\
\hline
\end{tabular}

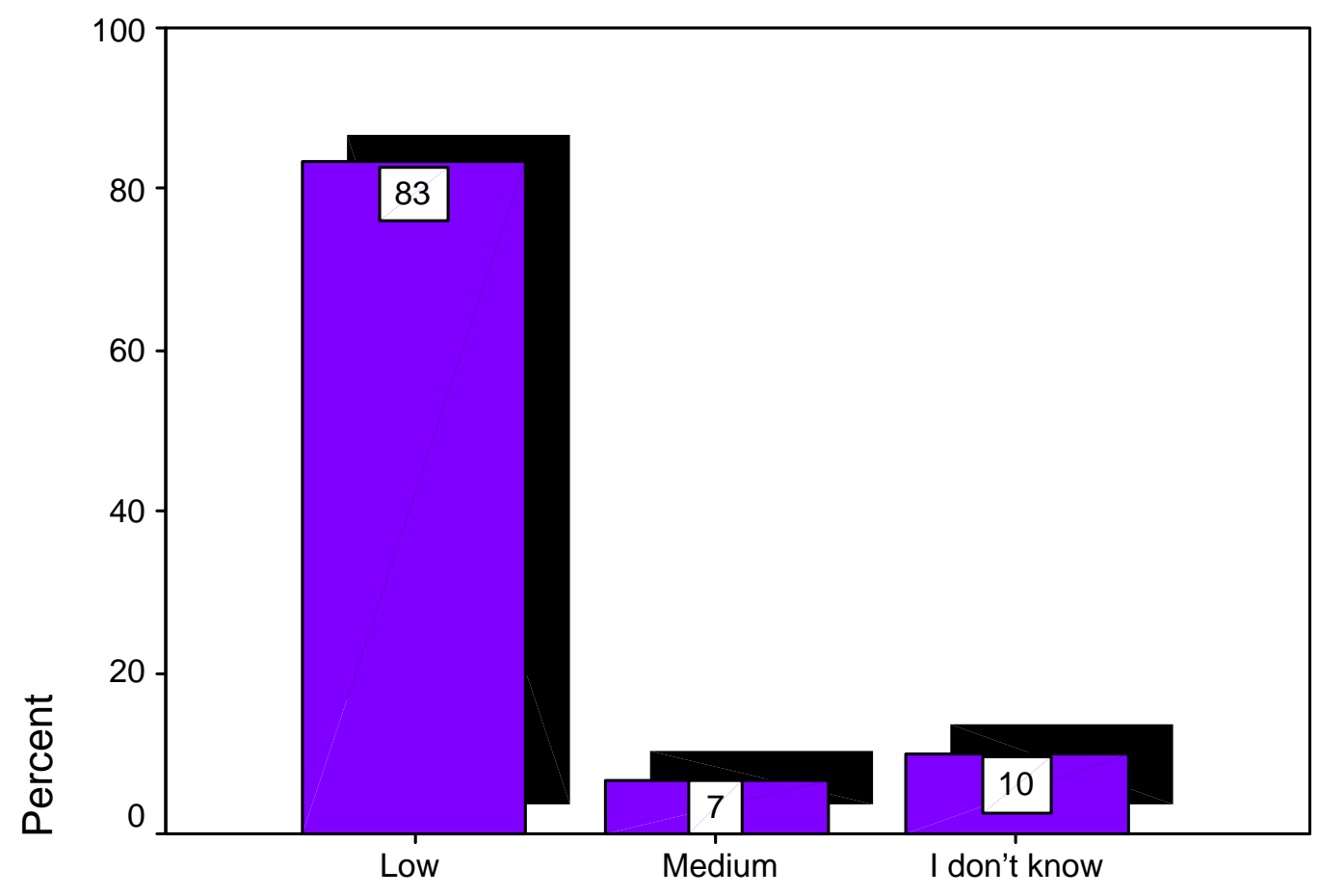

Figure A.15. Instructors ranking to fingerprint according to its health concerns 
Table A.42

Instructors Ranking to Iris Scan According to its Health Concerns

\begin{tabular}{|c|c|c|c|c|c|}
\hline & & Frequency & Percent & Valid Percent & $\begin{array}{c}\text { Cumulative } \\
\text { Percent }\end{array}$ \\
\hline \multirow[t]{5}{*}{ Valid } & Low & 13 & 43.3 & 43.3 & 43.3 \\
\hline & Medium & 10 & 33.3 & 33.3 & 76.7 \\
\hline & High & 2 & 6.7 & 6.7 & 83.3 \\
\hline & I don't know & 5 & 16.7 & 16.7 & 100.0 \\
\hline & Total & 30 & 100.0 & 100.0 & \\
\hline
\end{tabular}

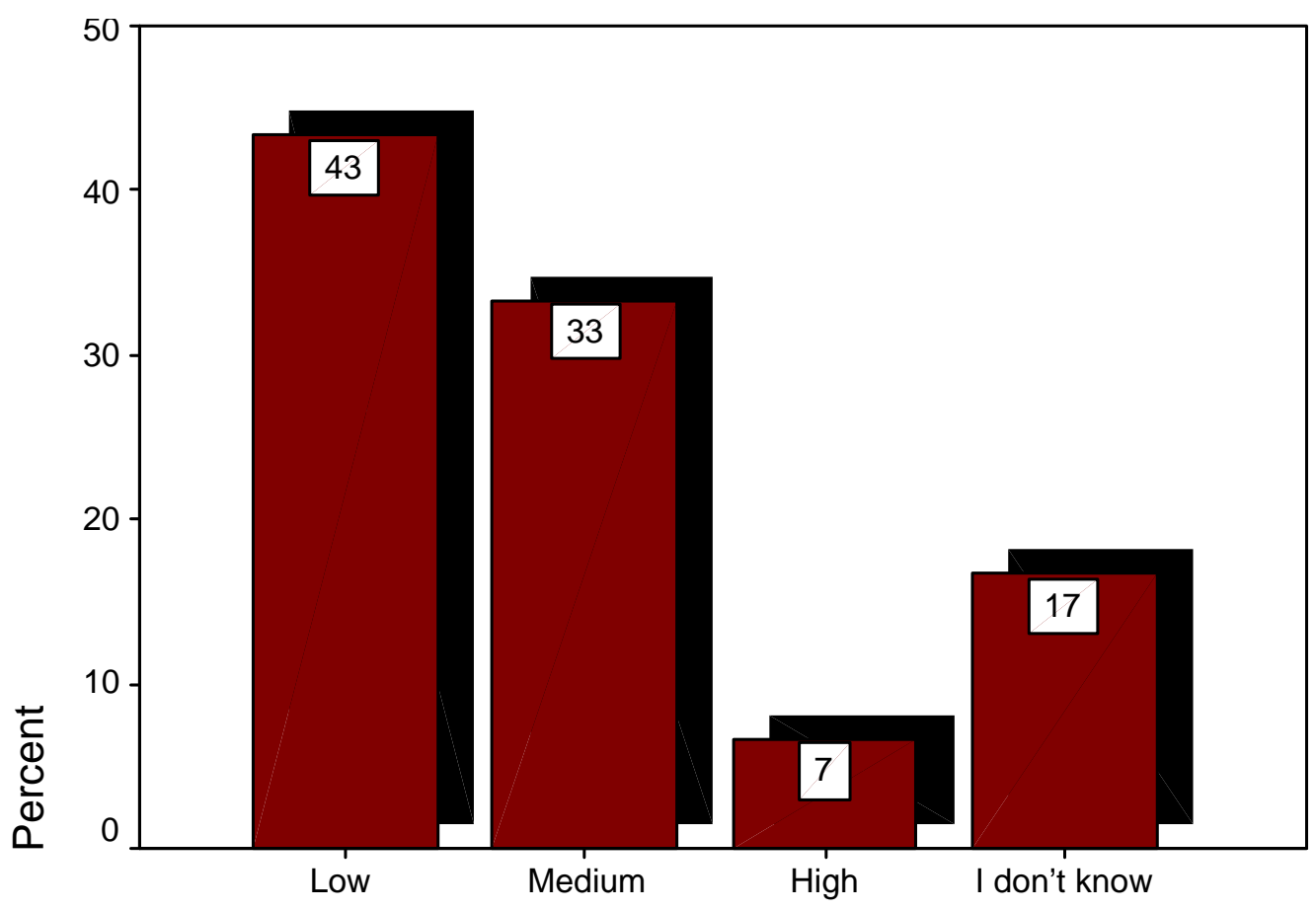

Figure A.16. Instructors ranking to iris scan according to its health concerns 
Table A.43

Instructors’ Ranking to Facial Recognition According to its Health Concerns

\begin{tabular}{|c|c|c|c|c|c|}
\hline & & Frequency & Percent & Valid Percent & $\begin{array}{c}\text { Cumulative } \\
\text { Percent }\end{array}$ \\
\hline \multirow[t]{4}{*}{ Valid } & Low & 22 & 73.3 & 73.3 & 73.3 \\
\hline & Medium & 5 & 16.7 & 16.7 & 90.0 \\
\hline & I don't know & 3 & 10.0 & 10.0 & 100.0 \\
\hline & Total & 30 & 100.0 & 100.0 & \\
\hline
\end{tabular}

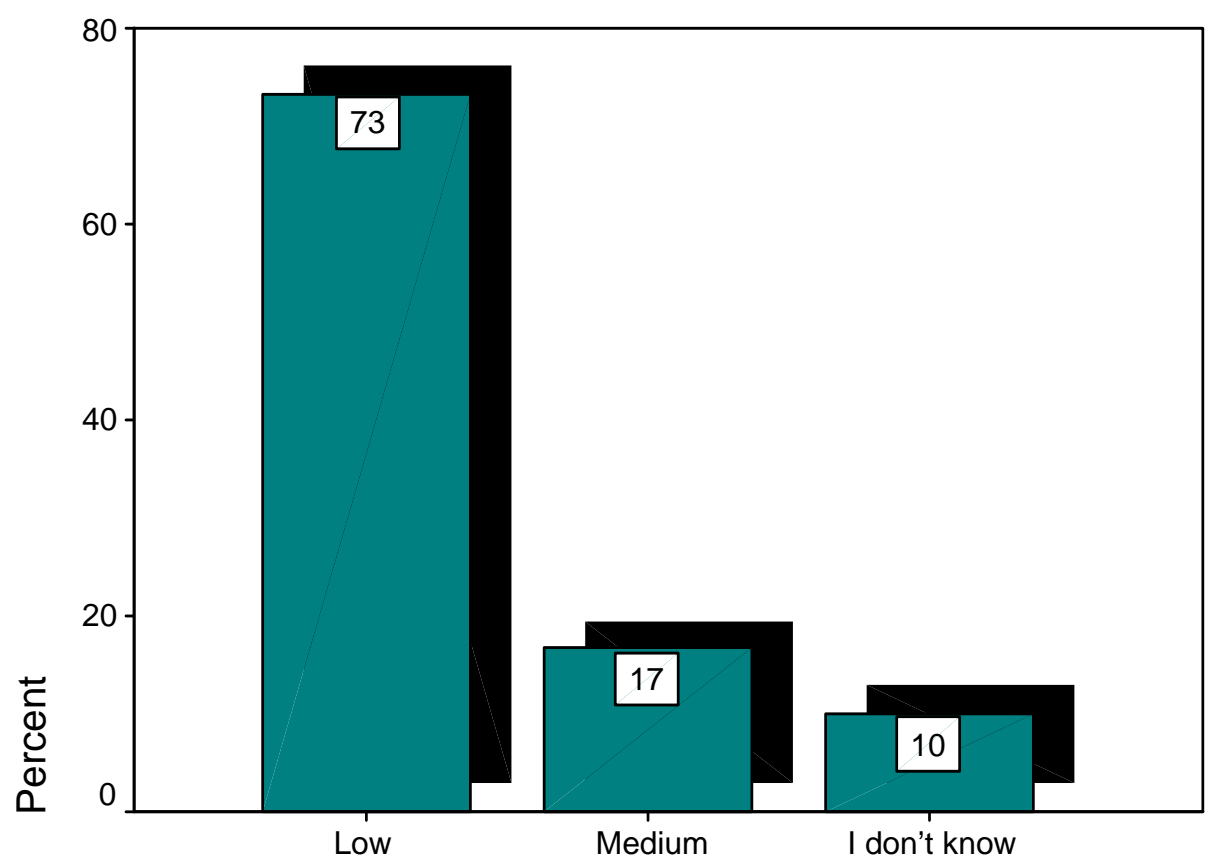

Figure A.17. Instructors ranking to facial recognition according to its health concerns 
Table A.44

Instructors’ Ranking to Hand Geometry According to its Health Concerns

\begin{tabular}{|c|c|c|c|c|c|}
\hline & & Frequency & Percent & Valid Percent & $\begin{array}{l}\text { Cumulative } \\
\text { Percent }\end{array}$ \\
\hline \multirow[t]{4}{*}{$\overline{\text { Valid }}$} & Low & 22 & 73.3 & 73.3 & 73.3 \\
\hline & Medium & 3 & 10.0 & 10.0 & 83.3 \\
\hline & I don't know & 5 & 16.7 & 16.7 & 100.0 \\
\hline & Total & 30 & 100.0 & 100.0 & \\
\hline
\end{tabular}

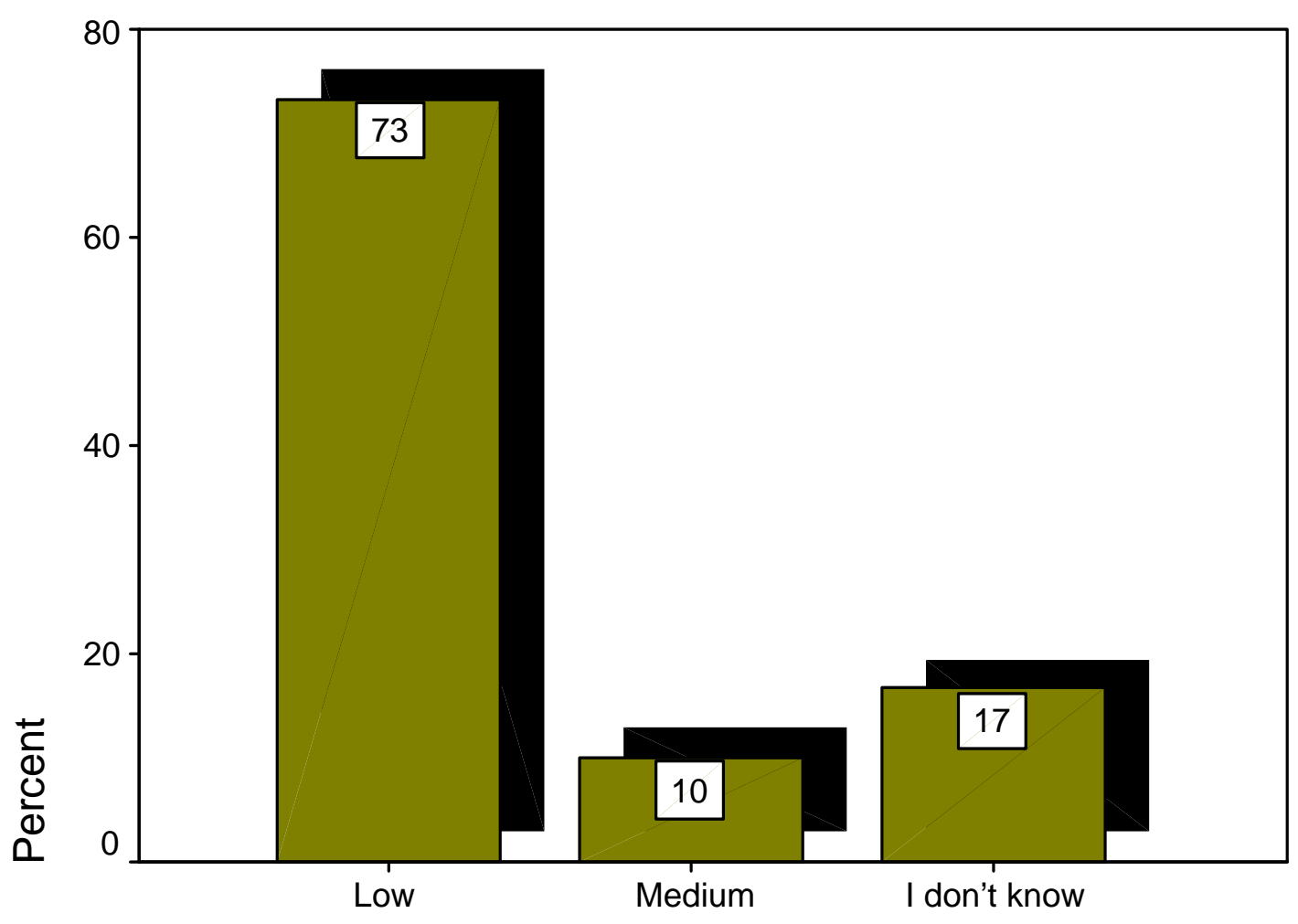

Figure A.18. Instructors ranking to hand geometry according to its health concerns 
Table A.45

Instructors' Ranking to Voice Recognition According to its Health Concerns

\begin{tabular}{|c|c|c|c|c|c|}
\hline & & Frequency & Percent & Valid Percent & $\begin{array}{c}\text { Cumulative } \\
\text { Percent }\end{array}$ \\
\hline \multirow[t]{4}{*}{ Valid } & Low & 23 & 76.7 & 76.7 & 76.7 \\
\hline & Medium & 4 & 13.3 & 13.3 & 90.0 \\
\hline & I don't know & 3 & 10.0 & 10.0 & 100.0 \\
\hline & Total & 30 & 100.0 & 100.0 & \\
\hline
\end{tabular}

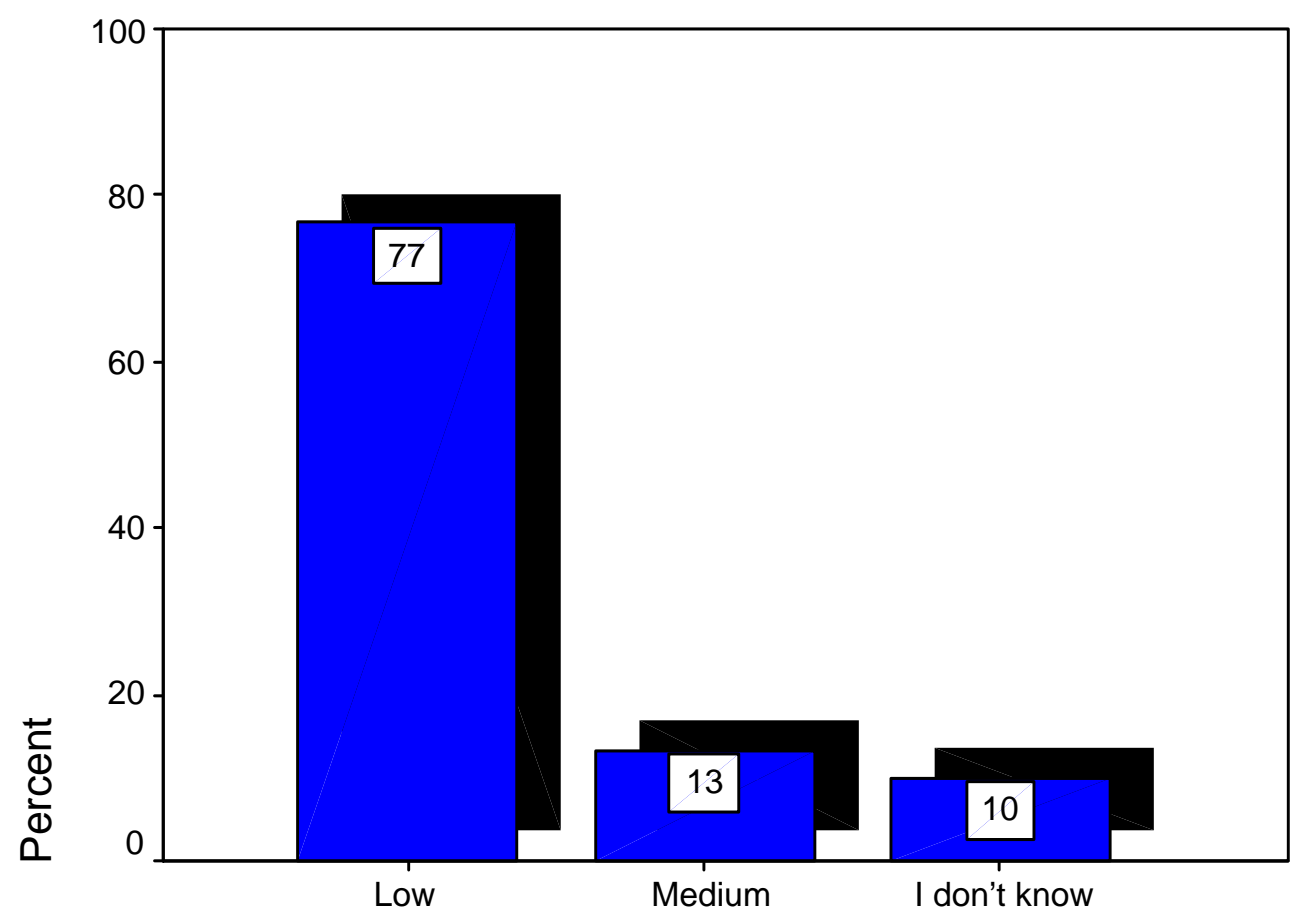

Figure A.19. Instructors ranking to voice recognition according to its health concerns 
Table A.56

Instructors’ Ranking to Signature Dynamic According to its Health Concerns

\begin{tabular}{|ll|r|r|r|r|}
\hline & & & & Cumulative \\
& & Frequency & Percent & Valid Percent & Percent \\
\hline Valid & Low & 22 & 73.3 & 73.3 & 73.3 \\
& Medium & 2 & 6.7 & 6.7 & 80.0 \\
I don't know & 6 & 20.0 & 20.0 & 100.0 \\
Total & 30 & 100.0 & 100.0 & \\
\hline
\end{tabular}

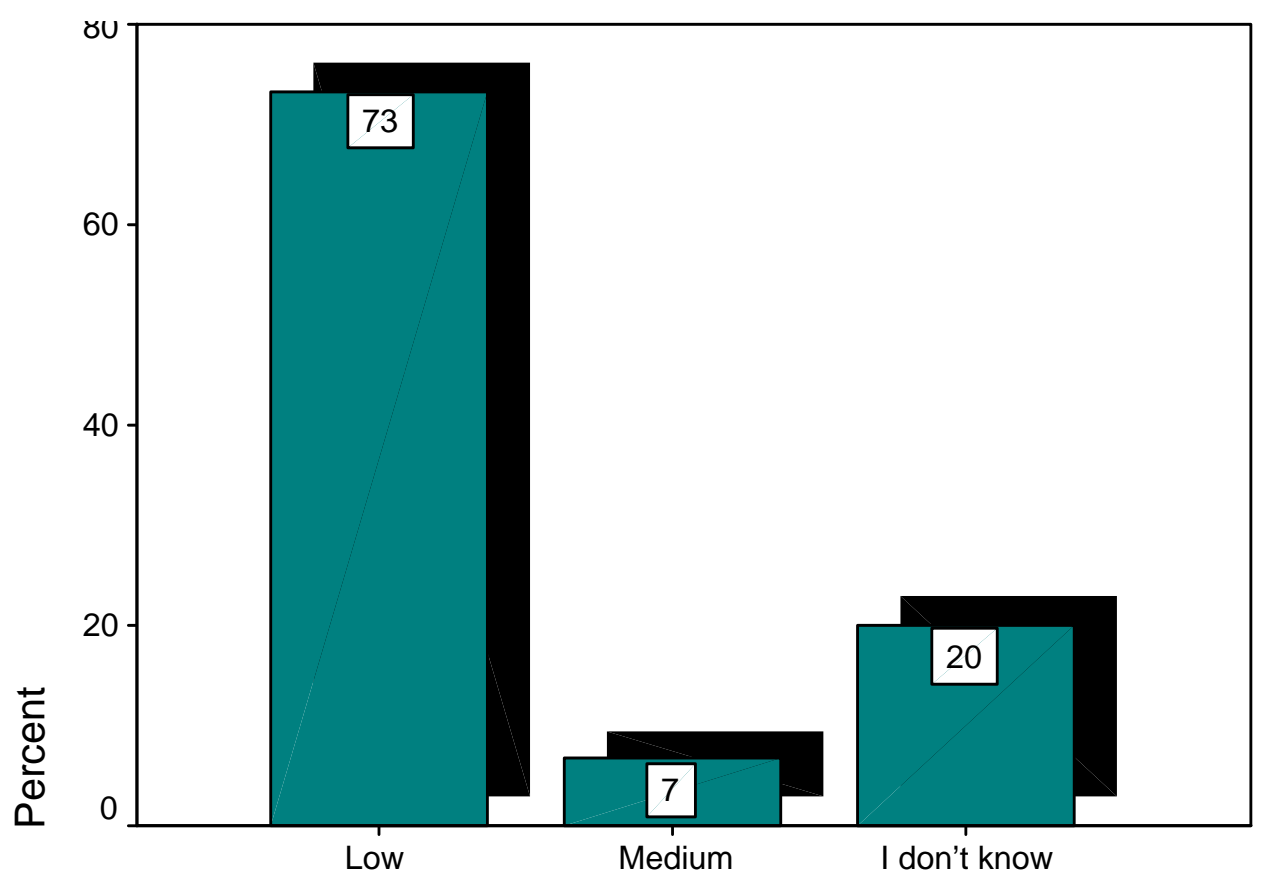

Figure A.20. Instructors ranking to signature dynamic according to its health concerns 
Health Concerns of Each Rated Biometric Technology (Comfortability)

Table A.47

Instructors' ranking to fingerprint According to its Level of Comfortability

\begin{tabular}{|c|c|c|c|c|c|}
\hline & & Frequency & Percent & Valid Percent & $\begin{array}{c}\text { Cumulative } \\
\text { Percent }\end{array}$ \\
\hline \multirow[t]{6}{*}{ Valid } & Very comfortable & 21 & $\overline{70.0}$ & 70.0 & 70.0 \\
\hline & Somewhat comfortable & 3 & 10.0 & 10.0 & 80.0 \\
\hline & Not very Comfortable & 2 & 6.7 & 6.7 & 86.7 \\
\hline & Not Comfortable & 2 & 6.7 & 6.7 & 93.3 \\
\hline & I don't know & 2 & 6.7 & 6.7 & 100.0 \\
\hline & Total & 30 & 100.0 & 100.0 & \\
\hline
\end{tabular}

I don't know

$6.7 \%$

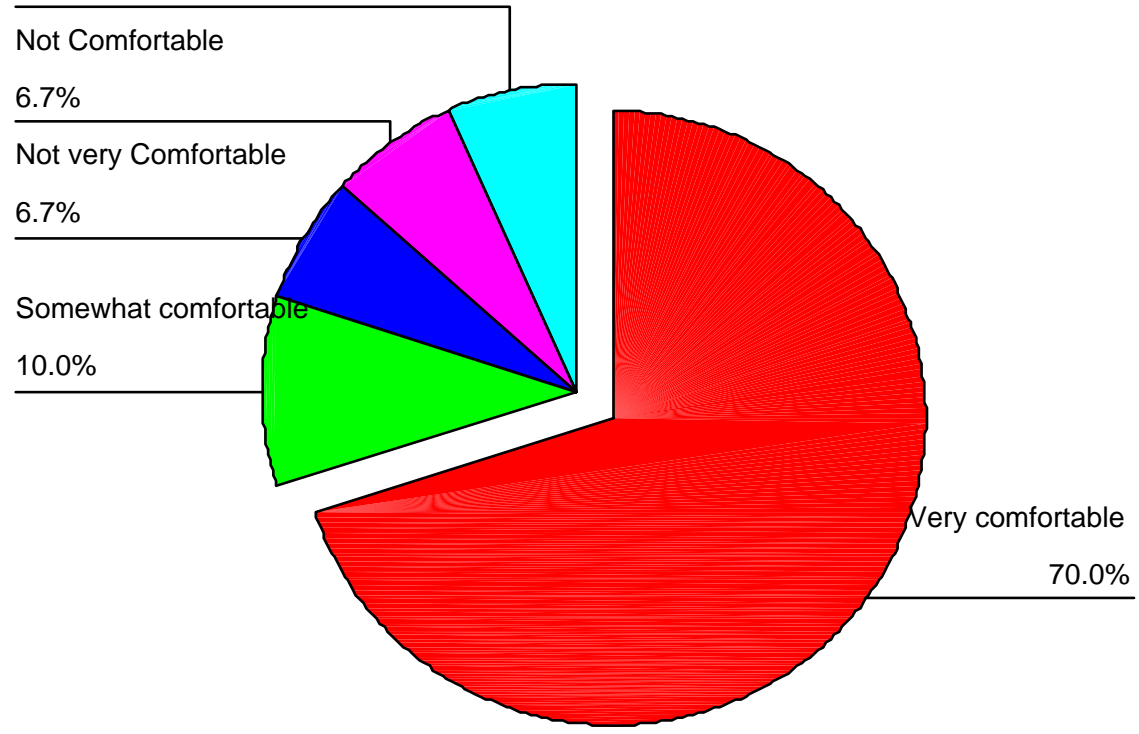

Figure A.21. Instructors' ranking to fingerprint according to its level of comfortability 
Table A.48

Instructors’ Ranking to Iris Scan According to its Level of Comfortability

\begin{tabular}{|ll|r|r|r|r|}
\hline & & & & Cumulative \\
& Frequency & Percent & Valid Percent & Percent \\
\hline Valid & Very comfortable & 11 & 36.7 & 36.7 & 36.7 \\
& Somewhat comfortable & 7 & 23.3 & 23.3 & 60.0 \\
Not very Comfortable & 5 & 16.7 & 16.7 & 76.7 \\
Not Comfortable & 4 & 13.3 & 13.3 & 90.0 \\
I don't know & 3 & 10.0 & 10.0 & 100.0 \\
Total & 30 & 100.0 & 100.0 & \\
\hline
\end{tabular}

I don't know

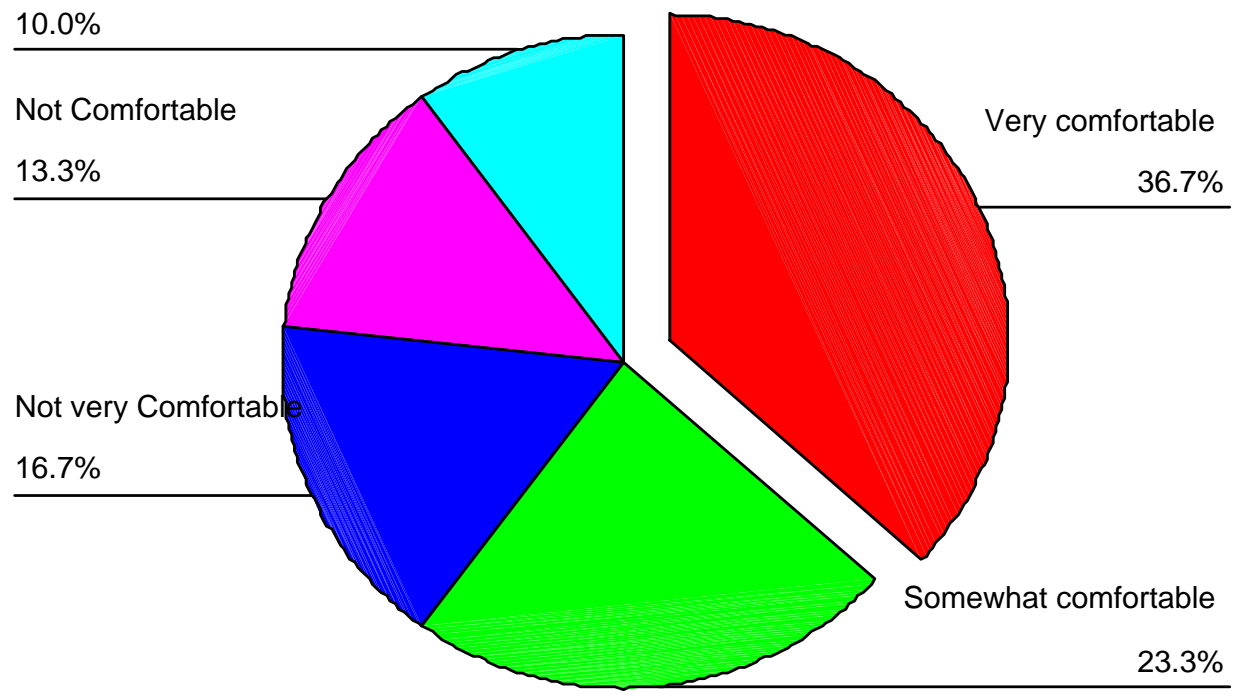

Figure A.22. Instructors' ranking to iris scan According to its Level of Comfortability 
Table A.49

Instructors’ Ranking to Facial Recognition According to its Level of Comfortability

\begin{tabular}{|ll|r|r|r|r|}
\hline & & & & $\begin{array}{c}\text { Cumulative } \\
\text { Percent }\end{array}$ \\
\hline Valid & Very comfortable & 19 & 63.3 & 63.3 & 63.3 \\
& Somewhat comfortable & 6 & 20.0 & 20.0 & 83.3 \\
Not very Comfortable & 1 & 3.3 & 3.3 & 86.7 \\
Not Comfortable & 1 & 3.3 & 3.3 & 90.0 \\
I don't know & 3 & 10.0 & 10.0 & 100.0 \\
Total & 30 & 100.0 & 100.0 & \\
\hline
\end{tabular}

I don't know

$10.0 \%$

Not Comfortable

$3.3 \%$

Not very Comfortable

$3.3 \%$

Somewhat comfortable

$20.0 \%$

Very comfortable

$63.3 \%$

Figure A.23. Instructors' ranking to facial recognition according to its level of comfortability 
Table A.50

Instructors’ Ranking to Hand Geometry According to its Level of Comfortability

\begin{tabular}{|c|c|c|c|c|c|}
\hline & & Frequency & Percent & Valid Percent & $\begin{array}{c}\text { Cumulative } \\
\text { Percent }\end{array}$ \\
\hline \multirow[t]{6}{*}{ Valid } & Very comfortable & 17 & 56.7 & 56.7 & 56.7 \\
\hline & Somewhat comfortable & 4 & 13.3 & 13.3 & 70.0 \\
\hline & Not very Comfortable & 1 & 3.3 & 3.3 & 73.3 \\
\hline & Not Comfortable & 3 & 10.0 & 10.0 & 83.3 \\
\hline & I don't know & 5 & 16.7 & 16.7 & 100.0 \\
\hline & Total & 30 & 100.0 & 100.0 & \\
\hline
\end{tabular}

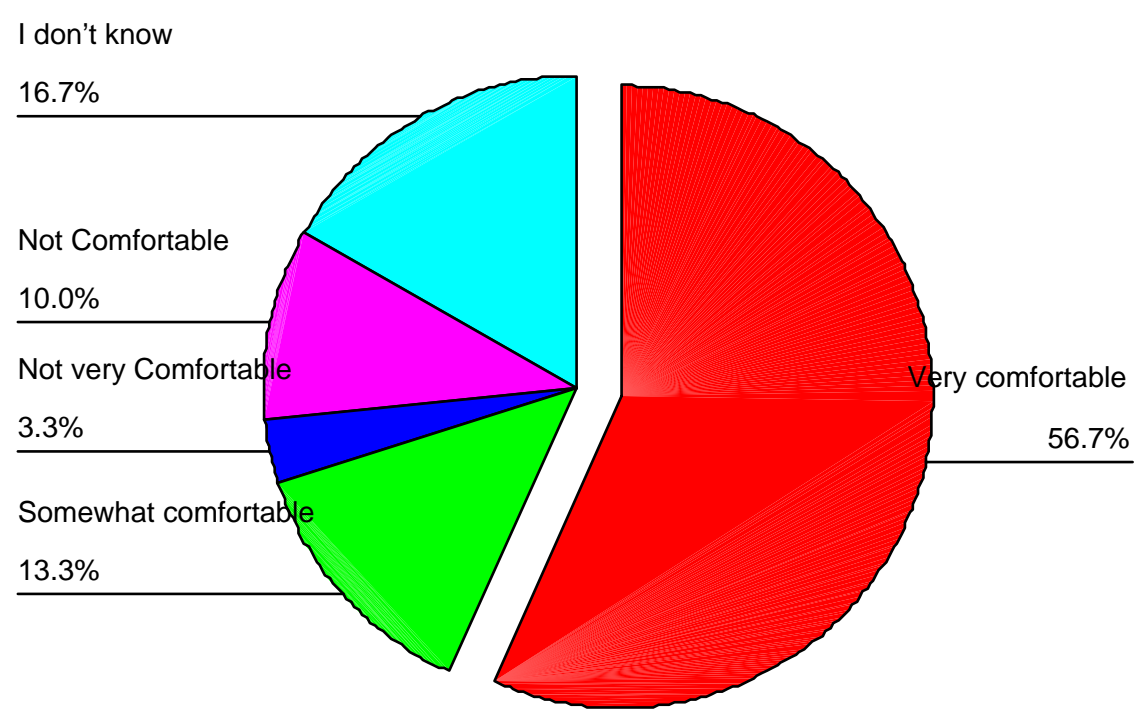

Figure A.24. Instructors' ranking to hand geometry according to its level of comfortability 
Table A.51

Instructors' Ranking to Voice Recognition According to its Level of Comfortability

\begin{tabular}{|c|c|c|c|c|c|}
\hline & & Frequency & Percent & Valid Percent & $\begin{array}{c}\text { Cumulative } \\
\text { Percent }\end{array}$ \\
\hline \multirow[t]{6}{*}{ Valid } & Very comfortable & 18 & 60.0 & 60.0 & 60.0 \\
\hline & Somewhat comfortabl & 4 & 13.3 & 13.3 & 73.3 \\
\hline & Not very Comfortable & 3 & 10.0 & 10.0 & 83.3 \\
\hline & Not Comfortable & 2 & 6.7 & 6.7 & 90.0 \\
\hline & I don't know & 3 & 10.0 & 10.0 & 100.0 \\
\hline & Total & 30 & 100.0 & 100.0 & \\
\hline
\end{tabular}

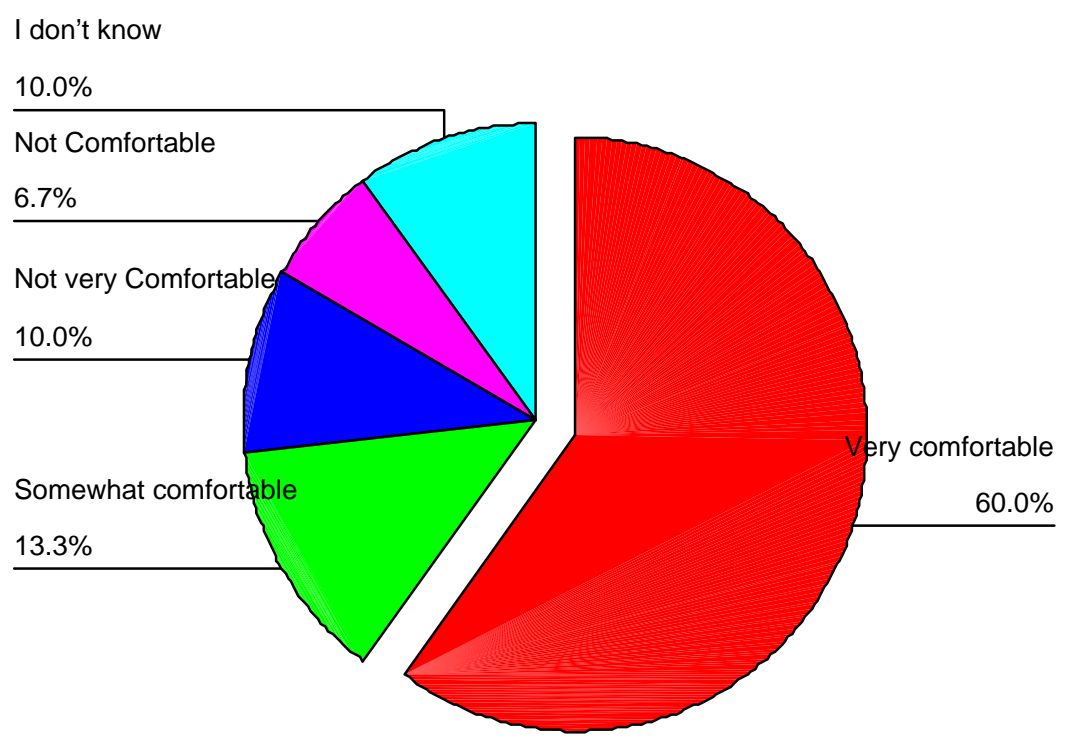

Figure A.25. Instructors' ranking to voice recognition according to its level of comfortability 
Table A.52

Instructors' Ranking to Signature Dynamic According to its Level of Comfortability

\begin{tabular}{|c|c|c|c|c|c|}
\hline & & Frequency & Percent & Valid Percent & $\begin{array}{c}\text { Cumulative } \\
\text { Percent }\end{array}$ \\
\hline \multirow[t]{6}{*}{$\overline{\text { Valid }}$} & Very comfortable & 20 & 66.7 & 66.7 & 66.7 \\
\hline & Somewhat comfortab & 3 & 10.0 & 10.0 & 76.7 \\
\hline & Not very Comfortable & 2 & 6.7 & 6.7 & 83.3 \\
\hline & Not Comfortable & 1 & 3.3 & 3.3 & 86.7 \\
\hline & I don't know & 4 & 13.3 & 13.3 & 100.0 \\
\hline & Total & 30 & 100.0 & 100.0 & \\
\hline
\end{tabular}

I don't know

$13.3 \%$

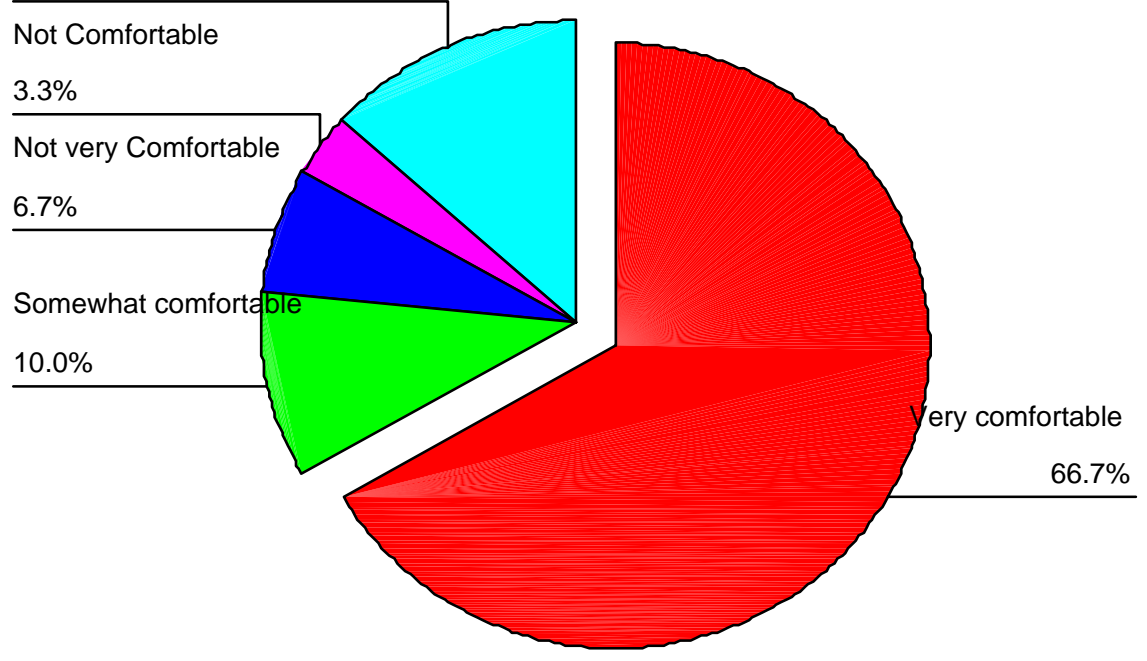

Figure A.26. Instructors' ranking to signature dynamic according to its level of comfortability 


\section{APPENDIX B}

Frequency tables and Figures related to the Research Question 2(RQ2)

\section{Students’ Group}


Table B.1

Students' majors

\begin{tabular}{|c|c|c|c|c|c|}
\hline & & Frequency & Percent & Valid Percent & $\begin{array}{l}\text { Cumulative } \\
\text { Percent }\end{array}$ \\
\hline \multirow[t]{13}{*}{ Valid } & Counseling & 2 & 1.1 & 1.1 & 1.1 \\
\hline & Counseling Psychology & 8 & 4.2 & 4.2 & 5.3 \\
\hline & Curriculum \& Instruction & 33 & 17.5 & 17.5 & 22.8 \\
\hline & Educational Leadership & 9 & 4.8 & 4.8 & 27.5 \\
\hline & Educational Psychology & 6 & 3.2 & 3.2 & 30.7 \\
\hline & Elementary Education & 13 & 6.9 & 6.9 & 37.6 \\
\hline & Reading & 15 & 7.9 & 7.9 & 45.5 \\
\hline & Secondary Education & 17 & 9.0 & 9.0 & 54.5 \\
\hline & Special Education & 41 & 21.7 & 21.7 & 76.2 \\
\hline & $\begin{array}{l}\text { Speech Pathology \& } \\
\text { Audiology }\end{array}$ & 12 & 6.3 & 6.3 & 82.5 \\
\hline & Technology Education & 17 & 9.0 & 9.0 & 91.5 \\
\hline & Other & 16 & 8.5 & 8.5 & 100.0 \\
\hline & Total & 189 & 100.0 & 100.0 & \\
\hline
\end{tabular}

Table B.2

Students gender distribution

\begin{tabular}{|c|c|c|c|c|c|}
\hline & & Frequency & Percent & Valid Percent & $\begin{array}{c}\text { Cumulative } \\
\text { Percent }\end{array}$ \\
\hline \multirow[t]{3}{*}{ Valid } & Male & 58 & 30.7 & 30.7 & 30.7 \\
\hline & Female & 131 & 69.3 & 69.3 & 100.0 \\
\hline & Total & 189 & 100.0 & 100.0 & \\
\hline
\end{tabular}


Table B.3

Students' Age Distribution

\begin{tabular}{|c|c|c|c|c|c|}
\hline & & Frequency & Percent & Valid Percent & $\begin{array}{l}\text { Cumulative } \\
\text { Percent }\end{array}$ \\
\hline \multirow[t]{6}{*}{ Valid } & $21-25$ & 68 & 36.0 & 36.0 & 36.0 \\
\hline & $26-30$ & 42 & 22.2 & 22.2 & 58.2 \\
\hline & $31-35$ & 22 & 11.6 & 11.6 & 69.8 \\
\hline & $36-40$ & 15 & 7.9 & 7.9 & 77.8 \\
\hline & 41 - above & 42 & 22.2 & 22.2 & 100.0 \\
\hline & Total & 189 & 100.0 & 100.0 & \\
\hline
\end{tabular}

Table B.4

Students' Race/Ethnicity

\begin{tabular}{|ll|r|r|r|r|}
\hline & & & & \multicolumn{2}{c|}{$\begin{array}{c}\text { Cumulative } \\
\text { Percent }\end{array}$} \\
\hline Valid & African American & 3 & 1.6 & 1.6 & 1.6 \\
& Asian/ Pacific Islander & 4 & 2.1 & 2.2 & 3.8 \\
& Hispanic & 3 & 1.6 & 1.6 & 5.5 \\
& Native American / & 1 & .5 & .5 & 6.0 \\
& American Indian & 172 & 91.0 & 94.0 & 100.0 \\
& White/non-Hispanic & 183 & 96.8 & 100.0 & \\
Missing & Total & 6 & 3.2 & & \\
Total & System & 189 & 100.0 & & \\
\hline
\end{tabular}


Table B.5

Students' Religion distribution

\begin{tabular}{|ll|r|r|r|r|}
\hline & & & & \multicolumn{2}{c|}{$\begin{array}{c}\text { Cumulative } \\
\text { Percent }\end{array}$} \\
\hline Valid & Atheist & 7 & 3.7 & Valid Percent & 4.0 \\
& Buddhist & 1 & .5 & .6 & 4.5 \\
& Christian & 161 & 85.2 & 91.0 & 95.5 \\
& Hindu & 1 & .5 & .6 & 96.0 \\
& Jewish & 2 & 1.1 & 1.1 & 97.2 \\
& Muslim & 5 & 2.6 & 2.8 & 100.0 \\
& Total & 177 & 93.7 & 100.0 & \\
Missing & System & 12 & 6.3 & & \\
Total & & 189 & 100.0 & & \\
\hline
\end{tabular}

Tables Frequencies for Students responses to questions related to using biometric technology at different locations.

Table B.6

Statistics

\begin{tabular}{|c|c|c|c|c|c|c|c|c|}
\hline & & $\begin{array}{l}\text {.1) Have you } \\
\text { ver used it in } \\
\text { Check all tha } \\
\text { apply): } \\
\text { - School }\end{array}$ & $\begin{array}{l}\text {.2) Have you } \\
\text { ever used it in } \\
\text { Check all tha } \\
\text { apply): } \\
\text { - Airport }\end{array}$ & $\begin{array}{l}\text {.3) Have you } \\
\text { ever used it in } \\
\text { Check all tha } \\
\text { apply): } \\
\text { - Bank }\end{array}$ & $\begin{array}{l}\text {.4) Have you } \\
\text { ever used it ire } \\
\text { Check all tha } \\
\text { apply): } \\
\text { - ATM }\end{array}$ & $\begin{array}{l}\text { 7.5) Have you } \\
\text { ever used it in } \\
\text { Check all tha } \\
\text { apply): } \\
\text { - Hospital }\end{array}$ & $\begin{array}{l}\text { 7.6) Have you } \\
\text { Cver used it in } \\
\text { Check all tha } \\
\text { apply): } \\
\text { - Federal } \\
\text { Building }\end{array}$ & $\begin{array}{l}\text { 7) Have you } \\
\text { Cher used it in } \\
\text { apply): } \\
\text { - Other } \\
\text { (Please } \\
\text { Specify) }\end{array}$ \\
\hline \multirow[t]{2}{*}{$\mathrm{N}$} & Valid & 25 & 9 & 25 & 11 & 7 & 11 & 29 \\
\hline & Missing & 164 & 180 & 164 & 178 & 182 & 178 & 160 \\
\hline \multicolumn{2}{|c|}{ Mean } & 1.00 & 2.00 & 3.00 & 4.00 & 5.00 & 6.00 & 7.00 \\
\hline \multicolumn{2}{|c|}{ Median } & 1.00 & 2.00 & 3.00 & 4.00 & 5.00 & 6.00 & 7.00 \\
\hline \multicolumn{2}{|c|}{ Mode } & 1 & 2 & 3 & 4 & 5 & 6 & 7 \\
\hline \multicolumn{2}{|c|}{ Std. Deviation } & .000 & .000 & .000 & .000 & .000 & .000 & .000 \\
\hline \multicolumn{2}{|c|}{ Variance } & .000 & .000 & .000 & .000 & .000 & .000 & .000 \\
\hline
\end{tabular}


Frequency Tables B.7- B.13

7.1) Have you ever used it in (Check all that apply):

- School

\begin{tabular}{|ll|r|r|r|c|}
\hline & & & & & Cumulative \\
& & Frequency & Percent & Valid Percent & Percent \\
\hline Valid & 1 & 25 & 13.2 & 100.0 & 100.0 \\
Missing & System & 164 & 86.8 & & \\
Total & 189 & 100.0 & & \\
\hline
\end{tabular}

7.2) Have you ever used it in (Check all that apply):

- Airport

\begin{tabular}{|ll|r|r|r|c|}
\hline & & Frequency & Percent & Valid Percent & $\begin{array}{c}\text { Cumulative } \\
\text { Percent }\end{array}$ \\
\hline Valid & 2 & 9 & 4.8 & 100.0 & 100.0 \\
Missing & System & 180 & 95.2 & & \\
Total & 189 & 100.0 & & \\
\hline
\end{tabular}

7.3) Have you ever used it in (Check all that apply):

- Bank

\begin{tabular}{|ll|r|r|r|c|}
\hline & & & & & Cumulative \\
Valid & 3 & 25 & 13.2 & 100.0 & 100.0 \\
Missing & System & 164 & 86.8 & & \\
Total & 189 & 100.0 & & \\
\hline
\end{tabular}

7.4) Have you ever used it in (Check all that apply):

- ATM

\begin{tabular}{|ll|r|r|r|c|}
\hline & & & & & Cumulative \\
Valid & 4 & 11 & 5.8 & 100.0 & 100.0 \\
Missing & System & 178 & 94.2 & & \\
Total & 189 & 100.0 & & \\
\hline
\end{tabular}

7.5) Have you ever used it in (Check all that apply):

- Hospital

\begin{tabular}{|ll|r|r|r|r|}
\hline & & Frequency & Percent & Valid Percent & $\begin{array}{c}\text { Cumulative } \\
\text { Percent }\end{array}$ \\
\hline Valid & 5 & 7 & 3.7 & 100.0 & 100.0 \\
Missing & System & 182 & 96.3 & & \\
Total & 189 & 100.0 & & \\
\hline
\end{tabular}


7.6) Have you ever used it in (Check all that apply): - Federal Building

\begin{tabular}{|ll|r|r|r|r|}
\hline & & & & $\begin{array}{c}\text { Cumulative } \\
\text { Percent }\end{array}$ \\
\hline Valid & 6 & 11 & 5.8 & 100.0 & 100.0 \\
Missing & System & 178 & 94.2 & & \\
Total & & 189 & 100.0 & & \\
\hline
\end{tabular}

7.7) Have you ever used it in (Check all that apply): - Other (Please Specify)

\begin{tabular}{|c|c|c|c|c|c|}
\hline & & Frequency & Percent & Valid Percent & $\begin{array}{c}\text { Cumulative } \\
\text { Percent }\end{array}$ \\
\hline Valid & $\overline{7}$ & 29 & 15.3 & \multirow[t]{3}{*}{100.0} & \multirow[t]{3}{*}{100.0} \\
\hline Missing & System & 160 & 84.7 & & \\
\hline Total & & 189 & 100.0 & & \\
\hline
\end{tabular}


Privacy issues

Table B. 14

Students' responses to the first question about privacy

9.1) A.The privacy issues - How concerned are you about having your biometric data collected?

\begin{tabular}{|ll|r|r|r|r|}
\hline & & & & Cumulative \\
& Frequency & Percent & Valid Percent & \multicolumn{1}{c|}{ Percent } \\
\hline Valid & Very Concerned & 31 & 16.4 & 16.4 & 16.4 \\
& Somewhat Concerned & 76 & 40.2 & 40.2 & 56.6 \\
Not very Concerned & 46 & 24.3 & 24.3 & 81.0 \\
Not Concerned & 29 & 15.3 & 15.3 & 96.3 \\
I don't know & 7 & 3.7 & 3.7 & 100.0 \\
Total & 189 & 100.0 & 100.0 & \\
\hline
\end{tabular}

\section{Table B.15}

Students' responses to the second question about privacy

9.2) A.The privacy issues - How concerned are you about having your biometric data stored in non-secure storage?

\begin{tabular}{|ll|r|r|r|r|}
\hline & & & & Cumulative \\
& Frequency & Percent & Valid Percent & Percent \\
\hline Valid & Very Concerned & 122 & 64.6 & 64.6 & 64.6 \\
& Somewhat Concerned & 44 & 23.3 & 23.3 & 87.8 \\
Not very Concerned & 8 & 4.2 & 4.2 & 92.1 \\
Not Concerned & 10 & 5.3 & 5.3 & 97.4 \\
I don't know & 5 & 2.6 & 2.6 & 100.0 \\
Total & 189 & 100.0 & 100.0 & \\
\hline
\end{tabular}


Table B.16

Students' responses to the third question about privacy

9.3) A.The privacy issues - How concerned are you about having your biometric data used by third party?

\begin{tabular}{|ll|r|r|r|r|}
\hline & & & Cumulative \\
& Frequency & Percent & Valid Percent & \multicolumn{1}{c|}{ Percent } \\
\hline Valid & Very Concerned & 113 & 59.8 & 59.8 & 59.8 \\
& 51 & 27.0 & 27.0 & 86.8 \\
& Somewhat Concerned & 13 & 6.9 & 6.9 & 93.7 \\
Not very Concerned & 7 & 3.7 & 3.7 & 97.4 \\
Not Concerned & 5 & 2.6 & 2.6 & 100.0 \\
I don't know & 189 & 100.0 & 100.0 & \\
Total & &
\end{tabular}

Table B.17

Students' responses to the fourth question about privacy

9.4) A.The privacy issues - How concerned are you about having your biometric data misused by WVU?

\begin{tabular}{|ll|r|r|r|r|}
\hline & & & & \multicolumn{2}{c|}{$\begin{array}{c}\text { Cumulative } \\
\text { Percent }\end{array}$} \\
\hline Valid & Very Concerned & 91 & 48.1 & 48.1 & 48.1 \\
& Somewhat Concerned & 52 & 27.5 & 27.5 & 75.7 \\
Not very Concerned & 27 & 14.3 & 14.3 & 89.9 \\
Not Concerned & 13 & 6.9 & 6.9 & 96.8 \\
I don't know & 6 & 3.2 & 3.2 & 100.0 \\
Total & 189 & 100.0 & 100.0 & \\
\hline
\end{tabular}


Table B. 18

Students' responses to the fifth question about privacy

9.5) A.The privacy issues - How concerned are you about the invasion of your privacy by WVU, when biometric technology is implemented?

\begin{tabular}{|ll|r|r|r|r|}
\hline & & & & \multicolumn{1}{c|}{ Cumulative } \\
& Frequency & Percent & Valid Percent & \multicolumn{1}{c|}{ Percent } \\
\hline Valid & Very Concerned & 80 & 42.3 & 42.3 & 42.3 \\
& Somewhat Concerned & 60 & 31.7 & 31.7 & 74.1 \\
Not very Concerned & 30 & 15.9 & 15.9 & 89.9 \\
Not Concerned & 15 & 7.9 & 7.9 & 97.9 \\
I don't know & 4 & 2.1 & 2.1 & 100.0 \\
Total & 189 & 100.0 & 100.0 & \\
\hline
\end{tabular}

Table B.19

Students' responses to the sixth question about privacy

9.6) A.The privacy issues - How concerned are you about the negative stigma attached to the use of biometric technology?

\begin{tabular}{|ll|r|r|r|r|}
\hline & & & & Cumulative \\
& Frequency & Percent & Valid Percent & \multicolumn{2}{c|}{ Percent } \\
\hline Valid & Very Concerned & 42 & 22.2 & 22.2 & 22.2 \\
& Somewhat Concerned & 65 & 34.4 & 34.4 & 56.6 \\
& Not very Concerned & 45 & 23.8 & 23.8 & 80.4 \\
Not Concerned & 27 & 14.3 & 14.3 & 94.7 \\
I don't know & 10 & 5.3 & 5.3 & 100.0 \\
Total & 189 & 100.0 & 100.0 & \\
\hline
\end{tabular}


Table B.20

Students' ranking to fingerprint

10.1) Rank each technology according to their intrusiveness - Fingerprint

\begin{tabular}{|ll|r|r|r|r|}
\hline & & & & \multicolumn{2}{c|}{$\begin{array}{c}\text { Cumulative } \\
\text { Percent }\end{array}$} \\
\hline Valid & Frequency & Percent & Valid Percent & 39.2 \\
& Medium & 74 & 39.2 & 39.2 & 63.5 \\
& 46 & 24.3 & 24.3 & 93.7 \\
& High & 57 & 30.2 & 30.2 & 100.0 \\
I don't know & 12 & 6.3 & 6.3 & \\
Total & 189 & 100.0 & 100.0 & \\
\hline
\end{tabular}

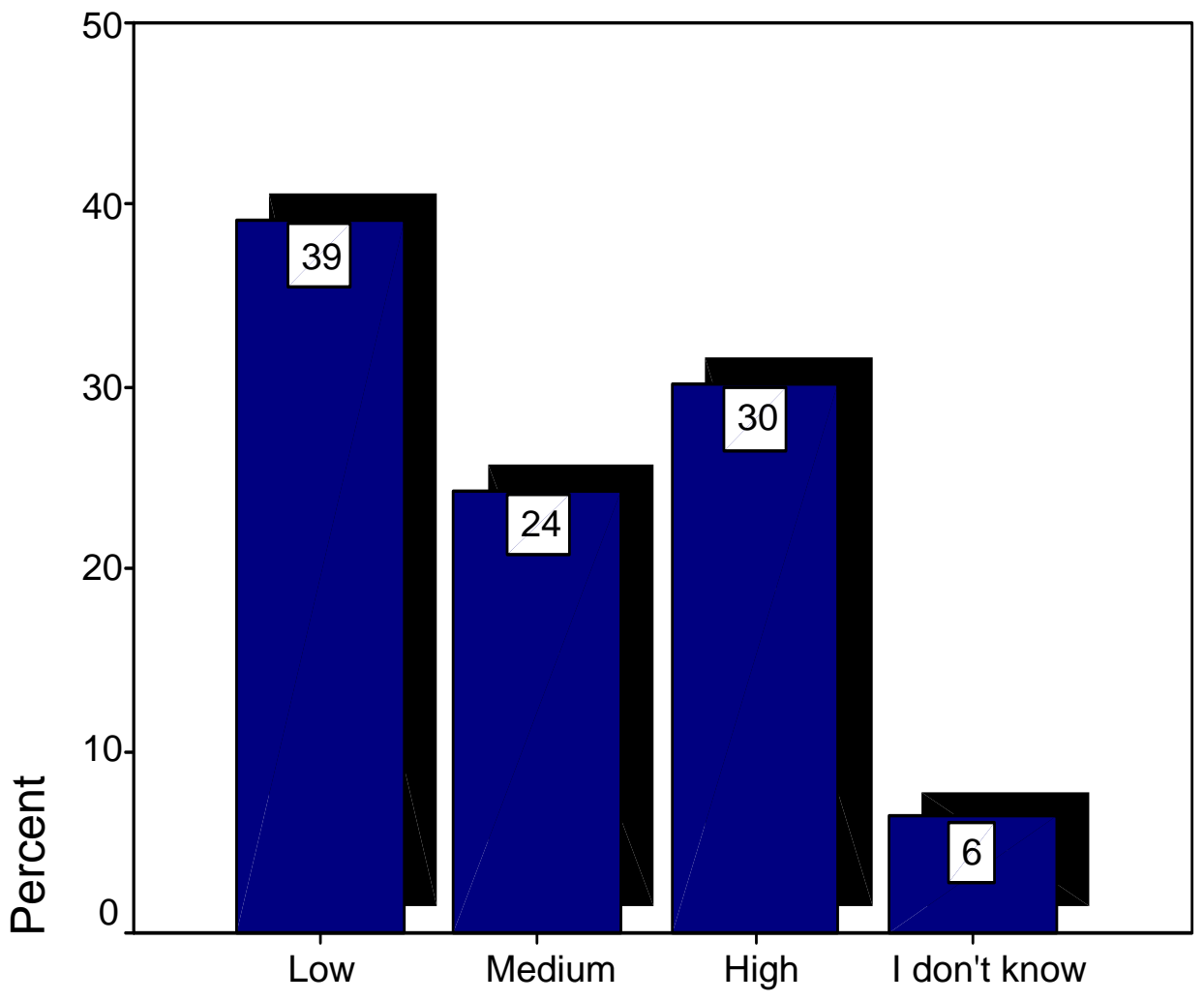

Figure B.1. Students' ranking to Fingerprint 
Table B.21

Students' ranking to Iris scan

10.2) Rank each technology according to their intrusiveness - Iris scans "eye scan"

\begin{tabular}{|ll|r|r|r|r|}
\hline & & & & \multicolumn{2}{c|}{$\begin{array}{c}\text { Cumulative } \\
\text { Percent }\end{array}$} \\
\hline Valid & Low & 21 & 11.1 & 11.1 & 11.1 \\
& Medium & 65 & 34.4 & 34.4 & 45.5 \\
& High & 88 & 46.6 & 46.6 & 92.1 \\
I don't know & 15 & 7.9 & 7.9 & 100.0 \\
Total & 189 & 100.0 & 100.0 & \\
\hline
\end{tabular}

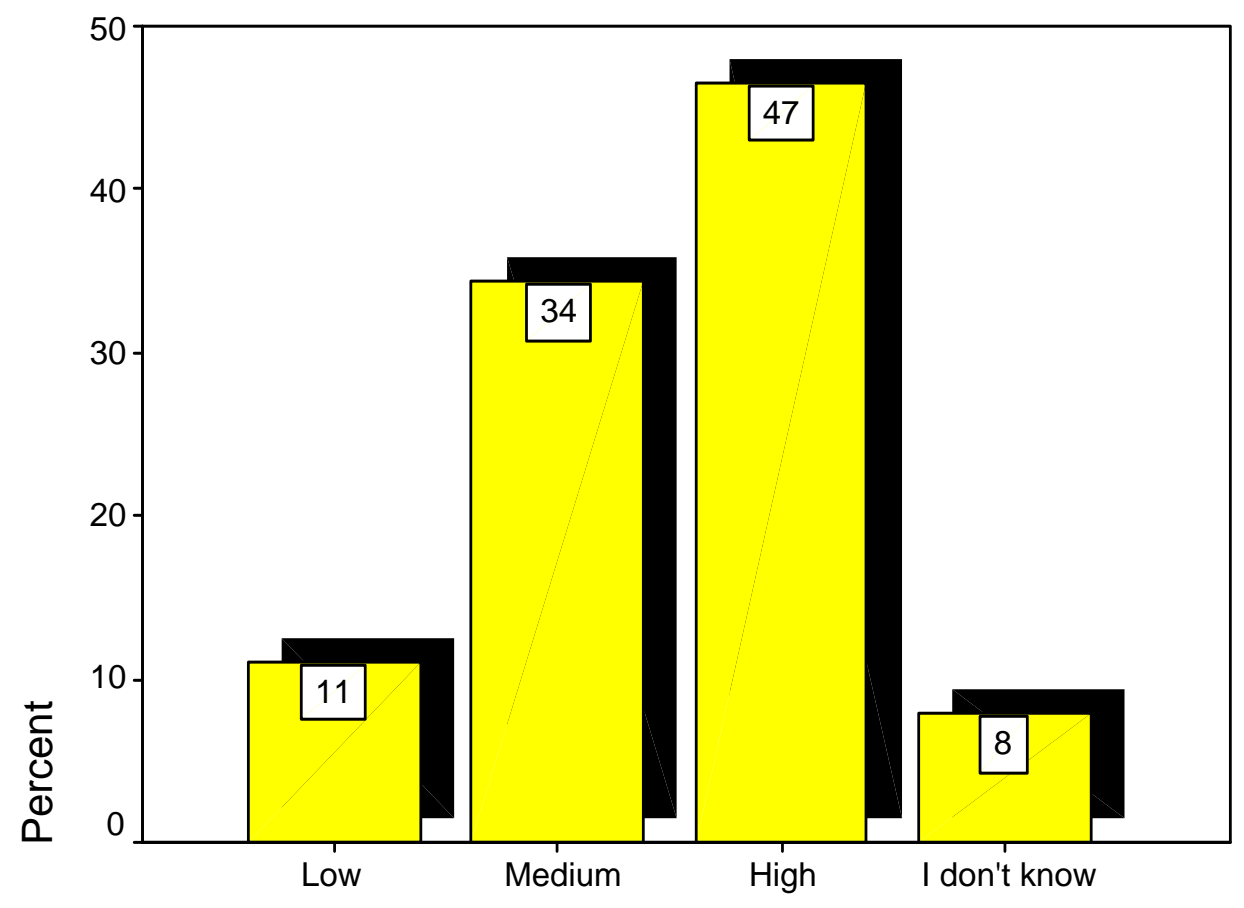

Figure B.2. Students' ranking to Iris scan 
Table B.22

Students' ranking to Facial recognition

10.3) Rank each technology according to their intrusiveness - Facial recognition

\begin{tabular}{|ll|r|r|r|r|}
\hline & & & & \multicolumn{2}{c|}{$\begin{array}{c}\text { Cumulative } \\
\text { Percent }\end{array}$} \\
\hline Valid & Frequency & Percent & Valid Percent & 20.1 \\
& Medium & 38 & 20.1 & 20.1 & 57.7 \\
& 71 & 37.6 & 37.6 & 92.6 \\
& High & 66 & 34.9 & 34.9 & 100.0 \\
I don't know & 14 & 7.4 & 7.4 & \\
Total & 189 & 100.0 & 100.0 & \\
\hline
\end{tabular}

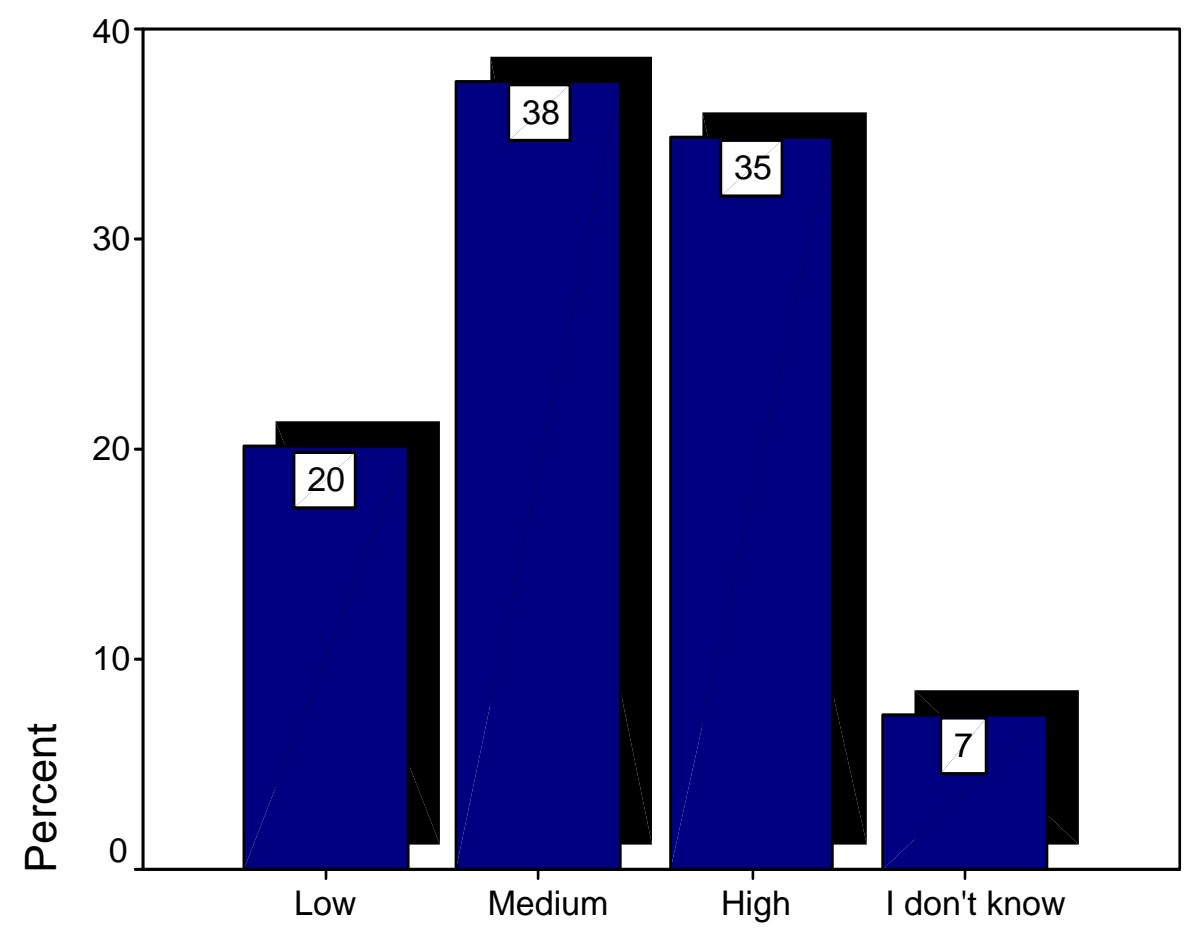

Figure B.3. Students' ranking to Facial recognition. 
Table B.23

Students' ranking to Hand geometry

10.4) Rank each technology according to their intrusiveness - Hand geometry

\begin{tabular}{|ll|r|r|r|r|}
\hline & Frequency & Percent & Valid Percent & $\begin{array}{c}\text { Cumulative } \\
\text { Percent }\end{array}$ \\
\hline Valid & Low & 56 & 29.6 & 29.6 & 29.6 \\
& Medium & 68 & 36.0 & 36.0 & 65.6 \\
High & 48 & 25.4 & 25.4 & 91.0 \\
I don't know & 17 & 9.0 & 9.0 & 100.0 \\
Total & 189 & 100.0 & 100.0 & \\
\hline
\end{tabular}

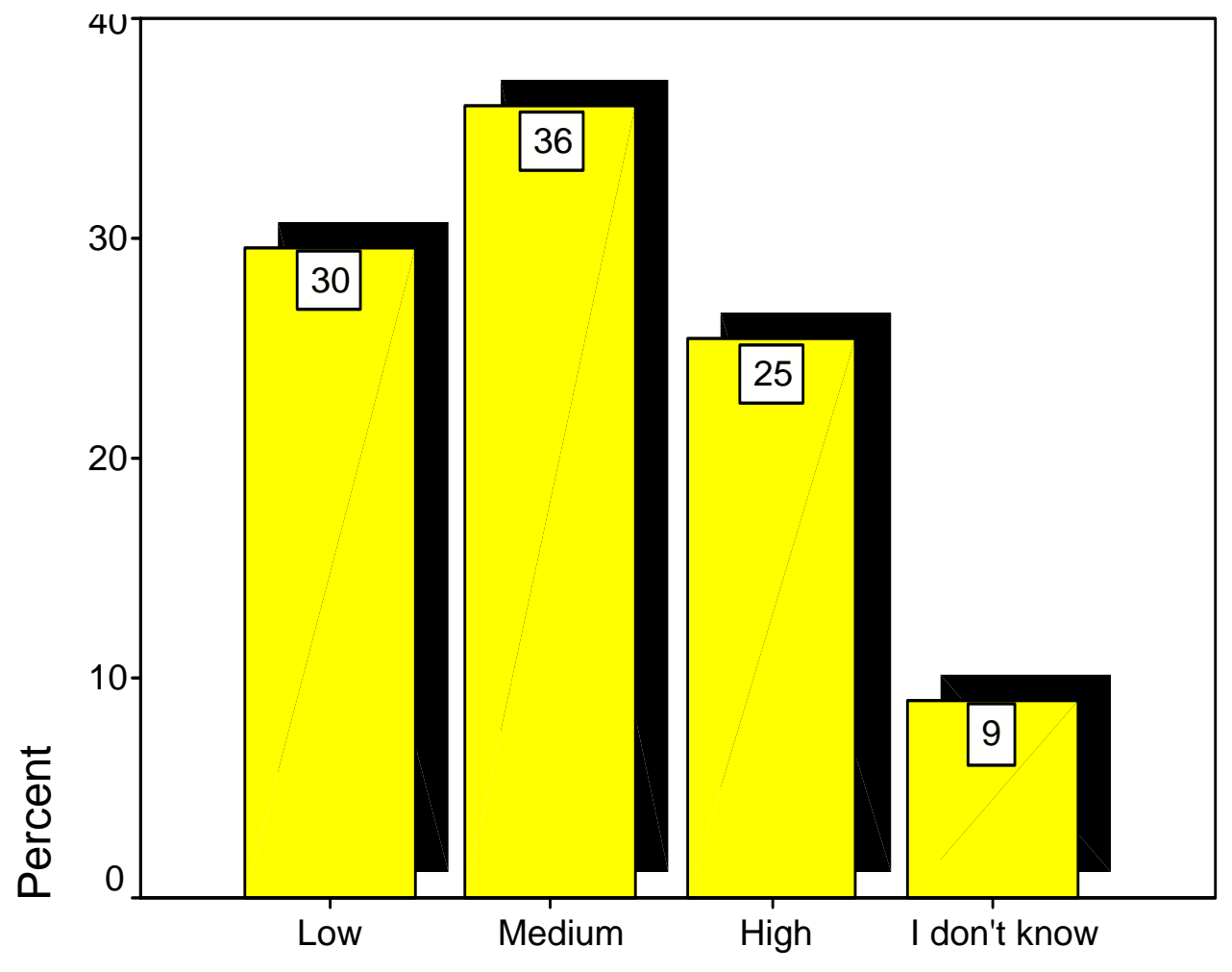

Figure B.4. Students' ranking to Hand geometry 
Table B.24

Students' ranking to Voice recognition

10.5) Rank each technology according to their intrusiveness - Voice recognition

\begin{tabular}{|ll|r|r|r|r|}
\hline & & & & \multicolumn{1}{c|}{$\begin{array}{c}\text { Cumulative } \\
\text { Percent }\end{array}$} \\
\hline Valid & Low & 51 & 27.0 & Valid Percent & 27.0 \\
& Medium & 71 & 37.6 & 37.6 & 64.6 \\
& High & 55 & 29.1 & 29.1 & 93.7 \\
& I don't know & 12 & 6.3 & 6.3 & 100.0 \\
Total & 189 & 100.0 & 100.0 & \\
\hline
\end{tabular}

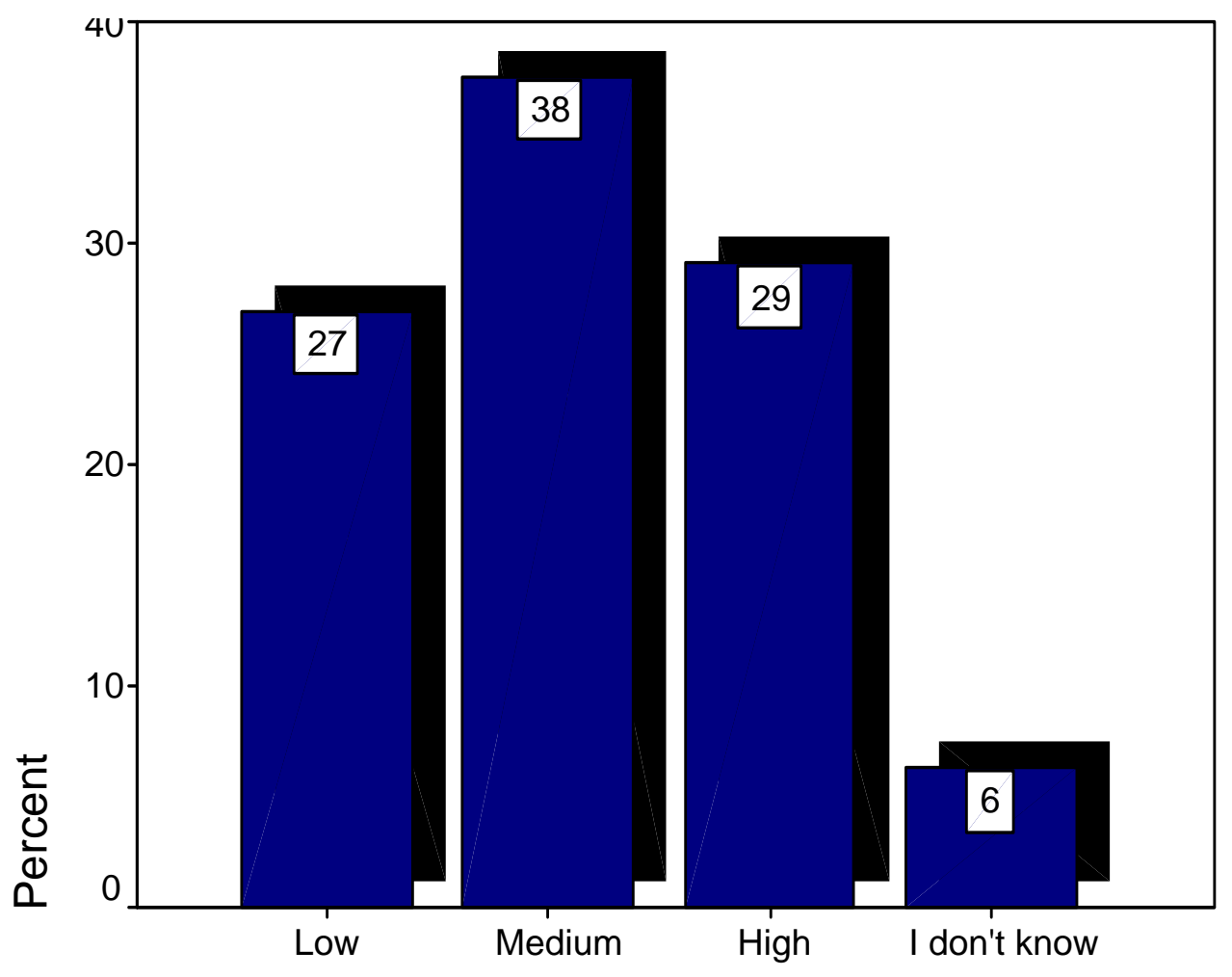

Figure B.5. Students' ranking to Voice recognition. 
Table B. 25

Students' ranking to Signature dynamic

10.6) Rank each technology according to their intrusiveness - Signature dynamic

\begin{tabular}{|c|c|c|c|c|c|}
\hline & & Frequency & Percent & Valid Percent & $\begin{array}{c}\text { Cumulative } \\
\text { Percent }\end{array}$ \\
\hline \multirow[t]{5}{*}{ Valid } & Low & 68 & 36.0 & 36.0 & 36.0 \\
\hline & Medium & 62 & 32.8 & 32.8 & 68.8 \\
\hline & High & 45 & 23.8 & 23.8 & 92.6 \\
\hline & I don't know & 14 & 7.4 & 7.4 & 100.0 \\
\hline & Total & 189 & 100.0 & 100.0 & \\
\hline
\end{tabular}

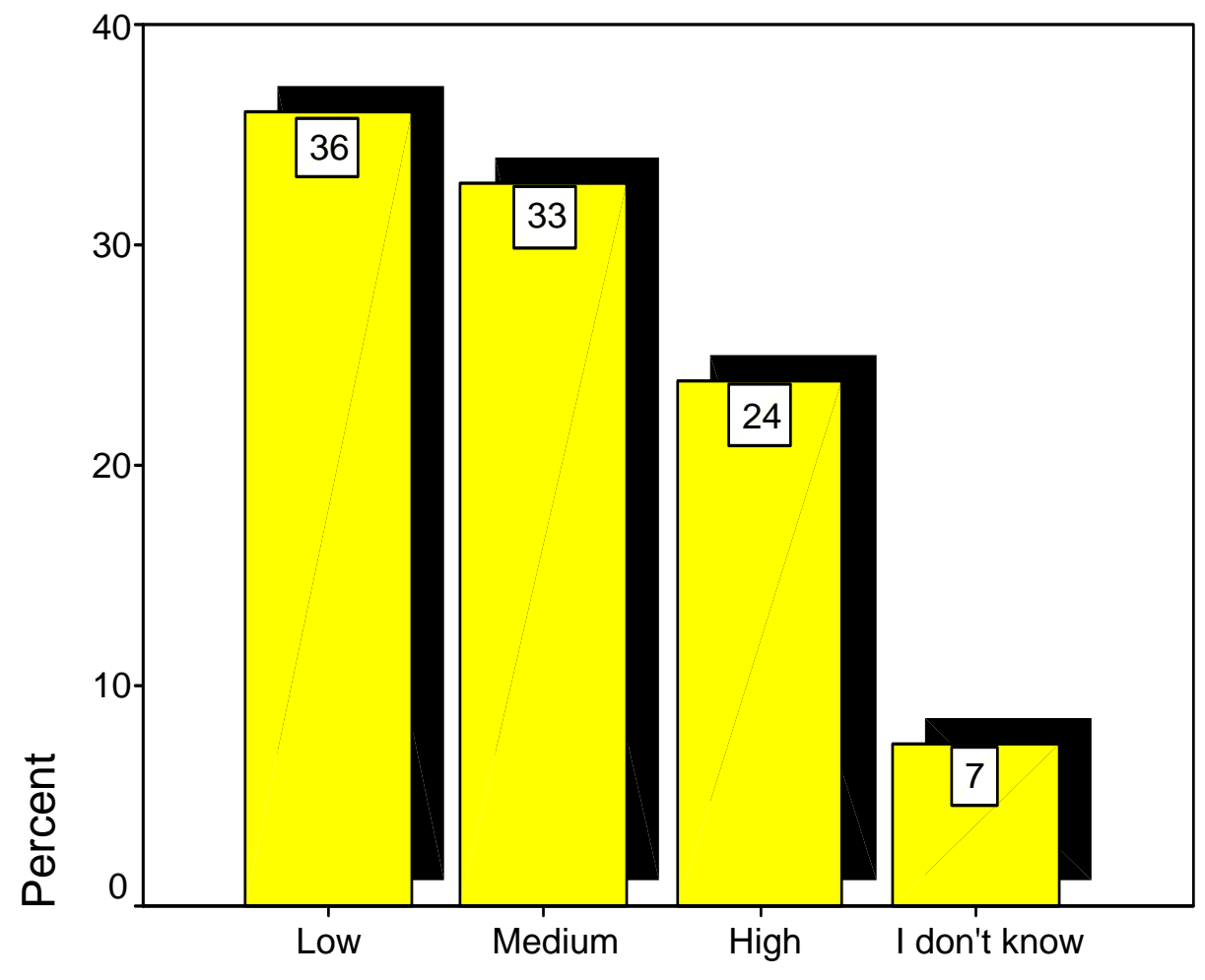

Figure B.6. Students' ranking to Signature dynamic. 
Religious issues

Table B.26

Students' responses to rank Fingerprint.

14.1) If biometric technology conflicts with your religious beliefs, please rank each technology according to your religious concerns: - Fingerprint

\begin{tabular}{|ll|r|r|r|r|}
\hline & & & & Cumulative \\
& Frequency & Percent & Valid Percent & Percent \\
\hline Valid & Low & 23 & 12.2 & 56.1 & 56.1 \\
& Medium & 2 & 1.1 & 4.9 & 61.0 \\
& High & 4 & 2.1 & 9.8 & 70.7 \\
& I don't know & 12 & 6.3 & 29.3 & 100.0 \\
& Total & 41 & 21.7 & 100.0 & \\
Missing & System & 148 & 78.3 & & \\
Total & & 189 & 100.0 & & \\
\hline
\end{tabular}

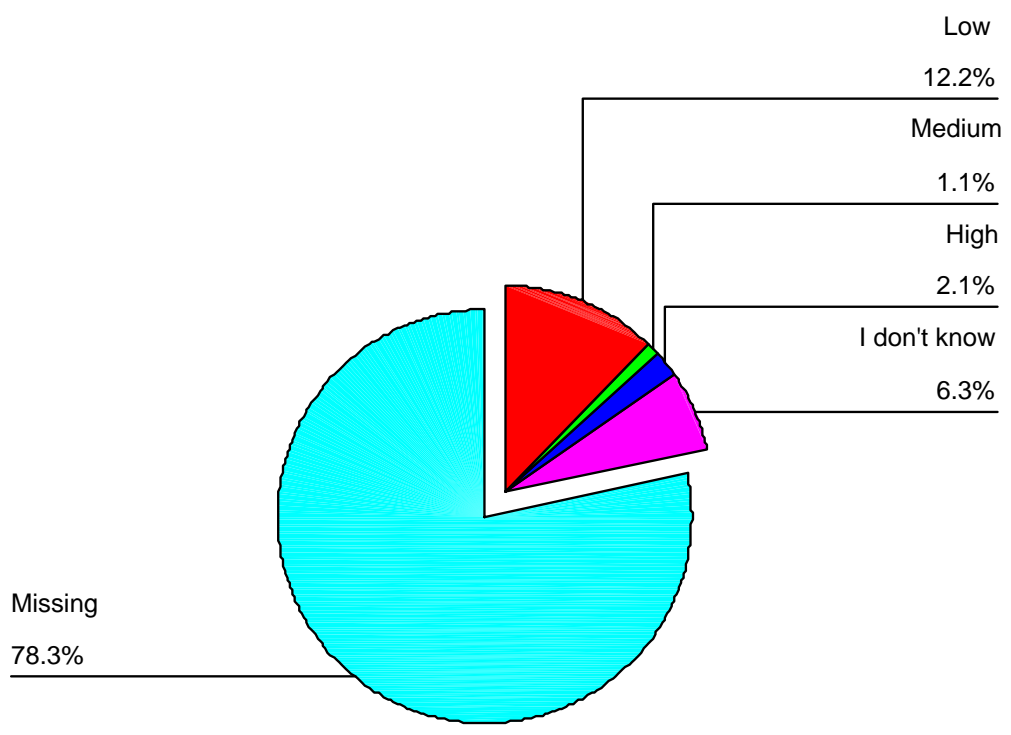

Figure B.7. Students' ranking to Fingerprint according to their religious concerns. 
Table B.27

students' ranking to Iris scan.

14.2) If biometric technology conflicts with your religious beliefs, please rank each technology according to your religious concerns: - Iris scans "eye scan"

\begin{tabular}{|ll|r|r|r|r|}
\hline & & & & \multicolumn{2}{c|}{$\begin{array}{c}\text { Cumulative } \\
\text { Percent }\end{array}$} \\
\hline Valid & Low & 16 & 8.5 & Valid Percent & 39.0 \\
& Medium & 3 & 1.6 & 7.3 & 46.3 \\
& High & 10 & 5.3 & 24.4 & 70.7 \\
& I don't know & 12 & 6.3 & 29.3 & 100.0 \\
& Total & 41 & 21.7 & 100.0 & \\
Missing & System & 148 & 78.3 & & \\
Total & & 189 & 100.0 & & \\
\hline
\end{tabular}

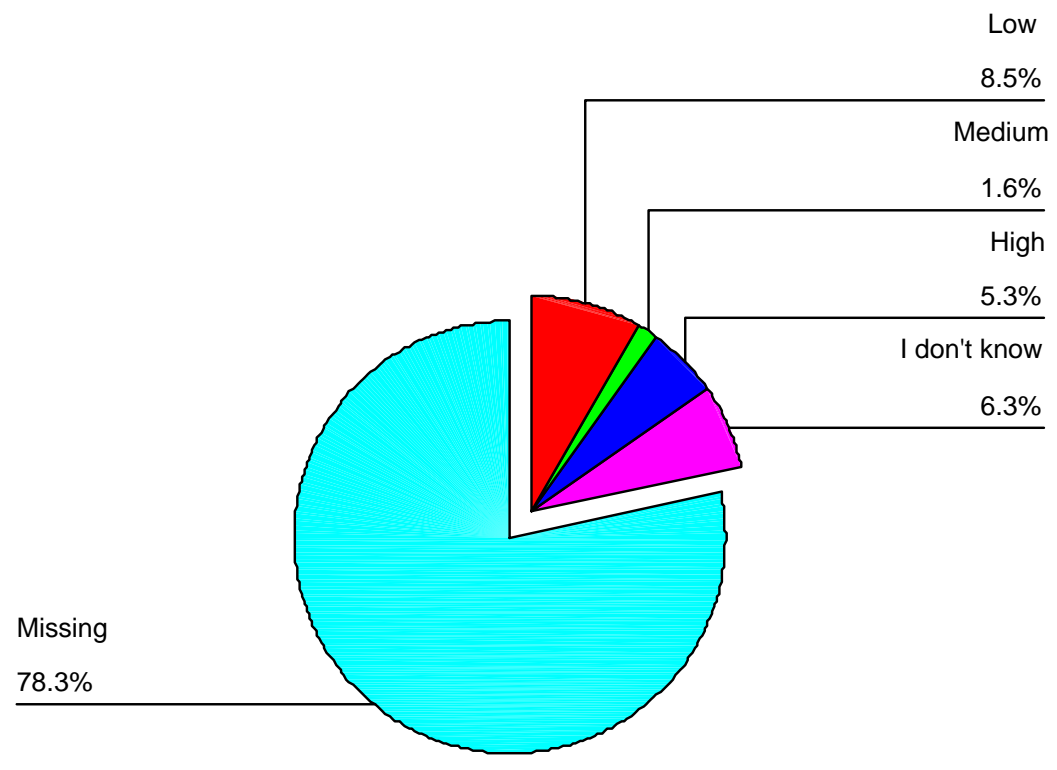

Figure B.8. Students' ranking to Iris scan according to their religious concerns. 
Table B.28

Students’ Ranking to Facial Recognition.

14.3) If biometric technology conflicts with your religious beliefs, please rank each technology according to your religious concerns: - Facial recognition

\begin{tabular}{|ll|r|r|r|r|}
\hline & & & & \multicolumn{2}{c|}{$\begin{array}{c}\text { Cumulative } \\
\text { Percent }\end{array}$} \\
\hline Valid & Low & Frequency & Percent & Valid Percent & 43.9 \\
& Medium & 5 & 9.5 & 43.9 & 56.1 \\
& High & 6 & 2.6 & 12.2 & 70.7 \\
& I don't know & 3.2 & 14.6 & 100.0 \\
& Total & 12 & 6.3 & 29.3 & \\
Missing & System & 14 & 21.7 & 100.0 & \\
Total & 148 & 78.3 & & \\
\hline
\end{tabular}

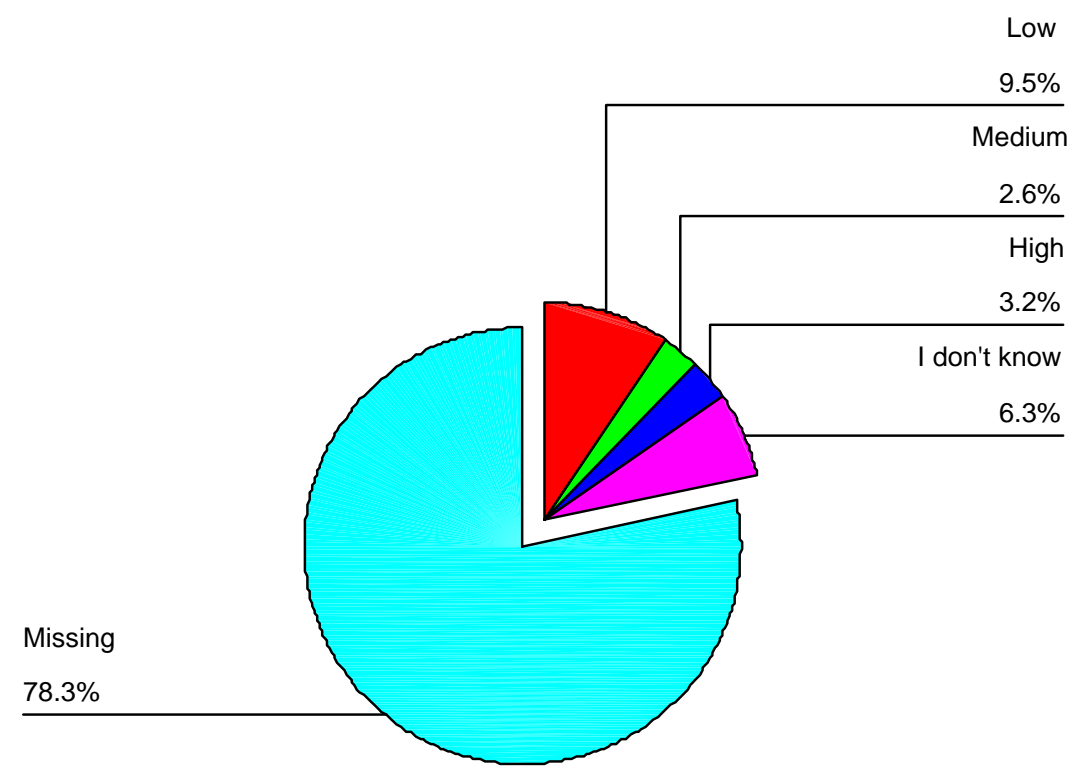

Figure B.9. Students' ranking to Facial recognition according to their religious concerns. 
Table B.29

Students' ranking to Hand geometry

14.4) If biometric technology conflicts with your religious beliefs, please rank each technology according to your religious concerns: - Hand geometry

\begin{tabular}{|ll|r|r|r|r|}
\hline & & & & \multicolumn{2}{c|}{$\begin{array}{c}\text { Cumulative } \\
\text { Percent }\end{array}$} \\
\hline Valid & Low & 18 & 9.5 & Valid Percent & 43.9 \\
& Medium & 5 & 2.6 & 12.2 & 53.9 \\
& High & 7 & 3.7 & 17.1 & 73.2 \\
& I don't know & 11 & 5.8 & 26.8 & 100.0 \\
& Total & 41 & 21.7 & 100.0 & \\
Missing & System & 148 & 78.3 & & \\
Total & & 189 & 100.0 & & \\
\hline
\end{tabular}

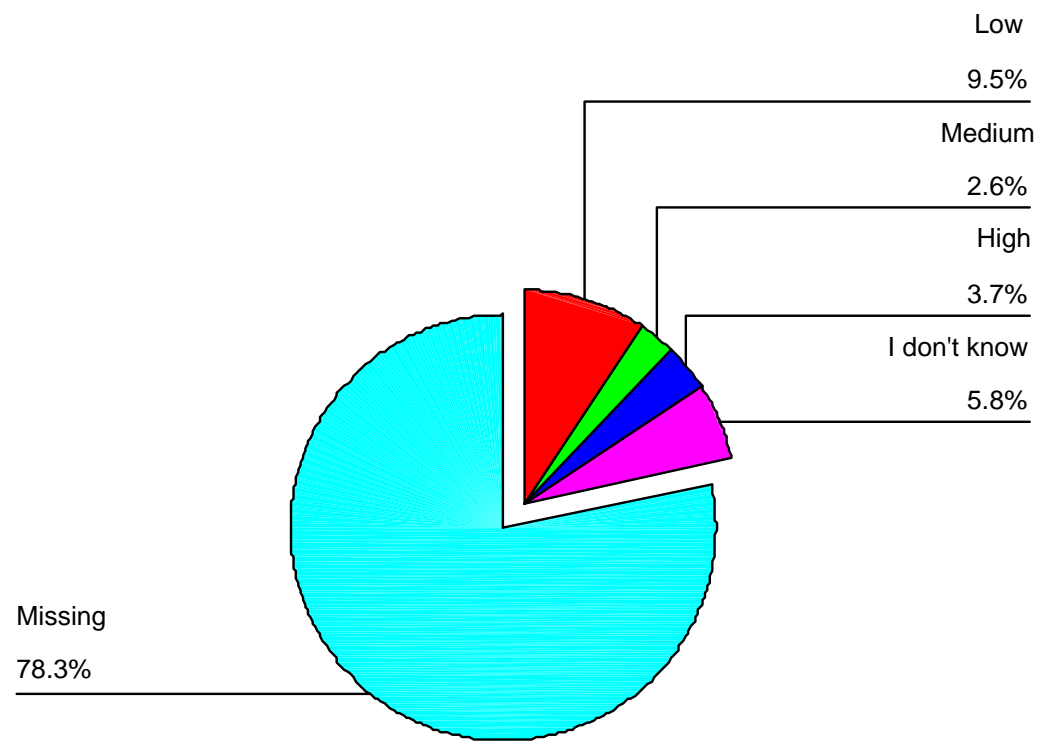

Figure B.10. Students' ranking to Hand geometry according to their religious concerns. 
Table B.30

Students' ranking to voice recognition

14.5) If biometric technology conflicts with your religious beliefs, please rank each technology according to your religious concerns: - Voice recognition

\begin{tabular}{|ll|r|r|r|r|}
\hline & & & & \multicolumn{2}{c|}{$\begin{array}{c}\text { Cumulative } \\
\text { Percent }\end{array}$} \\
\hline Valid & Low & Frequency & Percent & Valid Percent & 45.0 \\
& Medium & 18 & 9.5 & 45.0 & 65.0 \\
& High & 2 & 4.2 & 20.0 & 70.0 \\
& I don't know & 12 & 5.1 & 30.0 & 100.0 \\
& Total & 40 & 21.2 & 100.0 & \\
Missing & System & 149 & 78.8 & & \\
Total & & 189 & 100.0 & & \\
\hline
\end{tabular}

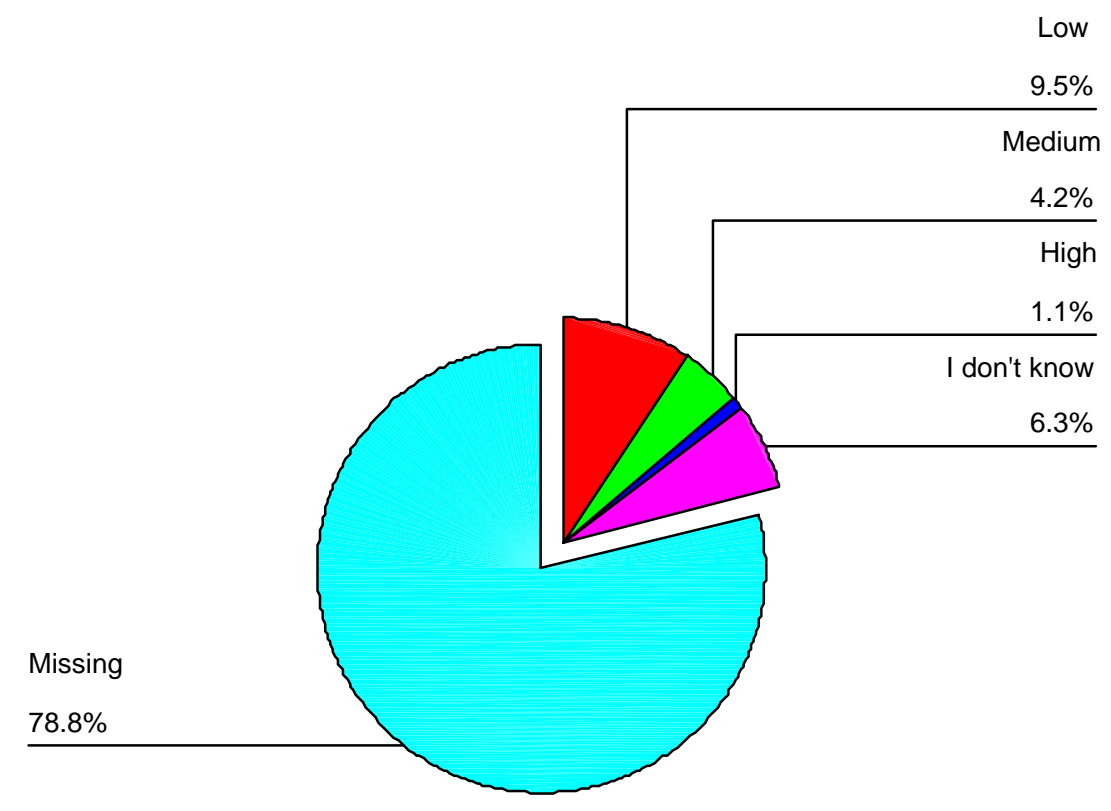

Figure B.11. Students' ranking to Voice recognition according to their religious concerns. 
Table B.31

Students' ranking to signature dynamic

14.6) If biometric technology conflicts with your religious beliefs, please rank each technology according to your religious concerns: - Signature dynamic

\begin{tabular}{|ll|r|r|r|r|}
\hline & & & & \multicolumn{1}{c|}{$\begin{array}{c}\text { Cumulative } \\
\text { Percent }\end{array}$} \\
\hline Valid & Low & 20 & 10.6 & 48.8 & 48.8 \\
& Medium & 5 & 2.6 & 12.2 & 61.0 \\
& High & 4 & 2.1 & 9.8 & 70.7 \\
& I don't know & 12 & 6.3 & 29.3 & 100.0 \\
& Total & 41 & 21.7 & 100.0 & \\
Missing & System & 148 & 78.3 & & \\
Total & & 189 & 100.0 & & \\
\hline
\end{tabular}

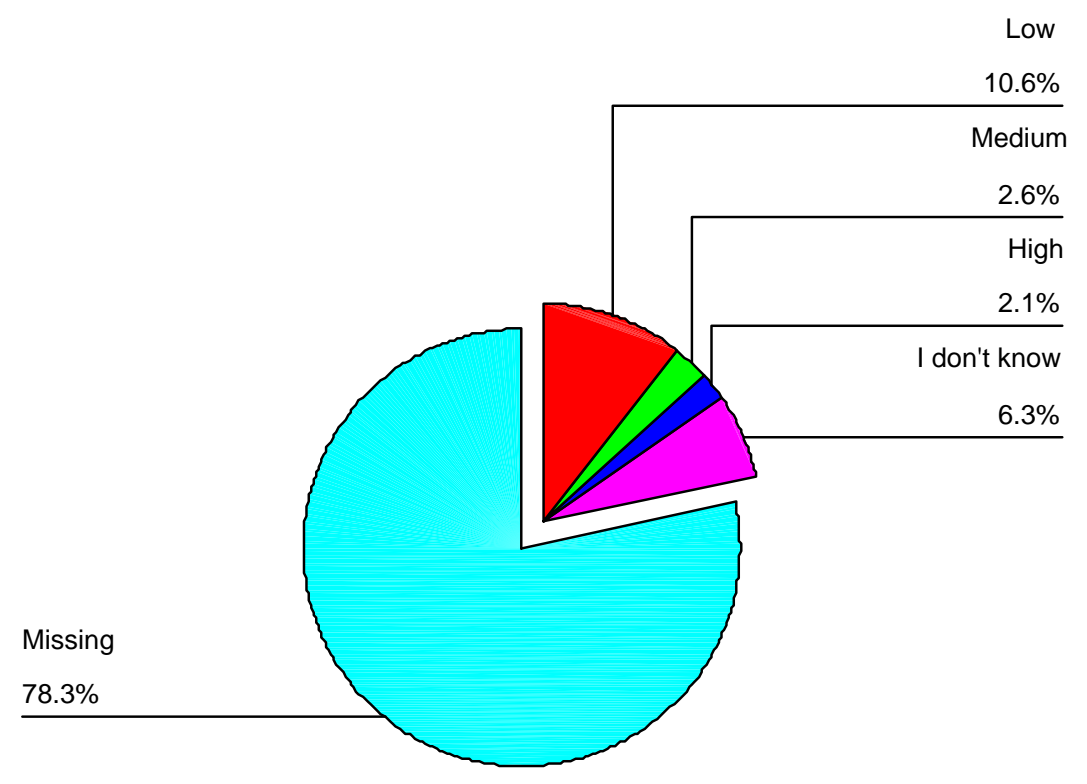

Figure B.12. Students' ranking to Signature dynamic according to their religious concerns. 
Health issues

Table B.32

Students' ranking to fingerprint

16.1) Rank each technology according to your health concerns: - Fingerprint

\begin{tabular}{|ll|r|r|r|r|}
\hline & & & & $\begin{array}{c}\text { Cumulative } \\
\text { Percent }\end{array}$ \\
\hline Valid & Low & 131 & 69.3 & 69.3 & 69.3 \\
& Medium & 32 & 16.9 & 16.9 & 86.2 \\
& High & 4.8 & 4.8 & 91.0 \\
I don't know & 17 & 9.0 & 9.0 & 100.0 \\
Total & 189 & 100.0 & 100.0 & \\
\hline
\end{tabular}

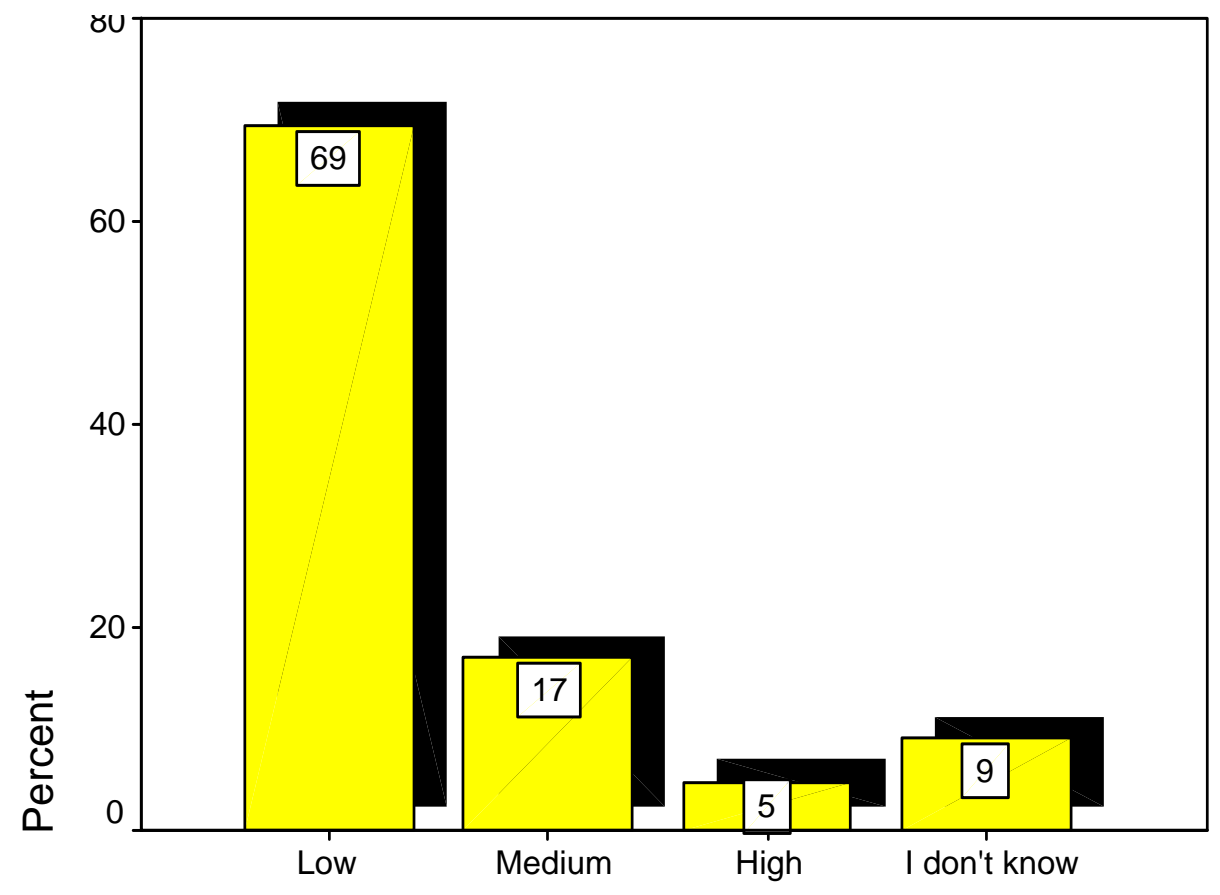

Figure B.13. Students' ranking of Fingerprint. 
Table B.33

Students' ranking to Iris scan

16.2) Rank each technology according to your health concerns: - Iris scans "eye scan"

\begin{tabular}{|ll|r|r|r|r|}
\hline & & & & \multicolumn{2}{c|}{$\begin{array}{c}\text { Cumulative } \\
\text { Percent }\end{array}$} \\
\hline Valid & Frequency & Percent & Valid Percent & 27.0 \\
& Medium & 51 & 27.0 & 27.0 & 56.1 \\
& 55 & 29.1 & 29.1 & 88.9 \\
& High & 32.8 & 32.8 & 100.0 \\
I don't know & 21 & 11.1 & 11.1 & \\
Total & 189 & 100.0 & 100.0 & \\
\hline
\end{tabular}

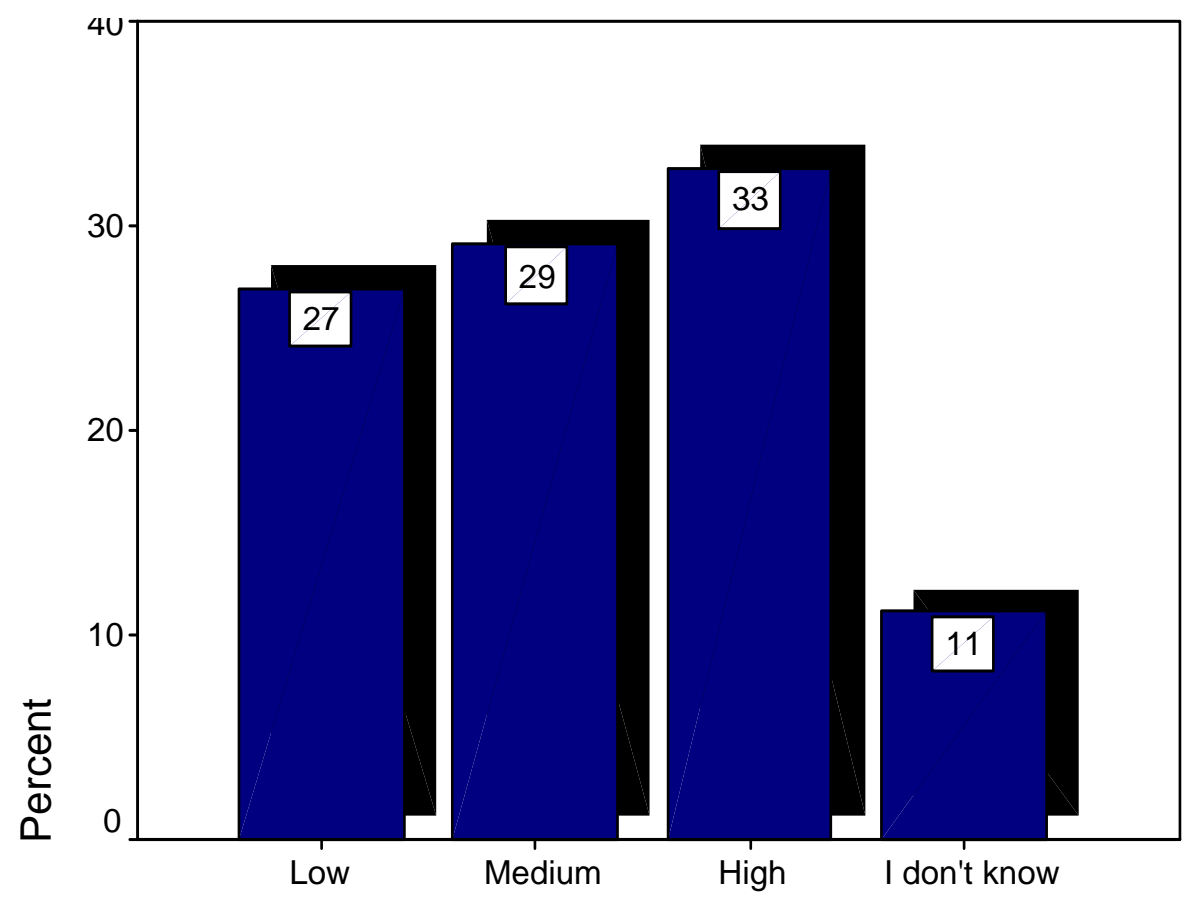

Figure B.14. Students' ranking of Iris scan. 
Table B.34

Students' ranking to Facial recognition

16.3) Rank each technology according to your health concerns: - Facial recognition

\begin{tabular}{|ll|r|r|r|r|}
\hline & & & & \multicolumn{1}{c|}{$\begin{array}{c}\text { Cumulative } \\
\text { Percent }\end{array}$} \\
\hline Valid & Low & 94 & 49.7 & 49.7 & 49.7 \\
& Medium & 43 & 22.8 & 22.8 & 72.5 \\
& High & 30 & 15.9 & 15.9 & 88.4 \\
I don't know & 22 & 11.6 & 11.6 & 100.0 \\
Total & 189 & 100.0 & 100.0 & \\
\hline
\end{tabular}

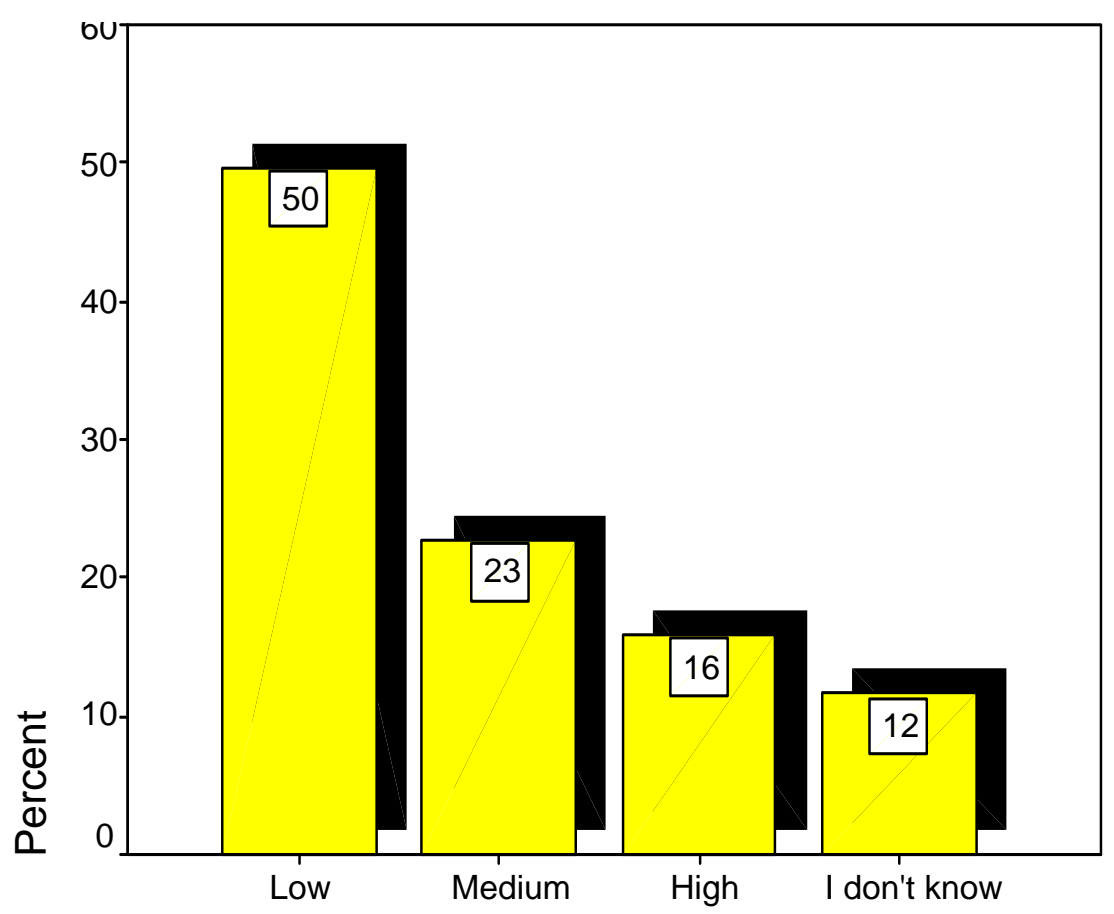

Figure B.15. Students' ranking of Facial recognition. 
Table B.35

Students' ranking to Hand geometry

16.4) Rank each technology according to your health concerns: - Hand geometry

\begin{tabular}{|ll|r|r|r|r|}
\hline & & & & \multicolumn{1}{c|}{$\begin{array}{c}\text { Cumulative } \\
\text { Percent }\end{array}$} \\
\hline Valid & Low & 105 & 55.6 & 55.6 & 55.6 \\
& Medium & 43 & 22.8 & 22.8 & 78.3 \\
& High & 9.0 & 9.0 & 87.3 \\
& 17 & 12.7 & 12.7 & 100.0 \\
& I don't know & 24 & 100.0 & \\
\hline
\end{tabular}

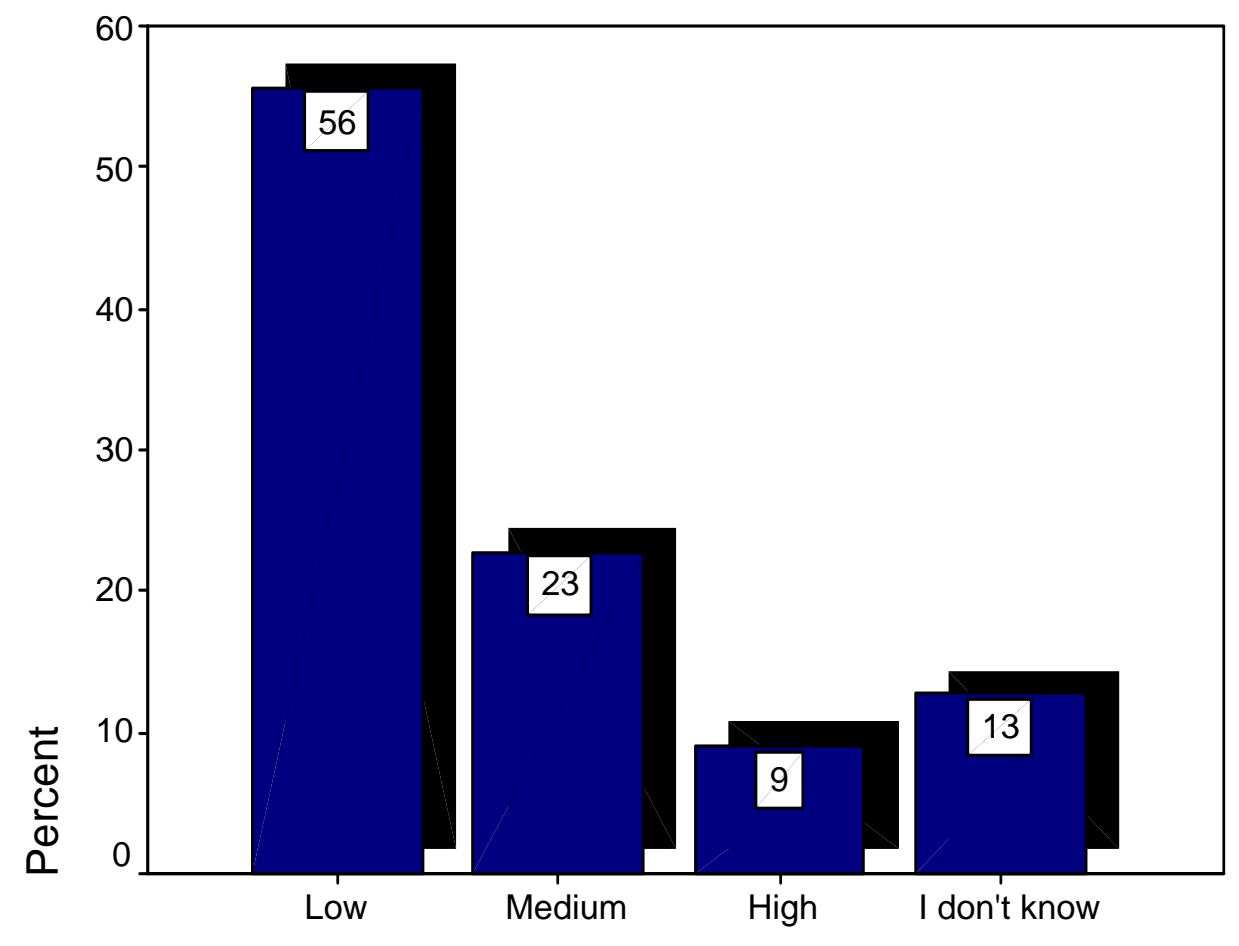

Figure B.16. Students' ranking of Hand geometry. 
Table B.36

Students' ranking to Voice recognition

16.5) Rank each technology according to your health concerns: - Voice recognition

\begin{tabular}{|ll|r|r|r|r|}
\hline & & & & \multicolumn{1}{c|}{$\begin{array}{c}\text { Cumulative } \\
\text { Percent }\end{array}$} \\
\hline Valid & Low & 124 & 65.6 & 65.6 & 65.6 \\
& Medium & 36 & 19.0 & 19.0 & 84.7 \\
& High & 10 & 5.3 & 5.3 & 89.9 \\
I don't know & 19 & 10.1 & 10.1 & 100.0 \\
Total & 189 & 100.0 & 100.0 & \\
\hline
\end{tabular}

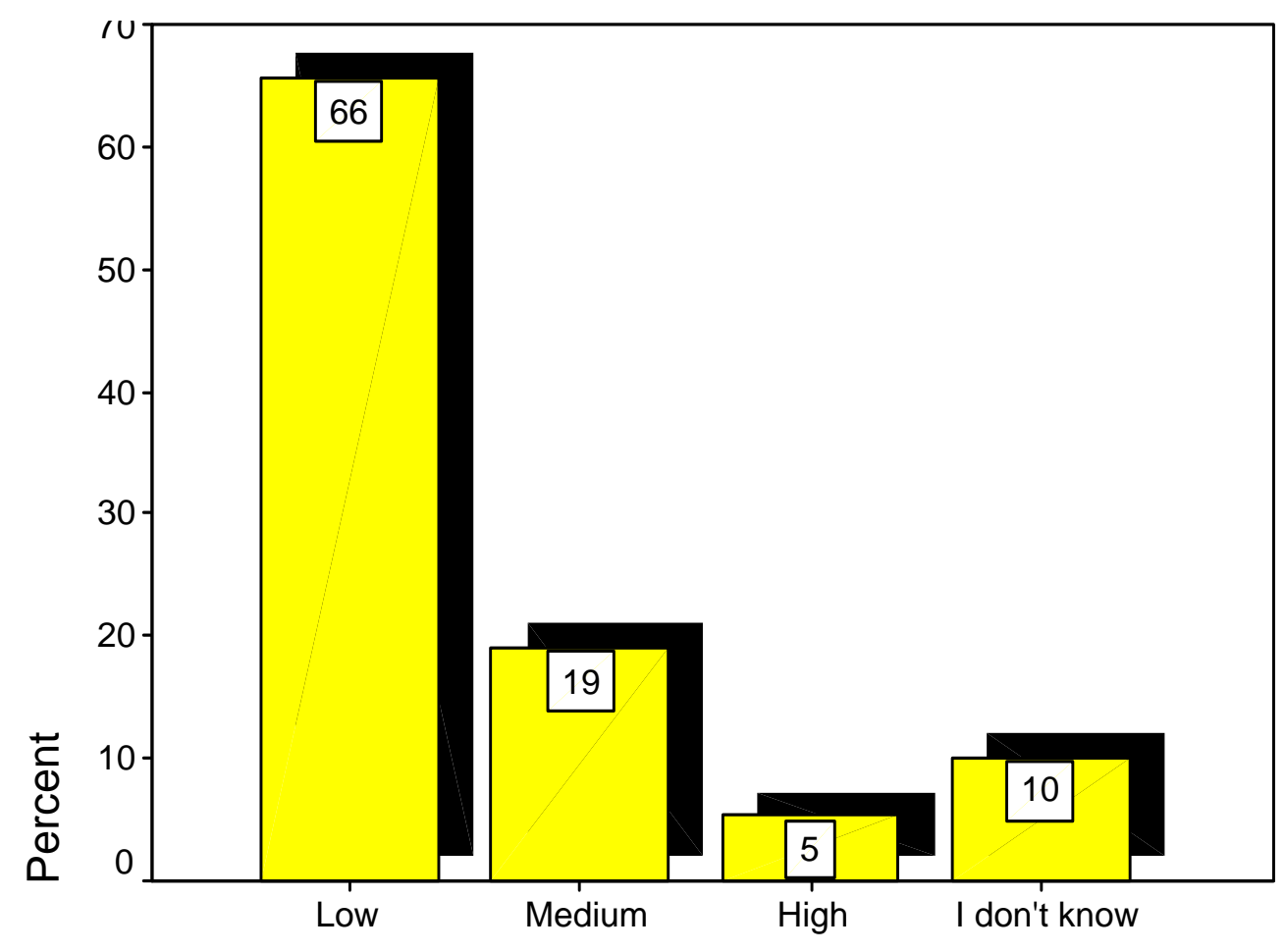

Figure B.17. Students' ranking of Voice recognition. 
Table B.37

Students' ranking to Signature dynamic

16.6) Rank each technology according to your health concerns: - Signature dynamic

\begin{tabular}{|ll|r|r|r|r|}
\hline & & & & Cumulative \\
& & Frequency & Percent & Valid Percent & \multicolumn{2}{c|}{ Percent } \\
\hline Valid & Low & 135 & 71.4 & 71.4 & 71.4 \\
& Medium & 29 & 15.3 & 15.3 & 86.8 \\
& High & 2.6 & 2.6 & 89.4 \\
I don't know & 20 & 10.6 & 10.6 & 100.0 \\
Total & 189 & 100.0 & 100.0 & \\
\hline
\end{tabular}

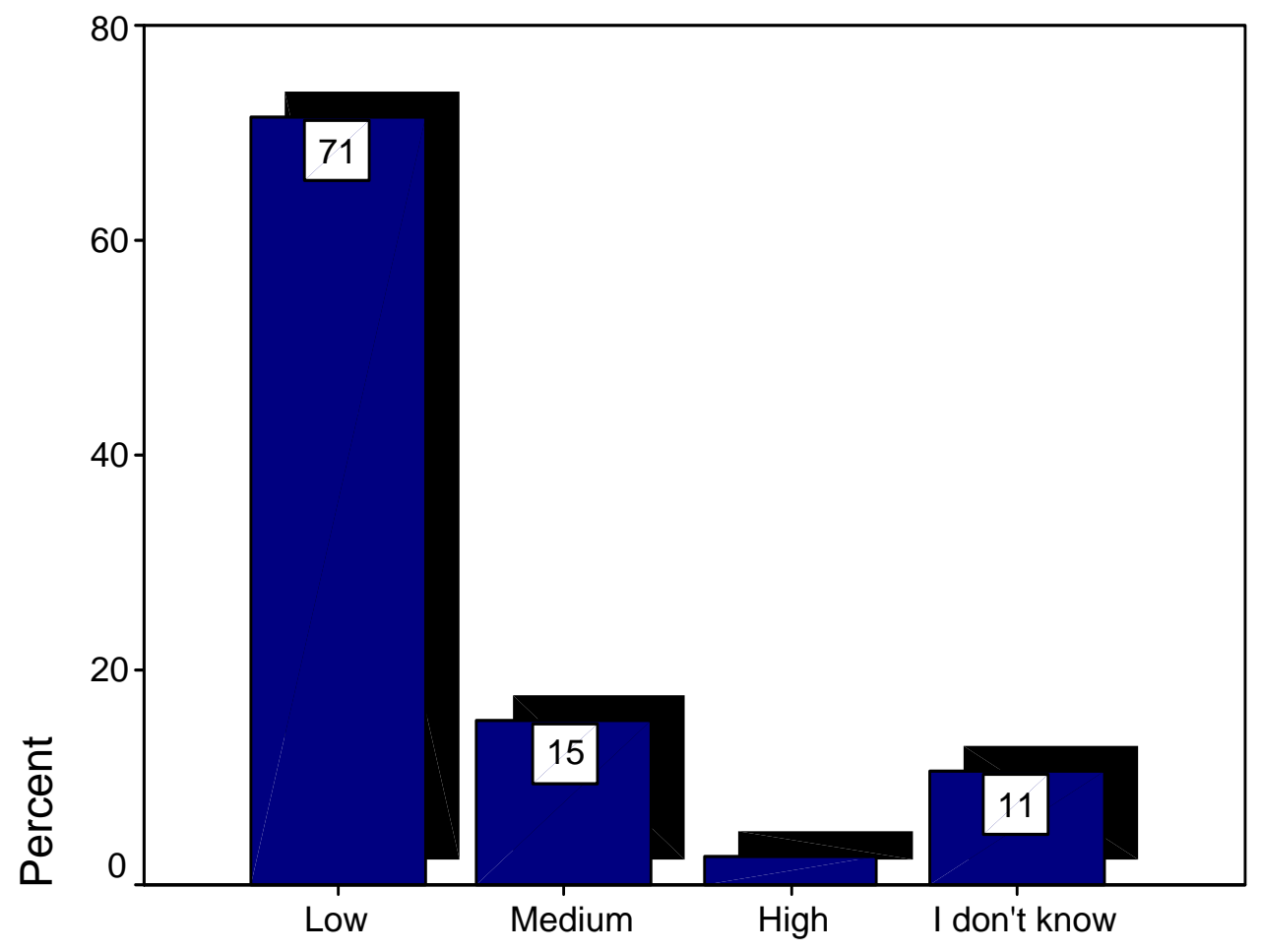

Figure B.18. Students' ranking of Signature dynamic. 
Health Concerns of Each Rated Biometric Technology (Comfortability)

Table B.38

The rank of Fingerprint from health point of view

17.1) In terms of health concerns, please rate your comfortability toward the use of these five biometric technologies - Fingerprint

\begin{tabular}{|c|c|c|c|c|c|}
\hline & & Frequency & Percent & Valid Percent & $\begin{array}{c}\text { Cumulative } \\
\text { Percent }\end{array}$ \\
\hline \multirow[t]{6}{*}{ Valid } & Very Comfortable & 90 & 47.6 & 47.6 & 47.6 \\
\hline & Somewhat Comfortable & 65 & 34.4 & 34.4 & 82.0 \\
\hline & Not Very Comfortable & 16 & 8.5 & 8.5 & 90.5 \\
\hline & Not Comfortable & 10 & 5.3 & 5.3 & 95.8 \\
\hline & I don't know & 8 & 4.2 & 4.2 & 100.0 \\
\hline & Total & 189 & 100.0 & 100.0 & \\
\hline
\end{tabular}

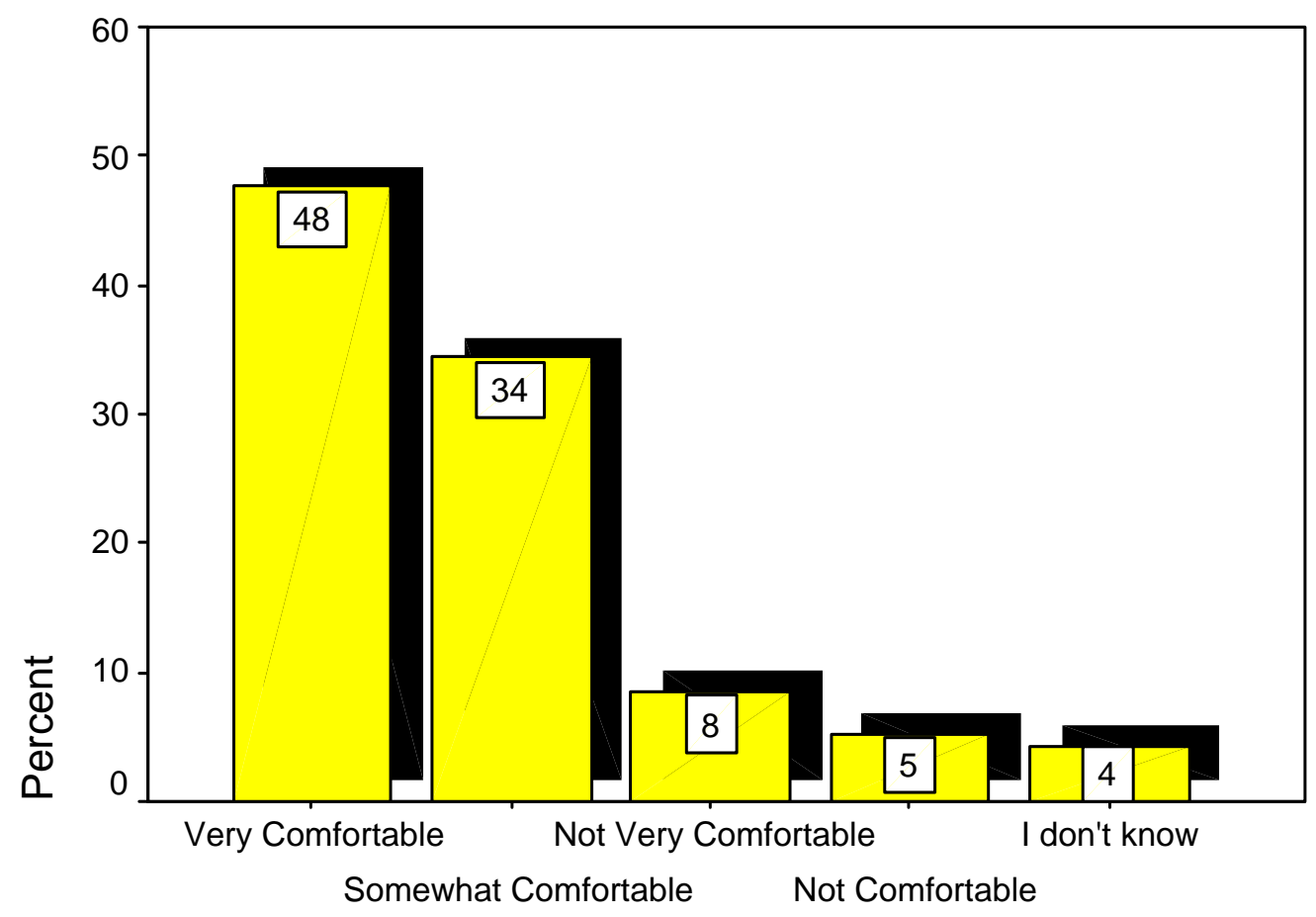

Figure B.19. Students' comfortability ranking of Fingerprint. 
Table B.39

The rank of Iris scan from health point of view.

17.2) In terms of health concerns, please rate your comfortability toward the use of these five biometric technologies - Iris scan â€ eye scanâ€

\begin{tabular}{|ll|r|r|r|r|}
\hline & & & & Cumulative \\
& Frequency & Percent & Valid Percent & Percent \\
\hline Valid & Very Comfortable & 28 & 14.8 & 14.8 & 14.8 \\
& Somewhat Comfortable & 44 & 23.3 & 23.3 & 38.1 \\
Not Very Comfortable & 52 & 27.5 & 27.5 & 65.6 \\
Not Comfortable & 50 & 26.5 & 26.5 & 92.1 \\
I don't know & 15 & 7.9 & 7.9 & 100.0 \\
Total & 189 & 100.0 & 100.0 & \\
\hline
\end{tabular}

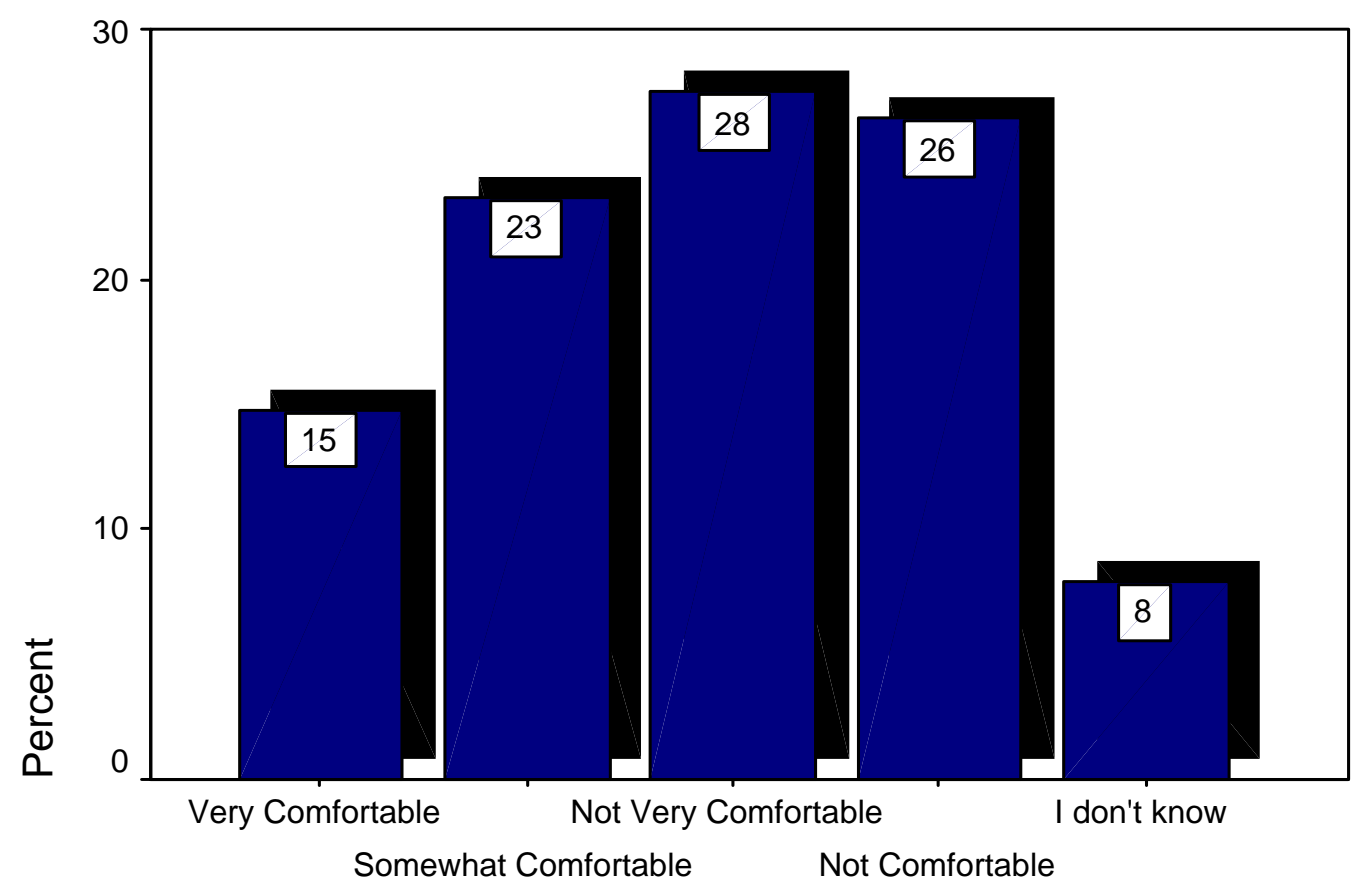

Figure B.20. Students' comfortability ranking of Iris scan. 
Table B.40

The rank of Facial recognition from health point of view

17.3) In terms of health concerns, please rate your comfortability toward the use of these five biometric technologies - Facial recognition

\begin{tabular}{|ll|r|r|r|r|}
\hline & & & & Cumulative \\
& Frequency & Percent & Valid Percent & Percent \\
\hline Valid & Very Comfortable & 43 & 22.8 & 22.8 & 22.8 \\
& Somewhat Comfortable & 56 & 29.6 & 29.6 & 52.4 \\
& Not Very Comfortable & 45 & 23.8 & 23.8 & 76.2 \\
Not Comfortable & 29 & 15.3 & 15.3 & 91.5 \\
I don't know & 16 & 8.5 & 8.5 & 100.0 \\
Total & 189 & 100.0 & 100.0 & \\
\hline
\end{tabular}

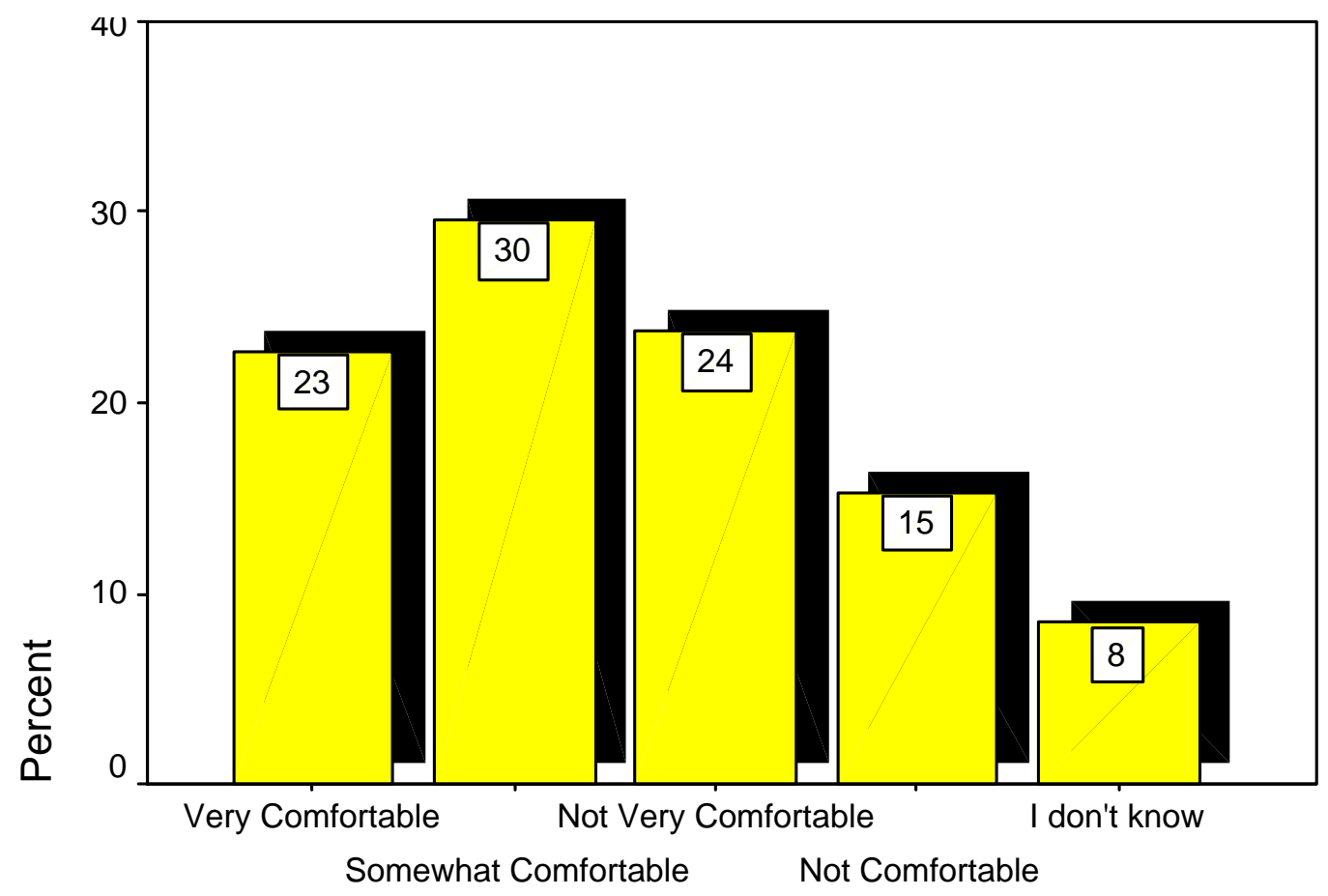

Figure B.21. Students' comfortability ranking of Facial recognition. 
Table B.41

The rank of Hand geometry from health point of view

17.4) In terms of health concerns, please rate your comfortability toward the use of these five biometric technologies - Hand geometry

\begin{tabular}{|c|c|c|c|c|c|}
\hline & & Frequency & Percent & Valid Percent & $\begin{array}{c}\text { Cumulative } \\
\text { Percent }\end{array}$ \\
\hline \multirow[t]{6}{*}{ Valid } & Very Comfortable & 52 & 27.5 & 27.5 & 27.5 \\
\hline & Somewhat Comfortable & 74 & 39.2 & 39.2 & 66.7 \\
\hline & Not Very Comfortable & 27 & 14.3 & 14.3 & 81.0 \\
\hline & Not Comfortable & 15 & 7.9 & 7.9 & 88.9 \\
\hline & I don't know & 21 & 11.1 & 11.1 & 100.0 \\
\hline & Total & 189 & 100.0 & 100.0 & \\
\hline
\end{tabular}

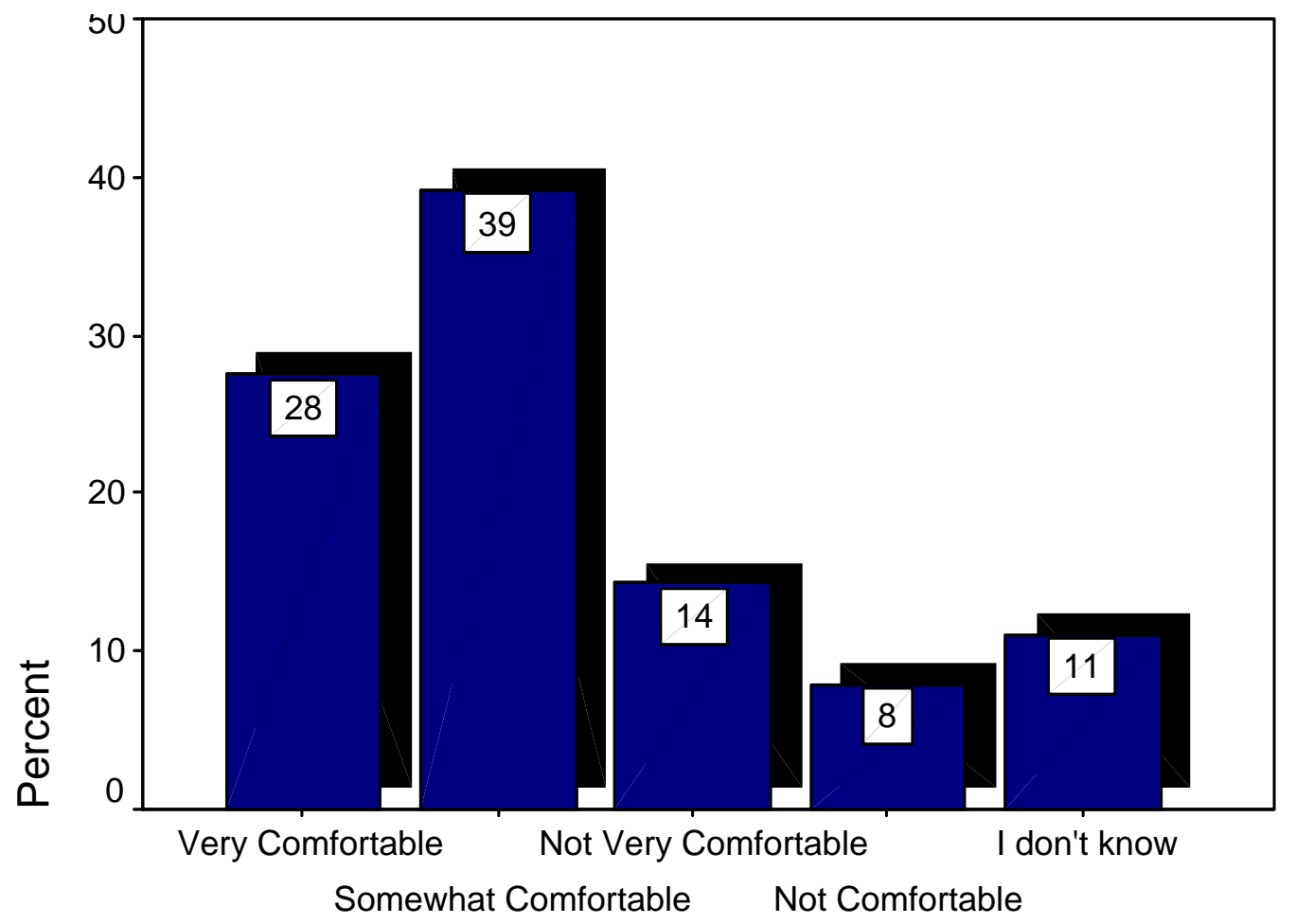

Figure B.22. Students' comfortability ranking of Hand geometry. 
Table B.42

The rank of Voice recognition from health point of view

17.5) In terms of health concerns, please rate your comfortability toward the use of these five biometric technologies - Voice recognition

\begin{tabular}{|c|c|c|c|c|c|}
\hline & & Frequency & Percent & Valid Percent & $\begin{array}{c}\text { Cumulative } \\
\text { Percent }\end{array}$ \\
\hline \multirow[t]{6}{*}{ Valid } & Very Comfortable & 61 & 32.3 & 32.3 & 32.3 \\
\hline & Somewhat Comfortable & 64 & 33.9 & 33.9 & 66.1 \\
\hline & Not Very Comfortable & 35 & 18.5 & 18.5 & 84.7 \\
\hline & Not Comfortable & 13 & 6.9 & 6.9 & 91.5 \\
\hline & I don't know & 16 & 8.5 & 8.5 & 100.0 \\
\hline & Total & 189 & 100.0 & 100.0 & \\
\hline
\end{tabular}

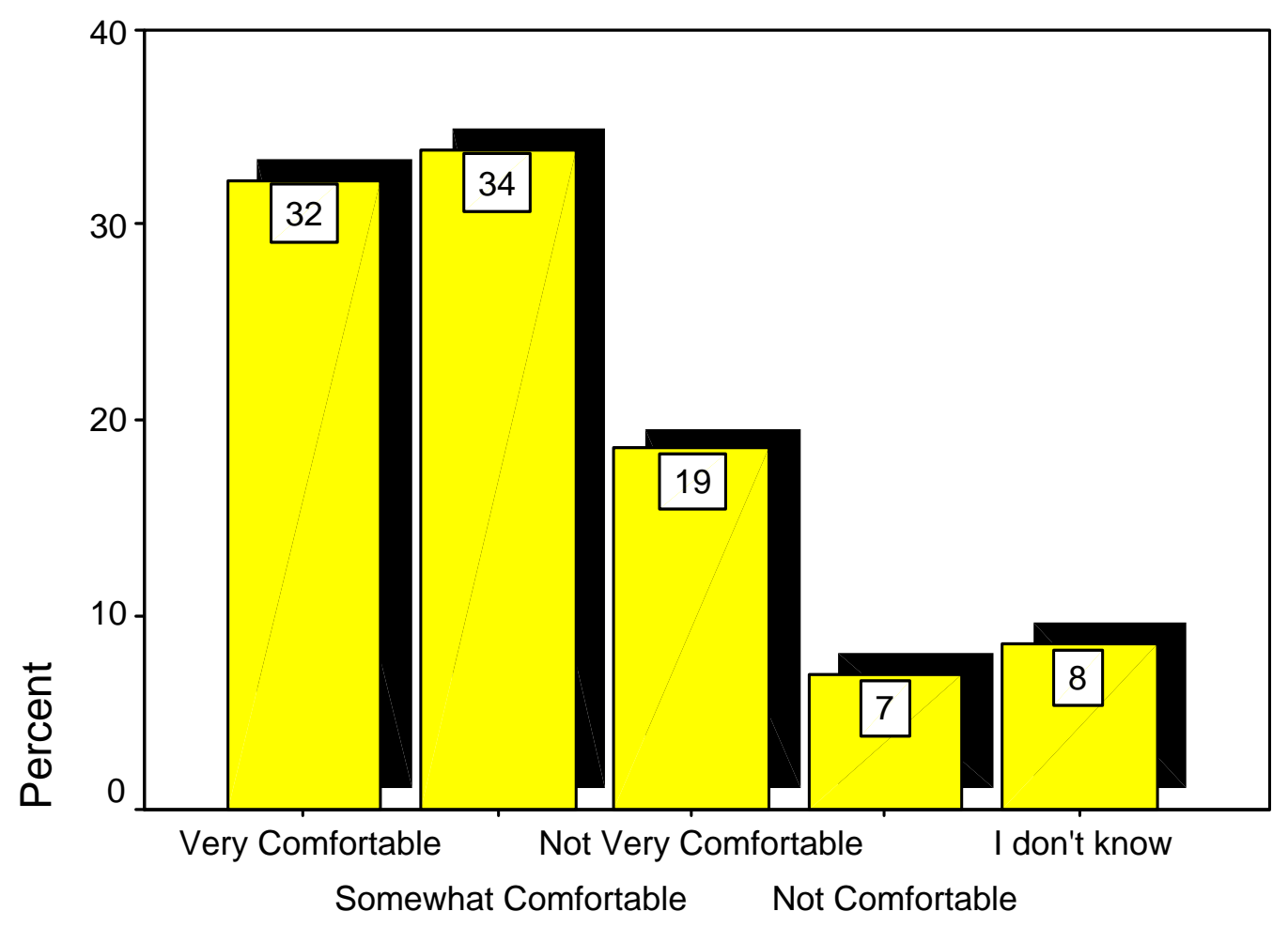

Figure B.23. Students' Comfortability ranking of Voice recognition. 
Table B.43

It shows the rank of Signature dynamic from health point of view.

17.6) In terms of health concerns, please rate your comfortability toward the use of these five biometric technologies - Signature dynamic

\begin{tabular}{|ll|r|r|r|r|}
\hline & & & & \multicolumn{2}{c|}{$\begin{array}{c}\text { Cumulative } \\
\text { Percent }\end{array}$} \\
\hline Valid & Frequency & Percent & Valid Percent & 38.6 & 38.6 \\
& Somewhat Comfortable & 73 & 38.6 & 36.0 & 74.6 \\
& Not Very Comfortable & 68 & 36.0 & 12.7 & 87.3 \\
Not Comfortable & 24 & 12.7 & 4.8 & 92.1 \\
I don't know & 9 & 4.8 & 7.9 & 100.0 \\
Total & 15 & 7.9 & 100.0 & \\
\hline
\end{tabular}

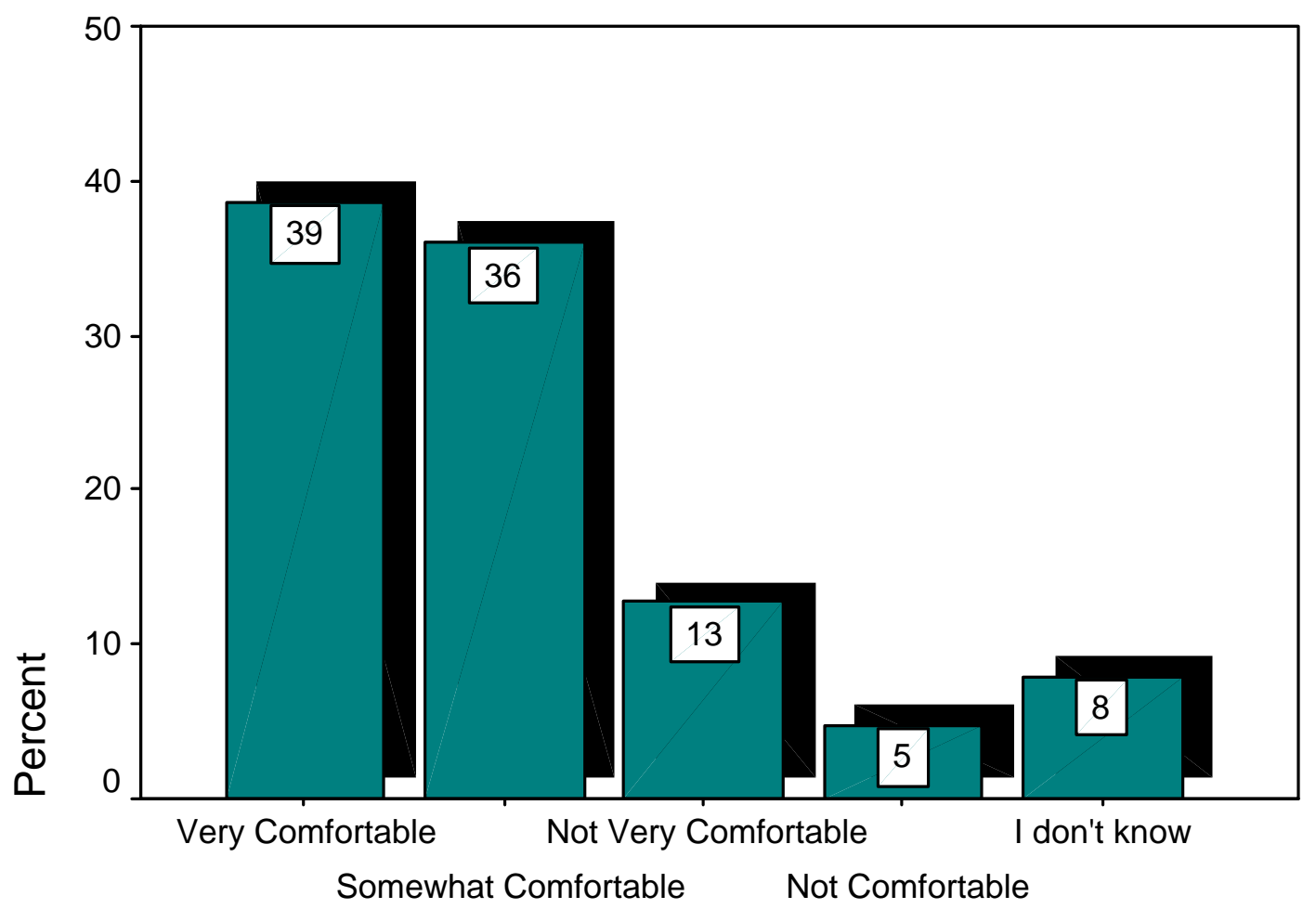

Figure B.24. Students' Comfortability ranking of Signature dynamic. 


\section{APPENDIX C}

Frequency tables and Figures related to the Research Question 3(RQ3)

3. The Differences Between Different Groups 
3. Analyzing Data Related to the Research Third Question (RQ3) Comparing Instructors and Students Groups

3.1 The difference between Students and Instructors groups in their attitude toward the

implementation of biometric technology in regard to:

Privacy issues.

Table C.1-C2

T-test tables to compare Students and Instructors groups regarding Privacy issues.

\section{Group Statistics}

\begin{tabular}{|ll|r|r|r|c|}
\hline & Groups & $\mathrm{N}$ & Mean & Std. Deviation & $\begin{array}{c}\text { Std. Error } \\
\text { Mean }\end{array}$ \\
\hline Privacy & instructors & 24 & 2.1111 & .60327 & .12314 \\
& students & 82 & 1.9045 & .67130 & .07413 \\
\hline
\end{tabular}

Independent Samples Test

\begin{tabular}{|c|c|c|c|c|c|c|c|c|c|}
\hline & \multicolumn{2}{|c|}{\begin{tabular}{|c|} 
Levene's Test for \\
Equality of Variances
\end{tabular}} & \multicolumn{7}{|c|}{ t-test for Equality of Means } \\
\hline & \multirow[b]{2}{*}{$\mathrm{F}$} & \multirow[b]{2}{*}{ Sig. } & \multirow[b]{2}{*}{$\mathrm{t}$} & \multirow[b]{2}{*}{ df } & \multirow[b]{2}{*}{ Sig. (2-tailed) } & \multirow{2}{*}{\begin{tabular}{|c|} 
Mean \\
Difference
\end{tabular}} & \multirow{2}{*}{$\begin{array}{l}\text { Std. Error } \\
\text { Difference }\end{array}$} & \multicolumn{2}{|c|}{$\begin{array}{l}\text { 95\% Confidence } \\
\text { Interval of the } \\
\text { Difference }\end{array}$} \\
\hline & & & & & & & & Lower & Upper \\
\hline $\begin{array}{c}\text { Privacy Equal variance } \\
\text { assumed }\end{array}$ & .259 & .612 & 1.356 & 104 & .178 & .2066 & .15244 & -.09566 & .50894 \\
\hline $\begin{array}{l}\text { Equal variance } \\
\text { not assumed }\end{array}$ & & & 1.438 & 41.157 & .158 & .2066 & .14373 & -.08360 & .49688 \\
\hline
\end{tabular}

Table C.3

Cross tabulation for privacy first item between Instructors and Students groups. 
Groups * 9.1) A.The privacy issues - How concerned are you about having your biometric data collected? Crosstabulation

\begin{tabular}{|c|c|c|c|c|c|c|c|}
\hline & & & \multicolumn{4}{|c|}{$\begin{array}{l}\text { 9.1) A. The privacy issues - How concerned are you about } \\
\text { having your biometric data collected? }\end{array}$} & \multirow[b]{2}{*}{ Total } \\
\hline & & & $\begin{array}{c}\text { Very } \\
\text { Concerned }\end{array}$ & $\begin{array}{l}\text { Somewhat } \\
\text { Concerned }\end{array}$ & $\begin{array}{l}\text { Not very } \\
\text { Concerned }\end{array}$ & $\begin{array}{l}\text { Not } \\
\text { Concerned }\end{array}$ & \\
\hline \multirow[t]{6}{*}{ Groups } & instructors & Count & 5 & 6 & 7 & 6 & 24 \\
\hline & & $\%$ within Groups & $20.8 \%$ & $25.0 \%$ & $29.2 \%$ & $25.0 \%$ & $100.0 \%$ \\
\hline & & $\%$ of Total & $4.7 \%$ & $5.7 \%$ & $6.6 \%$ & $5.7 \%$ & $22.6 \%$ \\
\hline & students & Count & 14 & 36 & 23 & 9 & 82 \\
\hline & & $\%$ within Groups & $17.1 \%$ & $43.9 \%$ & $28.0 \%$ & $11.0 \%$ & $100.0 \%$ \\
\hline & & $\%$ of Total & $13.2 \%$ & $34.0 \%$ & $21.7 \%$ & $8.5 \%$ & $77.4 \%$ \\
\hline \multirow{3}{*}{\multicolumn{2}{|c|}{ Total }} & Count & 19 & 42 & 30 & 15 & 106 \\
\hline & & $\%$ within Groups & $17.9 \%$ & $39.6 \%$ & $28.3 \%$ & $14.2 \%$ & $100.0 \%$ \\
\hline & & $\%$ of Total & $17.9 \%$ & $39.6 \%$ & $28.3 \%$ & $14.2 \%$ & $100.0 \%$ \\
\hline
\end{tabular}

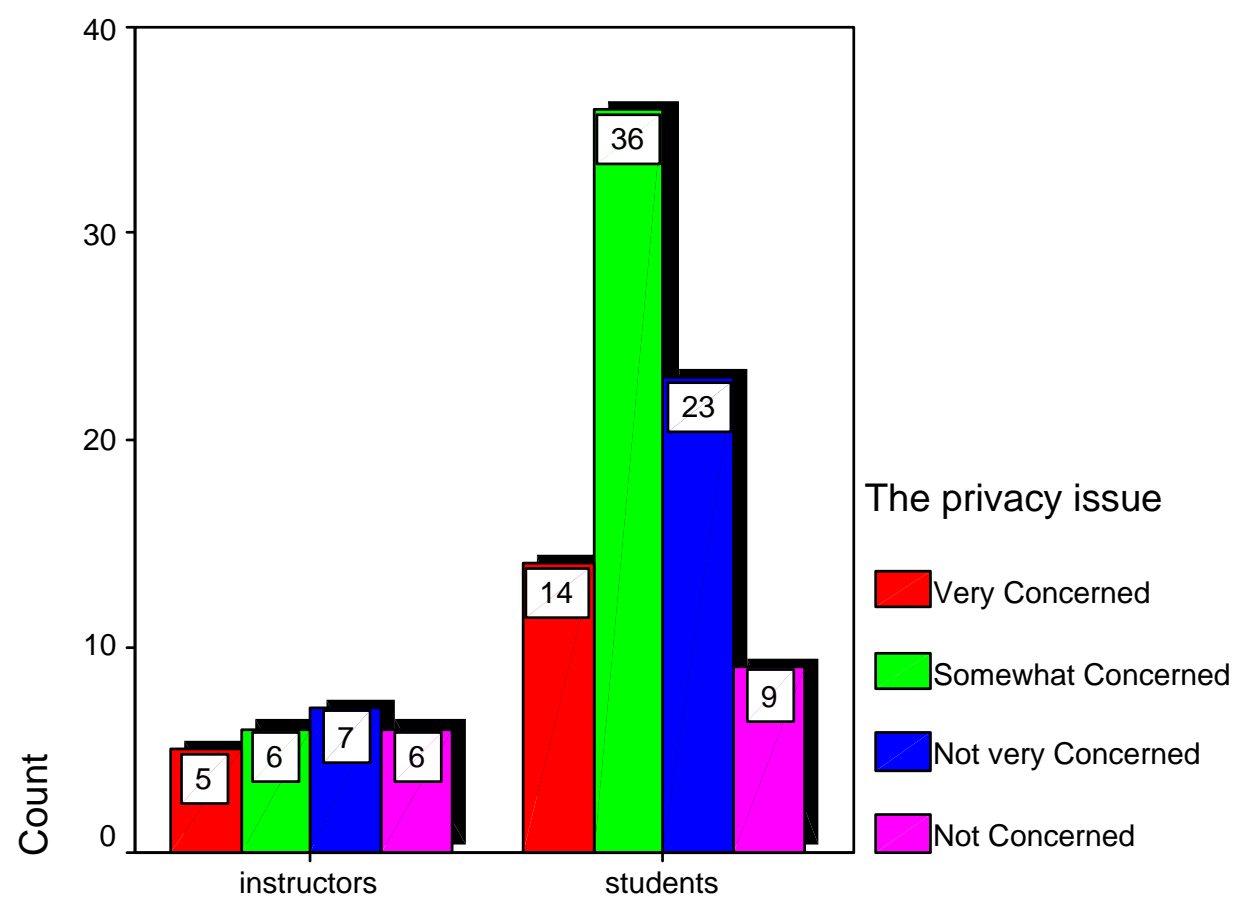

\section{Groups}

Figure C.1. Instructors and Students responses to first item of privacy issues. 
Table C.4

Cross tabulation for privacy second item between Instructors and Students groups.

Groups * 9.2) A.The privacy issues - How concerned are you about having your biometric data stored in non-secure storage? Crosstabulation

\begin{tabular}{|c|c|c|c|c|c|c|c|}
\hline & & & \multicolumn{4}{|c|}{$\begin{array}{l}\text { 9.2) A.The privacy issues - How concerned are you about } \\
\text { having your biometric data stored in non-secure storage? }\end{array}$} & \multirow[b]{2}{*}{ Total } \\
\hline & & & $\begin{array}{c}\text { Very } \\
\text { Concerned }\end{array}$ & $\begin{array}{l}\text { Somewhat } \\
\text { Concerned }\end{array}$ & $\begin{array}{l}\text { Not very } \\
\text { Concerned }\end{array}$ & $\begin{array}{c}\text { Not } \\
\text { Concerned }\end{array}$ & \\
\hline \multirow[t]{6}{*}{ Groups } & instructors & Count & 18 & 3 & 2 & 1 & 24 \\
\hline & & $\%$ within Groups & $75.0 \%$ & $12.5 \%$ & $8.3 \%$ & $4.2 \%$ & $100.0 \%$ \\
\hline & & $\%$ of Total & $17.0 \%$ & $2.8 \%$ & $1.9 \%$ & $.9 \%$ & $22.6 \%$ \\
\hline & students & Count & 56 & 21 & 2 & 3 & 82 \\
\hline & & $\%$ within Groups & $68.3 \%$ & $25.6 \%$ & $2.4 \%$ & $3.7 \%$ & $100.0 \%$ \\
\hline & & $\%$ of Total & $52.8 \%$ & $19.8 \%$ & $1.9 \%$ & $2.8 \%$ & $77.4 \%$ \\
\hline \multirow[t]{3}{*}{ Total } & & Count & 74 & 24 & 4 & 4 & 106 \\
\hline & & $\%$ within Groups & $69.8 \%$ & $22.6 \%$ & $3.8 \%$ & $3.8 \%$ & $100.0 \%$ \\
\hline & & $\%$ of Total & $69.8 \%$ & $22.6 \%$ & $3.8 \%$ & $3.8 \%$ & $100.0 \%$ \\
\hline
\end{tabular}

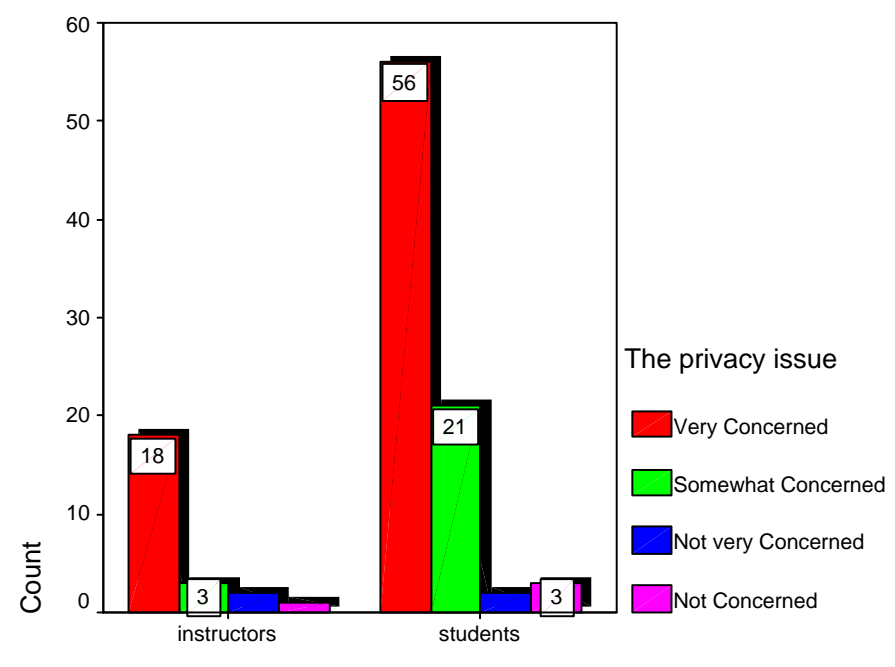

Groups

Figure C.2. Instructors and Students responses to second item of privacy issues.

Table C.5

Cross tabulation for privacy third item between Instructors and Students groups. 
Groups * 9.3) A.The privacy issues - How concerned are you about having your biometric data used by third party? Crosstabulation

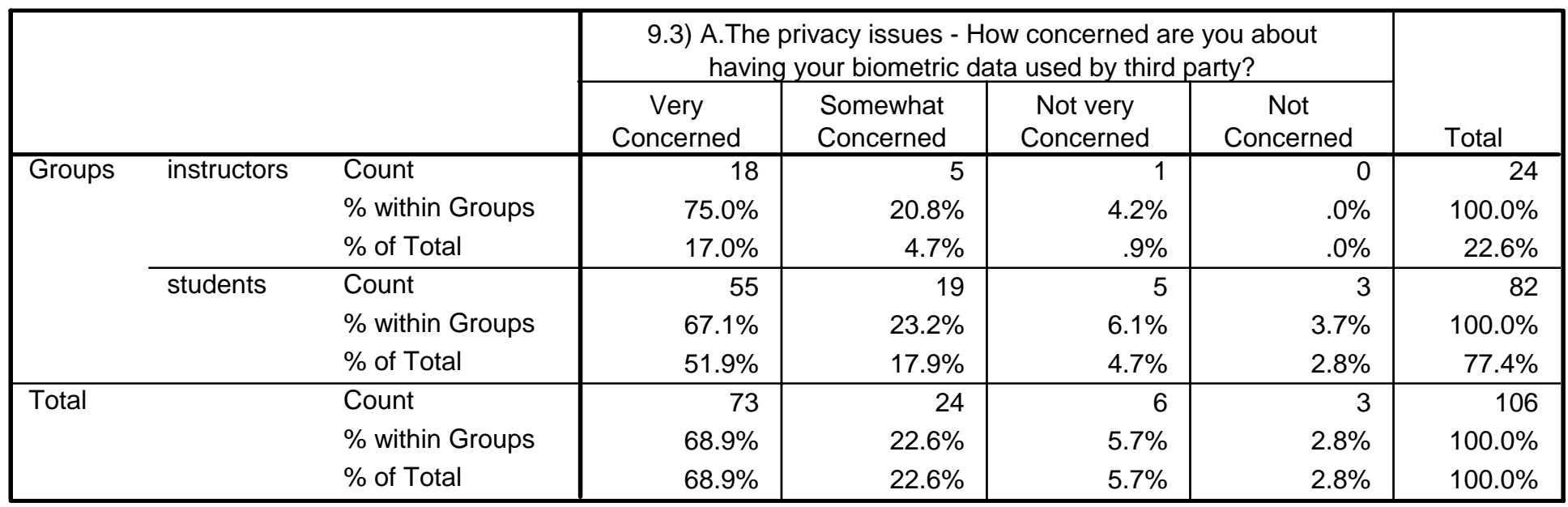

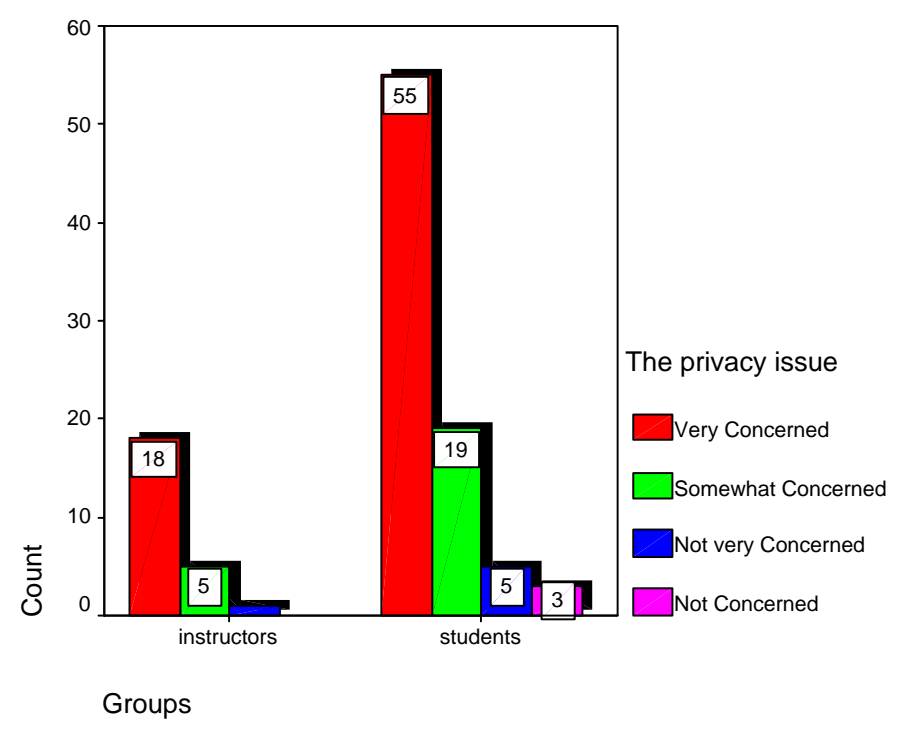

Figure C.3. Instructors and Students responses to third item of privacy issues. 
Table C.6

Cross tabulation for privacy fourth item between Instructors and Students groups.

Groups * 9.4) A.The privacy issues - How concerned are you about having your biometric data misused by WVU? Crosstabulation

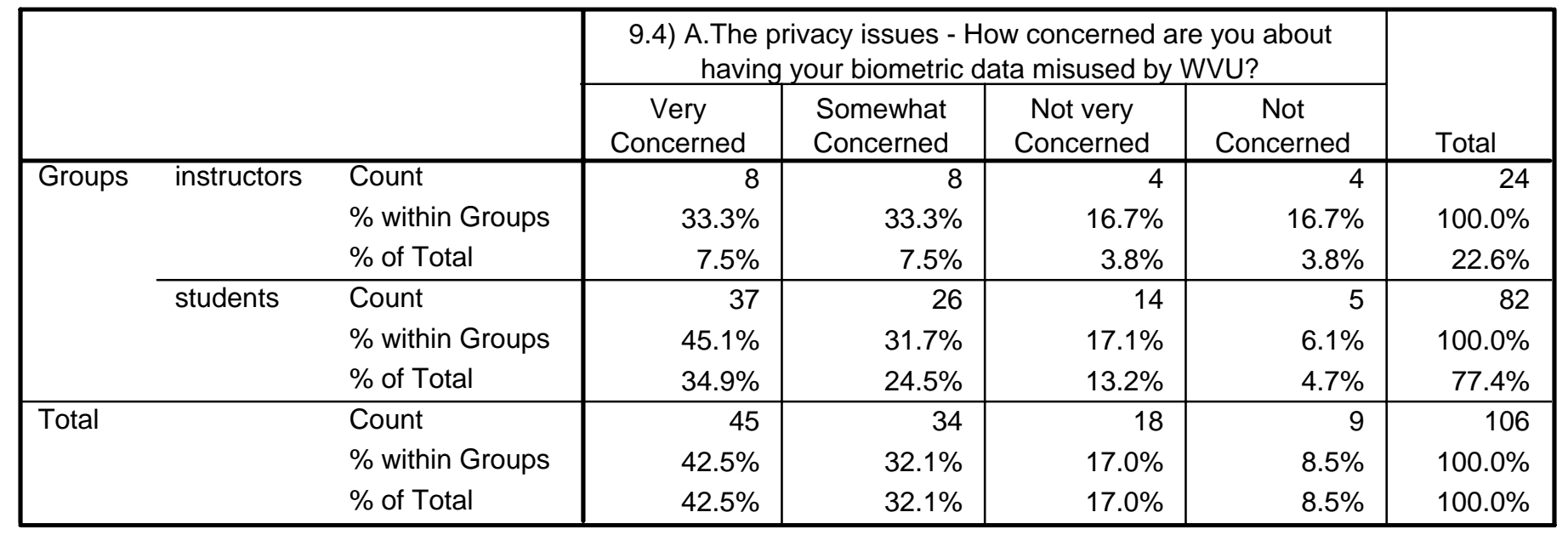

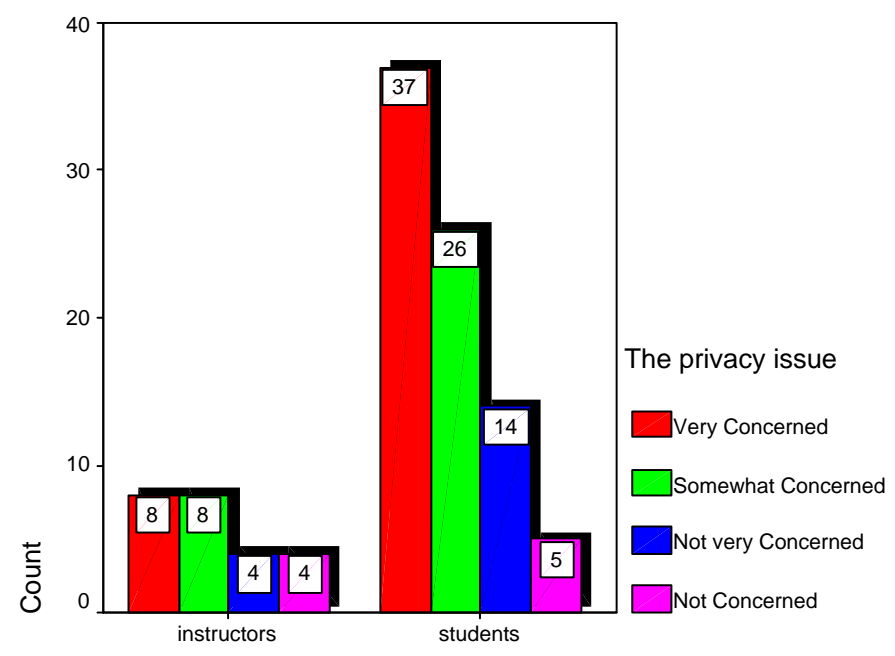

Groups

Figure C.4. Instructors and Students responses to fourth item of privacy issues. 
Table C.7

Cross tabulation for privacy fifth item between Instructors and Students groups.

Groups * 9.5) A.The privacy issues - How concerned are you about the invasion of your privacy by WVU, when biometric technology is implemented? Crosstabulation

\begin{tabular}{|c|c|c|c|c|c|c|c|}
\hline & \multicolumn{4}{|c|}{$\begin{array}{l}\text { 9.5) A. The privacy issues - How concerned are you about the } \\
\text { invasion of your privacy by WVU, when biometric technology } \\
\text { is implemented? }\end{array}$} & \multirow[b]{2}{*}{ Total } \\
\hline & & & $\begin{array}{c}\text { Very } \\
\text { Concerned }\end{array}$ & $\begin{array}{l}\text { Somewhat } \\
\text { Concerned }\end{array}$ & $\begin{array}{c}\text { Not very } \\
\text { Concerned }\end{array}$ & $\begin{array}{c}\text { Not } \\
\text { Concerned }\end{array}$ & \\
\hline \multirow[t]{6}{*}{ Groups } & instructors & Count & 4 & 10 & 7 & 3 & $\overline{24}$ \\
\hline & & $\%$ within Groups & $16.7 \%$ & $41.7 \%$ & $29.2 \%$ & $12.5 \%$ & $100.0 \%$ \\
\hline & & $\%$ of Total & $3.8 \%$ & $9.4 \%$ & $6.6 \%$ & $2.8 \%$ & $22.6 \%$ \\
\hline & students & Count & 29 & 34 & 12 & 7 & 82 \\
\hline & & $\%$ within Groups & $35.4 \%$ & $41.5 \%$ & $14.6 \%$ & $8.5 \%$ & $100.0 \%$ \\
\hline & & $\%$ of Total & $27.4 \%$ & $32.1 \%$ & $11.3 \%$ & $6.6 \%$ & $77.4 \%$ \\
\hline \multirow[t]{3}{*}{ Total } & & Count & 33 & 44 & 19 & 10 & 106 \\
\hline & & $\%$ within Groups & $31.1 \%$ & $41.5 \%$ & $17.9 \%$ & $9.4 \%$ & $100.0 \%$ \\
\hline & & $\%$ of Total & $31.1 \%$ & $41.5 \%$ & $17.9 \%$ & $9.4 \%$ & $100.0 \%$ \\
\hline
\end{tabular}

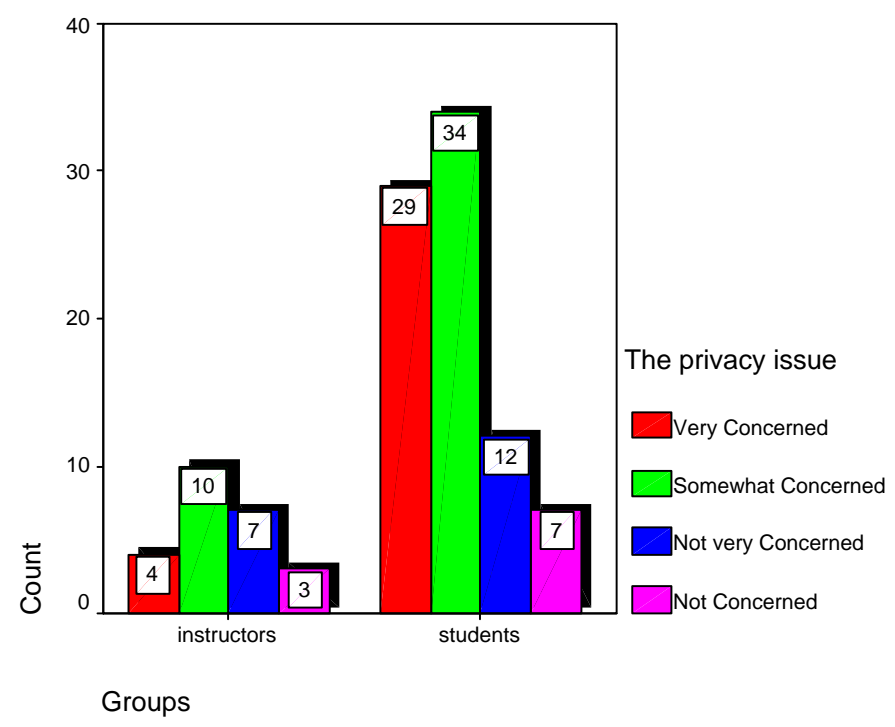

Figure C.5. Instructors and Students responses to fifth item of privacy issues. 
Table C.8

Cross tabulation for privacy sixth item between Instructors and Students groups.

Groups * 9.6) A.The privacy issues - How concerned are you about the negative stigma attached to the use of biometric technology? Crosstabulation

\begin{tabular}{|c|c|c|c|c|c|c|c|}
\hline & \multicolumn{4}{|c|}{$\begin{array}{l}\text { 9.6) A. The privacy issues - How concerned are you about the } \\
\text { negative stigma attached to the use of biometric technology? }\end{array}$} & \multirow[b]{2}{*}{ Total } \\
\hline & & & $\begin{array}{l}\text { Very } \\
\text { Concerned }\end{array}$ & $\begin{array}{l}\text { Somewhat } \\
\text { Concerned }\end{array}$ & $\begin{array}{l}\text { Not very } \\
\text { Concerned }\end{array}$ & $\begin{array}{c}\text { Not } \\
\text { Concerned }\end{array}$ & \\
\hline \multirow[t]{6}{*}{ Groups } & instructors & Count & 2 & 6 & 10 & 6 & 24 \\
\hline & & $\%$ within Groups & $8.3 \%$ & $25.0 \%$ & $41.7 \%$ & $25.0 \%$ & $100.0 \%$ \\
\hline & & $\%$ of Total & $1.9 \%$ & $5.7 \%$ & $9.4 \%$ & $5.7 \%$ & $22.6 \%$ \\
\hline & students & Count & 14 & 32 & 24 & 12 & 82 \\
\hline & & $\%$ within Groups & $17.1 \%$ & $39.0 \%$ & $29.3 \%$ & $14.6 \%$ & $100.0 \%$ \\
\hline & & $\%$ of Total & $13.2 \%$ & $30.2 \%$ & $22.6 \%$ & $11.3 \%$ & $77.4 \%$ \\
\hline \multirow[t]{3}{*}{ Total } & & Count & 16 & 38 & 34 & 18 & 106 \\
\hline & & $\%$ within Groups & $15.1 \%$ & $35.8 \%$ & $32.1 \%$ & $17.0 \%$ & $100.0 \%$ \\
\hline & & $\%$ of Total & $15.1 \%$ & $35.8 \%$ & $32.1 \%$ & $17.0 \%$ & $100.0 \%$ \\
\hline
\end{tabular}

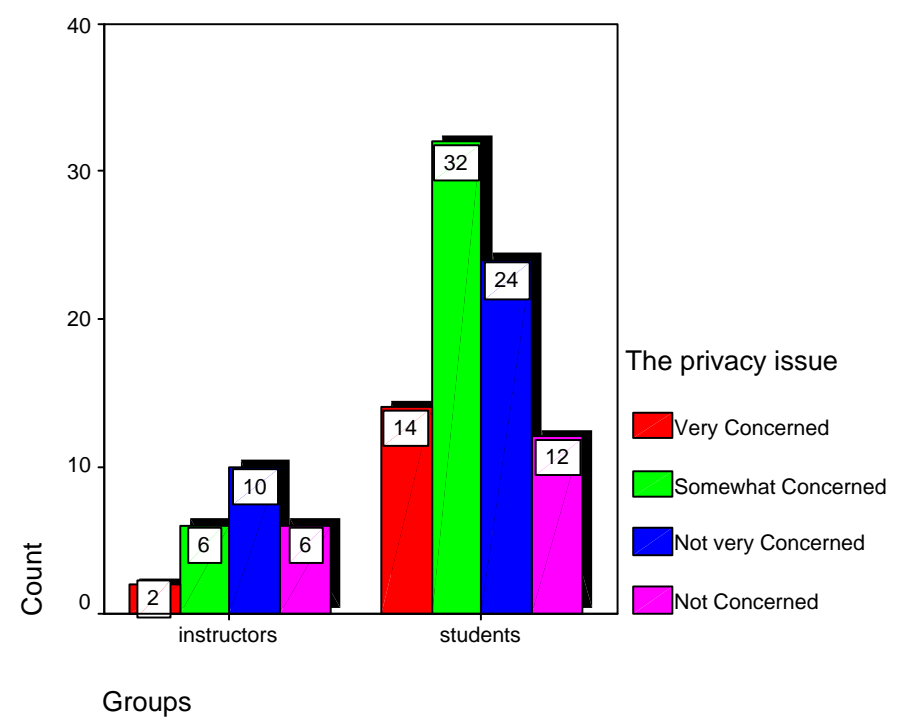

Figure C.6. Instructors and Students responses to sixth item of privacy issues. 


\section{Religious Issues}

Table C.9-C.10

T-test tables to compare Students and Instructors groups regarding religious issues.

\section{Group Statistics}

\begin{tabular}{|c|c|c|c|c|c|}
\hline & Groups & $\mathrm{N}$ & Mean & Std. Deviation & $\begin{array}{l}\text { Std. Error } \\
\text { Mean }\end{array}$ \\
\hline $\begin{array}{l}\text { 11.) In terms of } \\
\text { religious conflicts, how } \\
\text { appropriate do you } \\
\text { think of implementing } \\
\text { the biometric systems } \\
\text { as described in the } \\
\text { scenario below? }\end{array}$ & $\begin{array}{l}\text { instructors } \\
\text { students }\end{array}$ & 20 & 2.00 & .795 & $\begin{array}{r}.178 \\
.110\end{array}$ \\
\hline
\end{tabular}

Independent Samples Test

\begin{tabular}{|c|c|c|c|c|c|c|c|c|c|}
\hline & \multicolumn{2}{|c|}{$\begin{array}{l}\text { Levene's Test for } \\
\text { quality of Variances }\end{array}$} & \multicolumn{7}{|c|}{ t-test for Equality of Means } \\
\hline & \multirow[b]{2}{*}{$\mathrm{F}$} & \multirow[b]{2}{*}{ Sig. } & \multirow[b]{2}{*}{$\mathrm{t}$} & \multirow[b]{2}{*}{ df } & \multirow[b]{2}{*}{ Big. (2-tailed) } & \multirow{2}{*}{$\begin{array}{c}\text { Mean } \\
\text { Difference }\end{array}$} & \multirow{2}{*}{$\begin{array}{l}\text { Std. Error } \\
\text { Difference }\end{array}$} & \multicolumn{2}{|c|}{$\begin{array}{l}\text { 95\% Confidence } \\
\text { Interval of the } \\
\text { Difference }\end{array}$} \\
\hline & & & & & & & & Lower & Upper \\
\hline $\begin{array}{l}\text { 11.) In terms of Equal varianc } \\
\text { religious conflicts, I assumed } \\
\text { appropriate do you } \\
\text { think of implementi } \\
\text { the biometric syste Equal varianc } \\
\text { as described in the not assumed } \\
\text { scenario below? }\end{array}$ & .811 & .371 & -1.898 & 34.605 & .068 & -.40 & .214 & -.823 & .028 \\
\hline
\end{tabular}




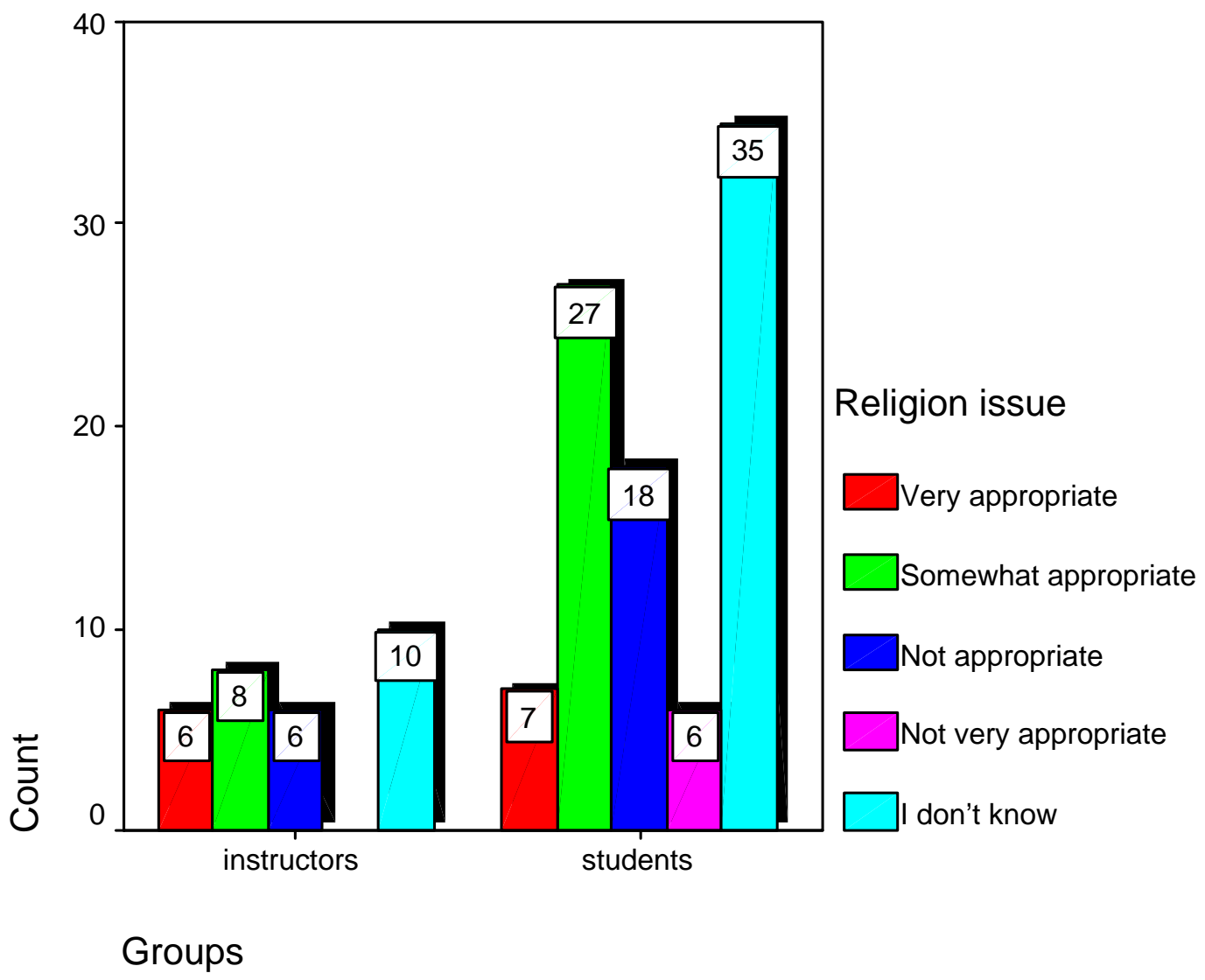

Figure C.7. Instructors and Students' responses to question regarding the religious issues. 


\section{Health Issues}

Table C.11-C.12

T-test tables to compare Students and Instructors groups regarding Health issues.

\section{Group Statistics}

\begin{tabular}{|ll|r|r|r|r|}
\hline & Groups & $\mathrm{N}$ & Mean & Std. Deviation & $\begin{array}{c}\text { Std. Error } \\
\text { Mean }\end{array}$ \\
\hline $\begin{array}{l}\text { 15.) When biometric } \\
\text { technology is } \\
\text { implemented, how } \\
\begin{array}{l}\text { concerned are you about } \\
\text { the health risk which } \\
\text { might be rendered: }\end{array}\end{array}$ & students & 29 & 3.31 & .761 & .141 \\
\hline
\end{tabular}

\section{Independent Samples Test}

\begin{tabular}{|c|c|c|c|c|c|c|c|c|c|}
\hline & $\begin{array}{l}\text { Levene' } \\
\text { quality o }\end{array}$ & $\begin{array}{l}\text { Test for } \\
\text { lariance }\end{array}$ & \multicolumn{7}{|c|}{$\mathrm{t}$-test for Equality of Means } \\
\hline & \multirow[b]{2}{*}{$\mathrm{F}$} & \multirow[b]{2}{*}{ Sig. } & \multirow[b]{2}{*}{$\mathrm{t}$} & \multirow[b]{2}{*}{ df } & \multirow[b]{2}{*}{ jig. (2-tailec } & \multirow{2}{*}{$\begin{array}{c}\text { Mean } \\
\text { Difference }\end{array}$} & \multirow{2}{*}{$\begin{array}{l}\text { Std. Error } \\
\text { Difference }\end{array}$} & \multicolumn{2}{|c|}{$\begin{array}{l}\text { 95\% Confidence } \\
\text { Interval of the } \\
\text { Difference }\end{array}$} \\
\hline & & & & & & & & Lower & Upper \\
\hline $\begin{array}{l}\text { 15.) When biometric Equal variand } \\
\text { technology is assumed } \\
\text { implemented, how } \\
\text { concerned are you c Equal variand } \\
\text { the health risk whick not assumed } \\
\text { might be rendered: }\end{array}$ & .789 & .377 & $\begin{array}{l}3.218 \\
3.454\end{array}$ & 56.932 & .001 & .59 & .172 & .250 & .939 \\
\hline
\end{tabular}

Table C.13-C.14

The Case Processing Summary for the health first question.

Case Processing Summary

\begin{tabular}{|c|c|c|c|c|c|c|}
\hline & \multicolumn{6}{|c|}{ Cases } \\
\hline & \multicolumn{2}{|c|}{ Valid } & \multicolumn{2}{|c|}{ Missing } & \multicolumn{2}{|c|}{ Total } \\
\hline & $\mathrm{N}$ & Percent & $\mathrm{N}$ & Percent & $\mathrm{N}$ & Percent \\
\hline $\begin{array}{l}\text { Groups * 15.) When } \\
\text { biometric technology is } \\
\text { implemented, how } \\
\text { concerned are you about } \\
\text { the health risk which } \\
\text { might be rendered: }\end{array}$ & 123 & $56.2 \%$ & 96 & $43.8 \%$ & 219 & $100.0 \%$ \\
\hline
\end{tabular}


Groups * 15.) When biometric technology is implemented, how concerned are you about the health risk which might be rendered: Crosstabulation

\begin{tabular}{|c|c|c|c|c|c|c|c|c|}
\hline & & & \multicolumn{5}{|c|}{$\begin{array}{l}\text { 15.) When biometric technology is implemented, how concerned are you } \\
\text { about the health risk which might be rendered: }\end{array}$} & \multirow[b]{2}{*}{ Total } \\
\hline & & & $\begin{array}{c}\text { Very } \\
\text { Concerned } \\
\end{array}$ & $\begin{array}{l}\text { Somewhat } \\
\text { Concerned }\end{array}$ & $\begin{array}{l}\text { Not very } \\
\text { Concerned }\end{array}$ & $\begin{array}{c}\text { Not } \\
\text { Concerned }\end{array}$ & I don't know & \\
\hline \multirow[t]{6}{*}{ Groups } & instructors & Count & 0 & 5 & 10 & 14 & 1 & 30 \\
\hline & & $\%$ within Groups & $.0 \%$ & $16.7 \%$ & $33.3 \%$ & $46.7 \%$ & $3.3 \%$ & $100.0 \%$ \\
\hline & & $\%$ of Total & $.0 \%$ & $4.1 \%$ & $8.1 \%$ & $11.4 \%$ & $.8 \%$ & $24.4 \%$ \\
\hline & students & Count & 6 & 28 & 30 & 17 & 12 & 93 \\
\hline & & $\%$ within Groups & $6.5 \%$ & $30.1 \%$ & $32.3 \%$ & $18.3 \%$ & $12.9 \%$ & $100.0 \%$ \\
\hline & & $\%$ of Total & $4.9 \%$ & $22.8 \%$ & $24.4 \%$ & $13.8 \%$ & $9.8 \%$ & $75.6 \%$ \\
\hline \multirow[t]{3}{*}{ Total } & & Count & 6 & 33 & 40 & 31 & 13 & 123 \\
\hline & & $\%$ within Groups & $4.9 \%$ & $26.8 \%$ & $32.5 \%$ & $25.2 \%$ & $10.6 \%$ & $100.0 \%$ \\
\hline & & $\%$ of Total & $4.9 \%$ & $26.8 \%$ & $32.5 \%$ & $25.2 \%$ & $10.6 \%$ & $100.0 \%$ \\
\hline
\end{tabular}

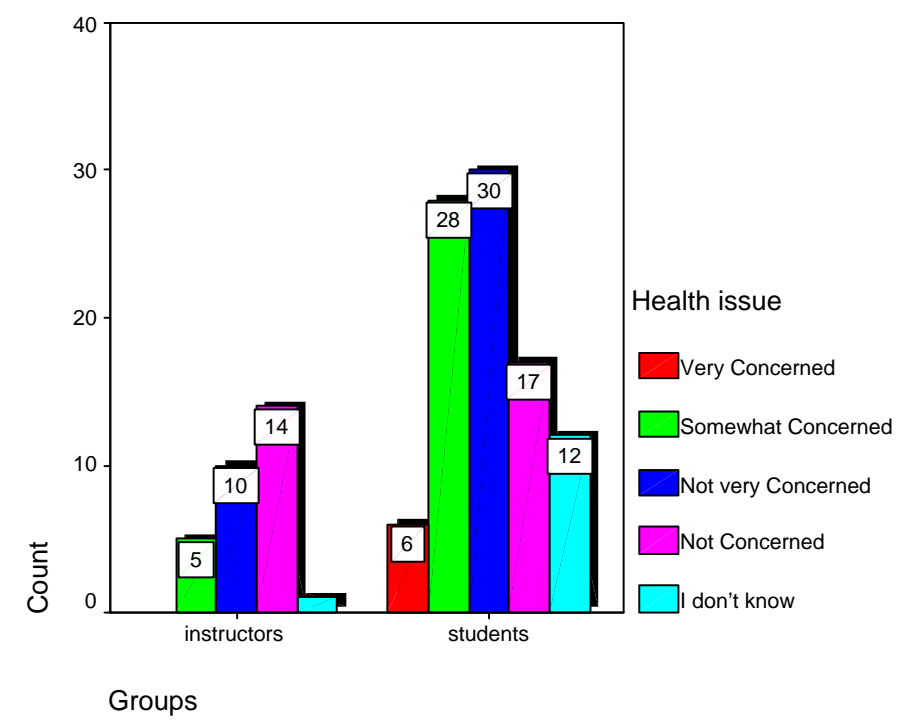

Figure C.8. Instructors and Students responses to question regarding the Health issues. 
3.2 The difference between Male and Female in the surveyed population in their attitude

toward the implementation of biometric technology in regard to:

Privacy issues.

Table C.15-C.16

T-test tables to compare Male and female in the whole population regarding privacy issues.

Group Statistics

\begin{tabular}{|ll|r|r|r|r|}
\hline & & & & \\
& 2.) Gender: & $\mathrm{N}$ & Mean & Std. Deviation & $\begin{array}{c}\text { Std. Error } \\
\text { Mean }\end{array}$ \\
\hline Privacy & Male & 64 & 2.0417 & .70648 & .08831 \\
& Female & 133 & 1.8822 & .71592 & .06208 \\
\hline
\end{tabular}

Independent Samples Test

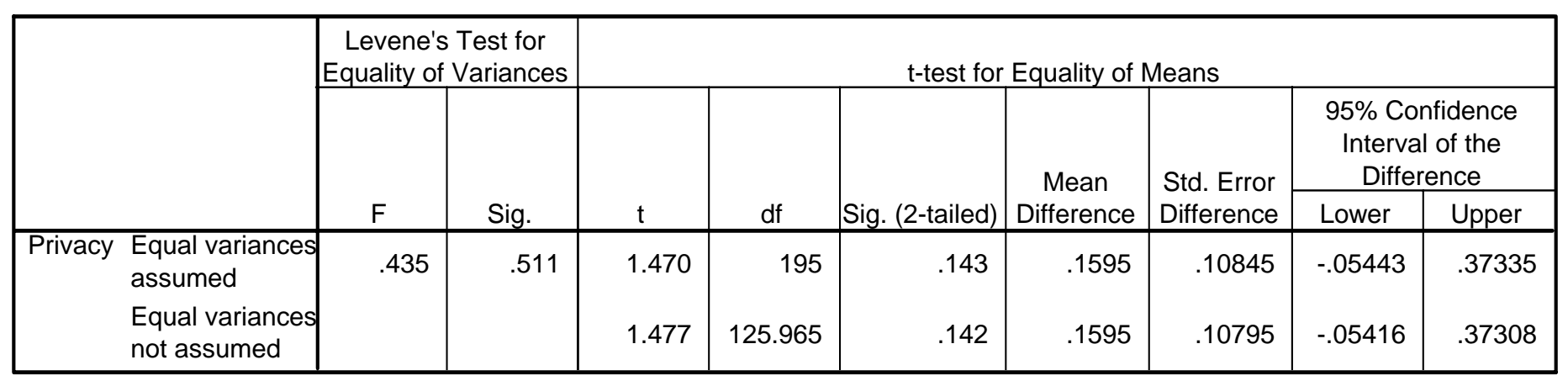


Table C. 17

Case Processing Summary

\begin{tabular}{|c|c|c|c|c|c|c|}
\hline & \multicolumn{6}{|c|}{ Cases } \\
\hline & \multicolumn{2}{|c|}{ Valid } & \multicolumn{2}{|c|}{ Missing } & \multicolumn{2}{|c|}{ Total } \\
\hline & $\mathrm{N}$ & Percent & $\mathrm{N}$ & Percent & $\mathrm{N}$ & Percent \\
\hline $\begin{array}{l}\text { 2.) Gender: }{ }^{*} \text { 9.1) A.The } \\
\text { privacy issues - How } \\
\text { concerned are you about } \\
\text { having your biometric data } \\
\text { collected? }\end{array}$ & 207 & $100.0 \%$ & 0 & $.0 \%$ & 207 & $100.0 \%$ \\
\hline $\begin{array}{l}\text { 2.) Gender: * } 9.2) \text { A. The } \\
\text { privacy issues - How } \\
\text { concerned are you about } \\
\text { having your biometric data } \\
\text { stored in non-secure } \\
\text { storage? }\end{array}$ & 207 & $100.0 \%$ & 0 & $.0 \%$ & 207 & $100.0 \%$ \\
\hline $\begin{array}{l}\left.\text { 2.) Gender: }{ }^{*} 9.3\right) \text { A. The } \\
\text { privacy issues - How } \\
\text { concerned are you about } \\
\text { having your biometric data } \\
\text { used by third party? }\end{array}$ & 207 & $100.0 \%$ & 0 & $.0 \%$ & 207 & $100.0 \%$ \\
\hline $\begin{array}{l}\text { 2.) Gender: * } 9.4 \text { ) A.The } \\
\text { privacy issues - How } \\
\text { concerned are you about } \\
\text { having your biometric data } \\
\text { misused by WVU? }\end{array}$ & 207 & $100.0 \%$ & 0 & $.0 \%$ & 207 & $100.0 \%$ \\
\hline $\begin{array}{l}\text { 2.) Gender: * } 9.5) \text { A.The } \\
\text { privacy issues - How } \\
\text { concerned are you about } \\
\text { the invasion of your } \\
\text { privacy by WVU, when } \\
\text { biometric technology is } \\
\text { implemented? }\end{array}$ & 207 & $100.0 \%$ & 0 & $.0 \%$ & 207 & $100.0 \%$ \\
\hline $\begin{array}{l}\text { 2.) Gender: * } 9.6) \text { A.The } \\
\text { privacy issues - How } \\
\text { concerned are you about } \\
\text { the negative stigma } \\
\text { attached to the use of } \\
\text { biometric technology? }\end{array}$ & 207 & $100.0 \%$ & 0 & $.0 \%$ & 207 & $100.0 \%$ \\
\hline
\end{tabular}


Table C. 18

2.) Gender: * 9.1) A.The privacy issues - How concerned are you about having your biometric data collected? Crosstabulation

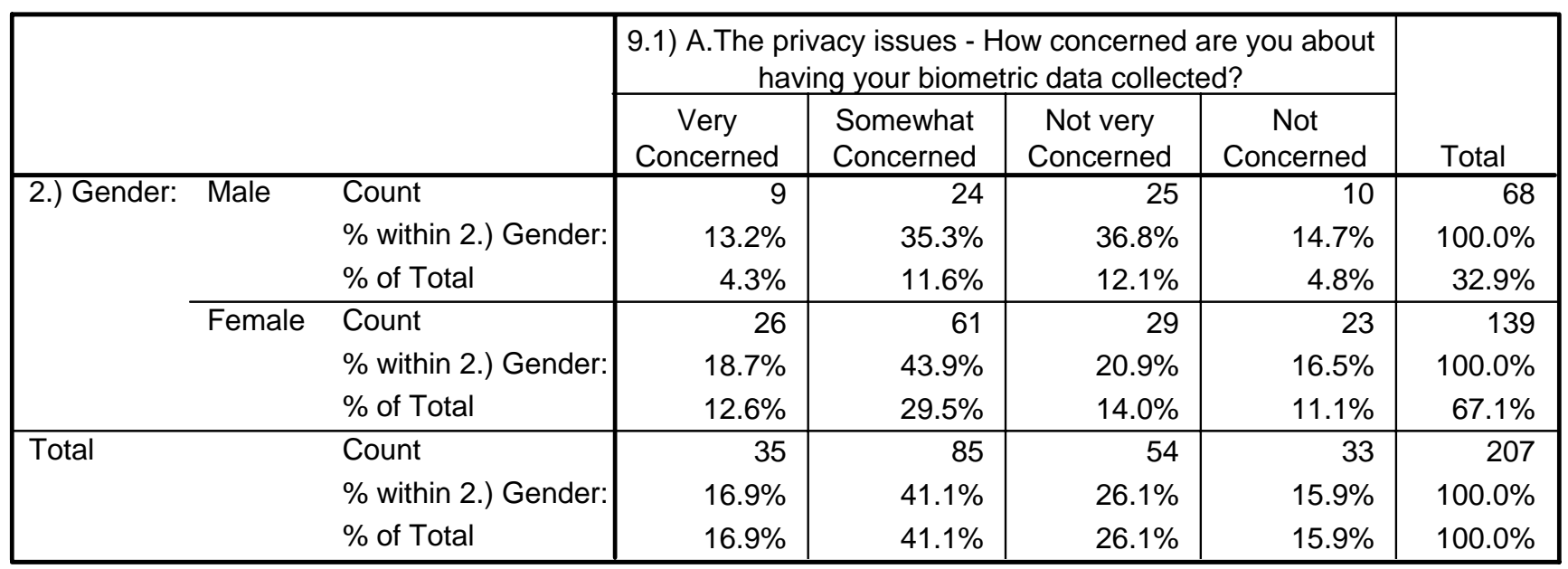

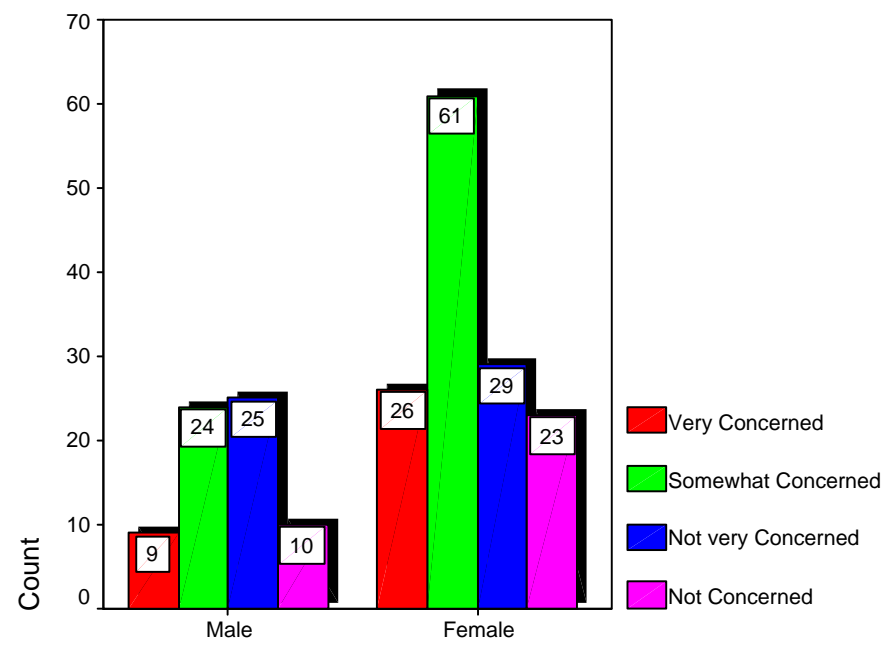

2.) Gender:

Figure C.9. Male and female responses to question regarding the privacy issues. 


\section{Table C.19}

iender: * 9.2) A.The privacy issues - How concerned are you about having your biometric data stored in non-ser storage? Crosstabulation

\begin{tabular}{|c|c|c|c|c|c|c|}
\hline & \multicolumn{4}{|c|}{$\begin{array}{l}\text { 9.2) A. The privacy issues - How concerned are you about } \\
\text { having your biometric data stored in non-secure storage? }\end{array}$} & \multirow[b]{2}{*}{ Total } \\
\hline & & $\begin{array}{c}\text { Very } \\
\text { Concerned }\end{array}$ & $\begin{array}{l}\text { Somewhat } \\
\text { Concerned }\end{array}$ & $\begin{array}{l}\text { Not very } \\
\text { Concerned }\end{array}$ & $\begin{array}{c}\text { Not } \\
\text { Concerned }\end{array}$ & \\
\hline \multirow[t]{6}{*}{ 2.) Gender: Male } & Count & 45 & 14 & 5 & 4 & 68 \\
\hline & \% within 2.) Gender: & $66.2 \%$ & $20.6 \%$ & $7.4 \%$ & $5.9 \%$ & $100.0 \%$ \\
\hline & $\%$ of Total & $21.7 \%$ & $6.8 \%$ & $2.4 \%$ & $1.9 \%$ & $32.9 \%$ \\
\hline & Count & 97 & 31 & 5 & 6 & 139 \\
\hline & \% within 2.) Gender: & $69.8 \%$ & $22.3 \%$ & $3.6 \%$ & $4.3 \%$ & $100.0 \%$ \\
\hline & $\%$ of Total & $46.9 \%$ & $15.0 \%$ & $2.4 \%$ & $2.9 \%$ & $67.1 \%$ \\
\hline \multirow[t]{3}{*}{ Total } & Count & 142 & 45 & 10 & 10 & 207 \\
\hline & \% within 2.) Gender: & $68.6 \%$ & $21.7 \%$ & $4.8 \%$ & $4.8 \%$ & $100.0 \%$ \\
\hline & $\%$ of Total & $68.6 \%$ & $21.7 \%$ & $4.8 \%$ & $4.8 \%$ & $100.0 \%$ \\
\hline
\end{tabular}

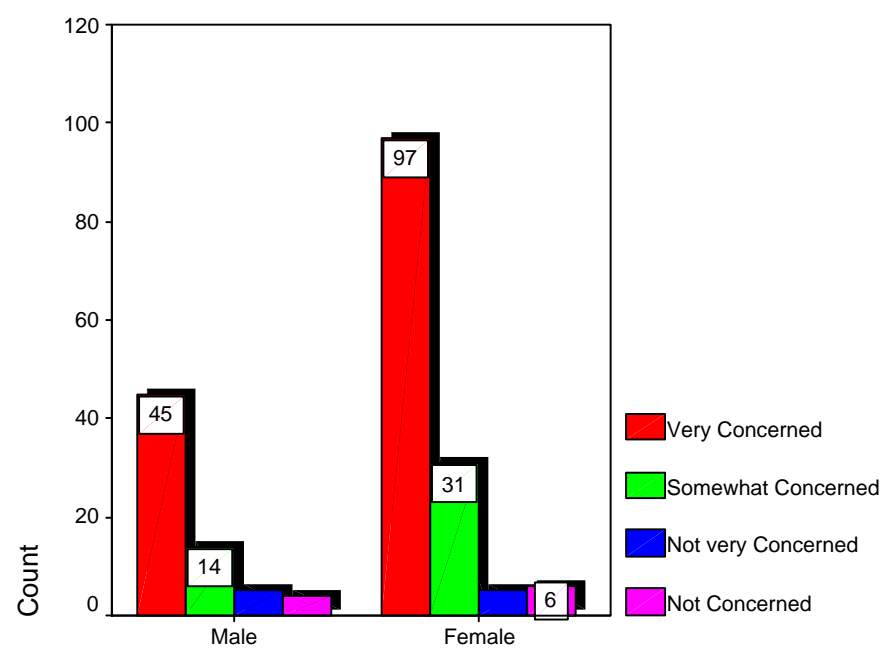

2.) Gender:

Figure C.10. Male and female responses to question regarding the privacy issues. 
Table C. 20

ender: * 9.3) A.The privacy issues - How concerned are you about having your biometric data used by third pi Crosstabulation

\begin{tabular}{|c|c|c|c|c|c|c|}
\hline & \multicolumn{4}{|c|}{$\begin{array}{l}\text { 9.3) A.The privacy issues - How concerned are you about } \\
\text { having your biometric data used by third party? }\end{array}$} & \multirow[b]{2}{*}{ Total } \\
\hline & & $\begin{array}{c}\text { Very } \\
\text { Concerned }\end{array}$ & $\begin{array}{l}\text { Somewhat } \\
\text { Concerned }\end{array}$ & $\begin{array}{l}\text { Not very } \\
\text { Concerned }\end{array}$ & $\begin{array}{l}\text { Not } \\
\text { Concerned }\end{array}$ & \\
\hline \multirow{6}{*}{ 2.) Gender: Male } & Count & 44 & 15 & $\overline{6}$ & 3 & 68 \\
\hline & $\%$ within 2.) Gender: & $64.7 \%$ & $22.1 \%$ & $8.8 \%$ & $4.4 \%$ & $100.0 \%$ \\
\hline & $\%$ of Total & $21.3 \%$ & $7.2 \%$ & $2.9 \%$ & $1.4 \%$ & $32.9 \%$ \\
\hline & Count & 89 & 39 & 7 & 4 & 139 \\
\hline & \% within 2.) Gender: & $64.0 \%$ & $28.1 \%$ & $5.0 \%$ & $2.9 \%$ & $100.0 \%$ \\
\hline & $\%$ of Total & $43.0 \%$ & $18.8 \%$ & $3.4 \%$ & $1.9 \%$ & $67.1 \%$ \\
\hline \multirow[t]{3}{*}{ Total } & Count & 133 & 54 & 13 & 7 & 207 \\
\hline & $\%$ within 2.) Gender: & $64.3 \%$ & $26.1 \%$ & $6.3 \%$ & $3.4 \%$ & $100.0 \%$ \\
\hline & $\%$ of Total & $64.3 \%$ & $26.1 \%$ & $6.3 \%$ & $3.4 \%$ & $100.0 \%$ \\
\hline
\end{tabular}

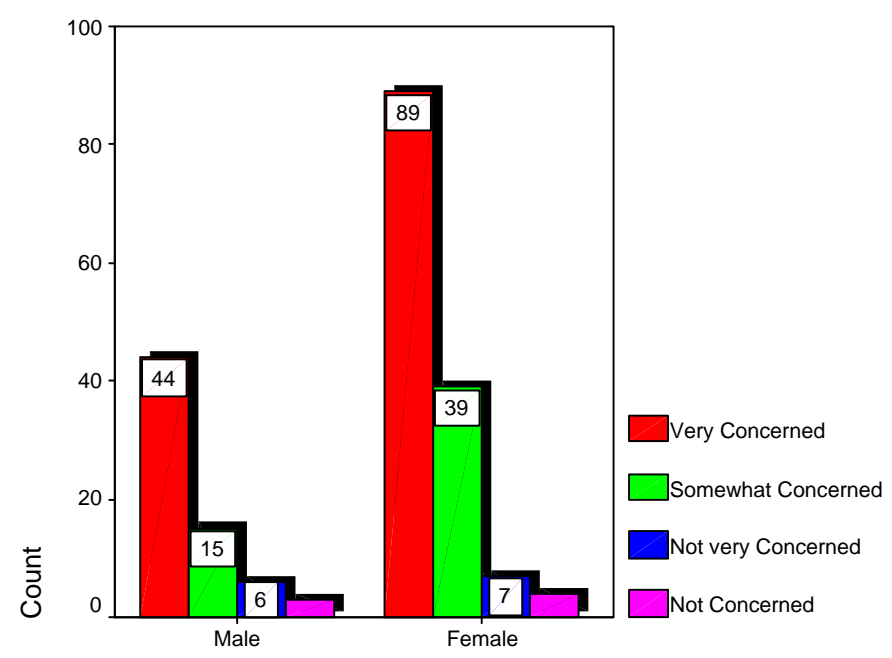

2.) Gender:

Figure C.11. Male and female responses to question regarding the privacy issues. 
Table C.21

Gender: * 9.4) A.The privacy issues - How concerned are you about having your biometric data misused by WV Crosstabulation

\begin{tabular}{|c|c|c|c|c|c|c|}
\hline & \multicolumn{4}{|c|}{$\begin{array}{l}\text { 9.4) A. The privacy issues - How concerned are you about } \\
\text { having your biometric data misused by WVU? }\end{array}$} & \multirow[b]{2}{*}{ Total } \\
\hline & & $\begin{array}{c}\text { Very } \\
\text { Concerned }\end{array}$ & $\begin{array}{l}\text { Somewhat } \\
\text { Concerned }\end{array}$ & $\begin{array}{l}\text { Not very } \\
\text { Concerned }\end{array}$ & $\begin{array}{c}\text { Not } \\
\text { Concerned }\end{array}$ & \\
\hline \multirow[t]{6}{*}{ 2.) Gender: Male } & Count & 27 & $\overline{19}$ & $\overline{14}$ & 8 & 68 \\
\hline & \% within 2.) Gender: & $39.7 \%$ & $27.9 \%$ & $20.6 \%$ & $11.8 \%$ & $100.0 \%$ \\
\hline & $\%$ of Total & $13.0 \%$ & $9.2 \%$ & $6.8 \%$ & $3.9 \%$ & $32.9 \%$ \\
\hline & Count & 69 & 42 & 19 & 9 & 139 \\
\hline & $\%$ within 2.) Gender: & $49.6 \%$ & $30.2 \%$ & $13.7 \%$ & $6.5 \%$ & $100.0 \%$ \\
\hline & $\%$ of Total & $33.3 \%$ & $20.3 \%$ & $9.2 \%$ & $4.3 \%$ & $67.1 \%$ \\
\hline \multirow[t]{3}{*}{ Total } & Count & 96 & 61 & 33 & 17 & 207 \\
\hline & \% within 2.) Gender: & $46.4 \%$ & $29.5 \%$ & $15.9 \%$ & $8.2 \%$ & $100.0 \%$ \\
\hline & $\%$ of Total & $46.4 \%$ & $29.5 \%$ & $15.9 \%$ & $8.2 \%$ & $100.0 \%$ \\
\hline
\end{tabular}

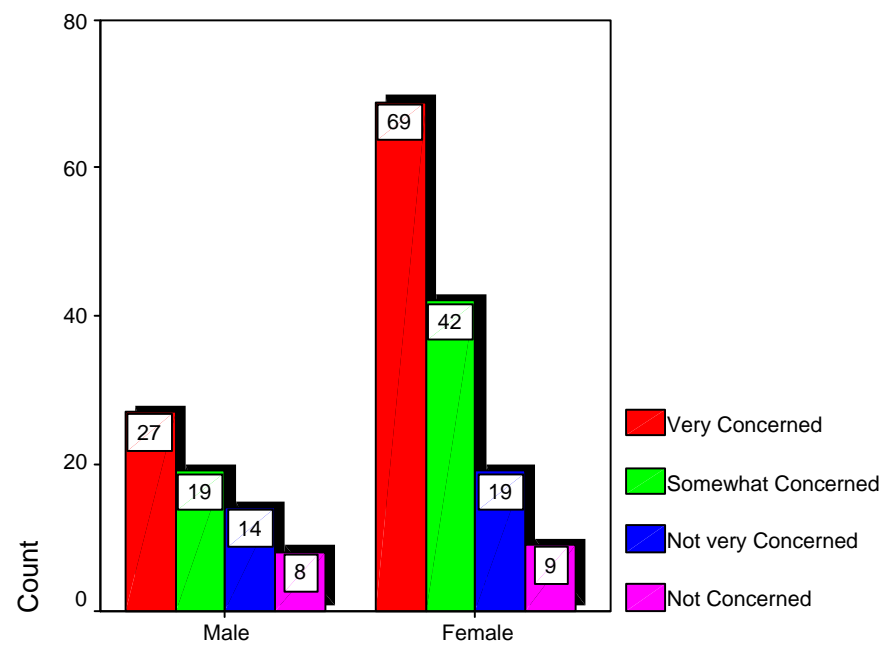

2.) Gender:

Figure C.12. Male and female responses to question regarding the privacy issues. 
Table C.22

Jender: * 9.5) A.The privacy issues - How concerned are you about the invasion of your privacy by WVU, wl biometric technology is implemented? Crosstabulation

\begin{tabular}{|c|c|c|c|c|c|c|}
\hline & \multicolumn{4}{|c|}{$\begin{array}{l}\text { 5) A. The privacy issues - How concerned are you about th } \\
\text { vasion of your privacy by WVU, when biometric technolog } \\
\text { is implemented? }\end{array}$} & \multirow[b]{2}{*}{ Total } \\
\hline & & $\begin{array}{c}\text { Very } \\
\text { Concerned }\end{array}$ & $\begin{array}{l}\text { Somewhat } \\
\text { Concerned }\end{array}$ & $\begin{array}{c}\text { Not very } \\
\text { Concerned }\end{array}$ & $\begin{array}{c}\text { Not } \\
\text { Concerned }\end{array}$ & \\
\hline \multirow[t]{6}{*}{ 2.) Gender: Male } & Count & 19 & 30 & 14 & 5 & 68 \\
\hline & \% within 2.) Gender & $27.9 \%$ & $44.1 \%$ & $20.6 \%$ & $7.4 \%$ & $100.0 \%$ \\
\hline & $\%$ of Total & $9.2 \%$ & $14.5 \%$ & $6.8 \%$ & $2.4 \%$ & $32.9 \%$ \\
\hline & Count & 61 & 43 & 23 & 12 & 139 \\
\hline & $\%$ within 2.) Gender & $43.9 \%$ & $30.9 \%$ & $16.5 \%$ & $8.6 \%$ & $100.0 \%$ \\
\hline & $\%$ of Total & $29.5 \%$ & $20.8 \%$ & $11.1 \%$ & $5.8 \%$ & $67.1 \%$ \\
\hline \multirow[t]{3}{*}{ Total } & Count & 80 & 73 & 37 & 17 & 207 \\
\hline & $\%$ within 2.) Gender & $38.6 \%$ & $35.3 \%$ & $17.9 \%$ & $8.2 \%$ & $100.0 \%$ \\
\hline & $\%$ of Total & $38.6 \%$ & $35.3 \%$ & $17.9 \%$ & $8.2 \%$ & $100.0 \%$ \\
\hline
\end{tabular}

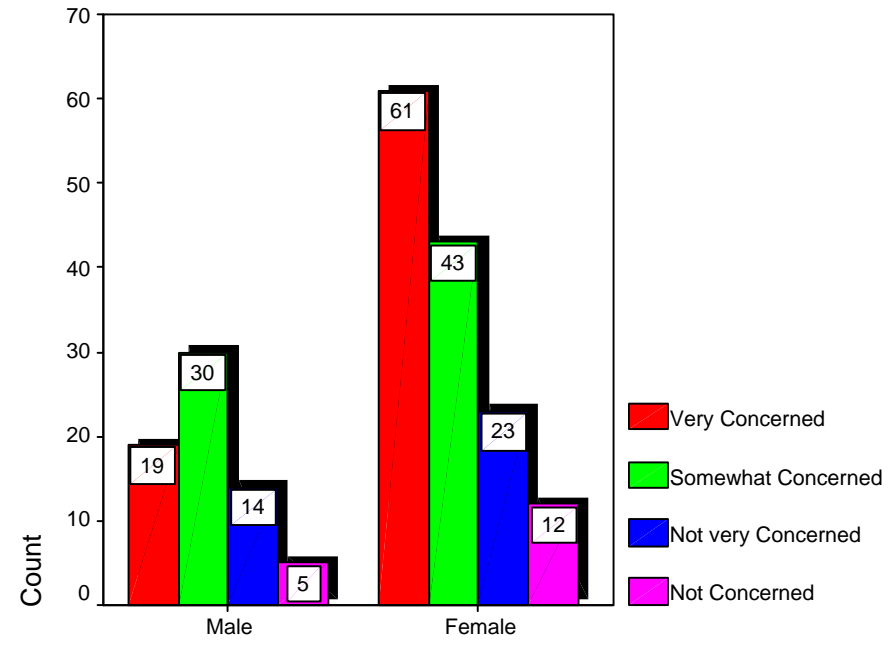

2.) Gender:

Figure C.13. Male and female responses to question regarding the privacy issues. 
Table C.23

der: * 9.6) A.The privacy issues - How concerned are you about the negative stigma attached to the use of bio technology? Crosstabulation

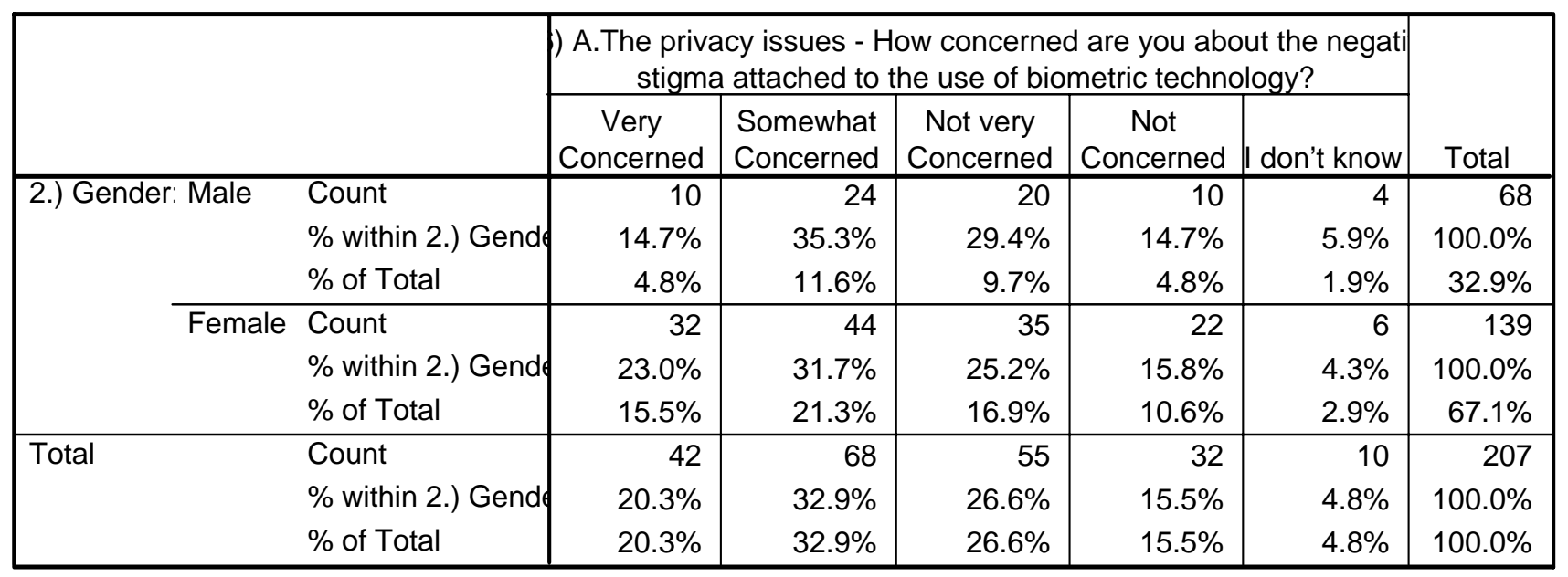

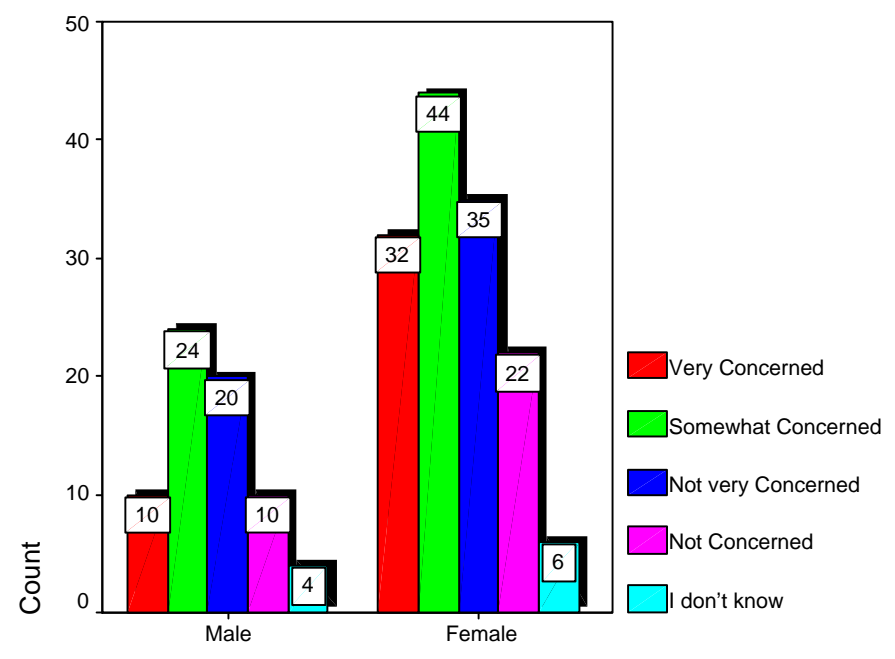

2.) Gender:

Figure C.14. Male and female responses to question regarding the privacy issues. 


\section{Religious Issues}

Table C.24, C.25, C.26 and C.27.

The summary case for first question related to religious issues.

Group Statistics

\begin{tabular}{|c|c|c|c|c|c|}
\hline & 2.) Gender: & $\mathrm{N}$ & Mean & Std. Deviation & $\begin{array}{l}\text { Std. Error } \\
\text { Mean }\end{array}$ \\
\hline $\begin{array}{l}\text { 11.) In terms of } \\
\text { religious conflicts, how } \\
\text { appropriate do you } \\
\text { think of implementing } \\
\text { the biometric systems } \\
\text { as described in the } \\
\text { scenario below? }\end{array}$ & $\begin{array}{l}\text { Male } \\
\text { Female }\end{array}$ & $\begin{array}{l}56 \\
83 \\
\end{array}$ & $\begin{array}{l}2.09 \\
2.43\end{array}$ & $\begin{array}{l}.900 \\
.784\end{array}$ & $\begin{array}{l}.120 \\
.086\end{array}$ \\
\hline
\end{tabular}

Independent Samples Test

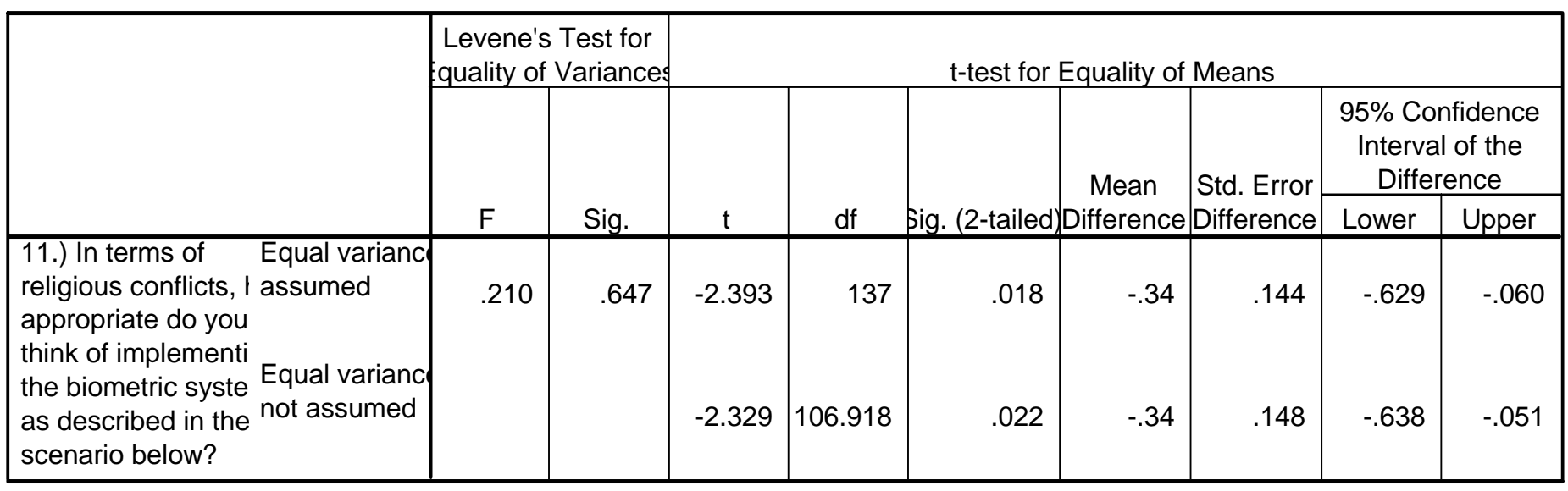

\section{Crosstabs}

Case Processing Summary

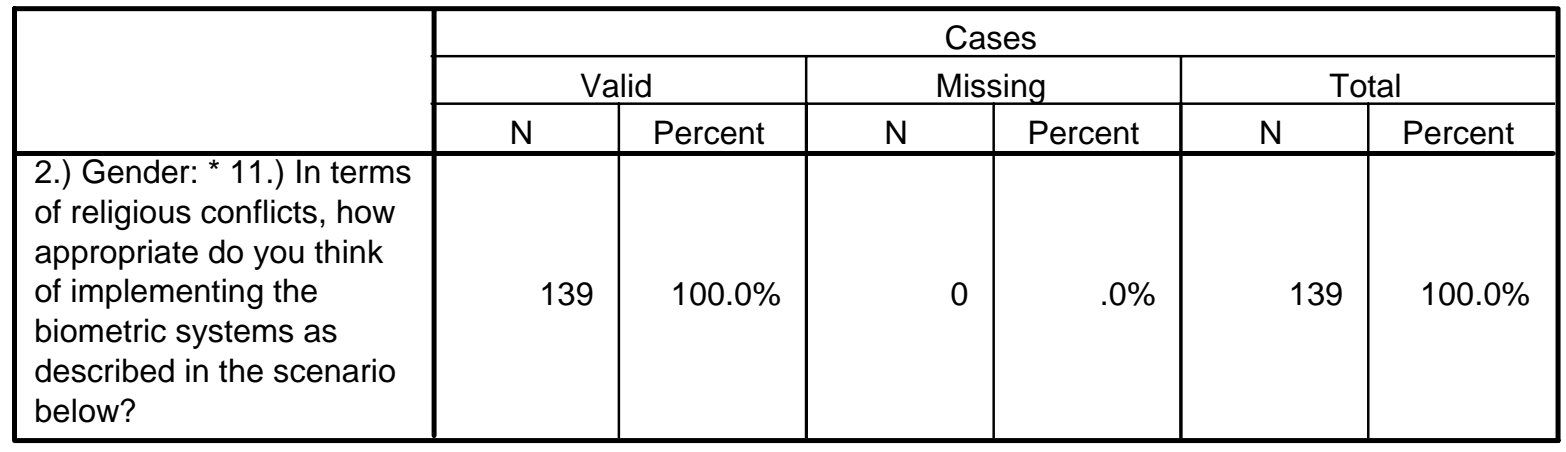


nder: * 11.) In terms of religious conflicts, how appropriate do you think of implementing the biometric systel described in the scenario below? Crosstabulation

\begin{tabular}{|c|c|c|c|c|c|c|}
\hline & & \multicolumn{4}{|c|}{$\begin{array}{l}\text { 11.) In terms of religious conflicts, how appropriate do you } \\
\text { hink of implementing the biometric systems as described in } \\
\text { the scenario below? }\end{array}$} & \multirow[b]{2}{*}{ Total } \\
\hline & & $\begin{array}{c}\text { Very } \\
\text { appropriate }\end{array}$ & $\begin{array}{l}\text { Somewhat } \\
\text { appropriate }\end{array}$ & $\begin{array}{c}\text { Not } \\
\text { appropriate }\end{array}$ & $\begin{array}{c}\text { Not very } \\
\text { appropriate }\end{array}$ & \\
\hline \multirow[t]{6}{*}{ 2.) Gender: Male } & Count & 14 & 29 & 7 & 6 & 56 \\
\hline & \% within 2.) Gender: & $25.0 \%$ & $51.8 \%$ & $12.5 \%$ & $10.7 \%$ & $100.0 \%$ \\
\hline & $\%$ of Total & $10.1 \%$ & $20.9 \%$ & $5.0 \%$ & $4.3 \%$ & $40.3 \%$ \\
\hline & Count & 9 & 35 & 33 & 6 & 83 \\
\hline & \% within 2.) Gender: & $10.8 \%$ & $42.2 \%$ & $39.8 \%$ & $7.2 \%$ & $100.0 \%$ \\
\hline & $\%$ of Total & $6.5 \%$ & $25.2 \%$ & $23.7 \%$ & $4.3 \%$ & $59.7 \%$ \\
\hline \multirow[t]{3}{*}{ Total } & Count & 23 & 64 & 40 & 12 & 139 \\
\hline & \% within 2.) Gender: & $16.5 \%$ & $46.0 \%$ & $28.8 \%$ & $8.6 \%$ & $100.0 \%$ \\
\hline & $\%$ of Total & $16.5 \%$ & $46.0 \%$ & $28.8 \%$ & $8.6 \%$ & $100.0 \%$ \\
\hline
\end{tabular}

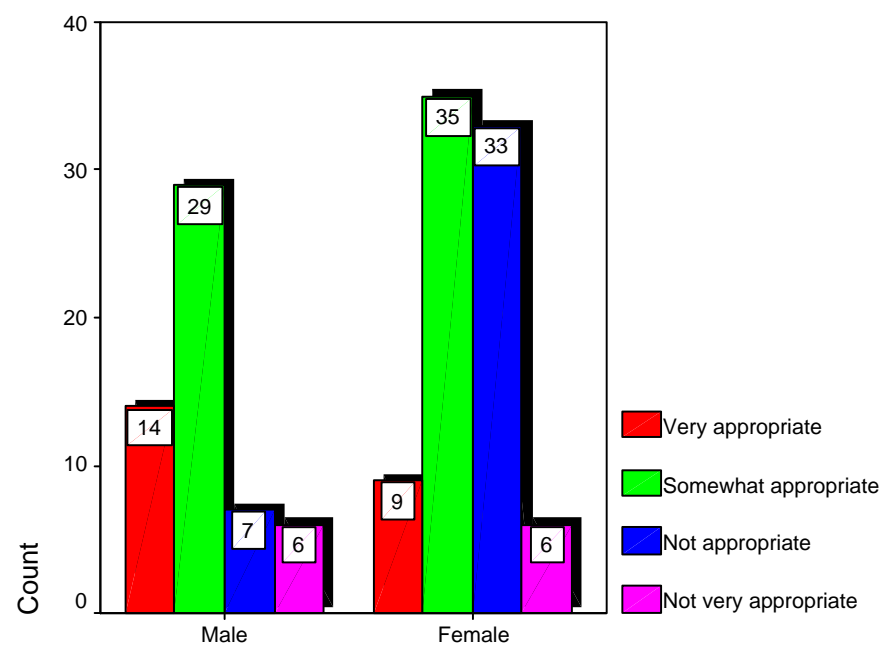

2.) Gender:

Figure C.15. Male and female responses to question regarding the religious issues. 


\section{Health Issues}

Table C.28, C.29, C.30, and C.31

The summary case for first question related to health issues.

Group Statistics

\begin{tabular}{|c|c|c|c|c|c|}
\hline & 2.) Gender: & $\mathrm{N}$ & Mean & Std. Deviation & $\begin{array}{l}\text { Std. Error } \\
\text { Mean }\end{array}$ \\
\hline $\begin{array}{l}\text { 15.) When biometric } \\
\text { technology is } \\
\text { implemented, how } \\
\text { concerned are you about } \\
\text { the health risk which } \\
\text { might be rendered: }\end{array}$ & $\begin{array}{l}\text { Male } \\
\text { Female }\end{array}$ & $\begin{array}{r}70 \\
127\end{array}$ & $\begin{array}{l}2.79 \\
2.67\end{array}$ & $\begin{array}{l}.797 \\
.960\end{array}$ & $\begin{array}{l}.095 \\
.085\end{array}$ \\
\hline
\end{tabular}

\section{Independent Samples Test}

\begin{tabular}{|c|c|c|c|c|c|c|c|c|c|}
\hline & \multicolumn{2}{|c|}{\begin{tabular}{|l|} 
Levene's Test for \\
quality of Variance
\end{tabular}} & \multicolumn{7}{|c|}{ t-test for Equality of Means } \\
\hline & \multirow[b]{2}{*}{$F$} & \multirow[b]{2}{*}{ Sig. } & \multirow[b]{2}{*}{$t$} & \multirow[b]{2}{*}{$d f$} & \multirow{2}{*}{ jig. (2-tailec } & \multirow{2}{*}{$\begin{array}{c}\text { Mean } \\
\text { Difference }\end{array}$} & \multirow{2}{*}{$\begin{array}{l}\text { Std. Error } \\
\text { Difference }\end{array}$} & \multicolumn{2}{|c|}{$\begin{array}{l}95 \% \text { Confidence } \\
\text { Interval of the } \\
\text { Difference }\end{array}$} \\
\hline & & & & & & & & Lower & Upper \\
\hline $\begin{array}{l}\text { 15.) When biometric Equal varianc } \\
\text { technology is assumed } \\
\text { implemented, how } \\
\text { concerned are you a Equal varianc } \\
\text { the health risk which not assumed } \\
\text { might be rendered: }\end{array}$ & 6.633 & .011 & $\begin{array}{l}.864 \\
.911\end{array}$ & 165.573 & .363 & .12 & .128 & -.136 & .369 \\
\hline
\end{tabular}

\section{Crosstabs}

Case Processing Summary

\begin{tabular}{|l|c|c|c|c|c|c|}
\hline \multirow{2}{*}{} & \multicolumn{3}{|c|}{ Cases } \\
\cline { 2 - 7 } & \multicolumn{2}{|c|}{ Valid } & \multicolumn{2}{c|}{ Missing } & \multicolumn{2}{c|}{ Total } \\
\cline { 2 - 7 } & $\mathrm{N}$ & Percent & $\mathrm{N}$ & Percent & $\mathrm{N}$ & Percent \\
\hline $\begin{array}{l}\text { 2.) Gender: * 15.) When } \\
\text { biometric technology is } \\
\text { implemented, how } \\
\begin{array}{l}\text { concerned are you about } \\
\text { the health risk which } \\
\text { might be rendered: }\end{array}\end{array}$ & 197 & $100.0 \%$ & & 0 & & \\
\end{tabular}


Ider: * 15.) When biometric technology is implemented, how concerned are you about the health risk which be rendered: Crosstabulation

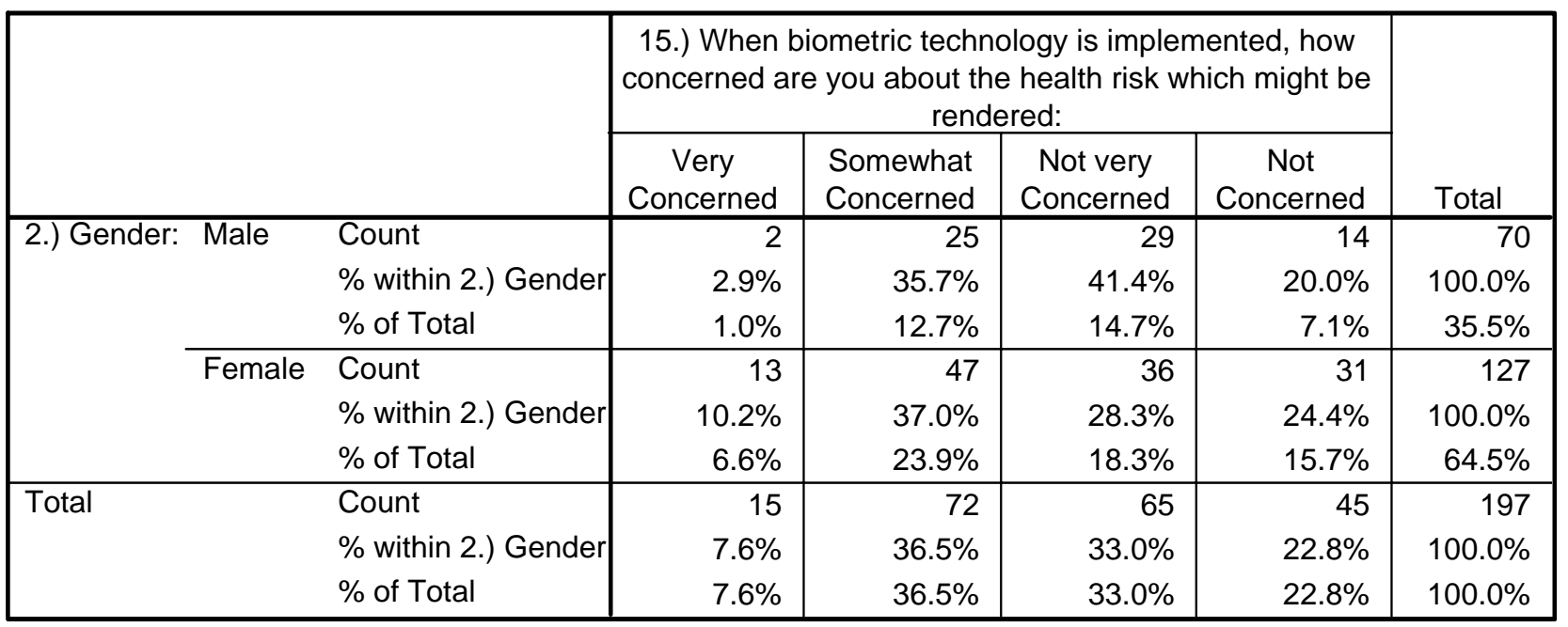

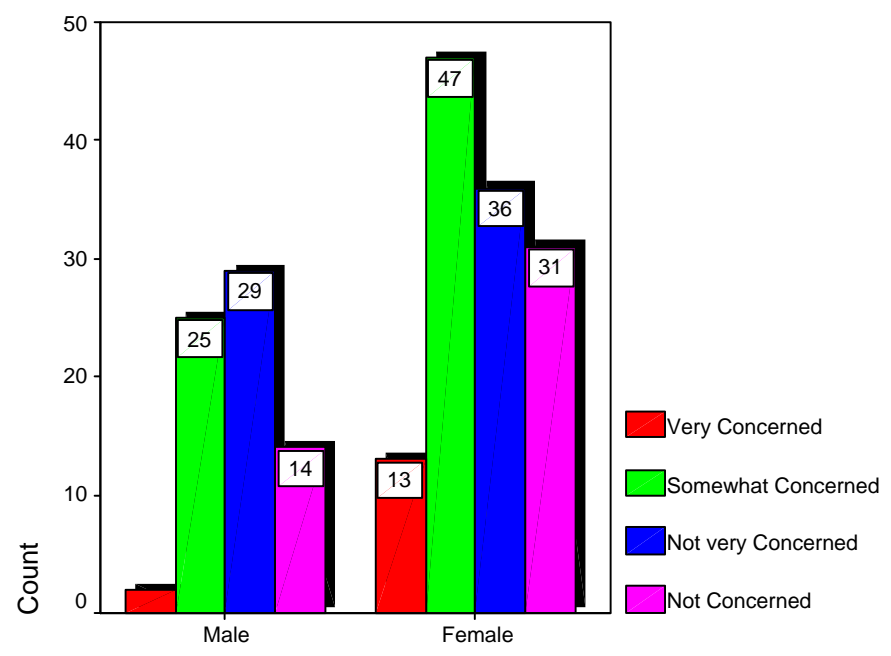

2.) Gender:

Figure C.16. Male and female responses to question regarding the health issues. 


\section{Instructors’ Group}

3.3 The differences between Male and Female within Instructors group in regard to:

Privacy issues.

Table C.32, C.33.

The t-test for the difference between Male and Female within Instructors group regarding

Privacy issues.

\section{Group Statistics}

\begin{tabular}{|c|c|c|c|c|c|}
\hline & 3.) Gender: & $\mathrm{N}$ & Mean & Std. Deviation & $\begin{array}{l}\text { Std. Error } \\
\text { Mean }\end{array}$ \\
\hline \multirow[t]{2}{*}{ Privacy } & Male & 12 & 1.9167 & .49492 & .14287 \\
\hline & Female & 12 & 2.3056 & .65841 & 19007 \\
\hline
\end{tabular}

Independent Samples Test

\begin{tabular}{|c|c|c|c|c|c|c|c|c|c|}
\hline & \multicolumn{2}{|c|}{$\begin{array}{c}\text { Levene's Test for } \\
\text { Equality of Variances }\end{array}$} & \multicolumn{7}{|c|}{ t-test for Equality of Means } \\
\hline & \multirow[b]{2}{*}{$\mathrm{F}$} & \multirow[b]{2}{*}{ Sig. } & \multirow[b]{2}{*}{$\mathrm{t}$} & \multirow[b]{2}{*}{$d f$} & \multirow[b]{2}{*}{ Sig. (2-tailed) } & \multirow{2}{*}{$\begin{array}{c}\text { Mean } \\
\text { Difference }\end{array}$} & \multirow{2}{*}{$\begin{array}{l}\text { Std. Error } \\
\text { Difference }\end{array}$} & \multicolumn{2}{|c|}{$\begin{array}{l}\text { 95\% Confidence } \\
\text { Interval of the } \\
\text { Difference }\end{array}$} \\
\hline & & & & & & & & Lower & Upper \\
\hline $\begin{array}{c}\text { Privacy Equal variance } \\
\text { assumed }\end{array}$ & .449 & .510 & -1.636 & 22 & .116 & -.3889 & .23778 & -.88201 & .10423 \\
\hline $\begin{array}{l}\text { Equal variance } \\
\text { not assumed }\end{array}$ & & & -1.636 & 20.423 & .117 & -.3889 & .23778 & -.88422 & .10645 \\
\hline
\end{tabular}

Table C.34

Cross tabulation for privacy first item between Male and female at Instructors' group. 
Gender: * 10.1) How concerned are you about having students' biometric data collected? Crosstabulation

\begin{tabular}{|c|c|c|c|c|c|c|c|}
\hline & & \multicolumn{5}{|c|}{$\begin{array}{l}\text { 10.1) How concerned are you about having students' biometric data } \\
\text { collected? }\end{array}$} & \multirow[b]{2}{*}{ Total } \\
\hline & & $\begin{array}{l}\text { Very } \\
\text { Concerned }\end{array}$ & $\begin{array}{l}\text { Somewhat } \\
\text { concerned }\end{array}$ & $\begin{array}{l}\text { Not very } \\
\text { Concerned }\end{array}$ & $\begin{array}{l}\text { Not } \\
\text { Concerned }\end{array}$ & I don't know & \\
\hline \multirow[t]{4}{*}{ Gender: Male } & Count & 2 & 4 & 6 & 3 & 0 & 15 \\
\hline & \% within 3.) Gender & $13.3 \%$ & $26.7 \%$ & $40.0 \%$ & $20.0 \%$ & $.0 \%$ & $100.0 \%$ \\
\hline & Count & 3 & 5 & 2 & 4 & 1 & 15 \\
\hline & \% within 3.) Gender & $20.0 \%$ & $33.3 \%$ & $13.3 \%$ & $26.7 \%$ & $6.7 \%$ & $100.0 \%$ \\
\hline \multirow[t]{2}{*}{ Total } & Count & 5 & 9 & 8 & 7 & 1 & 30 \\
\hline & \% within 3.) Gender & $16.7 \%$ & $30.0 \%$ & $26.7 \%$ & $23.3 \%$ & $3.3 \%$ & $100.0 \%$ \\
\hline
\end{tabular}

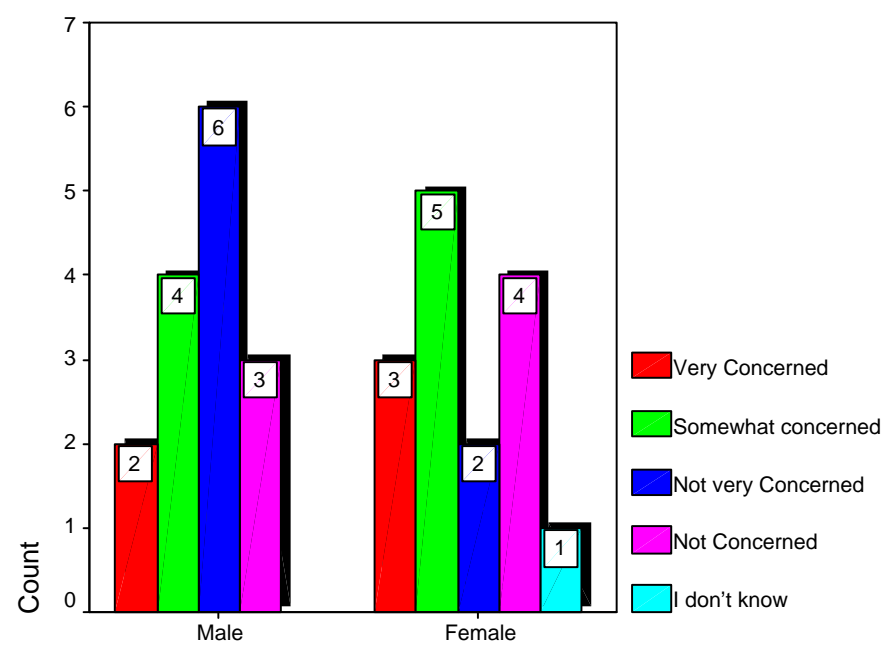

3.) Gender:

Figure C.17. Male and Female Instructors and their responses to first item of privacy issues. 
Table C.35

Cross tabulation for privacy second item between Male and female at Instructors' group.

Gender: * 10.2) How concerned are you about having students' biometric data stored in non-secure storage? Crosstabulation

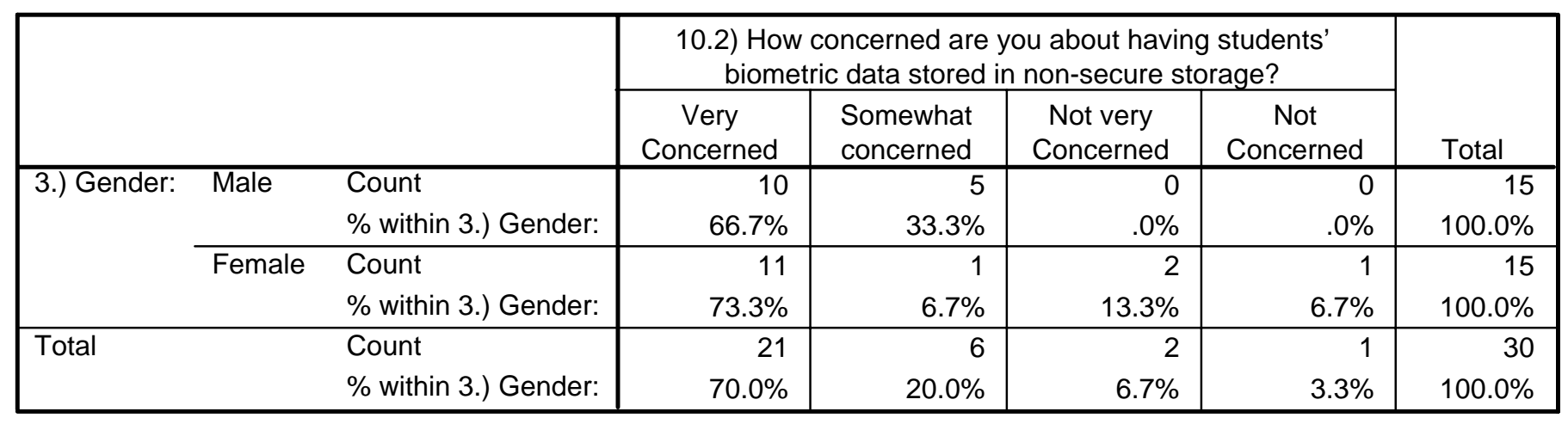

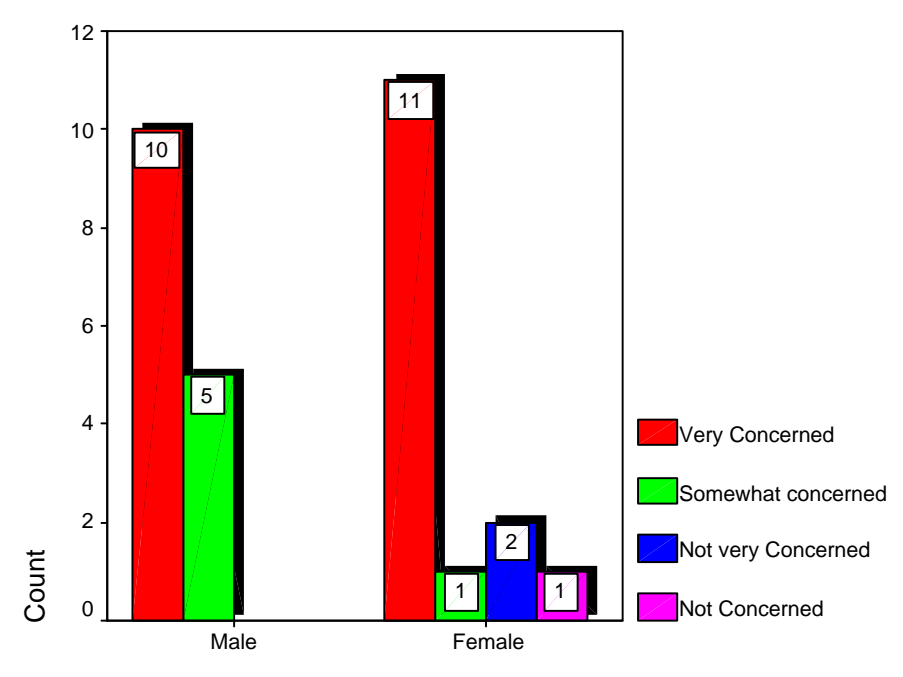

3.) Gender:

Figure C.18. Male and Female Instructors and their responses to second item of Privacy issues. 
Table C.36

Cross tabulation for privacy third item between Male and female at Instructors' group.

Gender: * 10.3) How concerned are you about having students' biometric data used by third party? Crosstabulation

\begin{tabular}{|c|c|c|c|c|c|c|}
\hline & & & \multicolumn{3}{|c|}{$\begin{array}{l}\text { 10.3) How concerned are you about having } \\
\text { students' biometric data used by third party? }\end{array}$} & \multirow[b]{2}{*}{ Total } \\
\hline & & & $\begin{array}{c}\text { Very } \\
\text { Concerned }\end{array}$ & $\begin{array}{l}\text { Somewhat } \\
\text { concerned }\end{array}$ & $\begin{array}{c}\text { Not very } \\
\text { Concerned }\end{array}$ & \\
\hline \multirow[t]{4}{*}{ 3.) Gender: } & Male & Count & 11 & 4 & 0 & 15 \\
\hline & & \% within 3.) Gender: & $73.3 \%$ & $26.7 \%$ & $.0 \%$ & $100.0 \%$ \\
\hline & Female & Count & 11 & 3 & 1 & 15 \\
\hline & & \% within 3.) Gender: & $73.3 \%$ & $20.0 \%$ & $6.7 \%$ & $100.0 \%$ \\
\hline \multirow{2}{*}{\multicolumn{2}{|c|}{ Total }} & Count & 22 & 7 & 1 & 30 \\
\hline & & \% within 3.) Gender: & $73.3 \%$ & $23.3 \%$ & $3.3 \%$ & $100.0 \%$ \\
\hline
\end{tabular}

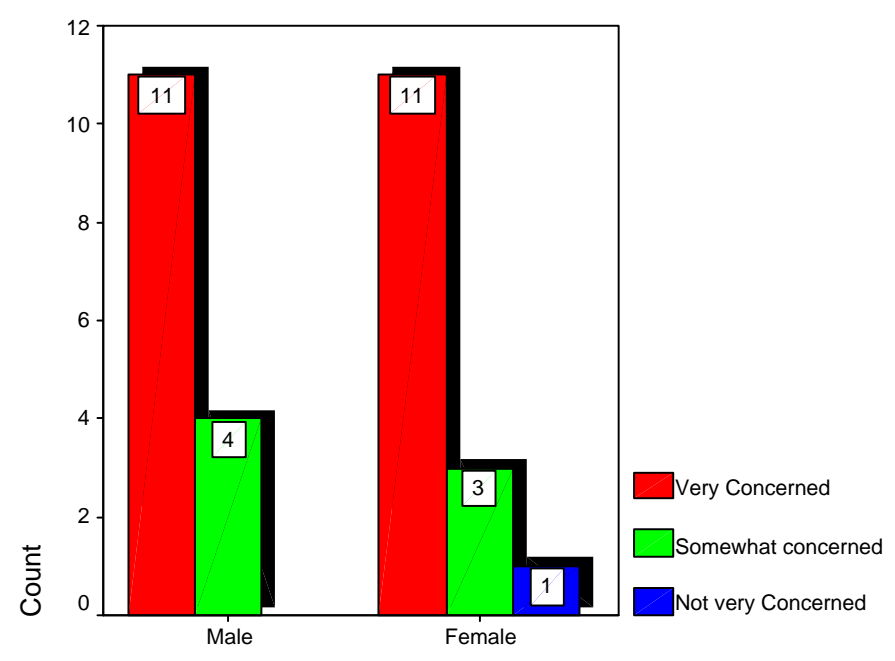

3.) Gender:

Figure C.19. Male and Female Instructors and their responses to third item of the Privacy issues. 
Table C.37

Cross tabulation for privacy fourth item between Male and female at Instructors' group.

Gender: * 10.4) How concerned are you about having students' biometric data misused by WVU? Crosstabulation

\begin{tabular}{|ll|r|r|r|r|r|}
\hline \multirow{2}{*}{} & & \multicolumn{2}{|c|}{$\begin{array}{c}\text { 10.4) How concerned are you about having students' biometric data } \\
\text { misused by WVU? }\end{array}$} \\
\cline { 3 - 8 } & & \multicolumn{1}{|c|}{$\begin{array}{c}\text { Very } \\
\text { Concerned }\end{array}$} & $\begin{array}{c}\text { Somewhat } \\
\text { concerned }\end{array}$ & $\begin{array}{c}\text { Not very } \\
\text { Concerned }\end{array}$ & $\begin{array}{c}\text { Not } \\
\text { Concerned }\end{array}$ & I don't know \\
Total \\
\hline 3.) Gender:
\end{tabular}

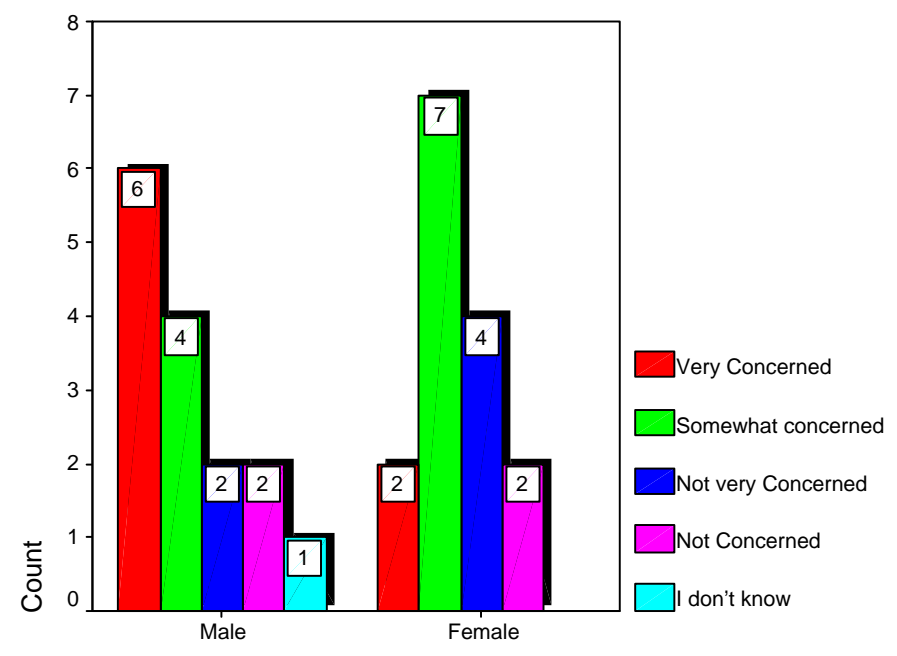

3.) Gender:

Figure C.20. Male and Female Instructors and their responses to fourth item of the

Privacy issues. 
Table C.38

Cross tabulation for privacy fifth item between Male and female at Instructors' group.

Gender: * 10.5) How concerned are you about the invasion of students' privacy by WVU, when biometric technology is implemented? Crosstabulation

\begin{tabular}{|c|c|c|c|c|c|c|c|c|}
\hline & & & \multicolumn{5}{|c|}{$\begin{array}{l}\text { 10.5) How concerned are you about the invasion of students' privacy by } \\
\text { WVU, when biometric technology is implemented? }\end{array}$} & \multirow[b]{2}{*}{ Total } \\
\hline & & & $\begin{array}{c}\text { Very } \\
\text { Concerned }\end{array}$ & $\begin{array}{l}\text { Somewhat } \\
\text { concerned }\end{array}$ & $\begin{array}{l}\text { Not very } \\
\text { Concerned }\end{array}$ & $\begin{array}{c}\text { Not } \\
\text { Concerned }\end{array}$ & I don't know & \\
\hline \multirow[t]{4}{*}{ 3.) Gender: } & Male & Count & 3 & 7 & 3 & 2 & 0 & 15 \\
\hline & & \% within 3.) Gender: & $20.0 \%$ & $46.7 \%$ & $20.0 \%$ & $13.3 \%$ & $.0 \%$ & $100.0 \%$ \\
\hline & Female & Count & 1 & 6 & 5 & 2 & 1 & 15 \\
\hline & & \% within 3.) Gender: & $6.7 \%$ & $40.0 \%$ & $33.3 \%$ & $13.3 \%$ & $6.7 \%$ & $100.0 \%$ \\
\hline \multirow{2}{*}{\multicolumn{2}{|c|}{ Total }} & Count & 4 & 13 & 8 & 4 & 1 & 30 \\
\hline & & \% within 3.) Gender: & $13.3 \%$ & $43.3 \%$ & $26.7 \%$ & $13.3 \%$ & $3.3 \%$ & $100.0 \%$ \\
\hline
\end{tabular}

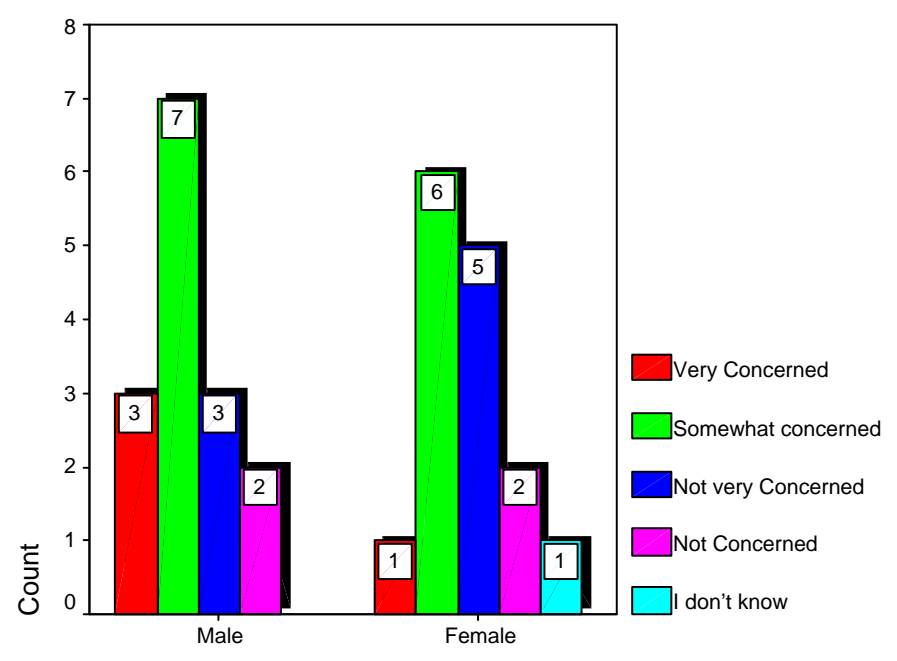

3.) Gender:

Figure C.21. Male and Female Instructors and their responses to fifth item of the Privacy issues. 
Table C.39

Cross tabulation for privacy sixth item between Male and female at Instructors' group.

Ider: * 10.6) How concerned are you about the negative stigma attached to the use of biometric technology? Crosstabulal

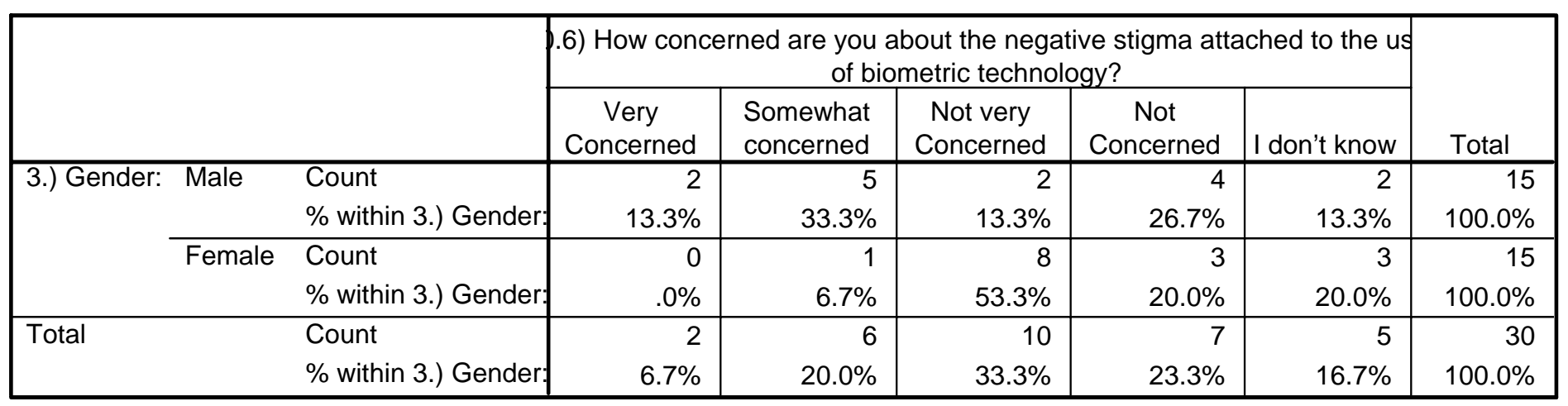

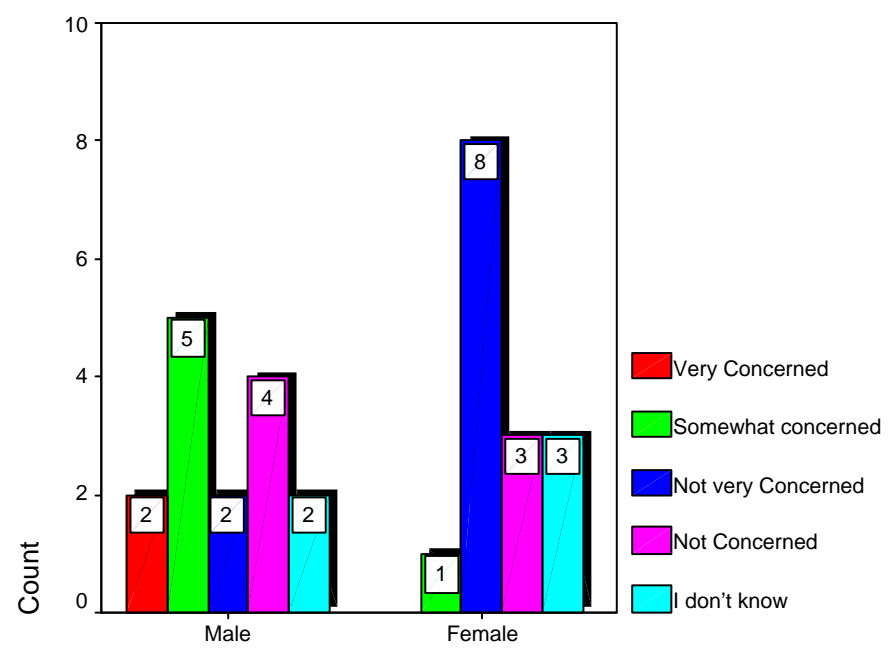

3.) Gender:

Figure C.22. Male and Female Instructors and their responses to sixth item of the Privacy issues. 


\section{Religious Issues}

Table C.40-C.41

The t-test for the difference between Male and Female within Instructors group regarding

Privacy issues.

Group Statistics

\begin{tabular}{|c|c|c|c|c|c|}
\hline & 3.) Gender: & $\mathrm{N}$ & Mean & Std. Deviation & $\begin{array}{l}\text { Std. Error } \\
\text { Mean }\end{array}$ \\
\hline $\begin{array}{l}\text { 12.) In terms of religious } \\
\text { conflicts, how appropriate } \\
\text { do you think the } \\
\text { implementing of the } \\
\text { biometric systems in the } \\
\text { WVU are? (as described } \\
\text { in the scenario above) }\end{array}$ & $\begin{array}{l}\text { Male } \\
\text { Female }\end{array}$ & 12 & $\begin{array}{l}1.75 \\
2.38\end{array}$ & .754 & $\begin{array}{r}.218 \\
.263\end{array}$ \\
\hline
\end{tabular}

Independent Samples Test

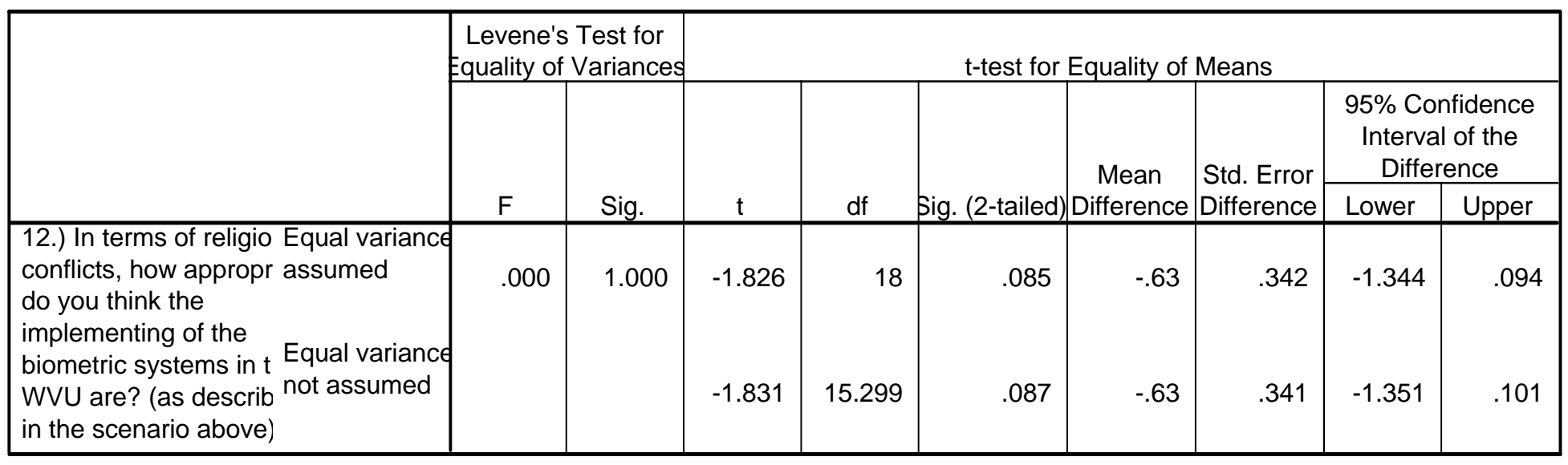

Table C.42

Cross tabulation for first question related to religious issues. 
jender: * 12.) In terms of religious conflicts, how appropriate do you think the implementing of the biometric system in the WVU are? (as described in the scenario above) Crosstabulation

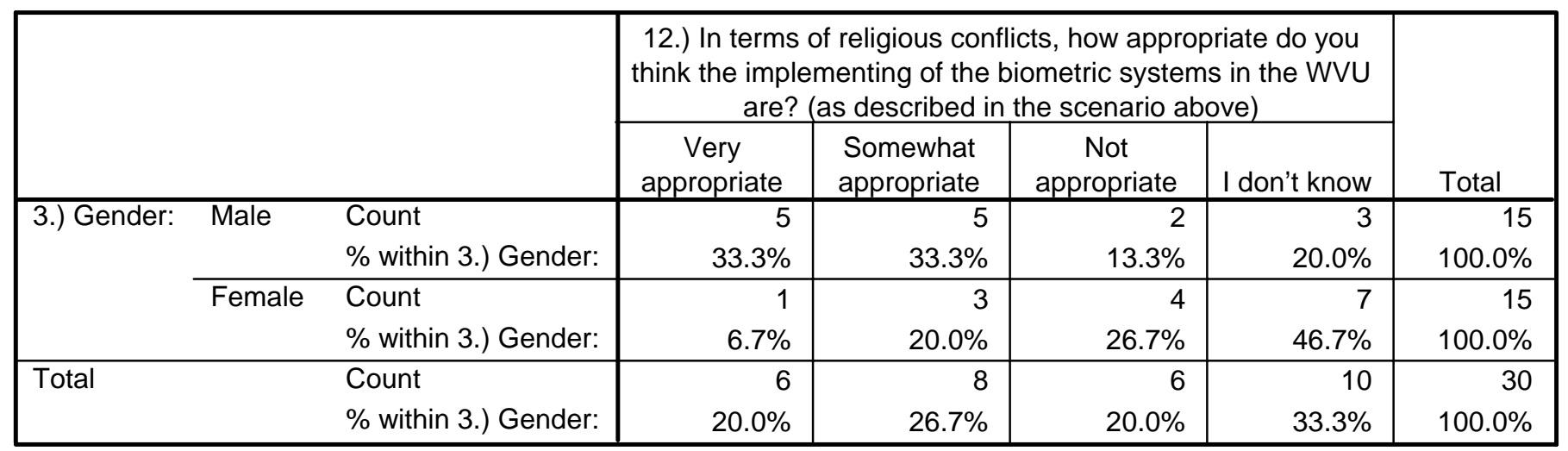

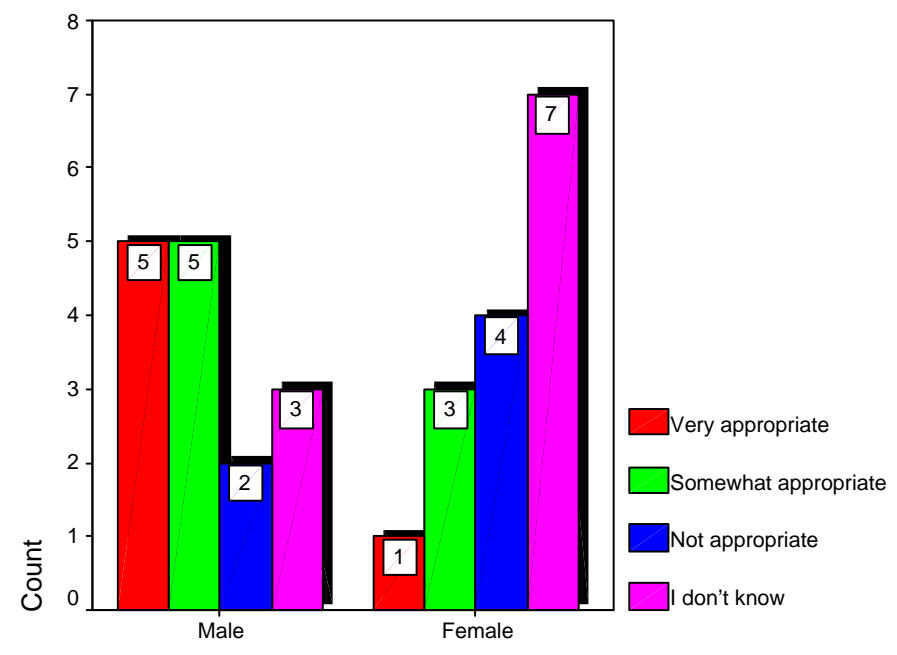

3.) Gender:

Figure C.23. Male and Female Instructors and their responses to first item regarding the Religious issues. 


\section{Table C.43}

Cross tabulation for second question related to religious issues.

\section{Gender: * 13.) Do you think the implementation of biometric technology at WVU contradicts your religious beliefs?}

\section{3.) Crosstabulation}

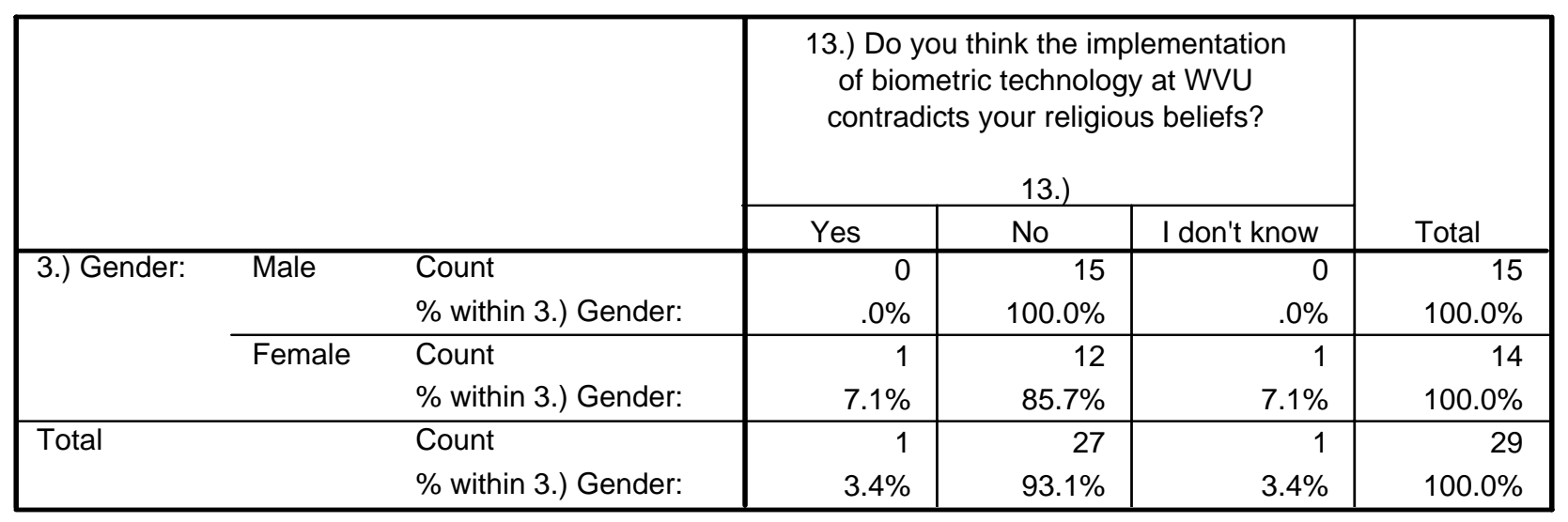

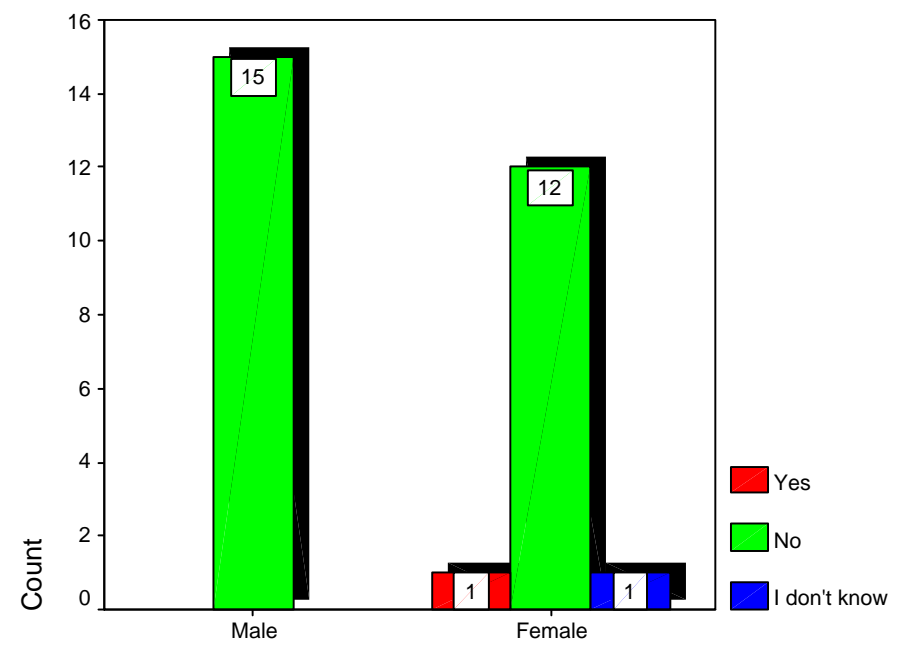

3.) Gender:

Figure C.24. Male and Female Instructors and their responses to second item regarding the Religious issues. 


\section{Health Issues}

Table C.44-C.45

The t-test for the difference between Male and Female within Instructors group regarding

Health issues.

Group Statistics

\begin{tabular}{|ll|r|r|r|r|}
\hline & 3.) Gender: & $\mathrm{N}$ & Mean & Std. Deviation & $\begin{array}{c}\text { Std. Error } \\
\text { Mean }\end{array}$ \\
\hline $\begin{array}{l}\text { 16.) When biometric } \\
\text { technology is } \\
\text { implemented, how } \\
\begin{array}{l}\text { concerned are you about } \\
\text { the health risk which } \\
\text { might be rendered: }\end{array}\end{array}$ & Male & 15 & 3.07 & .799 & .206 \\
\hline
\end{tabular}

Independent Samples Test

\begin{tabular}{|c|c|c|c|c|c|c|c|c|c|}
\hline & \multicolumn{2}{|c|}{$\begin{array}{l}\text { Levene's Test for } \\
\text { quality of Variance }\end{array}$} & \multicolumn{7}{|c|}{ t-test for Equality of Means } \\
\hline & \multirow[b]{2}{*}{$\mathrm{F}$} & \multirow[b]{2}{*}{ Sig. } & \multirow[b]{2}{*}{$\mathrm{t}$} & \multirow[b]{2}{*}{ df } & \multirow[b]{2}{*}{ jig. (2-tailed } & \multirow{2}{*}{$\begin{array}{c}\text { Mean } \\
\text { Difference }\end{array}$} & \multirow{2}{*}{$\begin{array}{l}\text { Std. Error } \\
\text { Difference }\end{array}$} & \multicolumn{2}{|c|}{$\begin{array}{l}95 \% \text { Confidence } \\
\text { Interval of the } \\
\text { Difference }\end{array}$} \\
\hline & & & & & & & & Lower & Upper \\
\hline $\begin{array}{l}\text { 16.) When biometric Equal variand } \\
\text { technology is assumed } \\
\text { implemented, how } \\
\text { concerned are you i Equal variand } \\
\text { the health risk which not assumed } \\
\text { might be rendered: }\end{array}$ & .230 & .635 & $\begin{array}{l}-1.862 \\
-1.876\end{array}$ & 26.490 & .073 & -.50 & .271 & \begin{tabular}{|l|}
-1.061 \\
-1.057
\end{tabular} & $\begin{array}{l}.051 \\
.048\end{array}$ \\
\hline
\end{tabular}

Table C.46

Cross tabulation for question related to Health issues. 
Gender: * 16.) When biometric technology is implemented, how concerned are you about the health risk which might be rendered: Crosstabulation

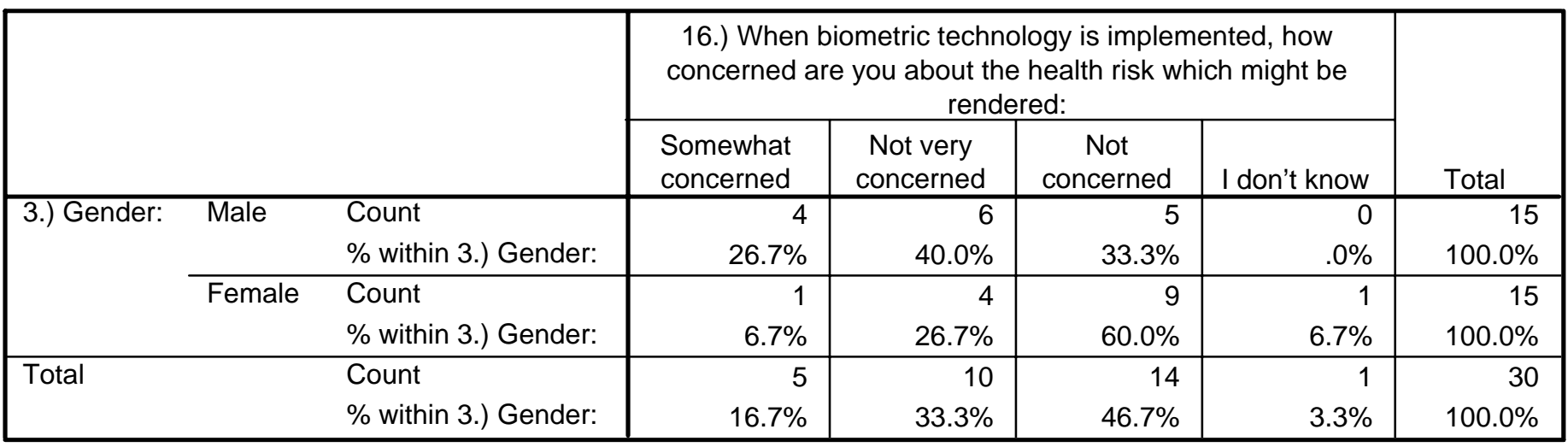

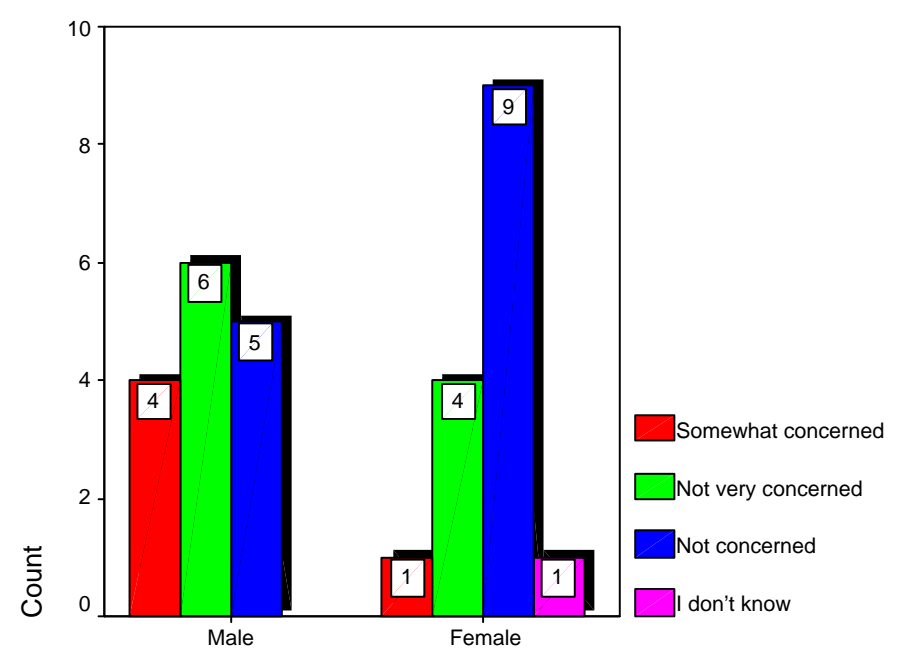

3.) Gender:

Figure C.25. Male and Female Instructors and their responses to question regarding the Health issues. 


\section{Students' Group}

3.4 The differences between Male and Female within Students group in regard to:

\section{Privacy Issues}

Table C.47-C.48

The t-test for the difference between Male and Female within Instructors group regarding

Privacy issues.

Group Statistics

\begin{tabular}{|ll|r|r|r|c|}
\hline & & & & Std. Error \\
& 2.) Gender: & $\mathrm{N}$ & Mean & Std. Deviation & \multicolumn{1}{c|}{ Mean } \\
\hline Privacy & Male & 52 & 2.0705 & .74780 & .10370 \\
& Female & 121 & 1.8402 & .71018 & .06456 \\
\hline
\end{tabular}

Independent Samples Test

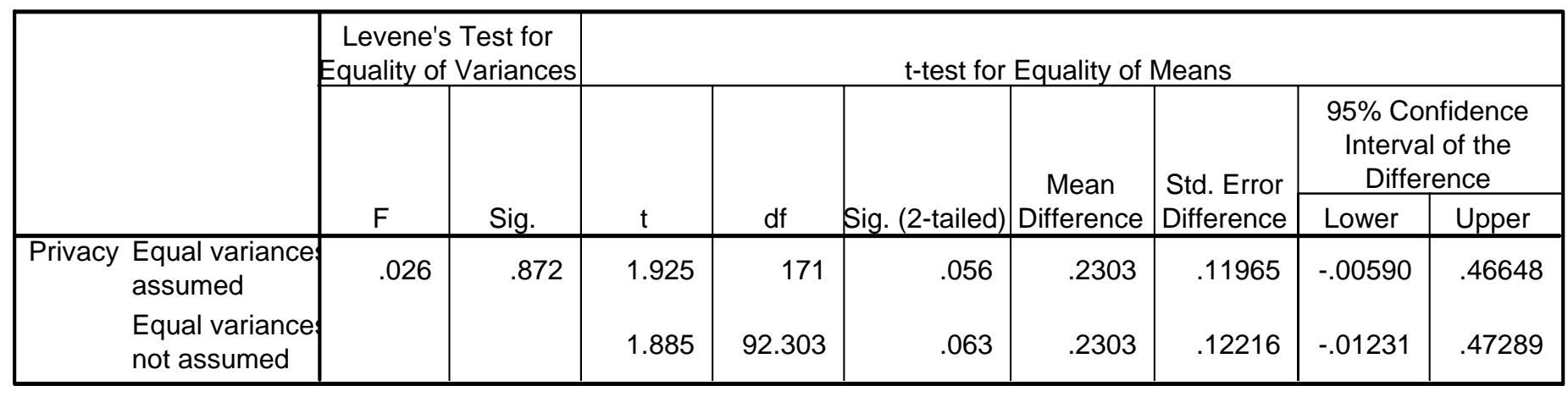

Table C.49

Cross tabulation for privacy first item between Male and female at Students' group. 
Gender: * 9.1) A.The privacy issues - How concerned are you about having your biometric data collected? Crosstabulation

\begin{tabular}{|c|c|c|c|c|c|c|c|}
\hline & & \multicolumn{5}{|c|}{$\begin{array}{l}\text { 9.1) A.The privacy issues - How concerned are you about having your } \\
\text { biometric data collected? }\end{array}$} & \multirow[b]{2}{*}{ Total } \\
\hline & & $\begin{array}{c}\text { Very } \\
\text { Concerned }\end{array}$ & $\begin{array}{l}\text { Somewhat } \\
\text { Concerned }\end{array}$ & $\begin{array}{c}\text { Not very } \\
\text { Concerned }\end{array}$ & $\begin{array}{c}\text { Not } \\
\text { Concerned }\end{array}$ & I don't know & \\
\hline \multirow[t]{4}{*}{ 2.) Gender: Male } & Count & 8 & 20 & 19 & 10 & 1 & 58 \\
\hline & \% within 2.) Gender: & $13.8 \%$ & $34.5 \%$ & $32.8 \%$ & $17.2 \%$ & $1.7 \%$ & $100.0 \%$ \\
\hline & Count & 23 & 56 & 27 & 19 & 6 & 131 \\
\hline & $\%$ within 2.) Gender: & $17.6 \%$ & $42.7 \%$ & $20.6 \%$ & $14.5 \%$ & $4.6 \%$ & $100.0 \%$ \\
\hline \multirow[t]{2}{*}{ Total } & Count & 31 & 76 & 46 & 29 & 7 & 189 \\
\hline & \% within 2.) Gender: & $16.4 \%$ & $40.2 \%$ & $24.3 \%$ & $15.3 \%$ & $3.7 \%$ & $100.0 \%$ \\
\hline
\end{tabular}

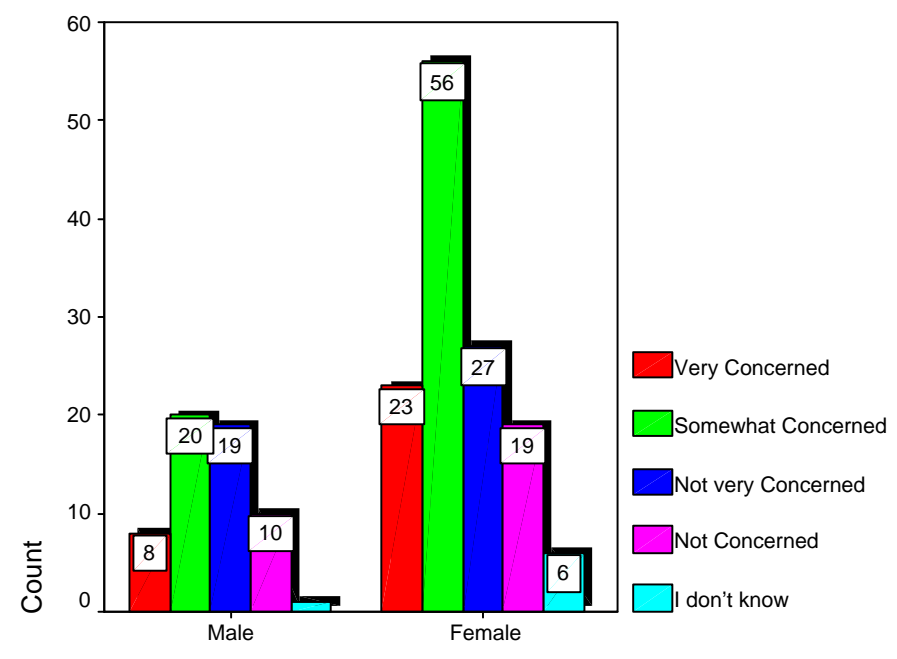

2.) Gender:

Figure C.26. Male and Female Students and their responses to first item of privacy issues. 
Table C.50

Cross tabulation for privacy second item between Male and female at Students' group.

Gender: * 9.2) A.The privacy issues - How concerned are you about having your biometric data stored in non-secure storage? Crosstabulation

\begin{tabular}{|c|c|c|c|c|c|c|c|}
\hline & \multicolumn{5}{|c|}{$\begin{array}{l}\text { 9.2) A.The privacy issues - How concerned are you about having your } \\
\text { biometric data stored in non-secure storage? }\end{array}$} & \multirow[b]{2}{*}{ Total } \\
\hline & & $\begin{array}{l}\text { Very } \\
\text { Concerned }\end{array}$ & $\begin{array}{l}\text { Somewhat } \\
\text { Concerned }\end{array}$ & $\begin{array}{l}\text { Not very } \\
\text { Concerned }\end{array}$ & $\begin{array}{l}\text { Not } \\
\text { Concerned }\end{array}$ & I don't know & \\
\hline \multirow[t]{4}{*}{ 2.) Gender: Male } & Count & 35 & 11 & 5 & 5 & 2 & 58 \\
\hline & \% within 2.) Gender: & $60.3 \%$ & $19.0 \%$ & $8.6 \%$ & $8.6 \%$ & $3.4 \%$ & $100.0 \%$ \\
\hline & Count & 87 & 33 & 3 & 5 & 3 & 131 \\
\hline & \% within 2.) Gender: & $66.4 \%$ & $25.2 \%$ & $2.3 \%$ & $3.8 \%$ & $2.3 \%$ & $100.0 \%$ \\
\hline \multirow[t]{2}{*}{ Total } & Count & 122 & 44 & 8 & 10 & 5 & 189 \\
\hline & \% within 2.) Gender: & $64.6 \%$ & $23.3 \%$ & $4.2 \%$ & $5.3 \%$ & $2.6 \%$ & $100.0 \%$ \\
\hline
\end{tabular}

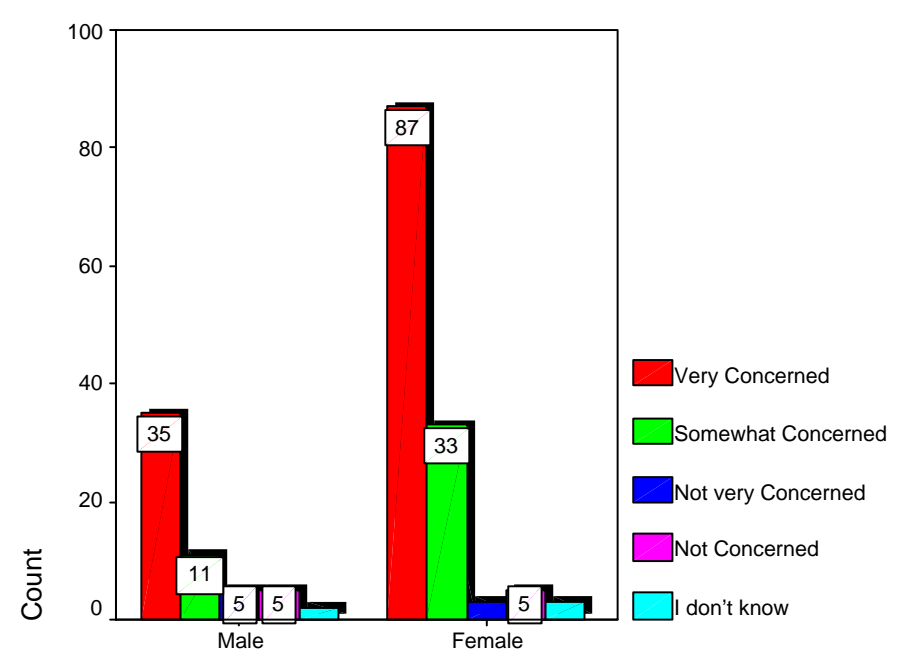

2.) Gender:

Figure C.27. Male and Female Students and their responses to second item of Privacy issues. 


\section{Table C.51}

Cross tabulation for privacy third item between Male and Female at Students' group.

* 9.3) A.The privacy issues - How concerned are you about having your biometric data used by third party? Crossta

\begin{tabular}{|c|c|c|c|c|c|c|c|}
\hline & \multicolumn{5}{|c|}{$\begin{array}{l}\text { 9.3) A.The privacy issues - How concerned are you about having your } \\
\text { biometric data used by third party? }\end{array}$} & \multirow[b]{2}{*}{ Total } \\
\hline & & $\begin{array}{c}\text { Very } \\
\text { Concerned }\end{array}$ & $\begin{array}{l}\text { Somewhat } \\
\text { Concerned }\end{array}$ & $\begin{array}{l}\text { Not very } \\
\text { Concerned }\end{array}$ & $\begin{array}{l}\text { Not } \\
\text { Concerned }\end{array}$ & I don't know & \\
\hline \multirow[t]{2}{*}{ 2.) Gender: Male } & Count & 33 & 12 & 7 & 3 & 3 & 58 \\
\hline & $\%$ within 2.) Gendel & $56.9 \%$ & $20.7 \%$ & $12.1 \%$ & $5.2 \%$ & $5.2 \%$ & $100.0 \%$ \\
\hline \multirow[t]{2}{*}{ Female } & Count & 80 & 39 & 6 & 4 & 2 & 131 \\
\hline & $\%$ within 2.) Gendel & $61.1 \%$ & $29.8 \%$ & $4.6 \%$ & $3.1 \%$ & $1.5 \%$ & $100.0 \%$ \\
\hline \multirow[t]{2}{*}{ Total } & Count & 113 & 51 & 13 & 7 & 5 & 189 \\
\hline & \% within 2.) Gendel & $59.8 \%$ & $27.0 \%$ & $6.9 \%$ & $3.7 \%$ & $2.6 \%$ & $100.0 \%$ \\
\hline
\end{tabular}

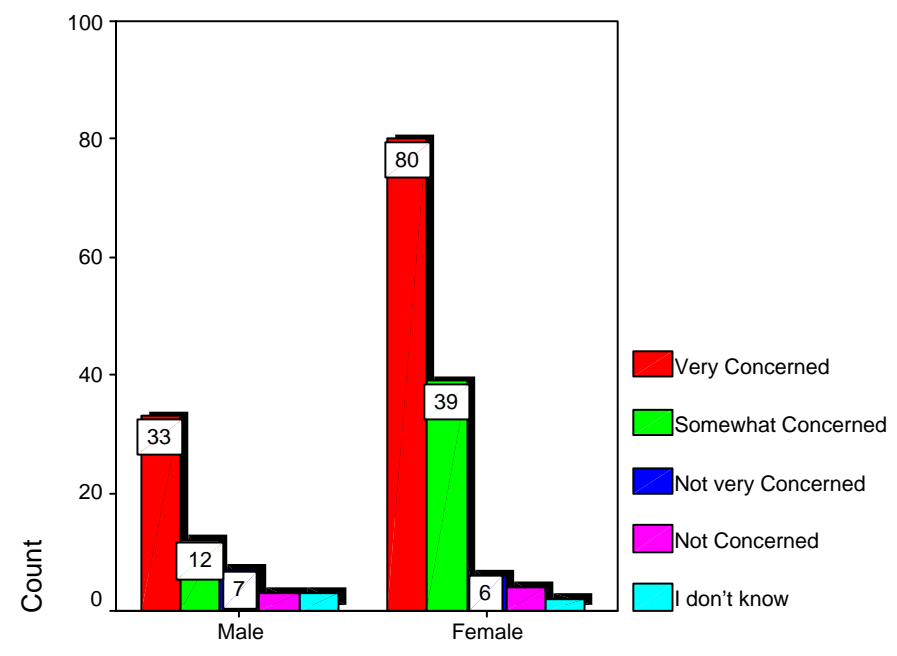

2.) Gender:

Figure C.28. Male and Female Students and their responses to third item of the Privacy issues. 
Table C.52

Cross tabulation for privacy fourth item between Male and female at Students' group.

4) A.The privacy issues - How concerned are you about having your biometric data misused by WVU? Crosstabulati

\begin{tabular}{|c|c|c|c|c|c|c|c|}
\hline & \multicolumn{5}{|c|}{$\begin{array}{l}\text { 9.4) A. The privacy issues - How concerned are you about having your } \\
\text { biometric data misused by WVU? }\end{array}$} & \multirow[b]{2}{*}{ Total } \\
\hline & & $\begin{array}{c}\text { Very } \\
\text { Concerned }\end{array}$ & $\begin{array}{l}\text { Somewhat } \\
\text { Concerned }\end{array}$ & $\begin{array}{l}\text { Not very } \\
\text { Concerned }\end{array}$ & $\begin{array}{l}\text { Not } \\
\text { Concerned }\end{array}$ & I don't know & \\
\hline \multirow[t]{2}{*}{ 2.) Gender: Male } & Count & 21 & 15 & 12 & 6 & 4 & 58 \\
\hline & \% within 2.) Gende & $36.2 \%$ & $25.9 \%$ & $20.7 \%$ & $10.3 \%$ & $6.9 \%$ & $100.0 \%$ \\
\hline \multirow[t]{2}{*}{ Female } & Count & 70 & 37 & 15 & 7 & 2 & 131 \\
\hline & $\%$ within 2.) Gende & $53.4 \%$ & $28.2 \%$ & $11.5 \%$ & $5.3 \%$ & $1.5 \%$ & $100.0 \%$ \\
\hline \multirow[t]{2}{*}{ Total } & Count & 91 & 52 & 27 & 13 & 6 & 189 \\
\hline & \% within 2.) Gende & $48.1 \%$ & $27.5 \%$ & $14.3 \%$ & $6.9 \%$ & $3.2 \%$ & $100.0 \%$ \\
\hline
\end{tabular}

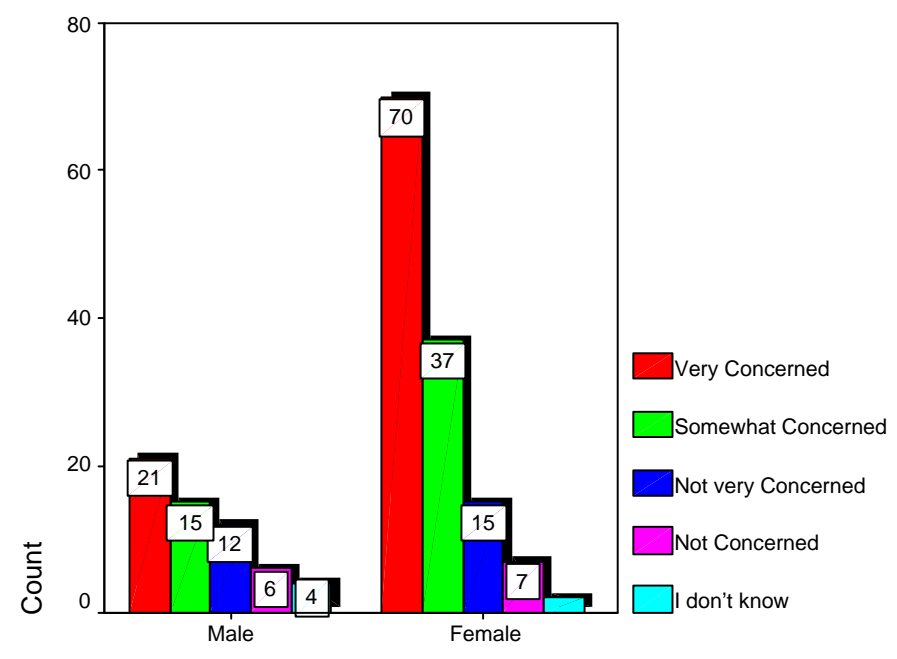

2.) Gender:

Figure C.29. Male and Female Student and their responses to fourth item of the Privacy issues. 


\section{Table C.53}

Cross tabulation for privacy fifth item between Male and female at Students' group.

$r:$ * 9.5) A.The privacy issues - How concerned are you about the invasion of your privacy by WVU, when biometric techno implemented? Crosstabulation

\begin{tabular}{|c|c|c|c|c|c|c|c|}
\hline & \multicolumn{5}{|c|}{$\begin{array}{l}\text { A.The privacy issues - How concerned are you about the invasion of yo } \\
\text { privacy by WVU, when biometric technology is implemented? }\end{array}$} & \multirow[b]{2}{*}{ Total } \\
\hline & & $\begin{array}{c}\text { Very } \\
\text { Concerned }\end{array}$ & $\begin{array}{l}\text { Somewhat } \\
\text { Concerned }\end{array}$ & $\begin{array}{l}\text { Not very } \\
\text { Concerned }\end{array}$ & $\begin{array}{c}\text { Not } \\
\text { Concerned }\end{array}$ & I don't know & \\
\hline \multirow{2}{*}{ 2.) Gender: Male } & \% within 2.) Gender: & $27.6 \%$ & $39.7 \%$ & $20.7 \%$ & $8.6 \%$ & $3.4 \%$ & $100.0 \%$ \\
\hline & Count & 64 & 37 & 18 & 10 & 2 & 131 \\
\hline \multirow[t]{2}{*}{ Total } & Count & 80 & 60 & 30 & 15 & 4 & 189 \\
\hline & \% within 2.) Gender: & $42.3 \%$ & $31.7 \%$ & $15.9 \%$ & $7.9 \%$ & $2.1 \%$ & $100.0 \%$ \\
\hline
\end{tabular}

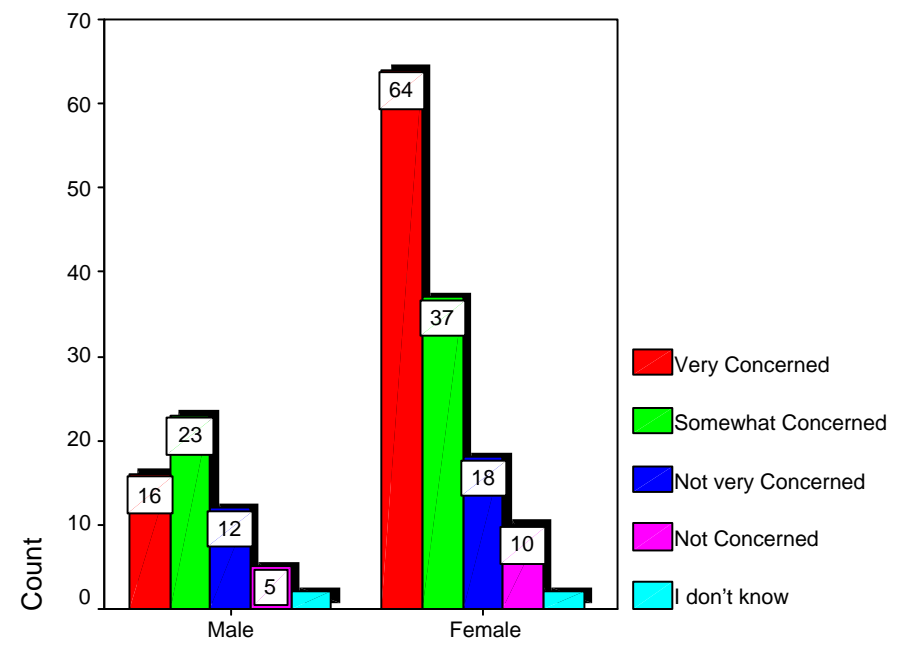

2.) Gender:

Figure C.30. Male and Female Students and their responses to fifth item of the Privacy issues. 


\section{Table C.54}

Cross tabulation for privacy sixth item between Male and female at Students' group.

Gender: * 9.6) A.The privacy issues - How concerned are you about the negative stigma attached to the use of biometric technology? Crosstabulation

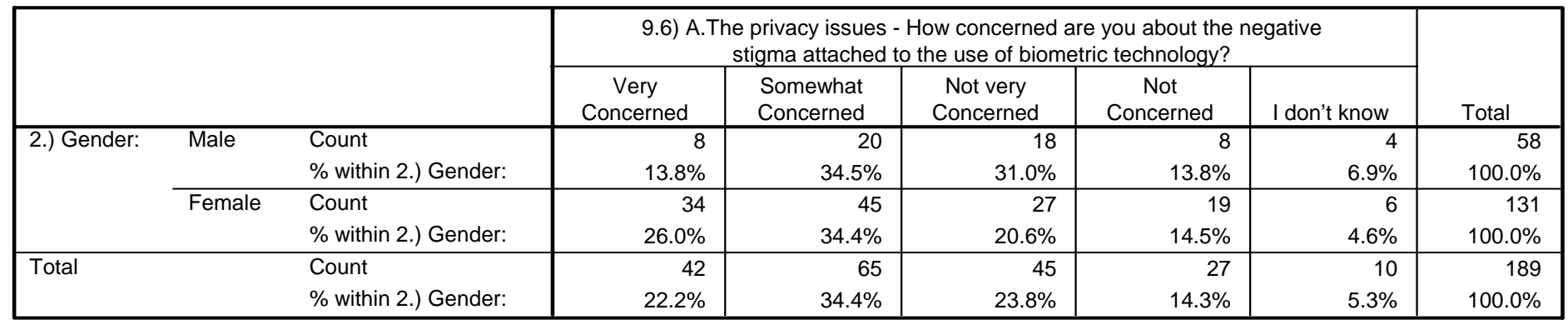

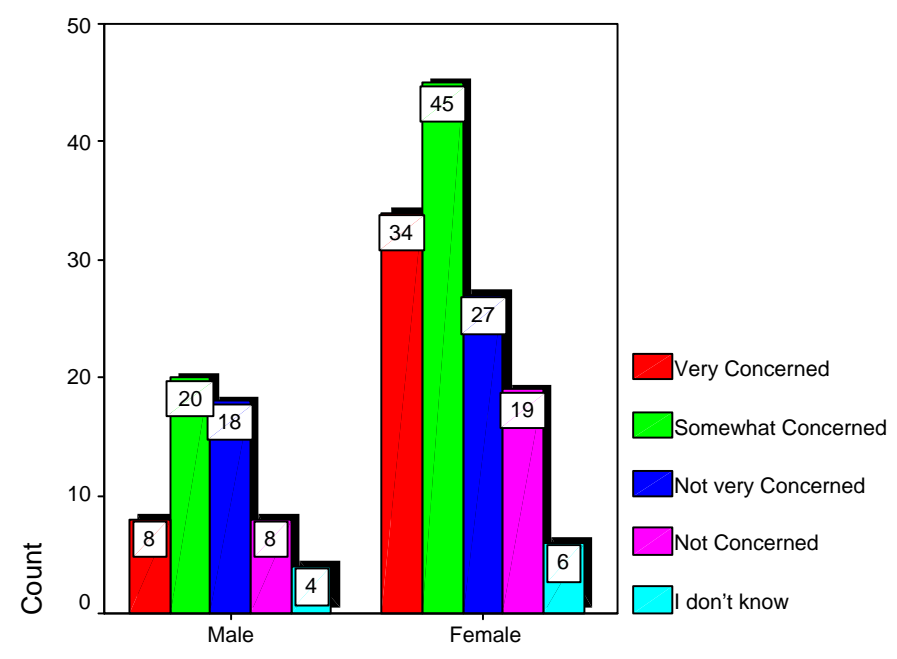

2.) Gender:

Figure C.31. Male and Female Students and their responses to sixth item of the Privacy issues. 


\section{Religious Issues}

Table C.55-C.56

The t-test for the difference between Male and Female within Instructors group regarding

Religious issues.

\section{Group Statistics}

\begin{tabular}{|c|c|c|c|c|c|}
\hline & 2.) Gender: & $\mathrm{N}$ & Mean & Std. Deviation & $\begin{array}{l}\text { Std. Error } \\
\text { Mean }\end{array}$ \\
\hline $\begin{array}{l}\text { 11.) In terms of } \\
\text { religious conflicts, how } \\
\text { appropriate do you } \\
\text { think of implementing } \\
\text { the biometric systems } \\
\text { as described in the } \\
\text { scenario below? }\end{array}$ & Male & 44 & 2.18 & .922 & $\begin{array}{l}.139 \\
.092\end{array}$ \\
\hline
\end{tabular}

Independent Samples Test

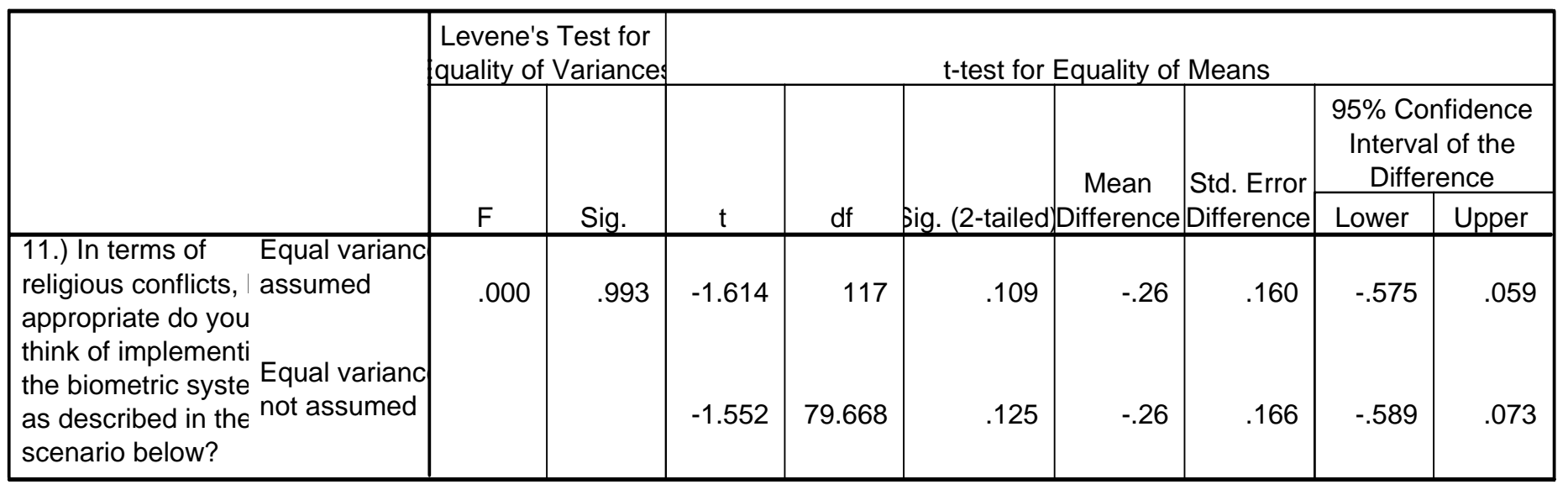

Table C.57

Cross tabulation for first question related to religious issues. 
Gender: * 11.) In terms of religious conflicts, how appropriate do you think of implementing the biometric systems as described in the scenario below? Crosstabulation

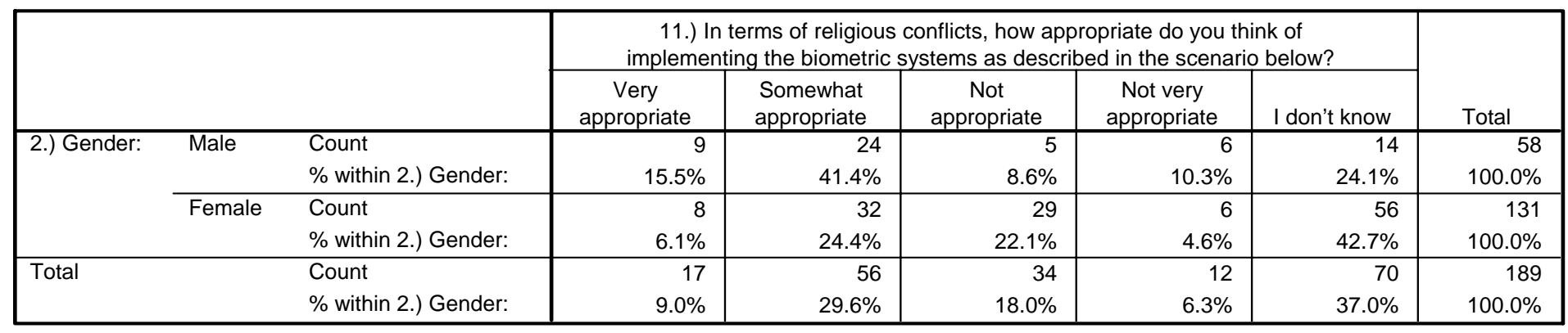

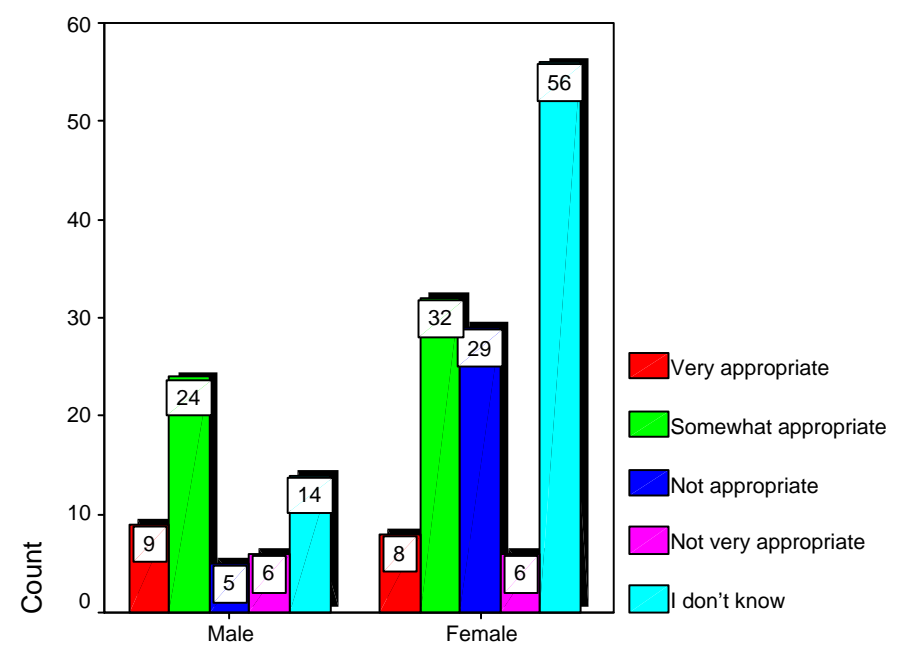

2.) Gender:

Figure C.32. Male and Female Instructors and their responses to first item regarding the

Religious issues. 
Table C.58

Cross tabulation for second question related to religious issues.

Gender: * 12.) Do you think the implementation of biometric technology at WVU contradicts your religious beliefs?

Crosstabulation

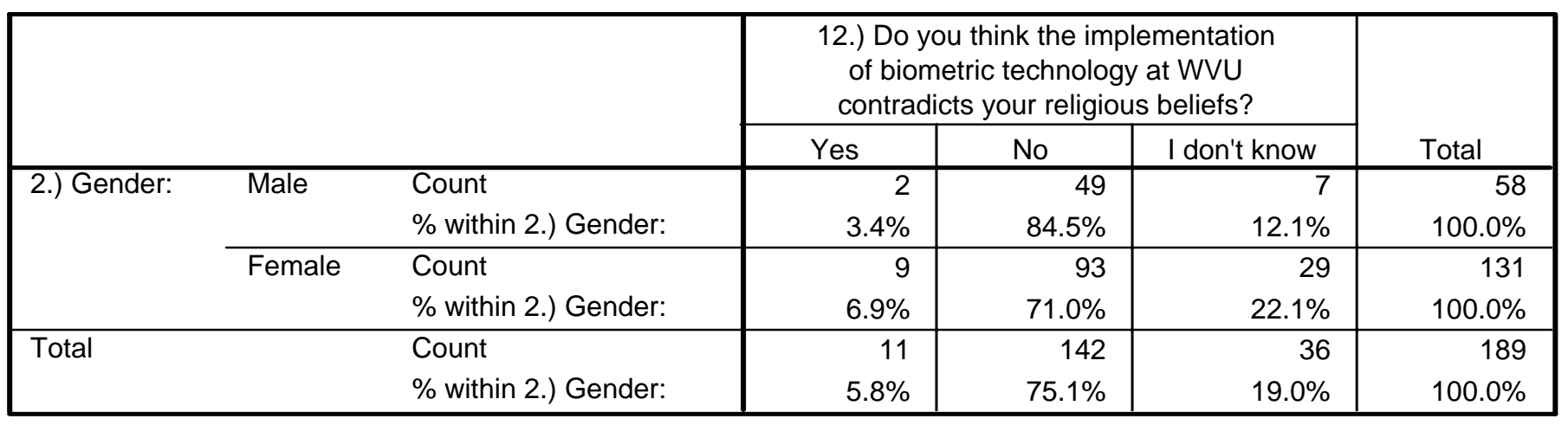

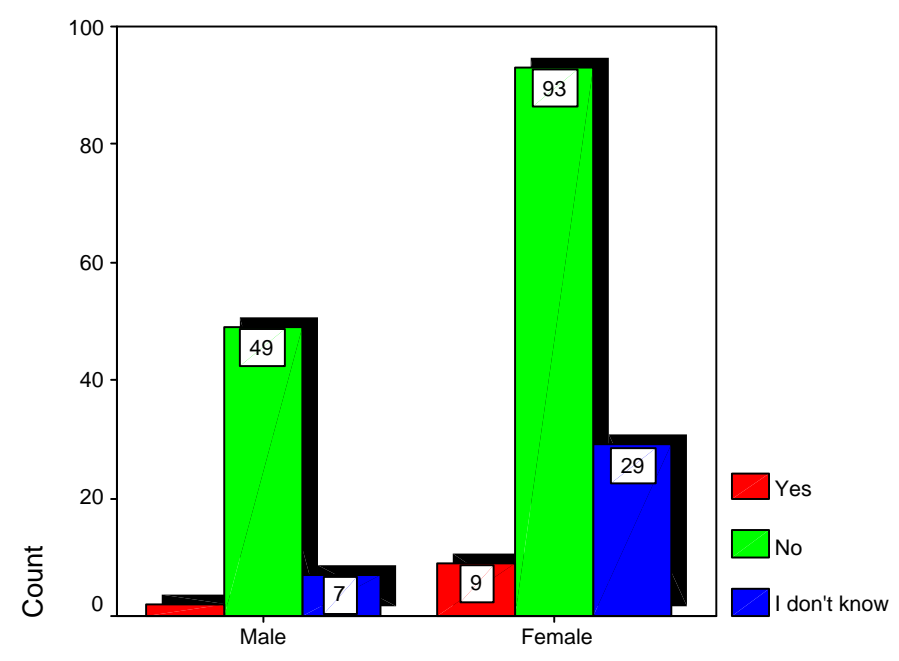

2.) Gender:

Figure C.33. Male and Female Instructors and their responses to second item regarding the Religious issues. 


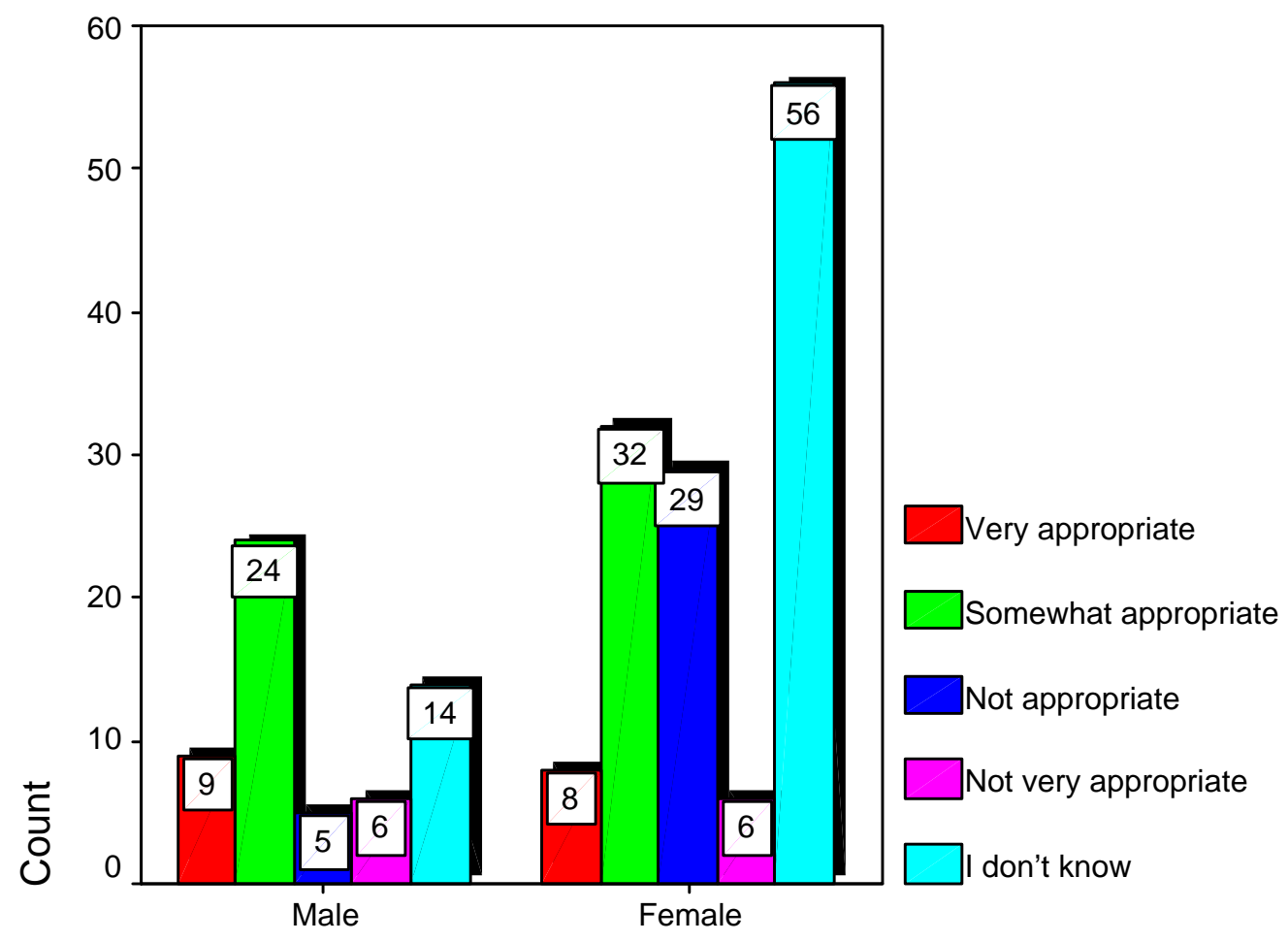

2.) Gender:

Figure C.34. Male and Female Instructors and their responses to first item regarding the Religious issues. 


\section{Health Issues}

Table C.59-C.60

The t-test for the difference between Male and Female within Instructors group regarding

Health issues.

\section{Group Statistics}

\begin{tabular}{|ll|r|r|r|c|}
\hline & 2.) Gender: & $\mathrm{N}$ & Mean & Std. Deviation & $\begin{array}{c}\text { Std. Error } \\
\text { Mean }\end{array}$ \\
\hline $\begin{array}{l}\text { 15.) When biometric } \\
\text { technology is } \\
\text { implemented, how } \\
\begin{array}{l}\text { concerned are you about } \\
\text { the health risk which } \\
\text { might be rendered: }\end{array}\end{array}$ & Male & 55 & 2.71 & .786 & .106 \\
\hline
\end{tabular}

Independent Samples Test

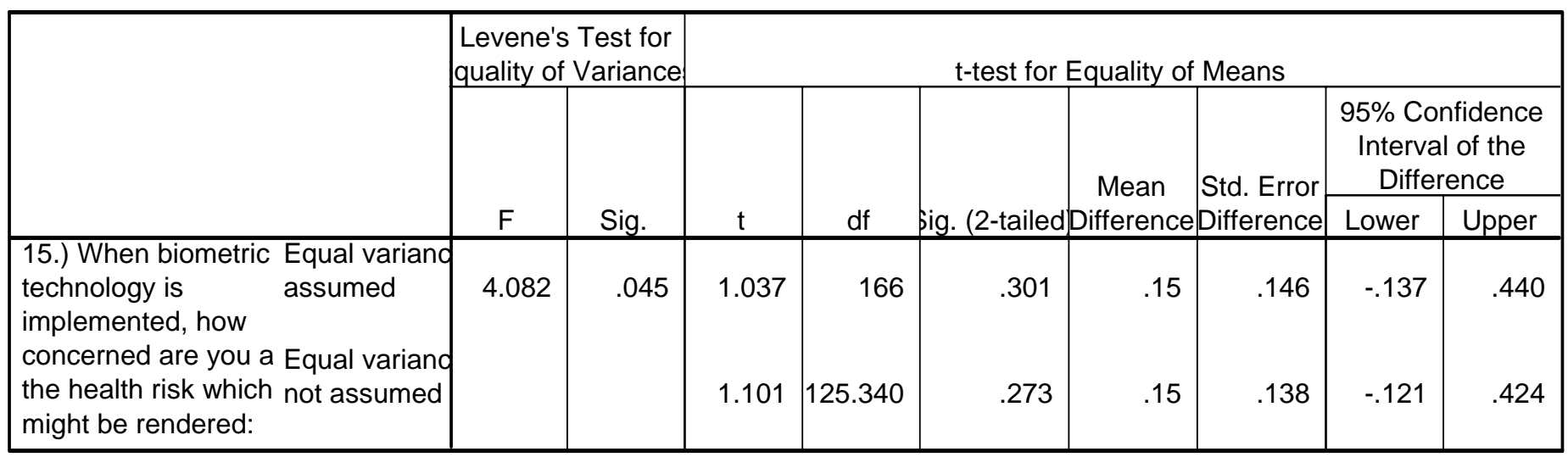

Figure C.100. Male and Female Instructors and their responses to question regarding the Health issues.

Table C.61

Cross tabulation for question related to Health issues. 
iender: * 15.) When biometric technology is implemented, how concerned are you about the health risk which might be renderec Crosstabulation

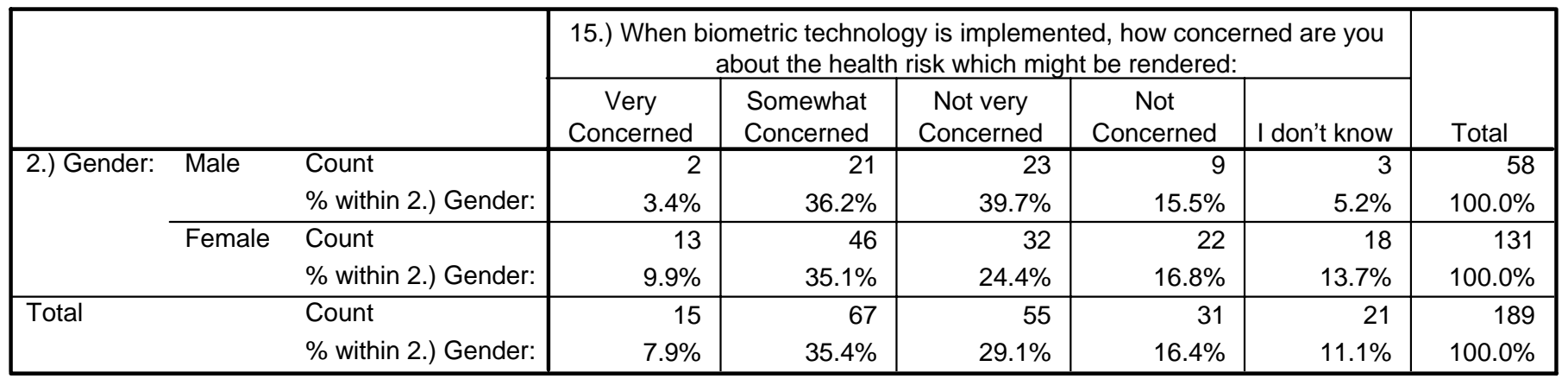

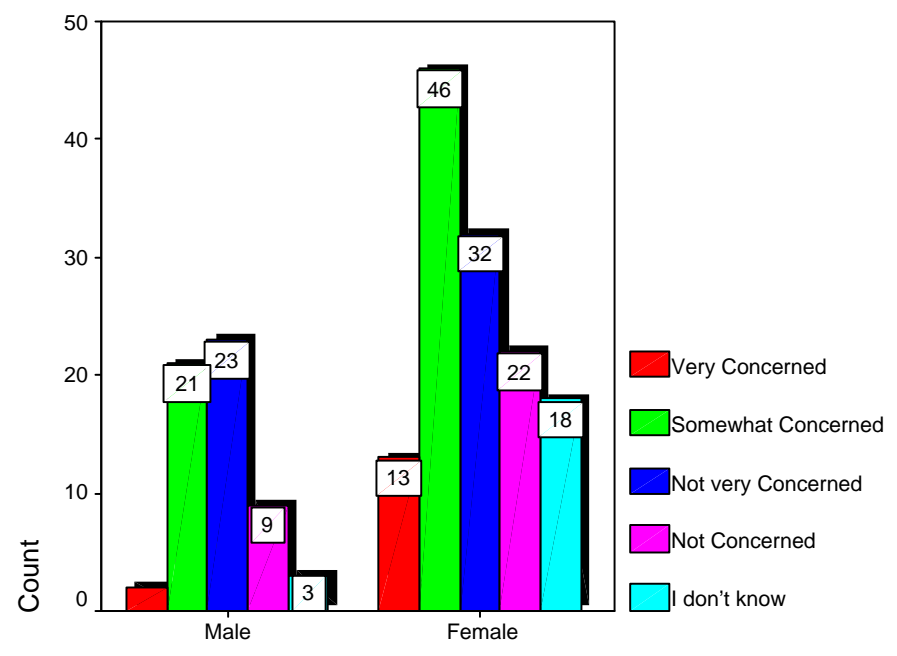

2.) Gender:

Figure C.35. Male and Female Instructors and their responses to question regarding the Health issues. 
APPENDIX D

Instructors and Students Surveys 
Instructors’ Questionnaire

Participant Code:

Purpose: This survey is designed to investigate the attitude of faculty member toward the implementation of Biometric Technology as Identification Method in Online Classes. Response will be kept strictly confidential; your participation is voluntary.

Keywords: Biometric is identifying people according to their physiological, behavioral characteristics.

Thank you for your time and cooperation.

\section{Part I}

Personal Information:

Department:

Gender: $\square$ Male

Age: $\square$ less than 20

$31-35$
Position:

Female

$\square 20-25 \square 26-30$

$36-40$

$\square 41-$ above

\section{Ethnicity/Race:}

$\square$ African American $\square$ Asian/ Pacific Islander $\square$ Hispanic

$\square$ Native American / American Indian $\quad \square$ White/non-Hispanic

$\square$ Other, please specify

\section{Religion:}

$\square$ Atheist $\square$ Buddhist $\quad \square$ Christian $\quad \square$ Hindu

$\square$ Jewish $\quad \square$ Muslim $\quad \square$ Other, please specify

\section{Biometric Technology Background:}

- Before this survey, have you ever read or heard about the Biometric Technology?
Yes
$\square$ No

- Have you ever used it in (Check all that apply):

$\square$ School

$\square$ Airport

$\square$ Bank

$\square$ ATM

$\square$ Hospital $\quad \square$ Federal Building $\square$ Others, please specify

- What type of technology did you use (check all that apply):

$\square$ Fingerprint $\square$ Iris scan "eye scan" $\square$ Facial recognition

$\square$ Hand geometry $\quad \square$ Voice recognition $\quad \square$ Signature dynamic 


\section{Part II}

The following scenario assesses the participants' attitude toward using biometric technology and its interference with privacy, religious issues and health implications:

West Virginia University plans to install a biometric system (fingerprints, iris scans, facial recognition, hand geometry and dynamic signature) to verify the identity of students taking online courses:

\section{A. The privacy issues}

\begin{tabular}{|l|l|l|l|l|l|}
\cline { 2 - 5 } \multicolumn{1}{l|}{} & $\begin{array}{c}\text { Very } \\
\text { Concerned }\end{array}$ & $\begin{array}{c}\text { Somewhat } \\
\text { concerned }\end{array}$ & $\begin{array}{c}\text { Not very } \\
\text { Concerned } \\
\text { about having students } \\
\text { biometric data collected? }\end{array}$ & $\begin{array}{c}\text { Not } \\
\text { Concerned }\end{array}$ & $\begin{array}{c}\text { Don't } \\
\text { know }\end{array}$ \\
\hline $\begin{array}{l}\text { 2. How concerned are you } \\
\text { about having students } \\
\text { biometric data stored in non- } \\
\text { secure storage? }\end{array}$ & & & & & \\
\hline $\begin{array}{l}\text { 3. How concerned are you } \\
\text { about having students' } \\
\text { biometric data used by third } \\
\text { party? }\end{array}$ & & & & & \\
\hline $\begin{array}{l}\text { 4. How concerned are you } \\
\text { about having students' } \\
\text { biometric data misused by }\end{array}$ & & & & & \\
WVU? & & & & & \\
\hline $\begin{array}{l}\text { 5. How concerned are you } \\
\text { about the invasion of students' } \\
\text { privacy by WVU, when } \\
\text { biometric technology is } \\
\text { implemented? }\end{array}$ & & & & & \\
\hline $\begin{array}{l}\text { 6. How concerned are you } \\
\text { about the negative stigma } \\
\text { attached to the use of } \\
\text { biometric technology? }\end{array}$ & & & & & \\
\hline
\end{tabular}

7. Rank each technology according to their intrusiveness:

\begin{tabular}{|l|l|l|l|l|}
\hline & Low & Medium & High & I don' know \\
\hline Fingerprint & & & & \\
\hline iris scans & & & & \\
\hline facial recognition & & & & \\
\hline hand geometry & & & & \\
\hline voice recognition & & & & \\
\hline signature dynamic & & & & \\
\hline
\end{tabular}




\section{B. Religious Issues}

1. In terms of religious conflicts, how appropriate do you think the implementing of the biometric systems in the WVU are?
$\square$ Very appropriate
$\square$ Somewhat appropriate
$\square$ Not appropriate

Not very appropriate

I do not know

2. Do you think the implementation of biometric technology at WVU contradicts your religious beliefs?
Yes
No
I do not know

3. If yes, which technologies conflict with your religious beliefs (Check all that apply):
$\square$ Fingerprint
$\square$ Iris scan "eye scan"
$\square$ Facial recognition

$\square$ Hand geometry $\quad \square$ Voice recognition $\quad \square$ Signature dynamic

4. If biometric technologies conflict with your religious beliefs, please rank each technology according to your religious concerns:

\begin{tabular}{|l|c|l|l|l|}
\hline & Low & Medium & High & I don' know \\
\hline Fingerprint & & & & \\
\hline Iris scans & & & & \\
\hline Facial recognition & & & & \\
\hline Hand geometry & & & & \\
\hline Voice recognition & & & & \\
\hline Signature dynamic & & & & \\
\hline
\end{tabular}

\section{Health Implications}

1. When biometric technology is implemented, how concerned are you about the health risk which might be rendered:
Very concerned
Somewhat concerned
Not very concerned

$\square$ Not concerned

\section{I don't know}

2. Rank each technology according to your health concerns:

\begin{tabular}{|l|l|l|l|l|}
\hline & Low & Medium & High & I don' know \\
\hline Fingerprint & & & & \\
\hline Iris scans & & & & \\
\hline Facial recognition & & & & \\
\hline Hand geometry & & & & \\
\hline Voice recognition & & & & \\
\hline Signature dynamic & & & & \\
\hline
\end{tabular}


3. In terms of health concerns, please rate your comfortability toward the use of these five biometric technologies:

\begin{tabular}{|l|l|l|l|l|l|}
\cline { 2 - 6 } \multicolumn{1}{c|}{} & $\begin{array}{l}\text { Very } \\
\text { comfortable }\end{array}$ & $\begin{array}{l}\text { Somewhat } \\
\text { comfortable }\end{array}$ & $\begin{array}{l}\text { Not very } \\
\text { Comfortable }\end{array}$ & $\begin{array}{l}\text { Not } \\
\text { Comfortable }\end{array}$ & $\begin{array}{l}\text { Don't } \\
\text { know }\end{array}$ \\
\hline Fingerprint & & & & & \\
\hline Iris scan "eye scan" & & & & & \\
\hline Facial recognition & & & & & \\
\hline Hand geometry & & & & & \\
\hline Voice recognition & & & & & \\
\hline Signature dynamic & & & & & \\
\hline
\end{tabular}

\section{Part III, open-ended questions:}

1. Do you have any comments or suggestions regarding the use of biometric technology as authentication method in online or distance learning classes?

2. Do you have any concerns or reservations, not mentioned in the survey, about the implementation of biometric technology in online course at WVU?

3. In your opinion, how can WVU improve the implementation of biometric technology? 
Students’ Questionnaire

Participant Code:

Purpose: This survey is designed to investigate the attitude of students toward the implementation of biometric technology as an identification method in distance learning classes. Responses will be kept strictly confidential; your participation is voluntary.

Keywords: Biometric is identifying people according to their physiological, behavioral characteristics.

Thank you for your time and cooperation.

\section{Part I}

Personal Information:

Major:

Level:

Gender: $\square$ Male

$\square$ Female

Age: $\square$ less than 20

$\square 21-25$

$26-30$

$31-35$

$36-40$

$\square 41$ - above

\section{Ethnicity/Race:}

$\square$ African American $\square$ Asian/ Pacific Islander $\square$ Hispanic

$\square$ Native American / American Indian

$\square$ White/non-Hispanic

$\square$ Other, please specify

\section{Religion:}

$\square$ Atheist $\square$ Buddhist $\square$ Christian $\square$ Hindu

$\square$ Jewish $\quad \square$ Muslim $\quad \square$ Other, please specify

\section{Biometric Technology Background:}

- Before this survey, have you ever read or heard about the Biometric Technology?
Yes
$\square$ No

- Have you ever used it in (Check all that apply):

$\square$ School

$\square$ Airport

$\square$ Bank

$\square$ ATM

$\square$ Hospital $\square$ Federal Building $\square$ Others, please specify

- What Type of Technology did you use (check all that apply):

$\square$ Fingerprint $\quad \square$ Iris scan "eye scan" $\square$ Facial recognition

$\square$ Hand geometry $\square$ Voice recognition $\square$ Signature dynamic 


\section{Part II}

The following scenario assesses the participants' attitude toward using biometric technology and its interference with privacy, religious issues and health implications:

West Virginia University plans to install a biometric system (fingerprints, iris scans, facial recognition, hand geometry and dynamic signature) to verify the identity of students taking online courses:

\section{A. The privacy issues}

\begin{tabular}{|l|l|l|l|l|l|}
\cline { 2 - 5 } \multicolumn{1}{c|}{} & $\begin{array}{c}\text { Very } \\
\text { Concerned }\end{array}$ & $\begin{array}{c}\text { Somewhat } \\
\text { concerned }\end{array}$ & $\begin{array}{c}\text { Not very } \\
\text { Concerned }\end{array}$ & $\begin{array}{c}\text { Not } \\
\text { Concerned }\end{array}$ & $\begin{array}{c}\text { Don't } \\
\text { know }\end{array}$ \\
\hline $\begin{array}{l}\text { about having your biometric } \\
\text { data collected? }\end{array}$ & & & & & \\
\hline $\begin{array}{l}\text { 2. How concerned are you } \\
\text { about having your biometric } \\
\text { data stored in non-secure } \\
\text { storage? }\end{array}$ & & & & & \\
\hline $\begin{array}{l}\text { 3. How concerned are you } \\
\text { about having your biometric } \\
\text { data used by third party? }\end{array}$ & & & & & \\
\hline $\begin{array}{l}\text { 4. How concerned are you } \\
\text { about having your biometric } \\
\text { data misused by WVU? }\end{array}$ & & & & & \\
\hline $\begin{array}{l}\text { 5. How concerned are you } \\
\text { about the invasion of your } \\
\text { privacy by WVU, when } \\
\text { biometric technology is } \\
\text { implemented? }\end{array}$ & & & & & \\
\hline $\begin{array}{l}\text { 6. How concerned are you } \\
\text { about the negative stigma } \\
\text { attached to the use of } \\
\text { biometric technology? }\end{array}$ & & & & & \\
\hline
\end{tabular}

7. Rank each technology according to their intrusiveness:

\begin{tabular}{|l|l|l|l|l|}
\hline & Low & Medium & High & I don' know \\
\hline Fingerprint & & & & \\
\hline Iris scans & & & & \\
\hline Facial recognition & & & & \\
\hline Hand geometry & & & & \\
\hline Voice recognition & & & & \\
\hline Signature dynamic & & & & \\
\hline
\end{tabular}




\section{B. Religious issues}

1. In terms of religious conflicts, how appropriate do you think of implementing the biometric systems as described in the above scenario?
$\square$ Very appropriate
$\square$ Somewhat appropriate
$\square$ Not appropriate

Not very appropriate

I do not know

2. Do you think the implementation of biometric technology at WVU contradicts your religious beliefs?
Yes
No
I do not know

3. If yes, which technologies conflict with your religious beliefs (Check all that apply):

$\square$ Fingerprint $\square$ Iris scan “eye scan” $\square$ Facial recognition

$\square$ Hand geometry $\quad \square$ Voice recognition $\quad \square$ Signature dynamic

4. If biometric technology conflicts with your religious beliefs, please rank each technology according to your religious concerns:

\begin{tabular}{|l|l|l|l|l|}
\hline & Low & Medium & High & I don' know \\
\hline Fingerprint & & & & \\
\hline Iris scans & & & & \\
\hline Facial recognition & & & & \\
\hline Hand geometry & & & & \\
\hline Voice recognition & & & & \\
\hline Signature dynamic & & & & \\
\hline
\end{tabular}

\section{Health issues}

1. When biometric technology is implemented, how concerned are you about the health risk which might be rendered:
Very concerned
$\square$ Somewhat concerned
Not very concerned

$\square$ Not concerned

I do not know

2. Rank each technology according to your health concerns:

\begin{tabular}{|l|l|l|l|l|}
\hline & Low & Medium & High & I don' know \\
\hline Fingerprint & & & & \\
\hline Iris scans & & & & \\
\hline Facial recognition & & & & \\
\hline Hand geometry & & & & \\
\hline Voice recognition & & & & \\
\hline Signature dynamic & & & & \\
\hline
\end{tabular}


3. In terms of health concerns, please rate your comfortability toward the use of these five biometric technologies:

\begin{tabular}{|l|l|l|l|l|l|}
\hline & $\begin{array}{c}\text { Very } \\
\text { comfortable }\end{array}$ & $\begin{array}{c}\text { Somewhat } \\
\text { comfortable }\end{array}$ & $\begin{array}{c}\text { Not very } \\
\text { Comfortable }\end{array}$ & $\begin{array}{c}\text { Not } \\
\text { Comfortable }\end{array}$ & $\begin{array}{c}\text { Don't } \\
\text { know }\end{array}$ \\
\hline Fingerprint & & & & & \\
\hline Iris scan "eye scan" & & & & & \\
\hline Facial recognition & & & & & \\
\hline Hand geometry & & & & & \\
\hline Voice recognition & & & & & \\
\hline Signature dynamic & & & & & \\
\hline
\end{tabular}

\section{Part III}

\section{Open-ended questions:}

1. Do you have any comments or suggestions regarding the use of biometric technology as an authentication method in online or distance learning classes?

2. Do you have any concerns or reservations, not mentioned in the survey, about the implementation of biometric technology in online course at WVU?

3. In your opinion, how can WVU improve the implementation of biometric technology? 
APPENDIX E

\author{
Interviews Protocol
}


Introductory Script

\section{The following letter will be read to participants prior to the beginning of each interview.}

Good (morning, afternoon, evening). Thank you for agreeing to participate in the research.

The goal of this study is to investigate the instructors and students' attitude toward using Biometric Technology as an Identification Method in Online courses. The data collected in this study will be used to fulfill dissertation requirements, and may be used for scholarly publications and professional conferences.

I would like to point out several things to you before we start the interview, however, please feel free to interrupt if you have any question.

1. Your participation is voluntary and you may not answer all questions.

2. Your responses will be kept as confidential as legally possible.

3. No attempt will be made that might reveal demographic or descriptive information concerning your current school and position.

4. Audio tape is necessary for the interview, but if you prefer not, you may refuse.

5. The data gathered will not be used other than to the purpose stated above.

6. You may request a copy of the transcript of the interview.

7. The interview will last for 30 minute to 1 hour.

Thank you for accepting my request to participate in this study. 


\section{The interview questions}

1. Please list the online courses you have taken/taught.

2. Describe the positive aspects of online courses.

3. Describe the negative aspects of online courses.

4. How was verification of student identity handled in the courses you took/taught?

5. Describe the positive aspects of the verification system you used.

6. Describe the negative aspects of the verification system you used.

7. There are several biometric systems that can be used to verify identity, as I list them, please describe your perspective regarding their use in online classes: fingerprints, iris scan, etc.

8. (If they do not describe these issues). Do you believe there are privacy issues related to the use of biometric systems? Cultural issues? Religious issues? Health issues?

9. Given the systems we have discussed, which would you prefer and why would you prefer that system? 


\section{Letters to all participants}

May 6, 2004

Dear Instructor/student,

I am a doctoral student at Technology Education department and conducting my dissertation research on instructors and students' attitude toward using Biometric Technology as an Identification Method in Online courses. To complete my dissertation research, however, I need your cooperation and help. I will appreciate if you could take your time to complete the survey enclosed. Please follow the instructions, but make sure that you do not write your name anywhere on the survey.

I would like to let you know that your participation in this research is completely voluntarily. You may not complete the survey, not answering all questions or withdraw from the study any time you wish. Nevertheless, if you decide to participate on my study, I will take all the necessary means to ensure that your identity will be kept as confidential as legally possible. The information that I collect during the study will only be used to fulfill the dissertation requirements, and may be used for scholarly publications and presentations.

If you have any questions or concerns, please do not hesitate to contact me. My phone number is (304) 2826622 . In addition, you may contact me through my email address at walbalaw@mix.wvu.edu

I really appreciate your help in participating voluntarily in this study.

Sincerely,

Wafi AlBalawi 